Lucas Fernando Vaquero Roviriego

\title{
PROPOSTA DE UMA METODOLOGIA PARA A AVALIAÇÃO DE SISTEMAS DE COLETA SELETIVA DE RESÍDUOS SÓLIDOS DOMICILIARES
}

Dissertação apresentada à Escola de Engenharia de São Carlos da Universidade de São Paulo, como parte dos requisitos para obtenção do título de Mestre em Engenharia Civil com ênfase em Transportes.

ORIENTADOR: Prof. Dr. Edson Martins de Aguiar 


\section{AGRADECIMENTOS}

Agradeço aos meus pais, José Carlos e Maria do Carmo pela presença sempre constante na minha vida. São eles, definitivamente, a inspiração que me faz alcançar meus sonhos.

Agradeço à minha família, principalmente meus queridos irmãos, Melissa e Daniel, pela total compreensão e apoio incondicional às minhas decisões e pontos de vista, mesmo que muitas vezes equivocados.

Um agradecimento especial ao grande mestre: Prof. Dr. Edson Martins de Aguiar, que sempre esteve solícito e disposto a me ajudar a compreender os meandros desta pesquisa assim como por todas às conversas esclarecedoras que tivemos.

Agradeço ao CNPq - Conselho Nacional de Desenvolvimento Científico e Tecnológico pela concessão da bolsa de estudos, sem a qual este trabalho não existiria.

À Coordenadora do programa de coleta seletiva municipal: Flávia Thiemerman, por disponibilizar informações importantes ao andamento desta pesquisa.

Aos amigos do NUMA da Escola de Engenharia de São Carlos, na figura do amigo Américo Guelere, e do Colaborative Resource Center 281 da Universidade Técnica de Berlim, particularmente ao Dipl.-Ing Carsten Franke. À Profa.Dra. Maria Zanin por suas sugestões preciosas assim como ao Prof. Amadeu Logarezzi e Graziele de Mônaco pela contribuição bibliográfica. Ao Prof. Dr. Antonio Nélson Rodrigues da Silva pelo apoio em todas as questões, principalmente no que diz respeito ao SIG.

Agradeço aos amigos que estiveram sempre presentes em todos os momentos: os grandes amigos da República Rodox (aos grandes irmãos: band, miséria, gordo, alemão, zola, turco, dodói, charlie, jerço, zini, ney, alba; enfim, todos os moradores e ex moradores, sem distinção), da República Rodox Pós, da República Mosteiro assim como todos os seus agregados, por me acolherem por esses anos; aos amigos de Catanduva pelo companheirismo inabalável; e aos amigos, professores e funcionários do Departamento de Transportes pela constante ajuda e amizade, sempre nos momentos difíceis.

À minha querida Lia, cuja paciência e carinho impulsionaram este trabalho. 


\section{RESUMO}

ROVIRIEGO, L. F. V. (2005). Proposta de uma metodologia para a avaliação de sistemas de coleta seletiva de resíduos sólidos domiciliares. Dissertação (Mestrado) Escola de Engenharia de São Carlos, Universidade de São Paulo, São Carlos, 2005.

Os sistemas de gerenciamento de resíduos sólidos urbanos prevêem fases que envolvem desde a sua geração até a disposição final. A atividade de coleta seletiva de materiais previamente segregados é uma parte importante deste gerenciamento. Os custos envolvidos neste tipo de coleta, normalmente mais elevados que os custos da coleta regular, fazem com que esta prática não seja efetuada pela maioria dos municípios brasileiros. Esses municípios tampouco são beneficiados por parcerias privadas, uma vez que o retorno financeiro gerado pela venda do material reciclável geralmente não cobre os custos de coleta, triagem e transporte. A partir deste panorama, este trabalho busca oferecer uma contribuição para o melhor entendimento dos custos envolvidos na operação de coleta destes resíduos. Neste trabalho foram analisados os custos de três sistemas de coleta seletiva de resíduos sólidos domiciliares: por pontos de entrega voluntária (PEVs), porta-a-porta, e um sistema híbrido entre os dois anteriores. A análise levou em conta os custos de transporte, que incluem custos operacionais e custos de capital para cada uma das alternativas. Um SIG-T foi utilizado para determinar a distância percorrida pelos veículos e uma metodologia para a determinação do custo total foi desenvolvida em função da quilometragem percorrida e quantidade de mão-de-obra e equipamentos utilizados. Conclui-se que o melhor método de coleta sempre estará intimamente ligado às características do local em que será implantado. Comparando os três sistemas, observou-se que para a área e para as condições apresentadas neste estudo, o sistema porta-a-porta se mostrou o mais eficaz.

Palavras chave: coleta seletiva, resíduos sólidos domiciliares; custos de coleta; SIG-T para a coleta de resíduos; logística reversa; SIG-T. 


\section{ABSTRACT}

ROVIRIEGO, L. F. V. (2005). Proposal of a methodology for cost evaluation of domestic solid waste selective collection systems. MSc. Dissertation - Escola de Engenharia de São Carlos, Universidade de São Paulo, São Carlos, 2005.

Urban solid waste management comprehends phases from its generation to its final disposal. The previously separated materials collection activity is an important part of this management. The costs involved in this type of collection, usually higher than conventional collection costs, make this practice not so used by Brazilian municipalities. These municipalities are neither benefited by private partnerships since the economic feedback from materials sale generally does not cover collection, separation and transport costs. From this point of view, this work seeks for a contribution to the best understanding of the involved costs in the collection operation activity. In this work the costs of three collection systems were studied: by voluntary delivery locations (VDLs), door-to-door, and a hybrid system between the preceding ones. The analysis took for granted the transportation costs to which one of the alternatives, which include operational costs and capital costs. A GIS-Trans had been used to define the traveled distance by the collection vehicles, and a cost determination methodology was developed as function of the traveled distance and the amount of labor and equipments used. It's concluded that the choice of the best collection method will always be related with implementation area peculiarities. Comparing the three collection systems described above, the door-to-door system is showed to be more efficient for the presented area and conditions assumed for this study.

Keywords: household solid waste, selective collection, collection costs, GISTrans for waste collection; reverse logistics; GIS-Trans. 
FIGURA 1. O PROCESSO DA COLETA DE RESÍDUOS SÓLIDOS E SUAS INTERRELAÇÕES

FIGURA 2. DIREÇÃO DAS RUAS DA CIDADE REPRESENTADAS PELAS SETAS (À ESQUERDA) E BASE DE DADOS COM OS NOMES DAS RUAS (À DIREITA) .. 43

FIGURA 3. CAIXA DE DIÁLOGO PARA A CRIAÇÃO DA REDE DE TRANSPORTES..........44

FIGURA 4. MATRIZ DE ROTEIRIZAÇÃO E CAIXA DE DIÁLOGO DO PROCEDIMENTO DE CRIAÇÃO DA MATRIZ DE ROTEIRIZAÇÃO ................................................. 45

FIGURA 5. ROTEAMENTO APLICADO AOS SISTEMAS, DA ESQUERDA PARA A DIREITA, SISTEMA PORTA-A-PORTA, SISTEMA POR PEV E SISTEMA HÍBRIDO. 46

FIGURA 6. ÁREA DE INFLUÊNCIA DOS PEVS E DOS PONTOS DE COLETA DO SISTEMA HÍBRIDO

FIGURA 7. CAIXAS DE DIÁLOGO PARA A CRIAÇÃO DA MATRIZ DE CUSTOS E PARA A LOCALIZAÇÃO DAS LIXEIRAS.

FIGURA 8. TABELA DA CAMADA DE PONTOS COM OS CAMPOS NECESSÁRIOS PARA EXECUTAR A ROTINA DO PROBLEMA DE TRANSPORTE. 50

FIGURA 9. CAIXA DE DIÁLOGO DA ROTINA QUE RESOLVE O PROBLEMA DO TRANSPORTE (A ESQUERDA) E REPRESENTAÇÃO DO FLUXO DAS RESIDÊNCIAS ATENDIDAS POR CADA PONTO (A DIREITA).

FIGURA 10. PROCEDIMENTO DE CLUSTERIZAÇÃO PARA DIVIDIR OS PONTOS OU RUAS DA ÁREA EM ESTUDO EM ÁREAS MENORES. 52

FIGURA 11. CAIXA DE DIÁLOGO PARA A CRIAÇÃO DA MATRIZ DE ROTEIRIZAÇÃO USADA NO PROCEDIMENTO DE ROTEIRIZAÇÃO DE VEÍCULOS ..

FIGURA 12. BASE DE DADOS DA CAMADA DE PONTOS PREPARADA PARA A EXECUÇÃO DA ROTINA DE ROTEIRIZAÇÃO DE VEÍCULOS ...........................54

FIGURA 13. TABELA DE VEÍCULOS COM AS INFORMAÇÕES DOS VEÍCULOS A SEREM UTILIZADOS NO PROCEDIMENTO..

FIGURA 14. ABAS DA CAIXA DE DIÁLOGO DA ROTINA DE ROTEIRIZAÇÃO DE VEÍCULOS

FIGURA 15. ITINERÁRIOS GERADOS PELA ROTEIRIZAÇÃO DOS VEÍCULOS E A ROTA INDICADA NO MAPA

FIGURA 16. RELATÓRIO DO PROCEDIMENTO COM OS PONTOS ÓRFÃOS INDICADOS.. 57

FIGURA 17. BASE DE DADOS DA CAMADA DE LINKS PREPARADA PARA A EXECUÇÃO DE ROTINA DE ROTEIRIZAÇÃO EM ARCO

FIGURA 18. CAIXA DE DIÁLOGO DA ROTINA DE ROTEIRIZAÇÃO EM ARCO (ABAIXO) E CAIXA DE DIÁLOGO COM AS PENALIDADES IMPOSTAS AOS MOVIMENTOS DO VEÍCULO NA REDE DE TRANSPORTES (ACIMA).

FIGURA 19. RESULTADOS DA ROTINA DE ROTEIRIZAÇÃO EM ARCO: ROTA MOSTRADA COMO UMA CAMADA DO MAPA E RELATÓRIO COM ITINERÁRIO

FIGURA 20. DETERMINAÇÃO DA DISTÂNCIA ENTRE O PONTO DE FIM/INÍCIO DAS ROTAS ATÉ A GARAGEM .

FIGURA 21. ÁREA ESCOLHIDA PARA AS SIMULAÇÕES DE COLETA (EM VERMELHO) E ÁREAS EM QUE AS COOPERATIVAS DE COLETA SELETIVA ATUAM (EM AMARELO, VERDE E VERMELHO) NA CIDADE DE SÃO CARLOS. 
FIGURA 22. MAPA PARA O SISTEMA POR PEVS - SELEÇÃO DA ÁREA DE ESTUDO DIVIDIDA EM ÁREAS MENORES E OS PONTOS INDICANDO OS PEVS SEPARADOS EM PEQUENAS ÁREAS

FIGURA 23. MAPA PARA O SISTEMA PORTA A PORTA - SELEÇÃO DA ÁREA DE ESTUDO SEPARADA EM ÁREAS MENORES E OS PONTOS INDICANDO AS RESIDÊNCIAS ATENDIDAS POR CADA ÁREA

FIGURA 24. MAPA PARA O SISTEMA HÍBRIDO - SELEÇÃO DA ÁREA DE ESTUDO COMO PONTOS INDICANDO AS RESIDÊNCIAS ATENDIDAS POR CADA ÁREA E OS PONTOS DE PARADA PARA CADA ÁREA .

FIGURA 25. ROTA DO VEÍCULO DE COLETA NA ÁREA 1 PARA OS CENÁRIOS PEV20, PEV40, PEV60 E PEV80.

FIGURA 26. ROTA DO VEÍCULO DE COLETA NA ÁREA 2 PARA OS CENÁRIOS PEV20, PEV40 E PEV60.

FIGURA 27. ROTA DO VEÍCULO DE COLETA NA ÁREA 3 PARA OS CENÁRIOS PEV20, PEV40, PEV60 E PEV80

FIGURA 28. ROTA DO VEÍCULO DE COLETA NA ÁREA 4 PARA OS CENÁRIOS PEV20, PEV40 E PEV60.

FIGURA 29. ROTA DO VEÍCULO DE COLETA NA ÁREA 5 PARA OS CENÁRIOS PEV20,

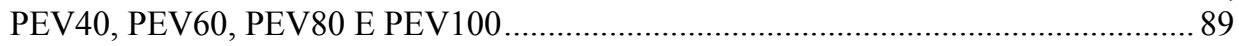

FIGURA 30. ROTAS DO VEÍCULO DE COLETA NA ÁREA 2 PARA O CENÁRIO PEV80 .......90

FIGURA 31. ROTAS DO VEÍCULO DE COLETA NA ÁREA 4 PARA O CENÁRIO PEV80.......90

FIGURA 32. ROTAS DO VEÍCULO DE COLETA NA ÁREA 1 PARA O CENÁRIO PEV100 ....91

FIGURA 33. ROTAS DO VEÍCULO DE COLETA NA ÁREA 2 PARA O CENÁRIO PEV100 ....91

FIGURA 34. ROTAS DO VEÍCULO DE COLETA NA ÁREA 3 PARA O CENÁRIO PEV100 ....99

FIGURA 35. ROTAS DO VEÍCULO DE COLETA NA ÁREA 4 PARA O CENÁRIO PEV100 ....99

FIGURA 36. ROTA DO VEÍCULO DE COLETA NA ÁREA 1 PARA OS CENÁRIOS POR20, POR40, POR60, POR80 E POR100 ………………................................................... 94

FIGURA 37. ROTA DO VEÍCULO DE COLETA NA ÁREA 2 PARA OS CENÁRIOS POR20, POR40, POR60 E POR80 ……………………………......................................... 94

FIGURA 38. ROTA DO VEÍCULO DE COLETA NA ÁREA 3 PARA OS CENÁRIOS POR20, POR40 E POR60. .95

FIGURA 39. ROTA DO VEÍCULO DE COLETA NA ÁREA 4 PARA OS CENÁRIOS POR20, POR40 E POR60

FIGURA 40. ROTA DO VEÍCULO DE COLETA NA ÁREA 5 PARA OS CENÁRIOS POR20,

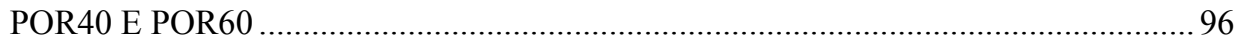

FIGURA 41. ROTAS DO VEÍCULO DE COLETA NA ÁREA 3 PARA O CENÁRIO POR80. NO DETALHE O CAMINHO MÍNIMO ENTRE O FIM DA $1^{\text {a }}$ ROTA - DEPÓSITO -

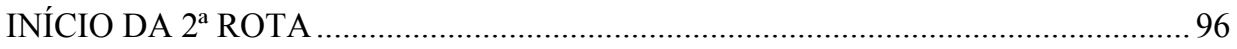

FIGURA 42. ROTAS DO VEÍCULO DE COLETA NA ÁREA 4 PARA O CENÁRIO POR80. NO DETALHE O CAMINHO MÍNIMO ENTRE O FIM DA $1^{\text {a }}$ ROTA - DEPÓSITO -

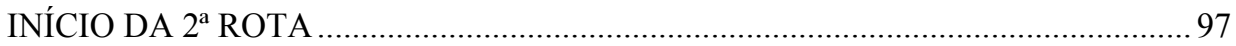

FIGURA 43. ROTAS DO VEÍCULO DE COLETA NA ÁREA 5 PARA O CENÁRIO POR80. NO DETALHE O CAMINHO MÍNIMO ENTRE O FIM DA $1^{\text {a }}$ ROTA - DEPÓSITO INÍCIO DA $2^{\mathrm{a}}$ ROTA...

FIGURA 44. ROTAS DO VEÍCULO DE COLETA NA ÁREA 2 PARA O CENÁRIO POR100. NO DETALHE O CAMINHO MÍNIMO ENTRE O FIM DA $1^{\mathrm{a}}$ ROTA - DEPÓSITO INÍCIO DA $2^{\mathrm{a}}$ ROTA 
FIGURA 45. ROTAS DO VEÍCULO DE COLETA NA ÁREA 3 PARA O CENÁRIO POR100. NO DETALHE O CAMINHO MÍNIMO ENTRE O FIM DA $1^{\text {a }}$ ROTA - DEPÓSITO INÍCIO DA $2^{\mathrm{a}}$ ROTA

FIGURA 46. ROTAS DO VEÍCULO DE COLETA NA ÁREA 4 PARA O CENÁRIO POR100. NO DETALHE O CAMINHO MÍNIMO ENTRE O FIM DA $1^{\mathrm{a}}$ ROTA - DEPÓSITO INÍCIO DA $2^{\mathrm{a}}$ ROTA

FIGURA 47. ROTAS DO VEÍCULO DE COLETA NA ÁREA 5 PARA O CENÁRIO POR100. NO DETALHE O CAMINHO MÍNIMO ENTRE O FIM DA $1^{\mathrm{a}}$ ROTA - DEPÓSITO INÍCIO DA $2^{\mathrm{a}}$ ROTA

FIGURA 48. ROTA DO VEÍCULO DE COLETA NA ÁREA 1 PARA O CENÁRIOS HIB20, HIB40, HIB60, HIB80 E HIB100 . 101

FIGURA 49. ROTA DO VEÍCULO DE COLETA NA ÁREA 2 PARA O CENÁRIOS HIB20, HIB40, HIB60 E HIB80 101

FIGURA 50. ROTA DO VEÍCULO DE COLETA NA ÁREA 3 PARA O CENÁRIOS HIB20, HIB40 E HIB60 102

FIGURA 51. ROTA DO VEÍCULO DE COLETA NA ÁREA 4 PARA O CENÁRIOS HIB20, HIB40 E HIB60 102

FIGURA 52. ROTA DO VEÍCULO DE COLETA NA ÁREA 5 PARA O CENÁRIOS HIB20, HIB40 E HIB60. 103

FIGURA 53. ROTAS DO VEÍCULO DE COLETA NA ÁREA 3 PARA O CENÁRIO HIB80..... 103 FIGURA 54. ROTAS DO VEÍCULO DE COLETA NA ÁREA 4 PARA O CENÁRIO HIB80...... 104 FIGURA 55. ROTAS DO VEÍCULO DE COLETA NA ÁREA 5 PARA O CENÁRIO HIB80..... 104 FIGURA 56. ROTAS DO VEÍCULO DE COLETA NA ÁREA 2 PARA O CENÁRIO HIB100... 105 FIGURA 57. ROTAS DO VEÍCULO DE COLETA NA ÁREA 3 PARA O CENÁRIO HIB100... 105 FIGURA 58. ROTAS DO VEÍCULO DE COLETA NA ÁREA 4 PARA O CENÁRIO HIB100... 106 FIGURA 59. ROTAS DO VEÍCULO DE COLETA NA ÁREA 5 PARA O CENÁRIO HIB100... 106 FIGURA 60. CUSTO TOTAL MENSAL DOS 3 SISTEMAS DE COLETA, PARA OS CENÁRIOS PROPOSTOS, DE ACORDO COM OS PARÂMETROS DE CUSTO DEFINIDOS INICIALMENTE 108

FIGURA 61. CUSTO POR QUILÔMETRO PERCORRIDO DOS 3 SISTEMAS DE COLETA, PARA OS CENÁRIOS PROPOSTOS, DE ACORDO COM OS PARÂMETROS DE CUSTO DEFINIDOS INICIALMENTE. 108

FIGURA 62. COMPOSIÇÃO DOS CUSTOS DE CADA SISTEMA 109

FIGURA 63. CUSTO POR METRO CÚBICO COLETADO DOS 3 SISTEMAS DE COLETA, PARA OS CENÁRIOS PROPOSTOS, DE ACORDO COM OS PARÂMETROS DE CUSTO DEFINIDOS INICIALMENTE.

FIGURA 64. CUSTO POR RESIDÊNCIA ATENDIDA DOS 3 SISTEMAS DE COLETA, PARA OS CENÁRIOS PROPOSTOS, DE ACORDO COM OS PARÂMETROS DE CUSTO DEFINIDOS INICIALMENTE.

FIGURA 65. VOLUME COLETADO POR QUILÔMETRO PERCORRIDO NOS 3 SISTEMAS DE COLETA, PARA OS CENÁRIOS PROPOSTOS

FIGURA 66. COMPOSIÇÃO DOS CUSTOS OPERACIONAIS FIXOS DE CADA SISTEMA COM OS PARÂMETROS DE CUSTO PROPOSTOS INICIALMENTE E COM DEMANDA MÁXIMA (100\%).

FIGURA 67. CUSTO TOTAL MENSAL DOS 3 SISTEMAS DE COLETA, PARA OS CENÁRIOS PROPOSTOS COM O PARÂMETRO DE VIDA ÚTIL AUMENTADO 
FIGURA 68. CUSTO POR QUILÔMETRO PERCORRIDO DOS 3 SISTEMAS DE COLETA, PARA OS CENÁRIOS PROPOSTOS COM O PARÂMETRO DE VIDA ÚTIL AUMENTADO

FIGURA 69. CUSTO POR METRO CÚBICO COLETADO DOS 3 SISTEMAS DE COLETA, PARA OS CENÁRIOS PROPOSTOS COM O PARÂMETRO DE VIDA ÚTIL AUMENTADO .

FIGURA 70. CUSTO POR RESIDÊNCIA ATENDIDA DOS 3 SISTEMAS DE COLETA, PARA OS CENÁRIOS PROPOSTOS COM O PARÂMETRO DE VIDA ÚTIL AUMENTADO .....

FIGURA 71. CUSTO TOTAL MENSAL DOS 3 SISTEMAS DE COLETA, PARA OS CENÁRIOS PROPOSTOS COM O PARÂMETRO DE VIDA ÚTIL AUMENTADO E TAXA DE REMUNERAÇÃO REDUZIDA 116

FIGURA 72. CUSTO POR QUILÔMETRO PERCORRIDO DOS 3 SISTEMAS DE COLETA, PARA OS CENÁRIOS PROPOSTOS COM O PARÂMETRO DE VIDA ÚTIL AUMENTADO E TAXA DE REMUNERAÇÃO REDUZIDA.....................................116

FIGURA 73. CUSTO POR RESIDÊNCIA ATENDIDA DOS 3 SISTEMAS DE COLETA, PARA OS CENÁRIOS PROPOSTOS COM O PARÂMETRO DE VIDA ÚTIL AUMENTADO E TAXA DE REMUNERAÇÃO REDUZIDA... 116

FIGURA 74. CUSTO POR METRO CÚBICO COLETADO DOS 3 SISTEMAS DE COLETA, PARA OS CENÁRIOS PROPOSTOS COM O PARÂMETRO DE VIDA ÚTIL AUMENTADO E TAXA DE REMUNERAÇÃO REDUZIDA.

FIGURA 75. CUSTO TOTAL MENSAL DOS 3 SISTEMAS DE COLETA, PARA OS CENÁRIOS PROPOSTOS COM O PARÂMETRO DE VIDA ÚTIL AUMENTADO, TAXA DE REMUNERAÇÃO REDUZIDA E SEM ENCARGOS SOBRE A MÃO-DE-OBRA ......

FIGURA 76. CUSTO POR QUILÔMETRO PERCORRIDO DOS 3 SISTEMAS DE COLETA, PARA OS CENÁRIOS PROPOSTOS COM O PARÂMETRO DE VIDA ÚTIL AUMENTADO, TAXA DE REMUNERAÇÃO REDUZIDA E SEM ENCARGOS SOBRE A MÃO-DE-OBRA . 118

FIGURA 77. CUSTO POR METRO CÚBICO COLETADO DOS 3 SISTEMAS DE COLETA, PARA OS CENÁRIOS PROPOSTOS COM O PARÂMETRO DE VIDA ÚTIL AUMENTADO E DE TAXA DE REMUNERAÇÃO REDUZIDO E SEM ENCARGOS SOBRE A MÃO-DE-OBRA.

FIGURA 78. CUSTO POR RESIDÊNCIA ATENDIDA DOS 3 SISTEMAS DE COLETA, PARA OS CENÁRIOS PROPOSTOS COM O PARÂMETRO DE VIDA ÚTIL AUMENTADO, TAXA DE REMUNERAÇÃO REDUZIDA E SEM ENCARGOS SOBRE A MÃO-DE-OBRA

FIGURA 79. CUSTO TOTAL MENSAL PARA CADA UMA DAS CONFIGURAÇÕES DE

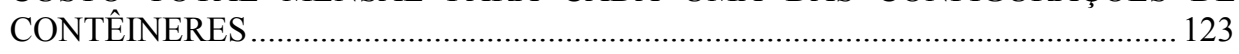

FIGURA 80. CUSTO POR QUILÔMETRO PARA CADA UMA DAS CONFIGURAÇÕES DE

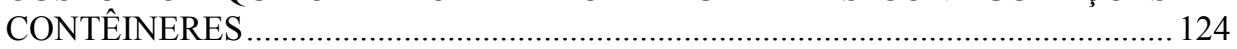

FIGURA 81. CUSTO POR METRO CÚBICO COLETADO PARA CADA UMA DAS

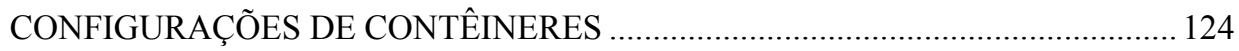

FIGURA 82. CUSTO POR RESIDÊNCIA ATENDIDA PELO SISTEMA PARA CADA UMA DAS CONFIGURAÇÕES DE CONTÊINERES

FIGURA 83. CUSTO TOTAL MENSAL DE CADA CENÁRIO DOS 3 SISTEMAS COM AS VARIAÇÕES NAS CONFIGURAÇÕES DOS CONTÊINERES DO SISTEMA PEV

FIGURA 84. CUSTO POR QUILÔMETRO DE CADA CENÁRIO DOS 3 SISTEMAS COM AS VARIAÇÕES NAS CONFIGURAÇÕES DOS CONTÊINERES DO SISTEMA PEV 
FIGURA 85. CUSTO POR METRO CÚBICO COLETADO DE CADA CENÁRIO DOS 3 SISTEMAS COM AS VARIAÇÕES NAS CONFIGURAÇÕES DOS CONTÊINERES

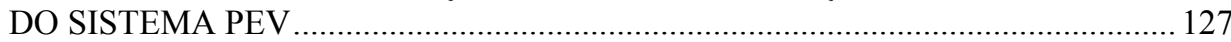

FIGURA 86. CUSTO POR RESIDÊNCIA ATENDIDA DE CADA CENÁRIO DOS 3 SISTEMAS COM AS VARIAÇÕES NAS CONFIGURAÇÕES DOS CONTÊINERES DO SISTEMA PEV 
TABELA 1. DIFERENTES SISTEMAS DE COLETA DE RESÍDUOS E SUAS RESPECTIVAS DESCRIÇÕES E APLICAÇÕES.................................................................. 27

TABELA 2. COMPARAÇÃO DE SISTEMAS ALTERNATIVOS DE COLETA DE RECICLÁVEIS. ........................................................................................... 31

TABELA 3. VANTAGENS DA COLETA SELETIVA MISTURADA VERSUS SEPARADA....... 32

TABELA 4. CAMPOS A SEREM PREENCHIDOS NA BASE DE DADOS DA CAMADA DA GARAGEM (CAMADA DE PONTOS) ...................................................... 53

TABELA 5. CAMPOS ADICIONAIS A SEREM PREENCHIDOS NA BASE DE DADOS DA CAMADA DOS PONTOS DE COLETA E DEPÓSITOS (CAMADA DE PONTOS) 54

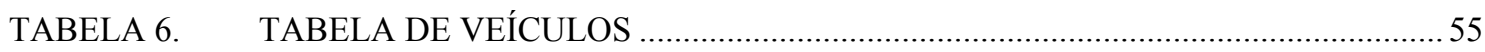

TABELA 7. CAMPOS A SEREM PREENCHIDOS NA BASE DE DADOS DA CAMADA DOS LINKS SERVIDOS PELA COLETA (CAMADA DE LINHAS) ................................58

TABELA 8. CAMPOS OPCIONAIS A SEREM PREENCHIDOS NA BASE DE DADOS DA CAMADA DOS LINKS SERVIDOS PELA COLETA (CAMADA DE LINHAS)......59

TABELA 9. CAMPOS A SEREM PREENCHIDOS NA BASE DE DADOS DA CAMADA DE PONTOS QUE LOCALIZAM OS DEPÓSITOS (CAMADA DE PONTOS)..............59

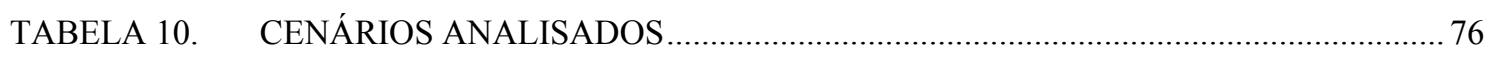

TABELA 11. PARÂMETROS DE CUSTO: CUSTOS FIXOS DE CAPITAL …...............................77

TABELA 12. PARÂMETROS DE CUSTO: CUSTOS FIXOS OPERACIONAIS ............................77

TABELA 13. PARÂMETROS DE CUSTO: CUSTOS VARIÁVEIS ..............................................78

TABELA 14. PARÂMETROS DE CUSTO: CUSTOS ADMINISTRATIVOS ….............................78

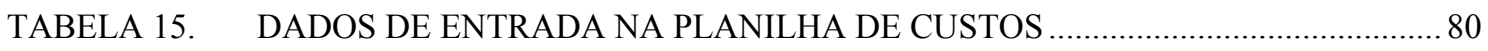

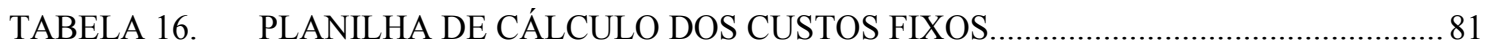

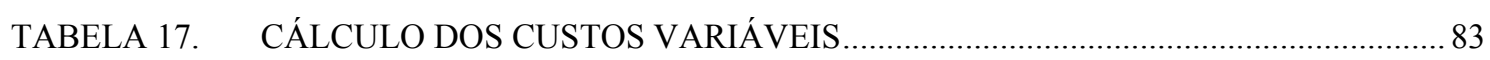

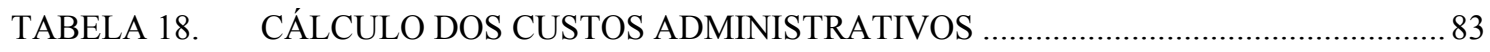

TABELA 19. CÁlCULO DO CUSTO TOTAL, POR QUILÔMETRO, POR METRO CÚBICO COLETADO E POR RESIDÊNCIA ATENDIDA .................................................. 84

TABELA 20. RESULTADOS DAS ROTINAS DE ROTEIRIZAÇÃO PARA AS VARIAÇÕES DA DEMANDA PROPOSTAS PARA O SISTEMA POR PEVS …............................... 86

TABELA 21. RESULTADOS DAS ROTINAS DE ROTEIRIZAÇÃO PARA AS VARIAÇÕES DA DEMANDA PROPOSTAS PARA O SISTEMA PORTA-A-PORTA .........................93

TABELA 22. RESULTADOS DAS ROTINAS DE ROTEIRIZAÇÃO PARA AS VARIAÇÕES DA DEMANDA PROPOSTAS PARA O SISTEMA HÍBRIDO ….................................. 100

TABELA 23. CAPACIDADES, CUSTOS E CONFIGURAÇÕES PREVISTAS PARA DIFERENTES TIPOS DE CONTÊINERES ......................................................... 120

TABELA 24. PARA CADA CONFIGURAÇÃO DE CONTÊINERES, A QUANTIDADE DE CADA TIPO DE CONTÊINER E A CAPACIDADE INSTALADA......................... 122

TABELA 25. CUSTOS DE CADA COMBINAÇÃO DE CONTÊINERES................................... 123

TABELA 26. CUSTOS DE TODOS OS SISTEMAS E DE CADA COMBINAÇÃO DE CONTÊINERES 
1.

1.1.

1.1.1.

1.1.2.

1.2 .

2.

2.1 .

2.2 .

2.2.1.

2.2.2.

2.3 .

2.4 .

2.5 .

3.

3.1 .

3.2 .

3.2.1.

3.2.2.

3.2.3.

3.2.4.

3.2.4.1

3.2.4.2

3.2.4.3

3.2.4.4

3.2.4.5

3.3 .

3.3.1.

3.3.1.1.

3.3.1.2.

3.3.2.

3.3.3.

4.

4.1.

4.1.1.

4.1.2.

4.1.3.

4.2 .

4.3.

4.4 .

5.

5.1 .

5.1.1.

5.1.2.

INTRODUÇÃO. 12

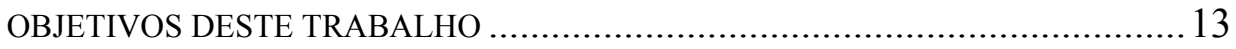

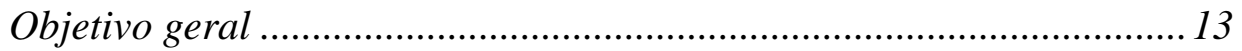

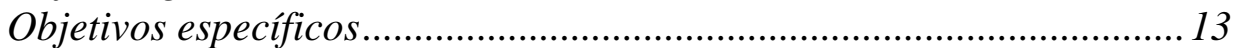

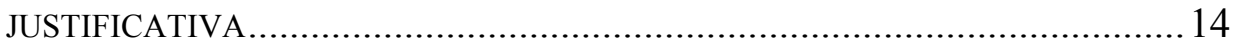

REVISÃO BIBLIOGRÁFICA........................................................ 16

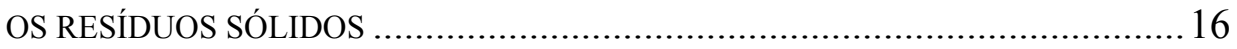

A GESTÃO DOS RESÍDUOS SÓLIDOS E A COLETA SELETIVA.......................... 18

A gestão e o gerenciamento dos resíduos sólidos ...................................18

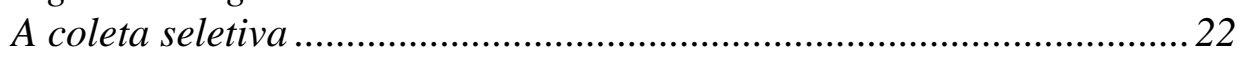

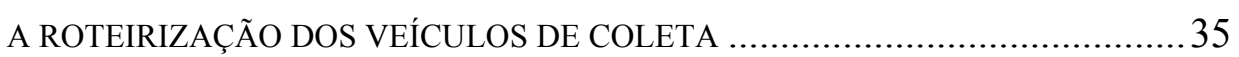

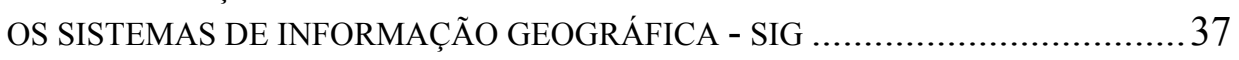

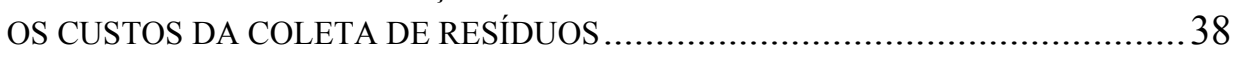

MATERIAIS E MÉTODOS ..........................................................41

SISTEMAS DE COLETA SELETIVA A SEREM ESTUDADOS ..............................41

UTILIZAÇÃO DO SOFTWARE DE ROTEIRIZAÇÃO ....................................... 42

Obtenção da base de dados geográfica .................................................. 42

Atualização do sistema viário e determinação do sentido de fluxo dos

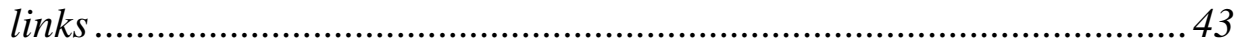

Preenchimento da base de dados...........................................................44

Descrição e utilização das rotinas do software SIG utilizado.................45

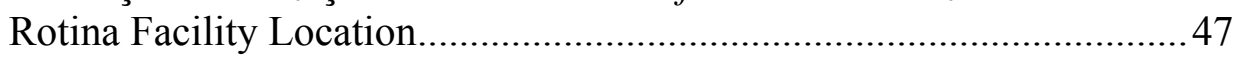

Rotina Transportation Problem.......................................................... 49

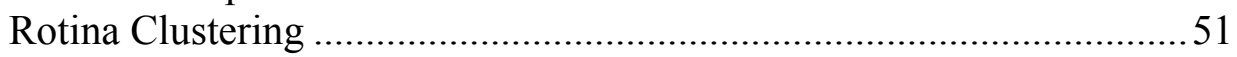

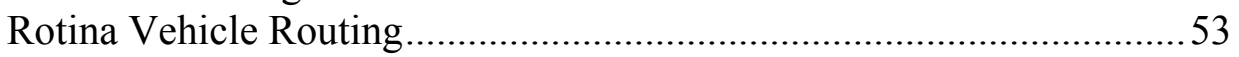

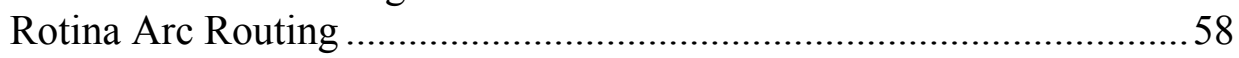

CUSTOS DE TRANSPORTES NA COLETA DE RESÍDUOS...............................63

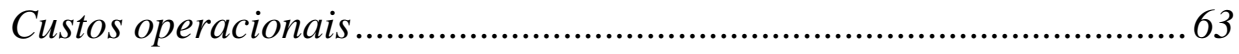

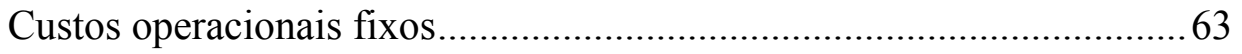

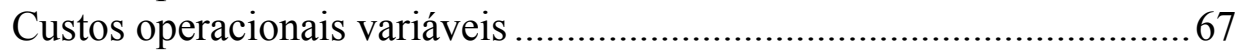

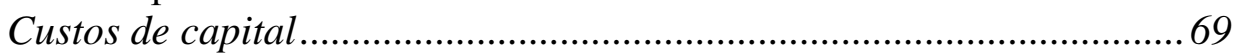

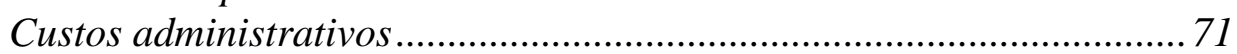

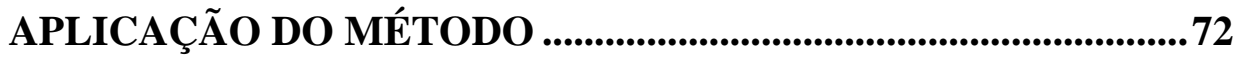

DELIMITAÇÃO DA ÁREA A SER ESTUDADA............................................... 72

Determinação da demanda residencial aproximada de São Carlos ...... 74

Definição dos cenários a serem analisados........................................... 75

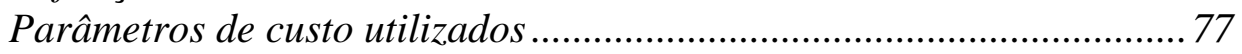

APLICAÇÃO DAS ROTINAS DO SOFTWARE .............................................. 78

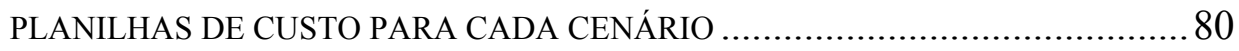

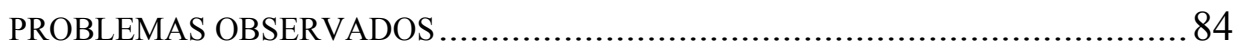

RESULTADOS E DISCUSSÃO ........................................................86

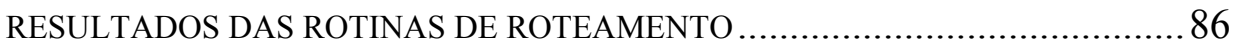

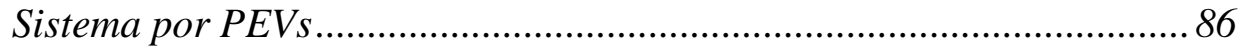

Sistema Porta-a-Porta ........................................................................ 93 


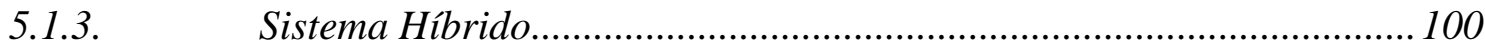

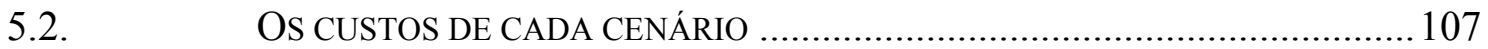

5.2.1. Custos de acordo com os parâmetros inicialmente propostos .............. 107

5.2.2. Custos com os parâmetros vida útil dos insumos depreciáveis aumentados (120 meses) ....................................................................... 113

5.2.3. $\quad$ Custos com os parâmetros da vida útil dos insumos depreciáveis aumentados (120 meses) e parâmetro da taxa de remuneração do capital investido diminuída pela metade (crédito mais barato) ........................ 115

5.2.4. $\quad$ Custos com os parâmetros da vida útil dos insumos depreciáveis aumentados (120 meses), parâmetro da taxa de remuneração do capital investido diminuída pela metade (crédito mais barato) e sem considerar encargos sobre a mão-de-obra (cooperativa) ...

5.3. COMPARAÇÃO DOS CUSTOS DO SISTEMA POR PEVS PARA ALGUMAS VARIAÇÕES NOS TIPOS DE CONTÊINERES UTILIZADOS .............................. 120

6. CONCLUSÕES E RECOMENDAÇÕES ....................................129

7. REFERÊNCIAS BIBLIOGRÁFICAS ............................................ 132

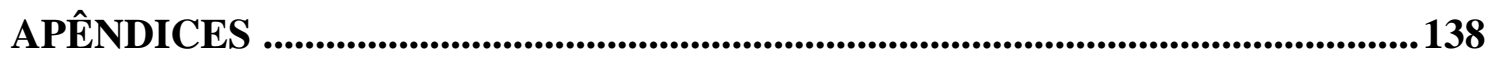

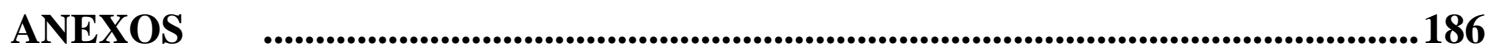




\section{INTRODUÇÃO}

O maior propósito da coleta seletiva é a reintegração dos materiais constituintes dos bens de pós-consumo, contribuindo para o processo de adequação da destinação dos resíduos urbanos.

No Brasil, a responsabilidade pela gestão dos resíduos sólidos domiciliares compete aos municípios, que enfrentam dificuldades no setor, como: o despreparo técnico e gerencial do pessoal designado para acompanhar todas as etapas que a questão dos resíduos sólidos exige; as dificuldades para a celebração de acordos intergovernamentais; à receita deficitária, o confronto permanente com os órgãos de controle ambiental; e à ausência de uma política de diretrizes para a gestão de resíduos sólidos no país envolvendo os três níveis de governo (LEITE, 1997).

Ainda segundo Leite (1997), o esforço de promoção da revalorização de resíduos deve incidir sobre:

- A investigação e o desenvolvimento de técnicas;

- A otimização dos sistemas de coleta e de triagem (coleta seletiva, triagem eletromecânica, etc.);

- A redução dos custos externos (coleta, triagem e transporte);

- A criação de mercados dos produtos provenientes da revalorização;

Apesar da coleta seletiva de resíduos sólidos ser apenas um instrumento auxiliar na gestão dos resíduos, e não uma medida definitiva para a solução do problema, esta atividade tem a característica de familiarizar a população com a questão dos resíduos sólidos e reintroduzir materiais na cadeia produtiva além, de gerar empregos e melhorar a qualidade de vida de catadores, que muitas vezes participam desses programas por meio de cooperativas e sobrevivem a partir da renda gerada pela venda do material reciclável.

O Compromisso Empresarial para a Reciclagem - CEMPRE (CEMPRE, 2004), mostra que a evolução da coleta seletiva no Brasil tem sido mais intensa nos últimos 
anos. O envolvimento de prefeituras municipais tende a crescer na medida em que a população passa a cobrar uma postura mais pró-ativa de seus governantes. Em 1994, 81 municípios faziam a coleta seletiva em escala significativa. Em 1999 este número pulou para 135, e em 2002 ultrapassou a marca de 200. Dados recentes do Instituto Brasileiro de Geografia e Estatítica - IBGE (IBGE 2000a) apontam para 451 municípios, ou seja, cerca de $8 \%$ do total nacional. A reciclagem de resíduos urbanos se aproxima de 5\%, com alguns tipos de materiais apresentando índices bastante elevados, como as latinhas de alumínio e o papelão.

Deluqui (1998) cita que a coleta de resíduos é uma das atividades mais importantes a serem desenvolvidas dentro de um sistema de gerenciamento de resíduos sólidos, sendo a sua importância decorrente de elevados custos operacionais (equipamentos e pessoal envolvido) bem como do aspecto estético a que está relacionada.

Portanto, que a sustentabilidade econômica é uma característica importante para o aperfeiçoamento de iniciativas como a coleta seletiva de resíduos sólidos. A considerável falta de publicações técnicas sobre os custos que incidem neste tipo de coleta motivou este trabalho.

\subsection{OBJETIVOS DESTE TRABALHO}

\subsubsection{Objetivo geral}

O objetivo deste trabalho é desenvolver uma metodologia para avaliar os custos de sistemas de coleta seletiva de resíduos sólidos domiciliares.

\subsubsection{Objetivos específicos}

- Aplicação um sistema de informação geográfica para a roteirização dos veículos de coleta seletiva de resíduos sólidos conferindo uma maior confiabilidade à análise;

- Comparação dos custos de transporte de três tipos de sistema de coleta seletiva de resíduos sólidos;

- Analise de viabilidade, sob o ponto de vista operacional, de Pontos de Entrega Voluntária (PEV); 
- Definição do posicionamento mais adequado dos coletores PEVs segundo o tipo de coleta e a facilidade para a entrega voluntária;

- Investigar a influência nos custos de transporte de diferentes combinações de coletores PEVs.

\subsection{JUSTIFICATIVA}

$\mathrm{Na}$ maioria dos municípios, o circuito dos resíduos sólidos apresenta características muito semelhantes, da geração à disposição final, envolvendo apenas as atividades de coleta regular, transporte e descarga final, em locais quase sempre selecionados pela disponibilidade de áreas e pela distância em relação ao centro urbano e às vias de acesso, ocorrendo a céu aberto, em valas etc. Em raras situações este circuito inclui procedimentos diferenciados: coleta seletiva, processos de compostagem, tratamento térmico etc., e, mesmo assim, frequentemente esses processos são mal planejados, o que dificulta a operação e torna-os inviáveis em curtíssimo prazo (LEITE, 1997).

Além disso, a coleta seletiva nas cidades brasileiras é uma prática relativamente recente, onde a maioria das iniciativas foi desenvolvida nos últimos anos. As peculiaridades locais estão sendo descobertas e a sustentabilidade econômica ainda não foi alcançada pela maioria desses programas.

Trabalhos que se aprofundem no tema e com isso desvendem suas particularidades, além de fornecerem subsídios para o tomador de decisões são de grande importância nesta fase da coleta seletiva no Brasil.

Cunha, C. ${ }^{1}$ et al. (1995, apud Sarkis 2000), citam que "os serviços de limpeza absorvem entre 7 e $15 \%$ dos recursos de um orçamento municipal, dos quais $50 \%$ são destinados à coleta e ao transporte do resíduos sólidos”. E este problema é agravado quando da terceirização do serviço de coleta.

\footnotetext{
${ }^{1}$ CUNHA, C. B., et al. (1995). Serviços de limpeza. In: JARDIM, N. S. coord. et al. Lixo Municipal: manual de gerenciamento integrado. São Paulo, Instituto de Pesquisas Tecnológicas - IPT/ Compromisso Empresarial para a Reciclagem - CEMPRE. Cap. 3, p37-71.

SARKIS, L. F. P. G. (2000). Resíduos de serviços de saúde em cidades de médio porte: caracterização de sistemas de coleta e aplicação de um Sistema de Informação Geográfica na roteirização de veículos de coleta e transporte. São Carlos. 216p. Dissertação (Mestrado) - Escola de Engenharia de São Carlos, Universidade de São Paulo.
} 
A análise da roteirização e otimização dos sistemas de coleta seletiva é uma maneira de reduzir os custos do processo, que freqüentemente é deficitário e de subsistência. Santos (1999) afirma que: "O ponto central na otimização de itinerários, em sistemas de entregas urbanas, fundamenta-se na resolução de questões relacionadas à administração da distribuição. Uma vez que alguns componentes de custos são de difícil redução na prática, o planejamento nos serviços de distribuição torna-se um canal de minimização de custos".

O custo da coleta seletiva é, geralmente, maior que o da coleta convencional, como mostrado em CEMPRE (2004) onde o custo médio por tonelada recicláveis coletados no ano de 2004 era de US\$ 114,00, seis vezes maior que a coleta convencional, fazendo com que essa prática seja limitada, principalmente, às regiões Sudeste e Sul do Brasil. Além de existirem diferenças nos próprios municípios, pois, mesmo nas regiões mais desenvolvidas do país, esse tipo de coleta tende a ser eficiente e regular nas áreas centrais ou mais desenvolvidas economicamente, com problemas nas áreas de difícil acesso e periferias.

Justifica-se assim, o empenho em pesquisas visando o planejamento dos sistemas de manejo de resíduos em termos de qualidade dos serviços, racionalização da frota e pessoal, aumento da produtividade e redução de custos.

A topografia e o emaranhado urbano são uma influência importante na localização de pontos de coleta. A utilização de um Sistema de Informações Geográficas, através da representação da rede viária de uma cidade, pode conferir representatividade e fidelidade às condições reais em que os deslocamentos do veículo coletor ocorrem, o que permite simular alternativas de roteirização de veículos.

Uma abordagem baseada em um SIG se mostra útil para determinar o número e a localização de depósitos de material reciclável, em um sistema municipal integrado de gerenciamento de resíduos sólidos como mostrado em Valeo, Baetz e Tsanis (1998).

Este estudo, então, propõe uma ferramenta capaz de quantificar os custos de vários sistemas de coleta para que possam ser comparados, e a melhor alternativa encontrada. 


\section{REVISÃO BIBLIOGRÁFICA}

\subsection{OS RESÍDUOS SÓLIDOS}

A Associação Brasileira de Normas Técnicas - (ABNT, 2004a), NBR 10.004, define resíduos sólidos como:

"Resíduos nos estados sólidos e semi-sólidos, que resultam de atividades de origem: industrial, doméstica, hospitalar, comercial, agrícola, de serviços e de varrição. Ficam incluídos nesta definição os lodos provenientes de sistemas de tratamento de água, aqueles gerados em equipamentos e instalações de controle de poluição, bem como determinados líquidos cujas particularidades tornem inviável seu lançamento na rede pública de esgoto ou corpos de água, ou exijam para isso soluções técnicas e economicamente inviáveis, em face à melhor tecnologia disponível.”

Normalmente os resíduos sólidos são classificados segundo a sua origem, como: urbanos; industriais; resíduos de serviços de saúde; resíduos de portos, aeroportos, terminais rodoviários e ferroviários; resíduos agrícolas; resíduos de construção e demolição e resíduos radioativos (JARDIM et al. ${ }^{2}$, 1995, apud SCHALCH et al., 2001).

Ainda, segundo Jardim et al. (1995, apud SCHALCH et al., 2001), os resíduos sólidos urbanos, cuja responsabilidade desde a coleta até a disposição final é atribuída às prefeituras, são dos tipos: domiciliar, comercial (co-responsável por quantidades pequenas) e de serviços.

Neste estudo, serão considerados os resíduos sólidos domiciliares (RSD’s), que são constituídos por restos alimentares, embalagens, como vasilhames plásticos, de vidro ou latas, papéis, papelão, plásticos, vidros, varredura, folhagens e outros (JARDIM et al., 1995, apud SCHALCH et al., 2001).

As características dos RSD's variam bastante. O principal objetivo da caracterização de resíduos sólidos é: definir a forma mais adequada de destinação final a

\footnotetext{
${ }^{2}$ JARDIM, N. S. coord. et al. Lixo Municipal: manual de gerenciamento integrado. São Paulo, Instituto de Pesquisas Tecnológicas - IPT/ Compromisso Empresarial para a Reciclagem - CEMPRE.

SCHALCH, V; LEITE, W. C. A., FERNANDES JR, J.L., CASTRO, M.C.A.A. (2001). Apostila do curso de "Gerenciamento de Resíduos Sólidos” do Programa de Pós-graduação em Hidráulica e Saneamento: agosto-dez. 2001 (Apostila). 169p. Escola de Engenharia de São Carlos, Universidade de São Paulo.
} 
ser aplicada aos resíduos sólidos gerados em uma determinada comunidade; viabilizar a implantação de algum sistema de tratamento, como por exemplo, a compostagem a partir dos resíduos orgânicos; e avaliar o aproveitamento do material inorgânico para instalação de usina de triagem e posterior venda dos materiais.

$\mathrm{Na}$ caracterização dos resíduos sólidos, cada tipo é identificado por suas propriedades físicas e composição química. A classificação de resíduos envolve a identificação do processo ou atividade que lhes deu origem e de seus constituintes e características. Além disso, possibilita a comparação destes constituintes com listagens de resíduos e substâncias cujo impacto à saúde e ao meio ambiente é conhecido (ABNT, 2004a).

Para os efeitos da NBR 10.004 (ABNT, 2004a), os resíduos são classificados em:

a) resíduos classe I - Perigosos;

b) resíduos classe II - Não perigosos;

- resíduos classe II A - Não inertes;

- resíduos classe II B - Inertes.

Os resíduos classe I são aqueles que apresentam a característica de periculosidade que, em função de suas propriedades físicas, químicas ou infectocontagiosas, podem apresentar riscos à saúde pública e ao meio ambiente. São classificados segundo: inflamabilidade, corrosividade, reatividade, toxicidade $\mathrm{e}$ patogenicidade quando a amostra ou extrato lixiviado, obtidos segundo os procedimentos descritos nas normas NBR 10.005 (ABNT, 2004b) e NBR 10.007 (ABNT, 2004d) apresentarem as propriedades equivalentes às descritas na norma NBR 10.004 (ABNT, 2004a).

Os resíduos classe II A são aqueles que não se enquadram nas classificações de resíduos classe I ou classe II B, nos termos da NBR 10.004 (ABNT, 2004a). Podem ter propriedades, tais como biodegradabilidade, combustibilidade ou solubilidade em água.

Os resíduos classe II B são quaisquer resíduos que, quando amostrados de uma forma representativa, segundo a NBR 10.007 (ABNT, 2004d), e submetidos a um contato dinâmico e estático com água destilada e desionizada, à temperatura ambiente 
conforme a NBR 10.006 (ABNT, 2004c), não apresentarem nenhum de seus constituintes solubilizados a concentrações superiores aos padrões de potabilidade de água, excetuando-se aspecto, cor, turbidez, dureza e sabor.

\subsection{A GESTÃO DOS RESÍDUOS SÓLIDOS E A COLETA SELETIVA}

\subsubsection{A gestão e o gerenciamento dos resíduos sólidos}

O conceito de gestão de resíduos sólidos abrange atividades referentes à tomada de decisões estratégicas e à organização do setor para esse fim, envolvendo instituições políticas, instrumentos legais e estratégias de ação, enquanto que o gerenciamento de resíduos sólidos refere-se aos aspectos tecnológicos e operacionais da questão como afirma Leite (1997).

Conforme mostrado na Figura 1, as atividades gerenciais ligadas aos resíduos sólidos podem ser agrupadas em seis elementos funcionais:

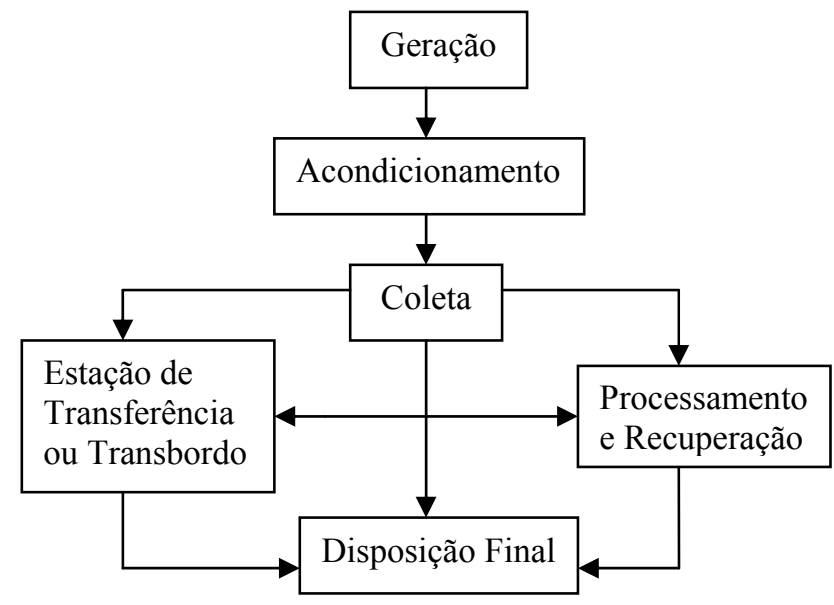

FIGURA 1. O processo da coleta de resíduos sólidos e suas inter-relações

Fonte: adaptado de Tchobanoglous (1977)

Segundo Cunha e Caixeta Filho (2002), tais atividades podem ser descritas da seguinte forma: 


\section{Geração}

A geração de resíduos por uma população é bastante variável e depende de uma série de fatores, como renda, época do ano, modo de vida, movimento da população nos períodos de férias e fins de semana, além de métodos de acondicionamento de mercadorias (como a utilização de embalagens não retornáveis).

\section{Acondicionamento, Coleta e Transporte}

A primeira etapa do processo de remoção dos resíduos sólidos corresponde à atividade de acondicionamento do resíduo. Podem ser utilizados diversos tipos de vasilhames, como vasilhas domiciliares, tambores, sacos plásticos, sacos de papel, contêineres comuns, contêineres basculantes, entre outros.

A operação de coleta engloba desde a partida do veículo de sua garagem, compreendendo todo o percurso realizado na viagem para a remoção dos resíduos, dos locais onde foram acondicionados aos locais de descarga, até o retorno ao ponto de partida.

A coleta normalmente pode ser classificada em dois tipos de sistemas: sistema especial de coleta de resíduos (resíduos contaminados) e sistema de coleta de resíduos não contaminados. Neste último, a coleta pode ser realizada de maneira convencional (resíduos encaminhados para o destino final) ou seletiva (resíduos recicláveis que são encaminhados para locais de tratamento e/ou recuperação).

O transporte é o movimento do resíduo até o seu destino final (incinerador, aterros, lixões, usinas de reciclagem, etc.). Em alguns casos são necessárias operações de transferência, onde os resíduos são acumulados em veículos com capacidades maiores e transportados ao seu destino final, e para isso são usadas as estações de transferência.

\section{Disposição final}

Para a disposição final dos resíduos sólidos, os aspectos econômicos muitas vezes sobrepõem-se a questões ambientais. Porém, atualmente, algumas técnicas de disposição, como depósitos a céu aberto (lixões) ou lançamento de resíduos em rios e 
mares, tornaram-se intoleráveis do ponto de vista ambiental e econômico. Assim, podem ser:

- Aterro Sanitário: Forma de disposição final de resíduos sólidos urbanos no solo através de confinamento em camadas cobertas com material inerte, geralmente, solo, de acordo com normas operacionais específicas, e de modo a evitar danos ou riscos à saúde pública e à segurança, minimizando os impactos ambientais (ABNT 1992). Assim, permite o confinamento seguro em termos de controle de poluição ambiental e proteção à saúde pública, sendo proibido o acesso de pessoas estranhas. Os gases liberados durante a decomposição são captados e podem ser queimados com sistema de purificação de ar ou ainda utilizados como fonte de energia (aterros energéticos).

- Aterro Controlado: esta forma de disposição produz, em geral, poluição localizada, pois similarmente ao aterro sanitário, a extensão da área de disposição é minimizada. Porém, geralmente não dispõe de impermeabilização de base (comprometendo a qualidade das águas subterrâneas), nem sistemas de tratamento de chorume ou de dispersão dos gases gerados (ABNT 1985). Este método é preferível ao lixão, mas, devido aos problemas ambientais que causa e aos seus custos de operação, sua qualidade é inferior à do aterro sanitário.

- Lixão: Inadequada disposição final de resíduos sólidos, que se caracteriza pela simples descarga sobre o solo sem medidas de proteção ao meio ambiente ou à saúde pública. É o mesmo que descarga de resíduos a céu aberto.

- Incineração: Processo de decomposição térmica, onde há redução do peso, do volume e das características de periculosidade dos resíduos, com a conseqüente eliminação da matéria orgânica e das características de patogenicidade (capacidade de transmissão de doenças) através da combustão controlada (ABNT 1990).

- Compostagem: Processo de reciclagem da matéria orgânica formando um composto. Esse processo permite um destino aos resíduos orgânicos domésticos, como restos de comidas e resíduos do jardim (ABNT, 1996). Os materiais mais utilizados na compostagem são cinzas, penas, lixo 
doméstico, aparas de grama, rocha moída e conchas, feno ou palha, podas de arbustos e cerca viva, resíduos de cervejaria, folhas, resíduos de couro, jornais, turfa, acículas de pinheiro, serragem, algas marinhas e ervas daninhas.

Nos anos 80, tendo em vista o grande crescimento do volume de resíduos, chegou-se à conclusão de que era necessário enfatizar a prevenção e a reciclagem de materiais secundários, principalmente nos países mais desenvolvidos, onde havia a denominada "crise de aceitação" por dificuldades políticas com as novas instalações de estações de tratamento e técnicas de disposição final de resíduos; deste modo, procurarse-ia minimizar o seu volume e a sua periculosidade (LEITE, 1997).

No trabalho de Leite (1997), foram analisadas as políticas de gerenciamento de resíduos sólidos de alguns países, e, todos aqueles estudados assumem como metas prioritárias a prevenção, através da redução do volume de resíduos na fonte (com ênfase no desenvolvimento de tecnologias mais limpas nas linhas de produção e análise do ciclo de vida de novos produtos a serem colocados no mercado); a reutilização e a reciclagem dos resíduos; a transformação, através de tratamentos físicos, químicos e biológicos, enfatizando a incineração com aproveitamento de energia como forma de redução do volume de resíduos, aumentando o período de vida útil dos aterros sanitários.

A Agenda 21 indica que o manejo dos resíduos sólidos deve ser não apenas o simples depósito ou aproveitamento dos resíduos gerados por métodos seguros, mas deve ir além, buscando resolver a causa fundamental do problema, procurando mudar os padrões não sustentáveis de produção e consumo. Implica, portanto, na utilização do conceito de manejo integrado do ciclo vital (AGENDA 21, 1992).

Gerenciar resíduos de forma integrada é articular ações normativas, operacionais, financeiras e de planejamento que uma administração municipal desenvolve, apoiada em critérios sanitários, ambientais e econômicos, para coletar, tratar e dispor o resíduo sólido de uma cidade, ou seja, é acompanhar de forma criteriosa todo o ciclo dos resíduos, da geração à disposição final (“do berço ao túmulo"), empregando técnicas e tecnologias mais compatíveis com a realidade local. $\mathrm{O}$ gerenciamento integrado de administração do ciclo de vida do resíduo sólido deve ser 
uma ação conjunta, onde todas as fases do ciclo de vida dos resíduos sólidos são acompanhadas para tentar minimizar os efeitos dos resíduos em cada uma de suas fases (LEITE, 1997).

No Brasil, 228.413 t de RSD são produzidos diariamente e $72 \%$ deste total é coletado. A produção nacional média de resíduos sólidos por habitante/dia é estimada em 600 gramas (IBGE, 2000a). A responsabilidade pela gestão dos resíduos sólidos domiciliares compete aos municípios, que enfrentam enormes dificuldades no setor, devido principalmente à falta de conscientização e vontade política de seus dirigentes; ao despreparo técnico e gerencial do pessoal designado para acompanhar todas as etapas que a questão dos resíduos sólidos exige; às dificuldades para a celebração de acordos intergovernamentais; à receita deficitária, ao confronto permanente com os órgãos de controle ambiental; à falta de informação ao público e, o que é pior, à ausência de uma política de diretrizes para a gestão de resíduos sólidos no país envolvendo os três níveis de governo (LEITE, 1997).

\subsubsection{A coleta seletiva}

Segundo Pieroni ${ }^{3}$ (apud CAMPOS, 1994) o conceito de coleta seletiva surge oficialmente na Itália em 1941, definido como: uma separação prévia de materiais que poderiam ser reaproveitados.

A Associação Brasileira de Normas Técnicas (ABNT, 1993), NBR 12980, define a coleta seletiva como: "Coleta que remove os resíduos previamente separados pelo gerador, tais como papéis, latas, vidros e outros".

A coleta seletiva tem como objetivo a separação, na própria fonte geradora, dos materiais que podem ser recuperados, com o acondicionamento diferenciado para cada material ou grupo de materiais. Para haver esse tipo de coleta faz-se necessária a existência de um mercado para os recicláveis e, além disso, o cidadão deve estar consciente da sua participação no processo.

\footnotetext{
${ }^{3}$ PIERONI, M. IVR (Instituto Valorizzacione Reciclo Material). CAMPOS, R. de (1994). Proposta de Sistematização e Reavaliação do Processo de Gerenciamento de Serviços de Coleta Seletiva de Resíduos Sólidos Domiciliares. São Carlos. 104p. Dissertação (Mestrado). Escola de Engenharia de São Carlos, Universidade de São Paulo.
} 
Esse tipo de coleta pode ser realizada nos domicílios, por veículo de carroceria adaptada, ou através de Postos de Entrega Voluntária (PEVs), mediante a instalação de caçambas e contêineres em pontos estratégicos, onde a população possa levar os materiais segregados.

Para Campos (1994) os sistemas de coleta seletiva podem ser dos tipos espontâneo e institucional.

A coleta seletiva espontânea é praticada por indivíduos ou empresas, freqüentemente em regime de subsistência, que coletam e vendem para empresas recicladoras com objetivos de subsistência ou lucro; a coleta seletiva de papéis e papelões é tradicionalmente praticada de forma espontânea.

A coleta seletiva institucional, que geralmente objetiva a proteção ambiental e o sentido de preservação da utilidade dos bens recuperados, pode ter três linhas de ação:

- Obrigatória por legislação específica;

- Supervisionada e induzida pelo poder público por meio de campanhas publicitárias e educacionais, com ou sem a participação governamental;

- Voluntária, através da ação comunitária catalisada por instituições de direito privadas, com ou sem ajuda do poder público.

Eigenheer (1999) cita que a primeira experiência sistemática de coleta seletiva de resíduos sólidos realizada no Brasil foi implantada em 1985, no estado do Rio de Janeiro, na cidade de Niterói. Este projeto teve como ênfase a descentralização administrativa e o caráter comunitário, privilegiando essencialmente a pequena escala, para com isso evitar os riscos inerentes a mudanças nas administrações municipais com suas usuais descontinuidades. A partir de 1988 foram desenvolvidas experiências de maior amplitude e não descentralizadas, implantadas por prefeituras, como as de Curitiba, Florianópolis, São Paulo, São Sebastião, São José dos Campos e outras.

Ainda, segundo Eigenheer (1999), pouca atenção foi dada, por parte das prefeituras, aos custos operacionais neste primeiro momento das experiências brasileiras. Os resultados políticos, a projeção na mídia e o retorno em educação ambiental eram para as administrações municipais extremamente compensadores. 
Campos (1994) diz que as considerações necessárias para a elaboração de um plano para planejamento, controle e manutenção da coleta seletiva são:

- Estágio da cultura organizacional;

- Processo de educação ambiental;

- Quantidade de resíduos produzidos;

- Tipo, característica e composição dos resíduos;

- Hábitos, costumes e necessidades do sistema a ser estudado;

- Sistemas, equipamentos e mão-de-obra operacional;

- Densidade populacional e malha urbana

- Rotas disponíveis: condições, capacidade, usos e características gerais;

- Nível e potencial econômico do sistema a ser estudado;

- Estudo das relações políticas, sociais e legais perante a população.

Leite (1997) salienta que a reciclagem é uma atividade econômica que deve ser vista como um elemento dentro do conjunto de atividades integradas no gerenciamento dos resíduos, não se traduzindo, portanto, como a principal "solução" para o resíduo sólido, já que nem todos os materiais são técnica ou economicamente recicláveis.

O tratamento ou a "industrialização dos resíduos" envolve um conjunto de atividades e processos cujo objetivo é promover a reciclagem de alguns de seus componentes, como o plástico, o papelão, os metais e os vidros, além de transformar a matéria orgânica em composto, para ser utilizado como fertilizante e condicionador do solo, ou em polpa para a utilização como combustível. O tratamento nunca constitui um sistema de destinação final completo ou definitivo, pois sempre há um remanescente inaproveitável. Entretanto, as vantagens decorrentes dessas ações, tornam-se mais claras após o equacionamento dos sistemas de manejo e de destinação final dos resíduos (LEITE, 1997).

Ribeiro e Lima (2000) citam que os obstáculos mais comuns encontrados na implementação da coleta seletiva dos resíduos sólidos nos casos analisados em seu trabalho foram:

- Dificuldades na comercialização;

- Inexistência de infra-estrutura para estocagem; 
- Falta de caminhão reserva, interferindo no cumprimento do roteiro da coleta, provocando descontentamento da população e alterando volume de materiais coletados;

- Dependência, por parte dos catadores, da estrutura operacional da prefeitura;

- Falta de prensa, devido ao volume ainda pequeno de material;

- Armazenamento inadequado dos materiais recicláveis;

- Dificuldade de capitalização da cooperativa para comprar equipamentos.

\section{O gerenciamento da coleta e o transporte dos resíduos sólidos}

Aguiar (1993), em seu trabalho, analisou como os aspectos da morfologia de uma cidade de médio porte e as características socioeconômicas de seus habitantes, influenciam o sistema de coleta de resíduos sólidos:

- Se a população da cidade cresce, preenchendo seus espaços vazios, o custo per capita de coleta e transporte de resíduos sólidos diminui;

- Numa área urbana a taxa de geração de resíduos sólidos varia bastante, e portanto, deveria ser considerada no planejamento dos serviços de coleta. Adotar uma taxa média para toda a cidade leva a aproximações grosseiras e tarefas de coleta desequilibradas. Entretanto, como a grande maioria das cidades não possui tais dados, a solução é planejar, em uma primeira etapa, as viagens, considerando uma taxa uniforme de geração de resíduo, e com o tempo ir redimensionando as áreas de coleta, em função dos tempos de coleta e/ou peso do resíduo por veículo;

- Os custos tanto médios como totais, crescem de forma acentuada com o aumento da taxa de geração de resíduo.

- A velocidade de um veículo de coleta na área urbana praticamente não influi nos custos do serviço.

- O uso de veículos de grande capacidade é desejável para as áreas de coleta, independente da sua densidade populacional. Em áreas estritamente residenciais, tem sido adequado definir as rotas com base no número de domicílios. Todavia, em outros locais, onde os tipos de construções são muito variados, tem se tornado difícil determinar uma função, que estime com razoável precisão, o tempo para cobrir um trecho de rua. 
Apesar do desenvolvimento de modelos de planejamento estratégico, as descrições de estratégias de separação dos recicláveis na fonte geradora são usualmente insuficientes para permitir o cálculo das quantidades de material coletado separadamente. A quantidade de material coletado separadamente em uma área depende de dois fatores: a cobertura do sistema de coleta aplicado e a atividade de separação dos produtores de resíduos, consistindo na taxa de participação e na eficiência de separação.

A cobertura de um sistema de coleta é definida como: a taxa de produção de um material naquelas propriedades em que a coleta seletiva está disponível e a quantidade do material em questão produzido em todas as propriedades da área. A taxa de participação é definida como a parte das pessoas que provêem materiais separados às lixeiras naquelas propriedades onde esta opção é viável (TANSKANEN, 2000).

\section{Os sistemas de coleta de resíduos sólidos}

Os sistemas de coleta se diferenciam principalmente pelo tipo de recolhimento, a tecnologia aplicada nesta operação e a natureza do material recolhido que pode ser por tipo, por grupos ou todos os recicláveis juntos.

Em Environmental Protection Agency - EPA4 (1995 apud GOULART, 2003), diferentes tipos de recolhimento de resíduos são descritos. A Tabela 1 apresenta uma breve descrição de cada tipo bem como sua aplicação.

\footnotetext{
4 EPA (1995). Decision Maker's Guide to Solid Waste Management - Collection and Transfer. Volume. United States Environmental Protection Agency.

GOULART, A. (2003). Comparison of deep collection system with traditional systems. Tampere Finlândia. 112 p. Dissertação (Msc). Tampere University of Technology.
} 
Tabela 1. Diferentes sistemas de coleta de resíduos e suas respectivas descrições e aplicações.

\begin{tabular}{|c|c|c|}
\hline $\begin{array}{c}\text { Sistema de } \\
\text { Recolhimento }\end{array}$ & Descrição & Aplicação \\
\hline Coleta de "Meio-Fio" & Contêineres na sarjeta & $\begin{array}{l}\text { Áreas urbanas e } \\
\text { suburbanas }\end{array}$ \\
\hline "Esquinas" & Contêineres em "becos", vielas e esquinas & $\begin{array}{l}\text { Áreas urbanas e } \\
\text { suburbanas }\end{array}$ \\
\hline $\begin{array}{l}\text { Recolhimento e devolução } \\
\text { do contêiner no quintal da } \\
\text { propriedade }\end{array}$ & $\begin{array}{l}\text { Duas equipes: } \\
\text { - uma para transportar os contêineres do quintal } \\
\text { - outra para esvaziar os contêineres }\end{array}$ & Áreas residenciais \\
\hline $\begin{array}{l}\text { Recolhimento no quintal da } \\
\text { propriedade }\end{array}$ & $\begin{array}{l}\text { A equipe entra na propriedade para transportar o } \\
\text { container até o veículo de coleta }\end{array}$ & Áreas residenciais \\
\hline Porta-a-Porta & $\begin{array}{l}\text { Os residentes põem o resíduo em sacos plásticos } \\
\text { ou de papel ou pequenas lixeiras fora das casas }\end{array}$ & Áreas urbanas \\
\hline Local específico de entrega & $\begin{array}{l}\text { Os residentes põem seus resíduos em local } \\
\text { específico: eco-centro ou estação de transferência }\end{array}$ & $\begin{array}{l}\text { Áreas com baixa } \\
\text { densidade } \\
\text { populacional, e áreas } \\
\text { rurais }\end{array}$ \\
\hline $\begin{array}{l}\text { Extração a vácuo ou } \\
\text { método pneumático }\end{array}$ & $\begin{array}{l}\text { Os residentes põem seus resíduos em condutos } \\
\text { que existem em cada andar do edifício; o resíduo é } \\
\text { colocado em sacos plásticos }\end{array}$ & $\begin{array}{l}\text { Edifícios e áreas } \\
\text { urbanas }\end{array}$ \\
\hline $\begin{array}{l}\text { Contêineres rebocáveis de } \\
\text { alta capacidade }\end{array}$ & $\begin{array}{l}\text { Contêineres rolantes com grande capacidade são } \\
\text { localizados na propriedade do gerador dos } \\
\text { resíduos e são transportados diretamente para uma } \\
\text { estação de transferência ou local de depósito }\end{array}$ & $\begin{array}{l}\text { Grandes edifícios e } \\
\text { complexos comerciais } \\
\text { e industriais }\end{array}$ \\
\hline
\end{tabular}

Fonte: adaptado de EPA (1995 apud GOULART, 2003).

Em áreas urbanas e suburbanas, os rejeitos podem ser coletados usando os métodos de coleta por "meio-fio" ou "esquinas". Nestes métodos, os moradores colocam os contêineres a serem esvaziados na sarjeta ou em becos e esquinas no dia da coleta. A equipe de coleta esvazia os contêineres dentro do veículo de coleta e os moradores retornam os contêineres ao local de armazenamento até a próxima coleta.

Outro método de coleta é o recolhimento e devolução do contêiner no quintal da propriedade onde os contêineres são carregados do quintal para a sarjeta por uma equipe especial e são esvaziados pela equipe de coleta. A equipe especial então transporta os contêineres de volta para seu local original de armazenagem.

A coleta porta-a-porta é o método onde os moradores colocam para fora os resíduos domésticos em sacos plásticos ou de papel ou em pequenas lixeiras e a equipe coleta o resíduo para dentro do veículo. 
A entrega em um local específico é o método onde os residentes transportam seus resíduos para um ponto específico que pode ser uma estação de transferência ou o local final de disposição. Este método é adequado para áreas com baixas densidades populacionais.

Sistemas especiais de coleta também existem para coletar os resíduos em áreas urbanas. No método de extração a vácuo ou pneumática, tubos são instalados pelo edifício e cada andar tem uma abertura para a colocação do resíduo em sacos plásticos ou de papel. No final dos tubos existem contêineres aonde os sacos são coletados. Os contêineres são esvaziados pela equipe de coleta no veículo.

Para grandes edifícios de apartamentos e complexos comerciais ou industriais, sistemas de contêineres rebocáveis são frequentemente usados. Os contêineres usados neste tipo de sistema têm capacidades acima de $38 \mathrm{~m}^{3}$. Eles são colocados na propriedade do gerador de resíduo, e quando estão cheios são transportados diretamente para o local de transferência ou disposição final.

No Brasil, a coleta seletiva é geralmente praticada das seguintes formas:

\section{- Coleta seletiva porta a porta}

Consiste na separação, pela população, dos materiais recicláveis existentes nos resíduos domésticos para que posteriormente os mesmos sejam coletados por um veículo específico. Na maioria das cidades onde existe o sistema, os roteiros de coleta seletiva são realizados semanalmente. Os principais aspectos negativos da coleta seletiva porta a porta são: o alto custo com o transporte e o alto valor unitário (\$/ton), quando comparada com a coleta convencional de resíduos sólidos (RESOL, 2004a).

Segundo Machado (1995), a coleta seletiva porta-a-porta pode ser:

Coleta combinada: a coleta combinada permite recolher simultaneamente resíduos domésticos e os resíduos recicláveis. Consiste em uma diferente organização dos operários e do material utilizado na coleta convencional.

Coleta separada, que pode ser dividida em: 
Coleta suplementar: necessita de um roteiro distinto do recolhimento convencional dos resíduos domésticos. Se este tipo tem o inconveniente de necessitar de uma organização particular, tem a vantagem de permitir a implementação de um roteiro adaptado especificamente aos resíduos recicláveis.

Coleta por substituição: substitui uma coleta convencional nos municípios onde esta se efetua mais de uma vez por semana. Assim, no caso de duas coletas convencionais por semana, pode-se substituir uma destas por uma de materiais recicláveis. Esta solução apresenta a vantagem de não necessitar, a princípio, de nenhuma organização da coleta de resíduos e de não ocasionar nenhum custo suplementar direto.

No Brasil, a coleta porta a porta tem sido o sistema mais utilizado tanto na coleta do lixo domiciliar misturado, como na coleta seletiva. Os coletores correm em média oito horas por dia atrás dos caminhões, carregando sacos de lixo, que podem chegar a pesar até $50 \mathrm{~kg}$ (RIBEIRO e LIMA, 2000).

\section{- Pontos de entrega voluntária (PEV)}

Consiste na instalação de contêineres ou recipientes em locais públicos para que a população, voluntariamente, possa fazer o descarte dos materiais separados em suas residências. As vantagens desse sistema são: o menor custo de transporte, se comparado com o custo da coleta porta a porta, e a melhor separação do material. As desvantagens são: o vandalismo e a depredação para o roubo do material reciclável, que obrigam os PEVs a serem localizados em locais seguros, que podem, em determinados casos, não ser os locais mais adequados às operações de coleta.

Mancini (1999), em seu trabalho, cita alguns problemas relacionados aos PEVs encontrados na implantação do programa de coleta seletiva em São Carlos: com freqüência sistemática, pessoas estranhas ao programa retiram dos PEVs os materiais com maior valor econômico (latinhas de alumínio, papel branco e papelão). Esta prática é um ponto de estrangulamento para o sucesso do programa, que fica apenas com o material de baixo valor (até mesmo sem valor algum) e com o ônus de arrumar e limpar os PEVs. 


\section{- Cooperativa de catadores}

A situação social existente no país obriga muitos desempregados a trabalhar como catadores de material reciclável. Eles trabalham nas ruas, vazadouros e aterros de lixo. A coleta seletiva por cooperativas se baseia na idéia de que estes catadores possam formar cooperativas de trabalho e se responsabilizar pela coleta de materiais recicláveis do município.

Cooperativa é uma sociedade de pessoas, de natureza civil, sem fins lucrativos, não sujeitas à concordata ou falência, constituídas para prestar serviços aos seus cooperantes. A Cooperativa em questão é uma sociedade auto gestionária, com características de microempresa, cujas atividades são a seleção e a comercialização de materiais recicláveis. Funciona em áreas com infraestrutura montada pela Prefeitura e essas estruturas são cedidas aos catadores sob a forma de comodato ou convênios.

As principais vantagens da existência de cooperativas de catadores são a geração de emprego e renda; o reconhecimento da profissão dos catadores, que muitas vezes são marginalizados pela sociedade; a organização do trabalho dos catadores nas ruas e a promoção da auto-estima e a cidadania.

Em locais onde o custo da mão-de-obra constitui-se um fator considerável nas planilhas de custos das empresas de limpeza urbana, investe-se cada vez mais em tecnologia na busca de soluções econômicas e eficientes, que garantam a qualidade dos serviços de coleta, transporte, tratamento e destino final de resíduos sólidos. Neste aspecto, a escolha da solução tecnológica mais adequada passa necessariamente pela colaboração efetiva de toda uma população atendida pelo sistema (RIBEIRO e LIMA, 2000). A Tabela 2 descreve as tecnologias usualmente utilizadas em países desenvolvidos, com suas vantagens e desvantagens. 
Tabela 2. Comparação de sistemas alternativos de coleta de recicláveis.

\begin{tabular}{|c|c|c|}
\hline Tecnologia & Vantagens & Desvantagens \\
\hline $\begin{array}{l}\text { Coleta automática (misturada) } \\
\text { Coleta misturada em veículos especiais } \\
\text { com automação total }\end{array}$ & $\begin{array}{l}\text { Melhor eficiência } \\
\text { Aumento da } \\
\text { compactação da } \\
\text { carga } \\
\text { Facilita a redução } \\
\text { da freqüência de } \\
\text { coleta } \\
\text { Custos de mão de } \\
\text { obra mais baixos }\end{array}$ & $\begin{array}{l}\text { Problemas devido à compactação e } \\
\text { quebra do vidro } \\
\text { Requer mais processamento ou } \\
\text { separação para os recicláveis misturados } \\
\text { Os veículos têm maiores custos iniciais e } \\
\text { maior manutenção } \\
\text { São necessários contêineres especiais; } \\
\text { A automação requer uma porcentagem } \\
\text { maior de ruas sem obstáculos }\end{array}$ \\
\hline $\begin{array}{l}\text { Coleta Separada } \\
\text { Veículos que, simultaneamente coletam } \\
\text { resíduos e recicláveis em compartimentos } \\
\text { separados }\end{array}$ & $\begin{array}{l}\text { Coleta em um só } \\
\text { veículo } \\
\text { Elimina rotas } \\
\text { extras de veículos } \\
\text { Eficiente em } \\
\text { cenários rurais }\end{array}$ & $\begin{array}{l}\text { Os locais de processamento e de } \\
\text { disposição para as duas cadeias devem } \\
\text { ser na mesma localização } \\
\text { Taxas desproporcionais de geração } \\
\text { podem fazer com que os caminhões } \\
\text { tenham que ir ao local de } \\
\text { descarregamento antes que os } \\
\text { compartimentos estejam cheios } \\
\text { Programas de coleta de resíduos verdes } \\
\text { (folhagens e de capina) ainda precisam } \\
\text { ser separados dos demais devido a } \\
\text { variações sazonais de volume }\end{array}$ \\
\hline $\begin{array}{l}\text { Sacos de "co-coleta" } \\
\text { Os recicláveis são colocados em sacos e } \\
\text { são coletados com os resíduos sólidos em } \\
\text { um compactador tradicional para serem } \\
\text { separados em uma instalação de } \\
\text { transferência }\end{array}$ & $\begin{array}{l}\text { Não necessita } \\
\text { novos veículos de } \\
\text { coleta } \\
\text { Elimina rotas } \\
\text { extras de veículos } \\
\text { Eficiente em } \\
\text { cenários rurais }\end{array}$ & $\begin{array}{l}\text { Contaminação aumentada } \\
\text { Custos de separação aumentados } \\
\text { Não permite recolhimento automático a } \\
\text { menos que os resíduos sejam misturados } \\
\text { em um contêiner } \\
\text { Se apenas um container é usado, } \\
\text { elimina-se a possibilidade de taxas } \\
\text { variáveis de geração }\end{array}$ \\
\hline $\begin{array}{l}\text { Secos/Molhados e três cadeias de coleta: } \\
\text { Coleta de "secos" e "molhados"; } \\
\text { molhados são os compostáveis, os secos } \\
\text { são separados em resíduos recicláveis e }\end{array}$ & $\begin{array}{l}\text { Boas taxas de } \\
\text { recuperação } \\
\text { Menos coletas } \\
\text { por semana }\end{array}$ & $\begin{array}{l}\text { Inicialmente pode ser confusa para os } \\
\text { moradores } \\
\text { Mudanças no processamento e coleta } \\
\text { tradicional }\end{array}$ \\
\hline
\end{tabular}
rejeito

Fonte: adaptado de SKUMATZ ${ }^{5}$ (1999 apud CIWMB, 2002)

A coleta seletiva pode ser realizada com os resíduos separados pelos usuários conforme suas características em diferentes compartimentos (mais usualmente em: plástico, papel e latas) ou com todos os resíduos recicláveis misturados.

Nos primeiros anos da implementação de programas coleta seletiva, programas com três latas separadas eram bastante comuns. Os administradores dos programas encorajavam os usuários a pensarem nos resíduos como uma fonte de matéria prima, e

\footnotetext{
${ }^{5}$ SKUMATZ ECONOMIC RESEARCH ASSOCIATES, INC., SKUMATZ, L. A. (1999) Achieving 50\% in California: Analysis of Recycling, Diversion, and Cost-Effectiveness Prepared for California chapters of SWANA. Seattle: SERA.

CIWMB (2002). Curbside Recycling, the Next Generation: A Model for Local Government Recycling and Waste Reduction. California Integrated Waste Management Board. Disponível em: $<$ http://www.ciwmb.ca.gov/LGLibrary/Innovations/Curbside/>, acesso em 16/06/05.
} 
não apenas outro fluxo da cadeia dos resíduos sólidos. Para adicionar, a contaminação e a qualidade dos materiais eram preocupações legítimas, pois centrais de triagem para programas de coleta misturada geralmente não estavam disponíveis (CIWMB, 2002).

A coleta dos resíduos misturados resulta em tonelagens extras de recicláveis e custos mais baixos. Entretanto, centrais de triagem adequadas são necessárias para que este trabalho tenha sucesso. A maior preocupação sobre a coleta misturada é que os resíduos recolhidos serão menos valiosos. Todavia, com marketing agressivo e programas de desenvolvimento de mercado este efeito pode ser eliminado (CIWMB, 2002).

Tanskanen e Kaila (2001) citam que a coleta misturada é um método economicamente mais eficiente que a coleta dos resíduos separados. Esta conclusão é sustentada apesar do custo extra da central de separação necessária para este tipo de coleta. A eficiência da coleta dos materiais separados diminui pela necessidade de sincronização das freqüências de coleta de diversos tipos de resíduos com diferentes taxas de acúmulo.

A tabela 3 mostra as vantagens e desvantagens da coleta dos resíduos recicláveis separados e misturados.

\section{Tabela 3. Vantagens da coleta seletiva misturada versus separada}

\begin{tabular}{|c|c|}
\hline Separada & Misturada \\
\hline $\begin{array}{l}\text { Materiais mais limpos para o mercado } \\
\text { Processamento pós coleta mais barato: não } \\
\text { necessita de equipamentos especiais ou de } \\
\text { instalação para separar os resíduos recicláveis } \\
\text { Maior consciência do consumidor sobre os } \\
\text { materiais } \\
\text { A coleta misturada usualmente separa ao menos } \\
\text { um material (vidro ou papel) }\end{array}$ & $\begin{array}{l}\text { Veículos e operação de coleta são menos } \\
\text { complicados: é necessário menos compartimentos } \\
\text { Coleta mais rápida/barata: pode usar sistemas de } \\
\text { coleta automatizados/semi-automatizados } \\
\text { Facilita a adição/subtração de materiais na cadeia de } \\
\text { coleta porque não é necessário mudar os } \\
\text { contêineres, e o espaço é livre } \\
\text { Os contêineres não são tão pequenos como os } \\
\text { contêineres da coleta separada } \\
\text { Podem ser usados contêineres maiores e cobertos } \\
\text { fazendo que a operação de coleta seja menos } \\
\text { freqüente } \\
\text { Mais conveniente para os usuários } \\
\text { Maior tonelagem dos resíduos recicláveis do que } \\
\text { em programas de coleta separada } \\
\text { Relativamente mais fácil para explicar aos usuários }\end{array}$ \\
\hline
\end{tabular}

Fonte: adaptado de CIWMB (2002) 
Ressalva-se aqui que apesar de a coleta misturada apresentar maiores tonelagens de resíduos recicláveis coletados, a quantidade de rejeitos também é maior quando se coleta materiais desta maneira, uma vez que a separação dos resíduos na fonte geradora não é tão criteriosa.

\section{A legislação brasileira sobre resíduos e a política nacional de resíduos} sólidos

Schalch et al. (2001) citam que a ausência de definições políticas e diretrizes brasileiras para a área de resíduos nos três níveis de governo (federal, estadual e municipal) se associa à escassez de recursos para solução do problema. Com relação aos aspectos legais, a legislação brasileira ainda é bastante restrita e genérica, por vezes impraticável, devido à falta de instrumentos adequados ou de recursos que viabilizem sua implementação.

Tradicionalmente, nota-se que muitas medidas ambientais, como programas de coleta seletiva, adotadas no Brasil têm caráter eleitoral, e são muitas vezes insustentáveis sob o ponto de vista técnico e operacional.

Junkes (2002) cita que em 1981 o Conselho Nacional do Meio Ambiente CONAMA instituiu a primeira lei sobre aproveitamento dos resíduos sólidos, em que considera que a reciclagem dos resíduos sólidos deve ser incentivada, facilitada e expandida no país, para reduzir o consumo de materias-primas, recursos naturais não renováveis, energia elétrica e água. Existem muitas outras resoluções como:

- A Resolução CONAMA no 258 de 30.06 .99 aprova as diretrizes para a formulação de uma política nacional de gestão de resíduos sólidos;

- A Resolução CONAMA n 275 de 25.04.01 se refere aos resíduos sólidos no Brasil, tratando sobre o estabelecimento do código de cores para identificação dos coletores e transportadores de resíduos sólidos.

Ainda, segundo Junkes (2002), a legislação brasileira, em se tratando de resíduos sólidos, não permite a elaboração de uma norma única, de caráter nacional, que obrigue os estados e municípios a adotarem um determinado modelo de gestão. Porém, pode-se editar normas gerais, como vem sendo feito, para fornecer as diretrizes para os órgãos da administração pública a respeito do assunto, sob o aspecto da proteção ambiental e 
da função pública de interesse comum, levando-se em consideração que muitos estados e/ou municípios já possuem legislação específica em vigor sobre a gestão dos resíduos sólidos.

No âmbito de se regulamentar a coleta seletiva, algumas leis estaduais foram criadas (RESOL, 2004b), como as leis $\mathrm{n}^{\circ} 1.831$, de 06 de julho de 1991, do estado do Rio de Janeiro e $\mathrm{n}^{\mathrm{o}} 10.856$, de 31 de agosto de 2001, que criam programas estaduais de coleta seletiva de resíduos sólidos nas escolas públicas com objetivos de promover a educação ambiental e expansão da consciência ecológica na sociedade. Assim como leis assistencialistas como as leis $\mathrm{n}^{\circ} 1.908$, de 28 de setembro de 1992, do município do Rio de Janeiro e a lei $\mathrm{n}^{\mathrm{o}}$ 14.557, de 15 de janeiro de 2003, do estado de Minas Gerais, que promovem apoio técnico e incentivam financeiramente iniciativas de implantações, sejam municipais ou de regiões do município, de programas de coleta seletiva de resíduos sólidos.

Alguns estados brasileiros, como: Rio Grande do Sul, Paraná, Goiás, Rio de Janeiro, Pernambuco e Ceará, possuem suas próprias políticas de resíduos sólidos. Estas políticas, no que tange a coleta seletiva, abrangem principalmente os seguintes aspectos: induzem os municípios a estabelecer políticas governamentais integradas para a gestão dos resíduos sólidos, obrigando-os a dar prioridade a processos de reaproveitamento dos resíduos sólidos urbanos, por meio da coleta seletiva e da implantação de projetos de triagem dos recicláveis e o reaproveitamento da fração orgânica na agricultura; obrigam os usuários dos sistemas de limpeza urbana a acondicionar os resíduos para coleta de forma adequada e em local acessível ao sistema público de coleta regular e os estimulam à atividade com incentivos fiscais, tributários e creditícios (RESOL, 2004b). Apesar disso, na maioria desses estados não existem muitos programas organizados de coleta seletiva.

Atualmente, encontra-se no congresso nacional o projeto de lei da Política Nacional de Resíduos Sólidos (BRASIL, 2004), que estabelece diretrizes e normas de ordem pública e interesse social para o gerenciamento dos diferentes tipos de resíduos sólidos. A seguir serão citados alguns princípios desta política:

- Responsabilidade pós-consumo compartilhada entre o Poder Público, os fabricantes, importadores, comerciantes e o consumidor, de maneira que este 
último cumpra as determinações de separação dos resíduos sólidos domiciliares e de adequada disponibilização para coleta;

- Gestão e gerenciamento integrado dos resíduos sólidos, considerando sempre o ciclo total do produto e todas as etapas dos serviços, sem privilégio de formas de tratamento;

- Precedência das soluções de redução, reutilização e reciclagem às formas de disposição final;

- Incentivo, estímulo e valorização das atividades de reutilização, coleta seletiva, compostagem e reciclagem de resíduos;

- Implantação, pelo fabricante ou importador, de sistema obrigatório de coleta e retorno de produtos ou resíduos tecnológicos, ficando os distribuidores e os pontos de venda obrigados a recebê-los em depósito;

- Atribuição de responsabilidade, junto com o Poder Público, o fabricante, o importador, o envasador e o usuário final, pelo gerenciamento dos resíduos de embalagens.

A normatização ambiental, representada pela série de normas ISO 14.000, tem auxiliado na conscientização no que se refere às questões ambientais, mostrando-se uma ferramenta relativamente independente da legislação, o que dá mais agilidade à questão dos resíduos, mesmo que por motivos mercadológicos.

\subsection{A ROTEIRIZAÇÃO DOS VEÍCULOS DE COLETA}

$\mathrm{Na}$ operação de veículos, a palavra roteirização costuma ser empregada junto com o termo programação. Este está ligado aos aspectos temporais dos roteiros e significa a definição dos horários requeridos a cada tarefa no roteiro. No sistema de entregas e coleta a programação cuida da seqüência, considerando a ordem em que os pontos deverão ser atendidos (paradas para almoço, duração da rota etc.).

A maioria dos problemas relacionados à rede de transporte e os procedimentos para sua solução envolvem conceitos e definições abrangidos pela teoria dos grafos. Noções sobre conectividade, distância entre dois pontos, caminhos mínimos, árvore de menor caminho e matriz de custo estão constantemente presentes em problemas de fluxos de redes inseridos na forma de subproblemas, e usados como sub-rotinas para 
problemas de roteirização de veículos. Os conceitos sobre teoria dos grafos aqui apresentados podem ser encontrados em Novaes (1989) e Saltorato (1998).

Um grafo $G$ é definido como sendo um par ordenado $(V, E)$ onde $V$ é um conjunto e $E$ uma relação binária sobre $V$. Os elementos $V$ são denominados vértices ou nós, e os pares ordenados de $E$ são denominados arestas ou arcos do grafo. A representação de um grafo é através de pontos e linhas.

Se as linhas têm sentido, o que é usualmente mostrado por uma seta, estas são chamadas de arcos e o grafo resultante é denominado de grafo orientado.

Pode-se então adotar três abordagens básicas para a roteirização de veículos: modelos de cobertura de arcos/arestas; modelos de cobertura de vértices; técnicas para achar o caminho mínimo entre um vértice origem e um vértice destino.

Os principais problemas de roteamento podem ser classificados, em resumo, da seguinte forma (SALTORATO, 1998):

- Problemas de roteamento sobre arcos, como por exemplo, o Problema do Carteiro Chinês (PCC) e suas variantes: quando a demanda se localiza em pontos próximos entre si, como casas ao longo de ruas ou avenidas que representem os arcos do grafo. O problema está em encontrar uma rota que percorra todos os arcos pelo menos uma vez minimizando a distância total percorrida. Alguns problemas de roteirização em arco são: programar rotas eficientes para leitura de medidas de água ou de eletricidade, criar rotas para entrega de correspondências ou para fazer serviços porta-a-porta (listas telefônicas, flyers etc.), coletar resíduos sólidos domiciliares ou material reciclável ao lado do meio-fio;

- Problemas de roteamento sobre nós, como por exemplo, o Problema do Caixeiro Viajante (PCV) e suas variantes: quando as entregas ou coletas precisam ser feitas em um conjunto de pontos freqüentemente distanciados entre si. Neste tipo de problema, a demanda localiza-se sobre pontos específicos da rede em questão, como esquinas numa rede urbana ou como cidades ao longo de uma estrada, que representam os nós do grafo. Um exemplo de aplicação desta abordagem é o roteamento dos caminhões de coleta de resíduos sólidos de saúde; 
- Problemas gerais de roteamento de veículos: quando a demanda se localiza sobre os nós e arcos do grafo, tem-se o modelo mais geral de roteamento que incorpora o problema de roteamento clássico e suas restrições quanto ao número de depósitos, veículos, capacidade etc. Neste tipo de abordagem se enquadram diversos problemas como: o problema de roteamento de nós com um depósito e vários veículos, o problema de roteamento de nós com vários depósitos e veículos e o problema de roteamento de arcos com restrição de capacidade.

\subsection{OS SISTEMAS DE INFORMAÇÃO GEOGRÁFICA - SIG}

Os SIGs foram criados para tratar dados referenciados espacialmente. Estes sistemas manipulam dados obtidos em fontes tais como mapas e imagens de satélites, entre outras, recuperando e combinando informações e permitindo vários tipos de análise. Os SIGs têm sido usados com freqüência crescente em diversas áreas tais como análise e monitoramento do meio ambiente, planejamento urbano e regional, estudo de recursos naturais, controle de redes de transporte, distribuição de energia (GALVÃO et al. 1997).

Segundo Silva, Melo e Brondino (1997), SIGs são programas de computador que permitem a combinação de bancos de dados alfanuméricos com imagens espaciais (ou geográficas). Os SIGs são muitas vezes confundidos com os sistemas CAD, que são programas que simplesmente se prestam à produção de desenhos, que são em geral simplesmente combinações de pontos e linhas, não interpretando as relações espaciais entre objetos.

A introdução do SIG como ferramenta para o planejamento de transportes foi uma conseqüência prática do desenvolvimento da computação gráfica nos anos 80 . Os modelos computacionais de Pesquisa Operacional (PO) estavam, concomitantemente, sendo analisados de maneira crítica. Por exemplo, estava se tornando cada vez menos aceitável apresentar resultados de simulação de sistemas operacionais na forma de simples tabelas e gráficos. Os modelos de PO teriam que ser cada vez mais embutidos em sistemas computacionais gráficos e de forma transparente ao usuário não especialista (GALVÃO et al. 1997). 
No planejamento, gerência, operação e análise de sistema de transporte, os SIGs representam uma poderosa ferramenta que pode integrar funções básicas de um SIG às rotinas específicas de logística, pesquisa operacional e transportes em geral. Estas rotinas permitem, dentre outras funções, determinar a rota de menor impedância entre nós e distribuir viagens entre zonas, resolver problemas convencionais de roteamento e programação de veículos, localização de instalações, alocação de recursos em redes, alocação de tráfego (SANTOS, 1999).

\subsection{OS CUSTOS DA COLETA DE RESÍDUOS}

"A palavra "custos" é geralmente reservada para expressar os gastos operacionais diretos (mão-de-obra, combustíveis e outros) e indiretos (supervisão, fiscalização, depreciação da garagem e outros), enquanto o termo "despesas" designa os gastos administrativos (escritório), comerciais (vendedores) e financeiros (juros)" (Sindicato das Empresas de Limpeza Urbana no Estado de São Paulo - SELUR, 2001).

Machado (1995) define os propósitos principais, para os quais se desejam informações de custos e despesas dos serviços de coleta, são eles:

- O lançamento da competente taxa de ressarcimento ou remuneratório dos serviços colocados à disposição;

- O orçamento para o próximo exercício;

- O controle das despesas efetuadas mensalmente;

- O planejamento dos serviços numa data futura.

Ainda, segundo Machado (1995), os custos podem ser classificados de acordo com os diversos critérios: grau de média, variabilidade, facilidade de atribuição e momento do cálculo. De acordo com o grau de média, são definidos os seguintes tipos de custos:

- Custo total: é o valor dos bens e serviços consumidos para fabricar um conjunto de unidades de serviços;

- Custo unitário: é o valor dos bens e serviços consumidos para fabricar uma unidade de produção. Este custo é obtido pela divisão do custo total pelo número de unidades produzidas. 
De acordo com o critério de variabilidade, são definidos os seguintes tipos de custos:

- Custo variável: é aquele que é constante por unidade, mas que flutua no seu total em forma proporcional às variações no volume de atividades;

- Custo fixo: é aquele que no seu total permanece constante e independe, no curto prazo, do volume de atividade. Em termos unitários, ele diminui à medida que o volume de produção aumenta;

- Custo semi-fixo: (semi-variável) é aquele que no seu total flutua de acordo com as variações no volume de atividade não proporcional. Exemplo: se num mês faz-se maior número de capina química que no outro por fatores climáticos.

De acordo com a facilidade atribuível são definidos os seguintes custos:

- Custo direto: é aquele que é facilmente atribuível a um determinado produto. Exemplo: pagamento do salário aos funcionários;

- Custo indireto: é aquele que apresenta algum grau de dificuldade para ser atribuído aos produtos. Exemplo: serviços complementares como copa e cozinha.

$\operatorname{Santos}^{6}$ (1991 apud MACHADO, 1995) cita que existem quatro maneiras de apresentação de custos unitários mais representativos em termos de operação de limpeza pública:

- Quantidade de lixo coletado em $\mathrm{R} \$ / \mathrm{t}$;

- Distância percorrida em $\mathrm{R} \$ / \mathrm{km}$;

- Combinação dos métodos anteriores;

- Quantidade de resíduos coletado por quilômetro em $\mathrm{R} \$ / \mathrm{t} . \mathrm{km}$.

\footnotetext{
${ }^{6}$ SANTOS, E. J. V. B. (1991) Custos. Comcap, Florianópolis - SC

MACHADO, G. E. (1995). Estudo comparativo de custos da coleta seletiva e regular de resíduos sólidos urbanos no bairro balneário do município de Florianópolis, SC. Dissertação (Mestrado). Florianópolis. p.130. Universidade Federal de Santa Catarina.
} 
Na coleta de resíduos, outras variáveis além das que formam o custo operacional podem ser adicionadas como aquelas que compõem os custos sociais e custos ambientais.

Segundo Oliveira e Reis (2002) estas "externalidades" podem ser alocadas aos custos de coleta, atribuindo os benefícios ou os malefícios que esta produz diretamente à opção de gerenciamento analisada. Estes benefícios podem ser quantificados como:

- Redução no consumo de matéria-prima virgem;

- Redução no consumo de água, energia;

- Redução na emissão de gases dos processos de produção e emissão de gases no processo de coleta;

- Geração de empregos;

- O valor das áreas utilizadas para aterros de disposição de resíduos sólidos.

Apesar de estes custos serem mais expressivos quando a comparação é feita entre o sistema de coleta tradicional e o sistema de coleta seletiva, eles também são significativos ao se comparar alguns sistemas de coleta seletiva, como por exemplo, a emissão de gases decorrentes do tipo de operação de coleta e o número de empregos gerados. 


\section{MATERIAIS E MÉTODOS}

Neste trabalho o objetivo é desenvolver uma ferramenta que possibilite a comparação dos custos de transporte de sistemas de coleta seletiva de resíduos sólidos. Para tanto, três sistemas foram analisados, com a implementação de um estudo de caso.

A obtenção da quilometragem percorrida em cada sistema foi uma das variáveis utilizada para a determinação dos custos. Um software possibilitou a modelação e a simulação de cada sistema.

Este software, o TransCAD, é baseado em um ambiente SIG. É chamado de SIG-T, específico para problemas de transporte, pois além de possuir as funções básicas de uma ferramenta SIG, também possui heurísticas específicas para solucionar problemas de roteirização, agrupamento de regiões e localização de instalações.

Para alcançar os objetivos propostos, o método foi dividido em três etapas:

- Determinação dos sistemas de coleta a serem estudados;

- Aquisição da base de dados geográfica e equacionamento de dados para a aplicação do software;

- Comparação dos custos obtidos para cada sistema de coleta seletiva.

\subsection{SISTEMAS DE COLETA SELETIVA A SEREM ESTUDADOS}

As alternativas de sistemas de coleta consideradas nas simulações foram: coleta por Postos de Entrega Voluntária - PEV, coleta Porta-a-Porta e um Sistema Híbrido de Coleta.

A coleta por PEVs, que é caracterizada pela instalação de contêineres ou recipientes em locais públicos na qual a população faz o descarte dos resíduos recicláveis separados em suas residências, foi escolhida por ser considerada, do ponto de vista dos custos de transporte, um sistema viável economicamente, além de ter sido muito utilizado para a coleta seletiva num primeiro momento de sua implantação nas cidades brasileiras. 
Apesar da realidade atual, caracterizada por vandalismos e depredações para o roubo do resíduo reciclável, que leva os PEVs a serem localizados em locais seguros, neste trabalho foi idealizada a situação em que os contêineres podem ser colocados nas melhores localizações para a operação de coleta.

A coleta seletiva Porta a Porta, em que os resíduos recicláveis são coletados por um veículo específico na porta de cada imóvel, foi escolhida pois é o sistema de coleta mais utilizado atualmente pelas cidades brasileiras, tanto na coleta seletiva quanto na coleta convencional.

O Sistema Híbrido de coleta foi escolhido por ser o tipo de coleta existente na área em que as simulações serão realizadas. Nesse tipo de coleta, o caminhão trafega por algumas ruas da área a ser servida e os catadores recolhem os resíduos nas portas das casas localizadas nas ruas adjacentes. Por essas características, esse tipo de coleta necessita de maiores custos com mão-de-obra, que podem ser compensados pela economia com o custo de transporte.

Para os três sistemas o método de coleta utilizado foi o da coleta misturada, onde o resíduo reciclável é apenas separado do resíduo não reciclável, não prevendo então separações na fonte geradora entre os diversos tipos de materiais recicláveis que compõem os resíduos.

\subsection{UTILIZAÇÃO DO SOFTWARE DE ROTEIRIZAÇÃO}

\subsubsection{Obtenção da base de dados geográfica}

A digitalização da base geográfica, contendo camadas de pontos e linhas, assim como a nomeação dos logradouros e definição dos sentidos dos links pode ser realizada em com o auxílio de uma mesa digitalizadora, e a utilização do software TransCAD. Para o início deste trabalho estava disponível a base de dados com informações referentes a cada link, tais como: número identificador, comprimento e nome do logradouro.

O local de estudo, que pode passar por algumas modificações como construções de novas ruas e de loteamentos, mudanças nos sentidos das ruas, além de 
complementações indispensáveis à realização do trabalho, as quais fazem com que seja necessária a atualização constante da base de dados.

\subsubsection{Atualização do sistema viário e determinação do sentido de fluxo dos links}

Para a atualização da base de dados existente, as informações sobre os sentidos das ruas, assim como um mapa digital em formato *.dwg (extensão normalmente fornecida pelo software AutoCAD), foram obtidas junto a órgãos públicos como a prefeitura municipal da cidade.

A partir do arquivo *.dwg, fez-se necessára a utilização de outro software, o Arcview, para a importação desses dados para o TransCAD. Após o reconhecimento do mapa pelo programa, ele foi inserido como um novo layer para que, então, com as ferramentas de edição de desenhos, fossem adicionados os links que faltavam por digitalização direta na tela do computador. Os nomes dos novos links foram adicionados manualmente, um a um, no arquivo *.$d b d$ (extensão do arquivo gerado pelo TransCAD, para o armazenamento de dados sobre os elementos geográficos) após terem sido adicionados os links. A definição da direção de cada link também foi feita manualmente, no arquivo de extensão *.dbd. A Figura 2 mostra a base de dados e o arquivo geográfico com seus atributos.

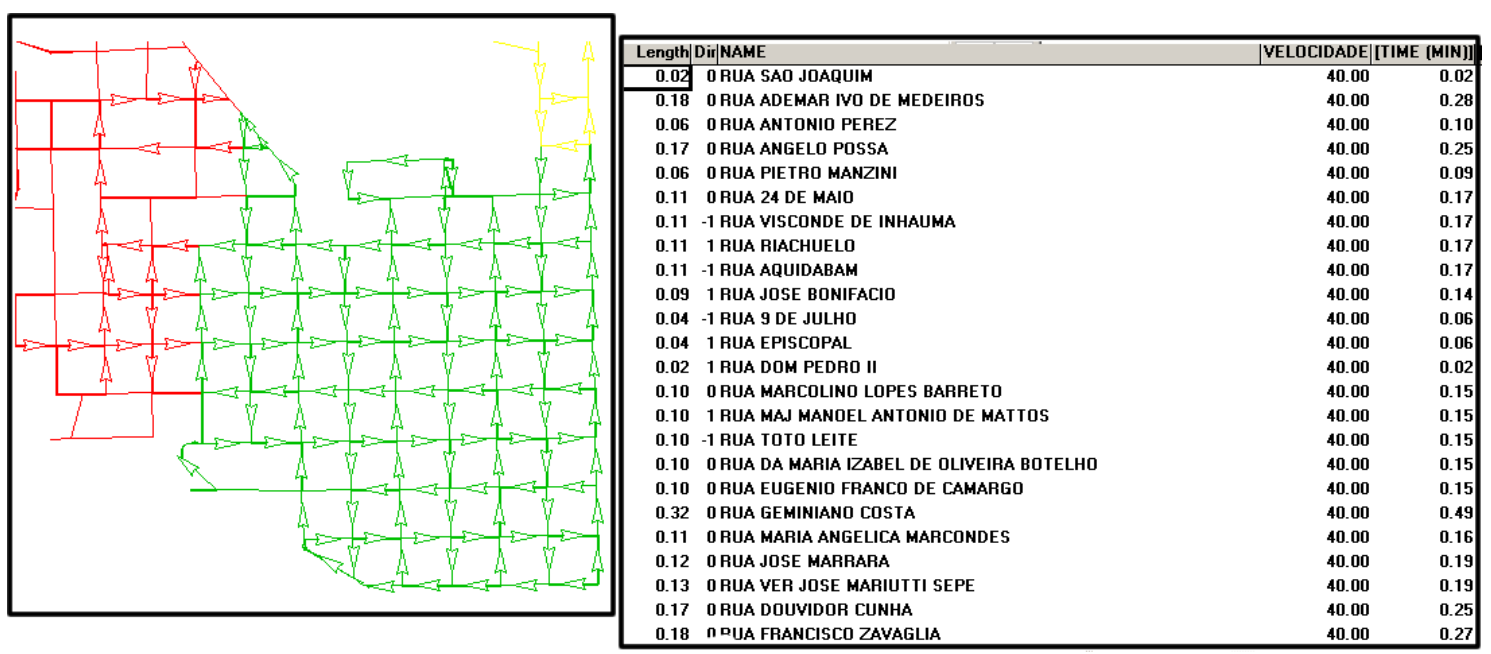

FIGURA 2. Direção das ruas da cidade representadas pelas setas (à esquerda) e base de dados com os nomes das ruas (à direita) 


\subsubsection{Preenchimento da base de dados}

Para a execução das rotinas foi necessária a construção da rede de transporte, a criação da matriz de roteirização, a resolução do problema de roteirização de veículos e a apresentação dos resultados.

A rede de transportes representa o sistema de transporte com suas características. Brasileiro (2004) descreve as redes como estruturas especializadas que representam as regras que gerenciam as viagens sobre uma rede viária. Como a rede é usada no processamento dos dados, são necessários alguns campos como comprimento (length) e tempo de viagem.

Para a criação da rede de transportes é necessário selecionar a camada de linhas e nós que representa as ruas e esquinas da área a ser estudada. Os campos de atributos de cada arco também devem ser selecionados, conforme a Figura 3.

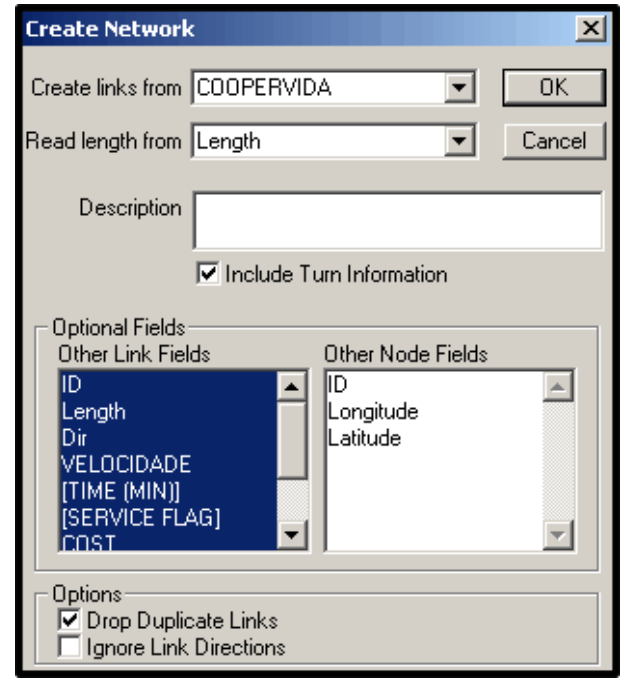

FIGURA 3. Caixa de diálogo para a criação da rede de transportes

A matriz de custos e a matriz de roteirização são elaboradas após a implantação da rede de transportes. A partir destas matrizes são obtidas as distâncias (ou qualquer outra variável que implique em custos) entre os pontos existentes no arquivo geográfico. $\mathrm{Na}$ criação da matriz de roteirização pode-se optar pelo cálculo com base nas distâncias em rede ou nas distâncias euclidianas. Nesse trabalho a opção foi por distâncias em rede 
pela possibilidade de se visualizar os roteiros gerados no mapa, além de ser a opção mais precisa.

Para criar a matriz de roteirização deve-se escolher o seguinte:

- Quais paradas incluir;

- Quais depósitos incluir;

- Quais métodos usar para medir distância e tempo.

Para a inclusão destes dados pode-se escolher entre todas as paradas e todos os depósitos, ou criar conjuntos de seleções (selection sets) contendo as paradas e os depósitos, conforme a Figura 4.

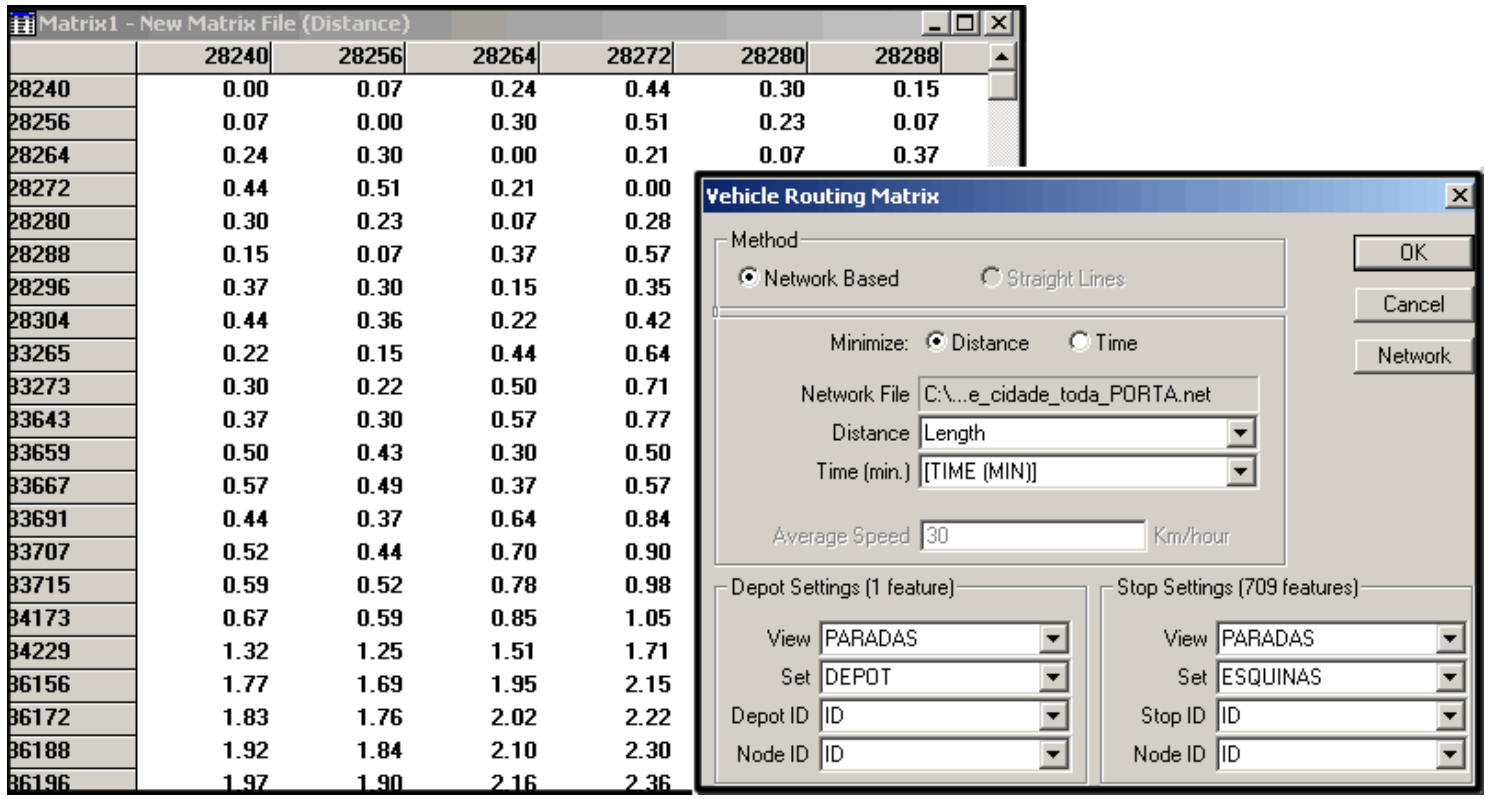

FIGURA 4. Matriz de roteirização e caixa de diálogo do procedimento de criação da matriz de roteirização

\subsubsection{Descrição e utilização das rotinas do software SIG utilizado}

Para os diferentes sistemas de coleta analisados foram utilizadas rotinas baseadas em procedimentos numéricos de pesquisa operacional. Estas rotinas foram aplicadas para a definição das variáveis definidas espacialmente, como localização de lixeiras, determinação da quantidade de resíduo a ser coletada em cada ponto e determinação do caminho ótimo para o recolhimento dos resíduos. 
Para o sistema de coleta Porta-a-Porta foi utilizada a rotina de roteamento em arco (arc routing), uma vez que o roteamento se caracteriza como o Problema do Carteiro Chinês, que busca encontrar uma rota que percorra todos os arcos pelo menos uma vez minimizando a distância total percorrida.

Para os sistemas de coleta por PEV foram utilizadas a rotina de localização de instalações (facility location), para a localização das lixeiras segundo restrições impostas pelo modelo definido neste trabalho e a rotina de roteamento de veículos (vehicle routing), pois o roteamento tem características do Problema do Caixeiro Viajante, que busca minimizar o trajeto percorrido para se coletar os resíduos em pontos específicos.

O sistema Híbrido de coleta também utiliza a rotina de roteamento de veículos (vehicle routing), pois neste sistema os veículos coletam os resíduos acumulados pelos catadores em esquinas selecionadas. Vide Figura 5, que ilustra o roteamento para os três sistemas.

Para os três sistemas foram utilizadas a rotina de "clusterização" (clustering), para a divisão da área de coleta em pequenas áreas que possam ser percorridas em turnos diários, e a rotina que resolve o problema do transporte (rotina transportation problem), para determinar a quantidade de residências atendidas por um ponto qualquer da rede de transportes.

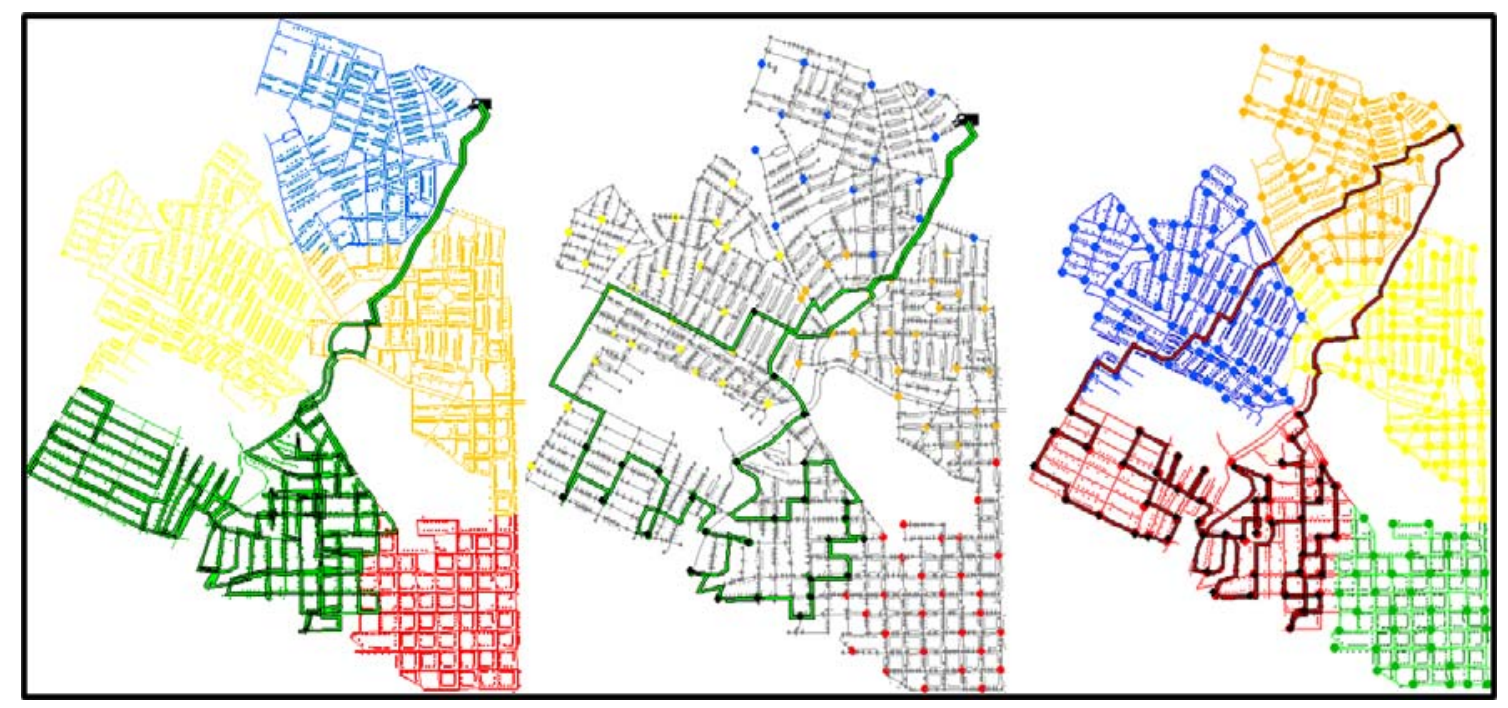

FIGURA 5. Roteamento aplicado aos sistemas, da esquerda para a direita, sistema Porta-a-Porta, sistema por PEV e sistema Híbrido. 


\subsubsection{Rotina Facility Location}

Problemas de localização como um todo tratam de decisões sobre onde localizar instalações, considerando clientes que devem ser servidos de forma a otimizar algum critério (LIMA, 2003).

A rotina de localização de instalações foi utilizada para determinar a localização dos PEVs assim como definir as esquinas por onde o veículo deva passar no sistema Híbrido.

Para adicionar um número fixo de instalações, o algoritmo desta rotina trabalha em dois estágios: identifica um conjunto de locais iniciais de instalações usando uma heurística e, posteriormente, tenta melhorar o conjunto inicial de locais ao trocar candidatos com instalações escolhidas numa base pareada até que nenhuma melhora possa ser feita. Uma heurística escolhe o próximo melhor local ao avaliar todos os candidatos e selecionar o que melhor alcança a função objetivo (CALIPER, 1996).

A localização dos PEVs idealizada neste trabalho é definida de modo que a distância máxima não exceda 250 metros do "usuário", representado pela localização geográfica das residências da cidade em uma camada de pontos no mapa. Essa consideração é pautada por estudos de Belton et al. (1994), Butler e Hooper (2000) e Torres, Di’Aza e Torres (2003), que propõem a distancia média de 1 quilômetro, considerando que os usuários que utilizam os sistemas estudados o faziam também em carros.

Pode-se citar o fato de que pontos de ônibus urbanos são locados a uma distância média de 400 metros dos usuários. $\mathrm{O}$ valor de 250 metros leva em consideração o fato de que a coleta seletiva é voluntária, se contrapondo aos pontos de ônibus onde os usuários se dirigem a esses lugares por necessidade. Além disso, existe o fato de que os usuários brasileiros não estão habituados a tal tipo de coleta, uma vez que a coleta convencional é feita porta-a-porta.

Procedimento análogo foi utilizado para o sistema Híbrido, onde se definiu que os pontos de parada do veículo coletor poderiam ser distantes no máximo 400 metros. A determinação desta distância deve-se ao fato de que os catadores caminham nas duas ruas paralelas ao caminhamento do veículo coletor e, considerando-se que a distância 
média entre duas ruas paralelas seja de 150 metros, tem-se que a distância média entre as ruas em que o veículo deverá passar seja de 400 metros.

A Figura 6 mostra a área de abrangência de cada ponto selecionado por esta rotina.

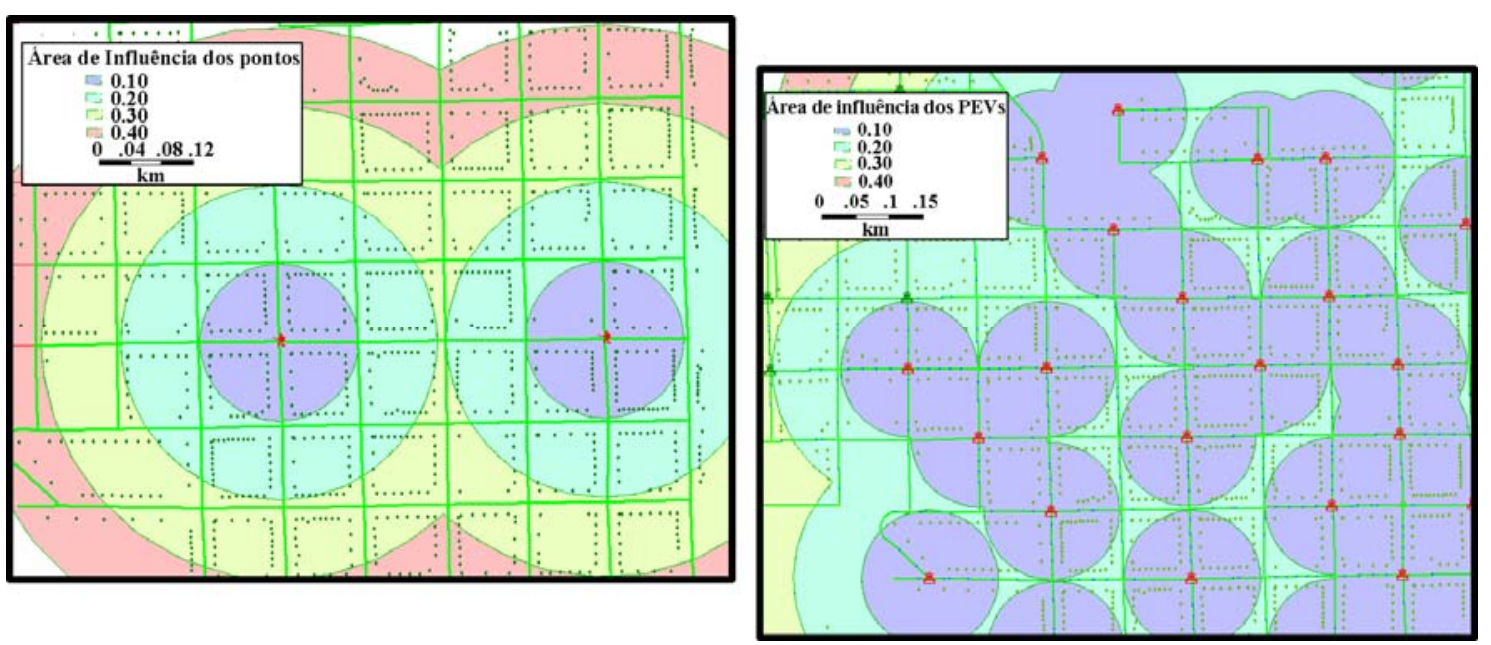

FIGURA 6. Área de influência dos PEVs e dos pontos de coleta do sistema Híbrido

Para a localização destes pontos, a rotina de localização de instalações (facility location) foi utilizada. Para a execução desta rotina é necessária a criação de uma matriz de custos (cost matrix) baseada nas distâncias em rede entre os nós da camada de vias (que correspondem às esquinas das quadras) e os nós correspondentes aos endereços das residências. Após este procedimento a rotina de localização é executada, impondo que o máximo custo (que é baseado nas distâncias em rede) entre os clientes (residências) e as instalações, os PEVs ou pontos de passagem, seja igual a 250 metros ou 400 metros respectivamente. A Figura 7 mostra as caixas de diálogo utilizadas para a resolução deste procedimento. 

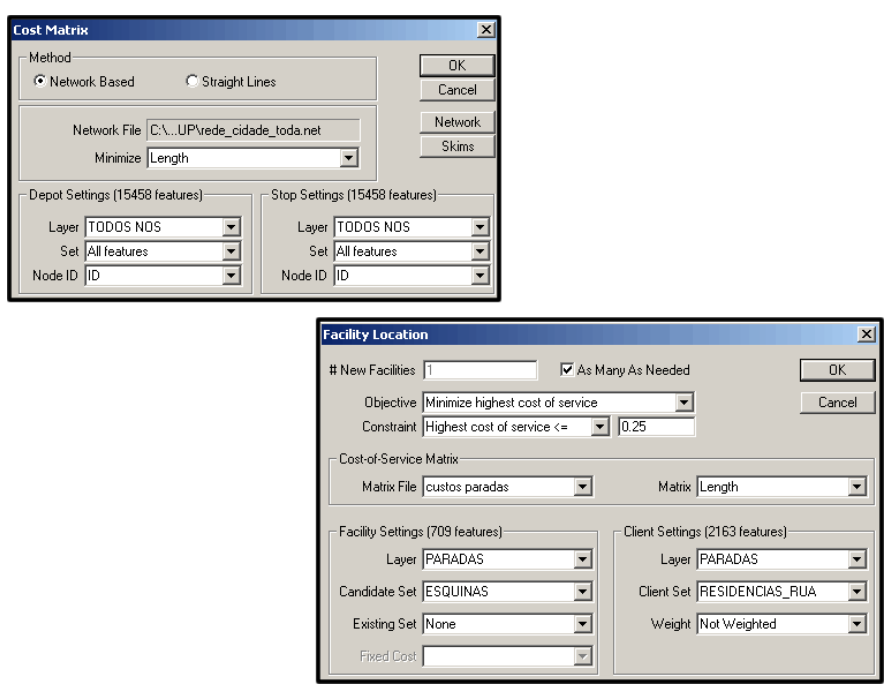

FIGURA 7. Caixas de diálogo para a criação da matriz de custos e para a localização das lixeiras

\subsubsection{Rotina Transportation Problem}

Para determinar a quantidade de residências que serão servidas por cada ponto, seja este ponto a esquina mais próxima (para o sistema por PEVs ou Híbrido) ou um ponto na rua indicando a projeção desta residência na rede de transportes (para o sistema Porta a Porta), foi utilizada a rotina que resolve o problema de transporte.

O problema de transporte envolve identificar o caminho mais eficiente para servir um conjunto de destinos por um conjunto de origens. $\mathrm{O}$ procedimento do software para resolver este problema usa uma adaptação do método simplex para programação linear. O algoritmo é baseado numa importante característica do problema de Hitchcock: quando a solução ótima é alcançada, o número de ligações carregando o fluxo iguala-se ao numero mínimo de ligações que pode conectar nós de produção a nós de demanda (isto é, o número total de nós de produção e de demanda menos 1); e todas as outras ligações estão vazias. Detalhadamente, o algoritmo começa com uma solução inicial possível com este número mínimo de fluxo carregando nós, então verifica se a solução pode ser melhorada ao usar uma ligação atualmente vazia. Se do mesmo modo uma ligação é encontrada, o algoritmo determina a quantidade de fluxo que pode ser alocada à nova ligação sem violar qualquer restrição, ajusta o fluxo em todas outras ligações de fluxo carregado, e atualiza a rede. O processo se repete até que nenhuma melhoria a mais possa ser encontrada ao trocar ligações (CALIPER, 1996). 
Para alocar as residências a esses pontos, utiliza-se a rotina Transportation Problem com as origens (source) sendo os pontos que servirão as residências e os destinos (sinks) os pontos que indicam as residências. Os campos que representam a demanda (quantity), que devem obrigatoriamente ser igual a 1 para os pontos que indicam as residências, e um número suficientemente grande para os pontos que servirão as residências, assim são definidos para o procedimento não alocar mais de um ponto por residência, garantindo com isto que apenas um ponto sirva a uma residência.

A Figura 8 mostra a tabela da camada de pontos com os campos adicionados para a execução do procedimento e a Figura 9 mostra a caixa de diálogo e a representação gráfica do procedimento.

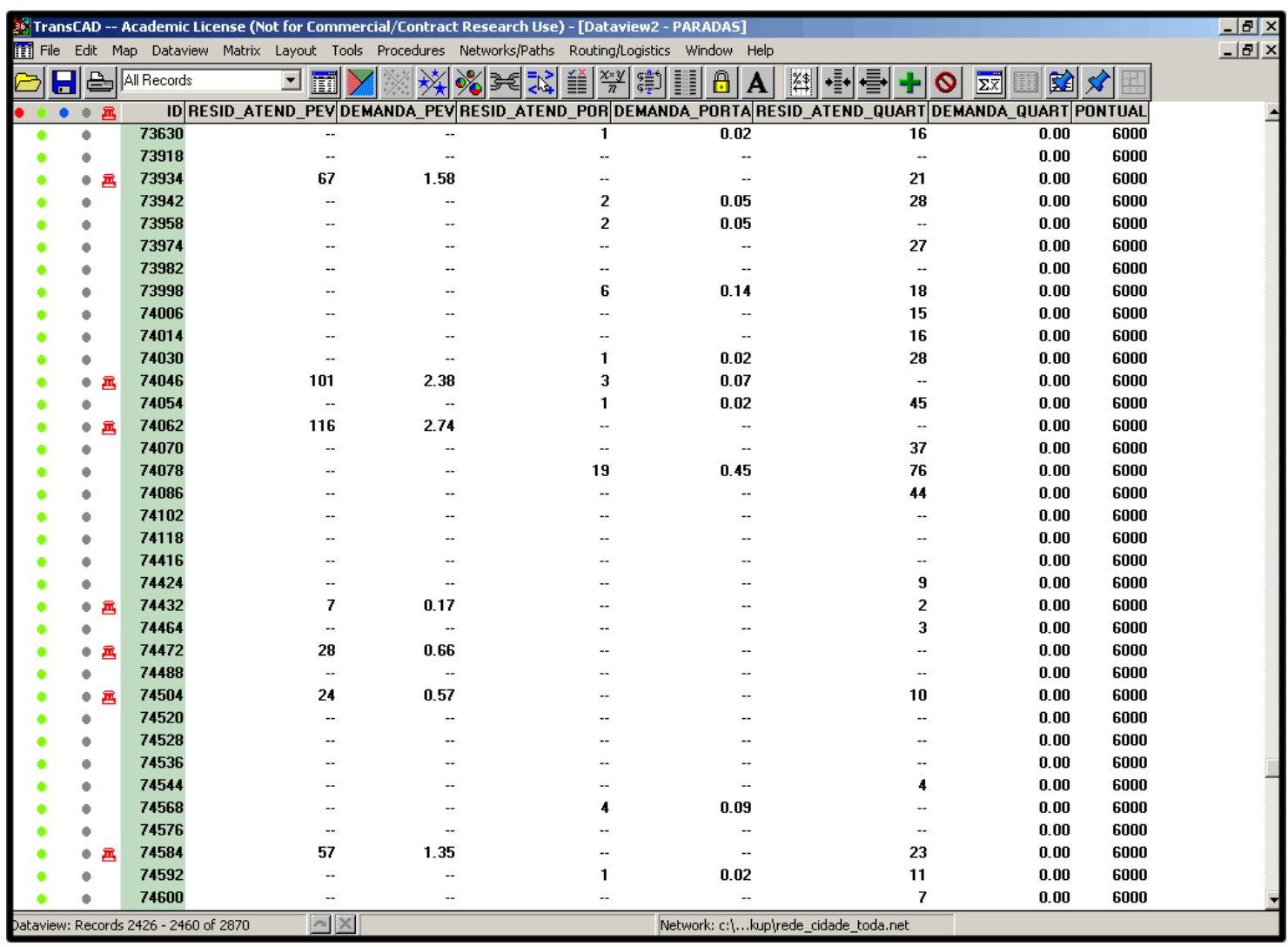

FIGURA 8. Tabela da camada de pontos com os campos necessários para executar a rotina do problema de transporte 


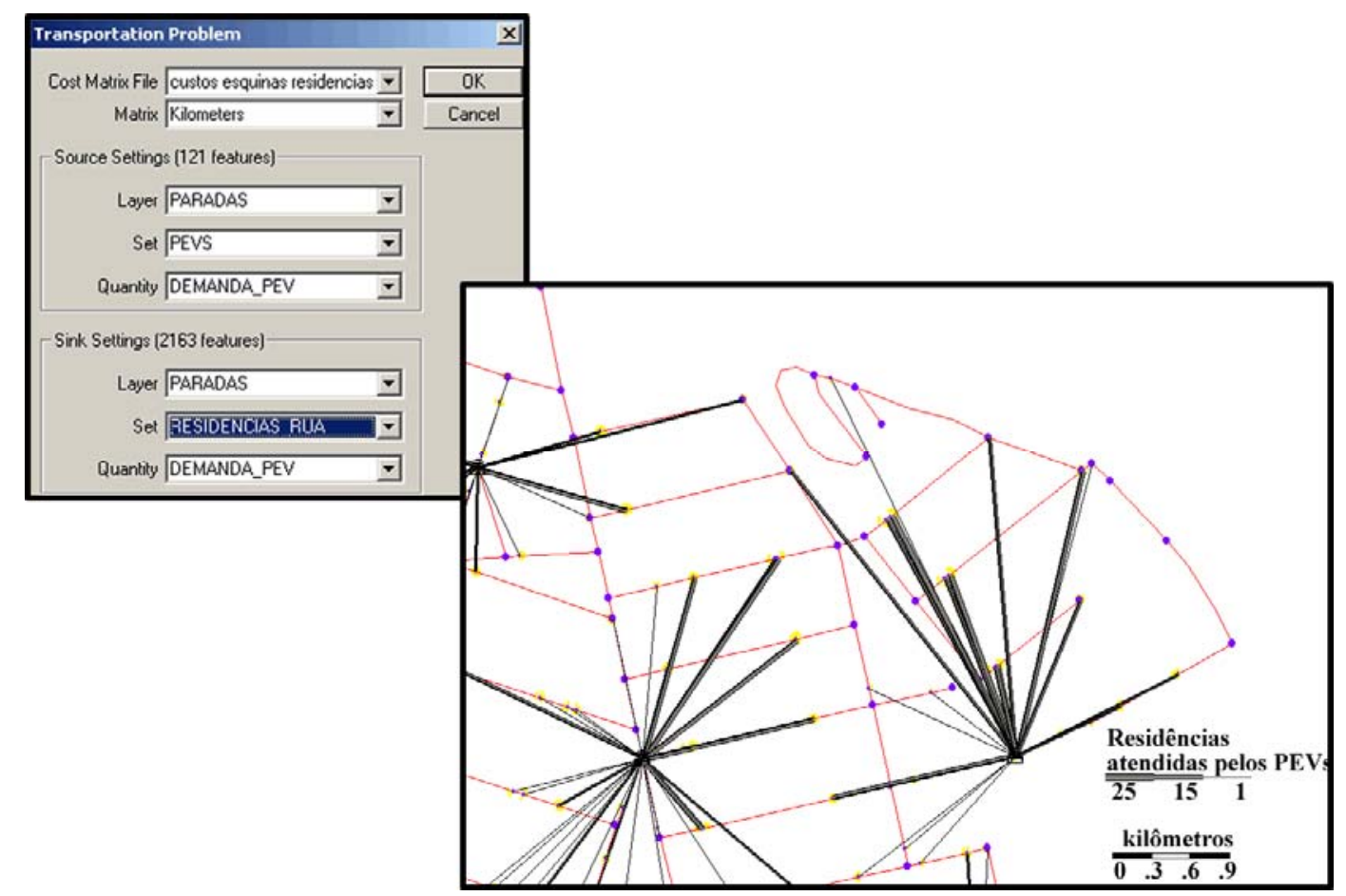

FIGURA 9. Caixa de diálogo da rotina que resolve o problema do transporte (a esquerda) e representação do fluxo das residências atendidas por cada ponto (a direita)

\subsubsection{Rotina Clustering}

A rotina de "clusterização" (clustering) é utilizada para a divisão da área de coleta em pequenas áreas que possam ser cobertas por turnos diários, foi utilizada para os três sistemas, em que a camada de pontos foi "clusterizada" e, posteriormente os links adjacentes aos pontos de cada área foram selecionados.

O objetivo do procedimento de "clusterização" é criar grupos que minimizem o custo total de viajar entre cada origem de grupo e os elementos no grupo, sem violar a restrição de capacidade do grupo.

O algoritmo usado pelo procedimento começa com um conjunto aleatório inicial de sementes, e usa uma heurística para alocar clientes às sementes. Após todos os grupos serem formados, o algoritmo identifica a semente em cada grupo que minimiza o custo total de alocações de cada grupo. Estas novas sementes são então usadas como a base para uma outra iteração da heurística. $\mathrm{O}$ algoritmo termina quando as sementes ficam inalteradas de uma iteração para a próxima, ou o número máximo de iterações é 
alcançado, ou um ciclo fechado nos locais de sementes é identificado (por exemplo, as sementes na mesma iteração são idênticas às sementes encontradas numa iteração anterior) (CALIPER, 1996).

Para a execução da rotina, foram "cluterizados" os nós da camada de links escolhendo o número de clusters igual a cinco (representando os cinco dias úteis da semana) e definindo a capacidade de cada cluster como um quinto do número de residências da área a ser estudada. A demanda de cada ponto é dada pelo campo de residências atendidas para cada sistema e este campo é determinado pela rotina que resolve o problema de transportes.

Na Figura 10 é mostrada a caixa de diálogo para o procedimento de clusterização e o mapa com os pontos clusterizados.

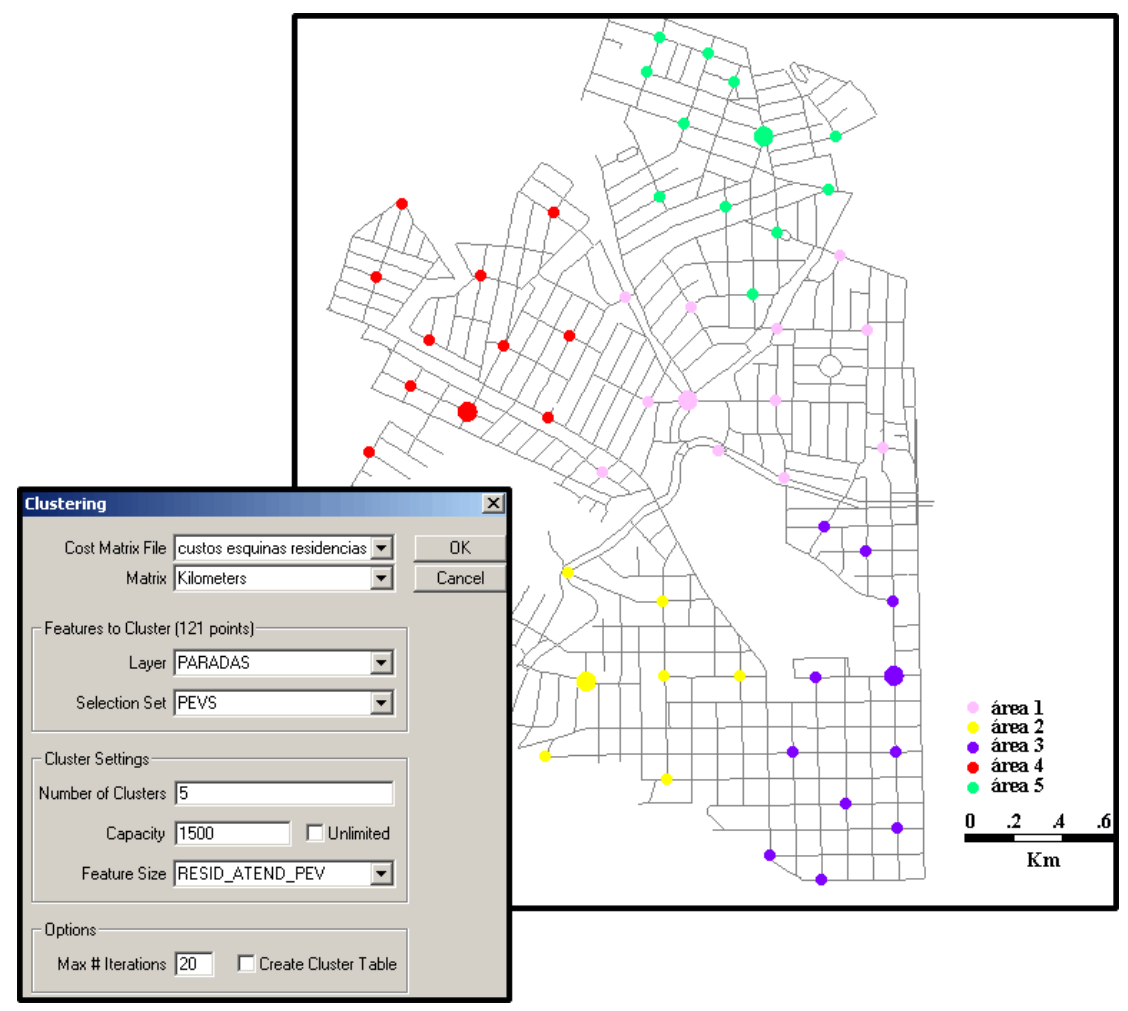

FIGURA 10. Procedimento de clusterização para dividir os pontos ou ruas da área em estudo em áreas menores 


\subsubsection{Rotina Vehicle Routing}

Para a roteirização de veículos, o software utiliza a heurística das economias de Clarke e Wright (1964) com a alteração de um parâmetro de forma, proposto por Yellow (1970). Esse algoritmo constrói rotas combinando as paradas nas rotas e o custo de se adicionar uma nova rota até encontrar a rota mais eficiente (CALIPER, 1996).

Para a execução deste procedimento é necessário criar uma matriz de roteirização para cada uma das áreas escolhidas minimizando a distância, e escolher como depósitos a camada de nós (da camada de links) e a seleção de nós da área em que se deseja fazer a roteirização, e como paradas a camada de nós (da camada de links) e também a seleção de nós da área em que se deseja fazer a roteirização, conforme a Figura 11.

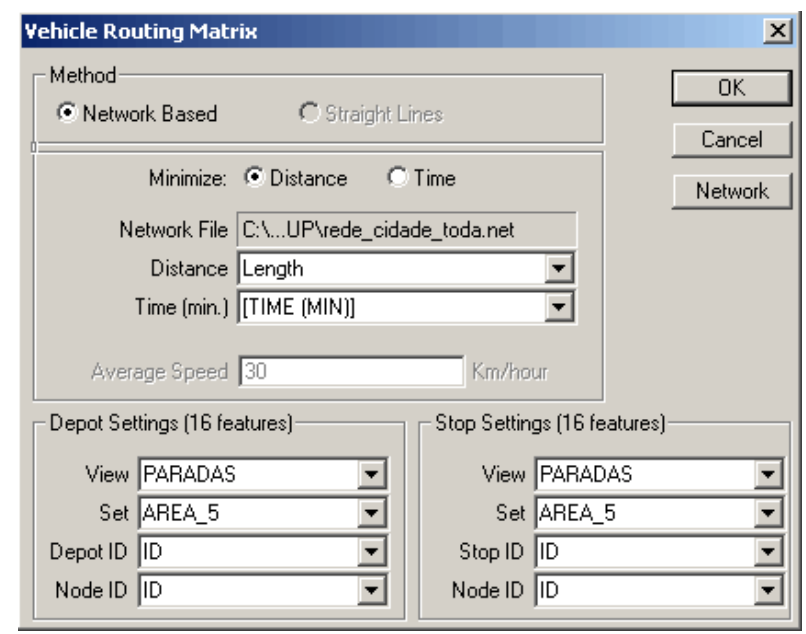

FIGURA 11. Caixa de diálogo para a criação da matriz de roteirização usada no procedimento de roteirização de veículos

Para a execução desta rotina o banco de dados de atributos da base geográfica (tabela de dados da camada de pontos) deve ser formatado de acordo com as Tabelas $4 \mathrm{e}$ 5 e Figura 12. Como a camada de pontos de coleta e garagem é uma só, todos estes campos estarão presentes em uma única base de dados.

Tabela 4. Campos a serem preenchidos na base de dados da camada da garagem (camada de pontos) 


\begin{tabular}{lll}
\hline Campo & Tipo & Conteúdo \\
\hline ID & inteiro & Um número que unicamente identifica a parada \\
\hline Name & caractere ou inteiro & $\begin{array}{l}\text { Um nome ou número que é usado para identificar a parada } \\
\text { nos relatórios de rota }\end{array}$ \\
\hline Demand & numérico & A demanda na parada \\
\hline Open Time & inteiro & O primeiro horário que na parada pode ser prestado serviço \\
\hline Close Time & Inteiro & O último horário que na parada pode ser prestado serviço \\
\hline
\end{tabular}

Fonte: adaptado de Caliper (1996)

Dependendo das opções que se escolher para a roteirização, os seguintes campos adicionais podem ser necessários (Tabela 5):

Tabela 5. Campos adicionais a serem preenchidos na base de dados da camada dos pontos de coleta e depósitos (camada de pontos)

\begin{tabular}{lll}
\hline Campo & Tipo & Conteúdo \\
\hline Node ID & inteiro & O ID do nó de rede mais próximo a cada parada \\
\hline Fixed Time & numérico & $\begin{array}{l}\text { O tempo mínimo requerido a prestar serviço na parada (em } \\
\text { minutos) }\end{array}$ \\
\hline Time per Unit & numérico & $\begin{array}{l}\text { O tempo de serviço requerido para cada unidade de demanda } \\
\text { (em minutos) }\end{array}$ \\
\hline Depot Assigned & inteiro & O ID do depósito que presta serviço na parada \\
\hline
\end{tabular}

Fonte: adaptado de Caliper (1996)

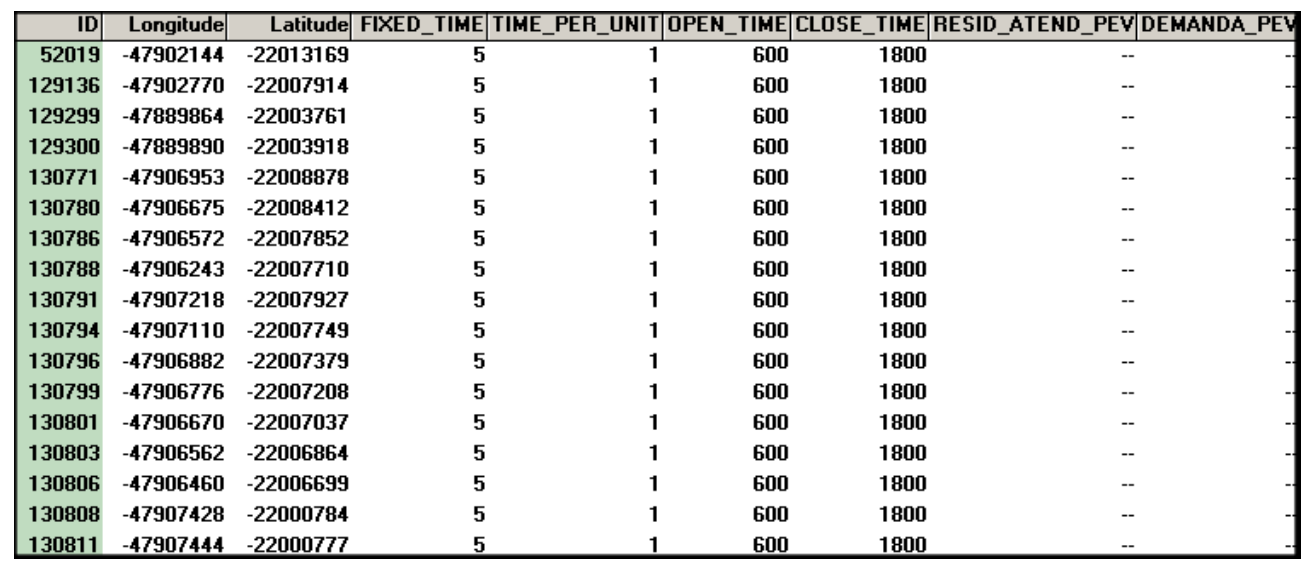

FIGURA 12. Base de dados da camada de pontos preparada para a execução da rotina de roteirização de veículos 
Além de camada de pontos, deve ser inserida uma tabela de veículos, com a descrição dos veículos e a quais depósitos servem. A tabela de veículos (Tabela 6 e Figura 13) deve ter os seguintes campos:

Tabela 6. Tabela de veículos

\begin{tabular}{lll}
\hline Campo & Tipo & Conteúdo \\
\hline Depot ID & inteiro & O nó ID do depósito para cada tipo de veículo \\
\hline Type & inteiro & $\begin{array}{l}\text { Código do veículo tipo, deve ser único dentro de cada } \\
\text { depósito }\end{array}$ \\
\hline Capacity & real & A capacidade de cada tipo de veículo \\
\hline Num_vehs & inteiro & O número dos veículos em cada tipo \\
\hline Cost & real & Custo de compra/operação/aluguel de cada tipo de veículo \\
\hline
\end{tabular}

Fonte: adaptado de Caliper (1996)

\begin{tabular}{|c|c|c|}
\hline 睢Dataview. & EH_TAB & $-|\square| x$ \\
\hline DEPOT_ID & COST|TYPE & CAPACITY|NUM_VEHS \\
\hline 86778 & 1.00 Vehic para $6 \mathrm{~m} 3$ & 24.68 \\
\hline
\end{tabular}

FIGURA 13. Tabela de veículos com as informações dos veículos a serem utilizados no procedimento

Para a execução da rotina, na aba stop da caixa de diálogo foi escolhida a camada de PARADAS e a seleção da área escolhida e na aba de depot a camada de PARADAS foi escolhida a seleção DEPOT, que representa o depósito a que o veículo retornará após a coleta (Figura 14). 

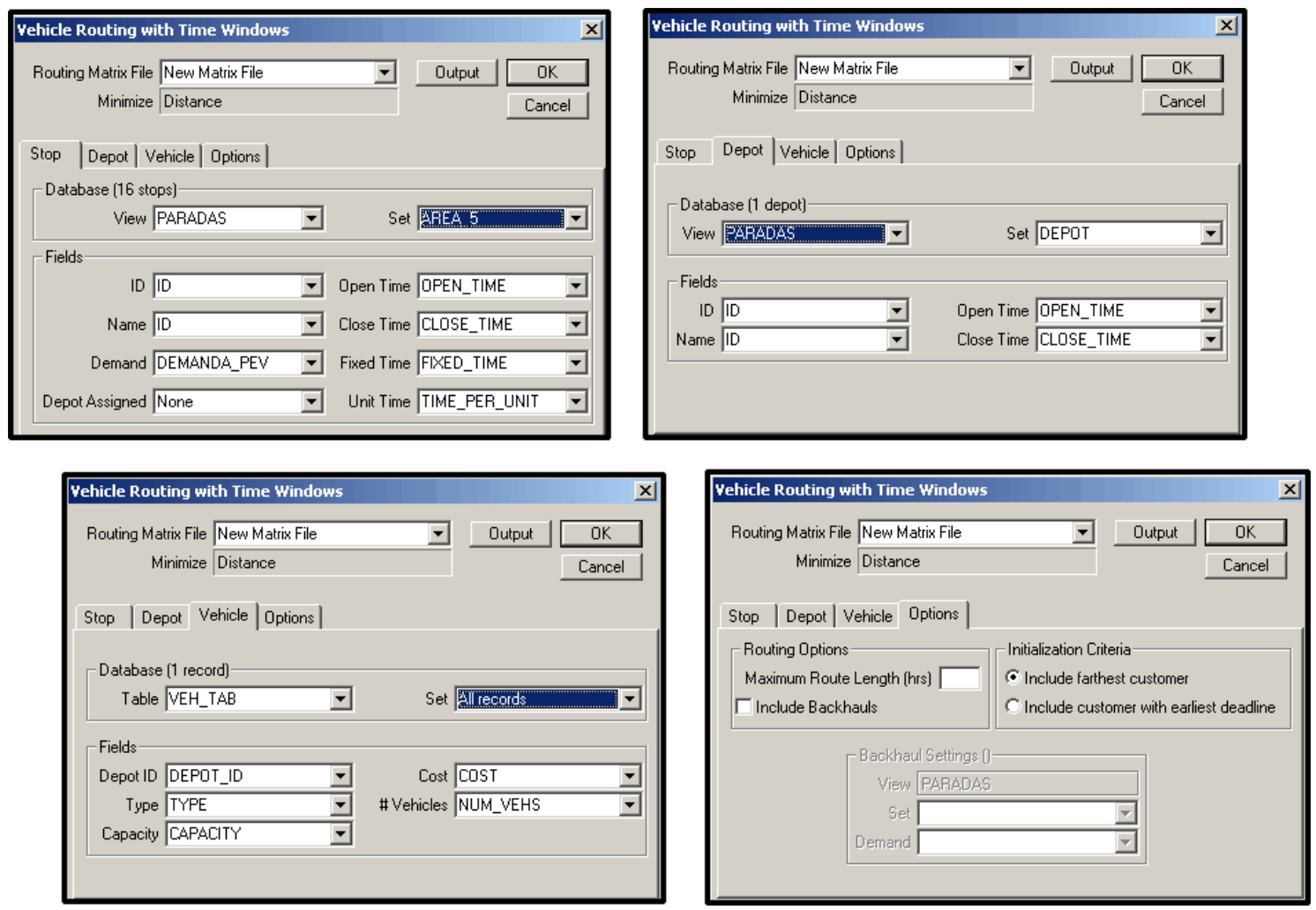

FIGURA 14. Abas da caixa de diálogo da rotina de roteirização de veículos

O procedimento de roteirização de veículos produz dois ou três arquivos de saída (Figuras 15 e 16):

- Um arquivo de texto contendo o itinerário de cada veículo;

- Uma tabela (a tabela de roteiro) contendo a listagem das paradas em cada rota (este relatório é produzido somente se a matriz de roteirização foi baseada em uma rede de transporte);

- Um relatório de resumo (este relatório, é produzido se a opção Procedure Report File é escolhida na caixa de diálogo Procedure Settings);

- Se a matriz de roteirização foi criada usando uma rede, pode-se criar um sistema de rotas que mostre os roteiros como uma camada (layer) no mapa. 


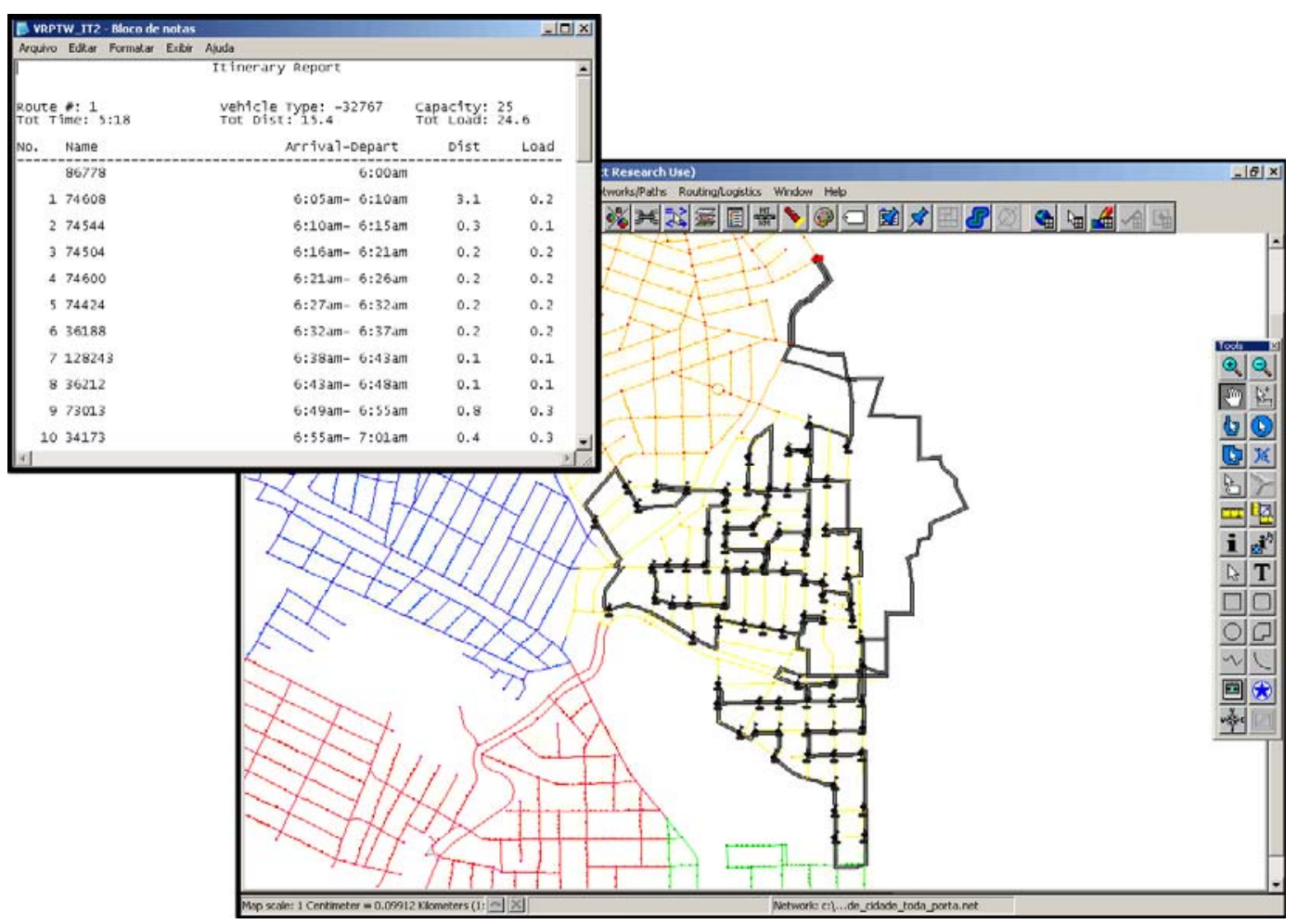

FIGURA 15. Itinerários gerados pela roteirização dos veículos e a rota indicada no mapa

Quando na roteirização, a carga do veículo for completada, o procedimento o faz retornar ao depósito e indica a seleção de pontos órfãos que não foram atendidos. $\mathrm{O}$ próximo passo, então, é roteirizar somente a seleção de pontos órfãos até que não exista mais rota que complete o carregamento do veículo.

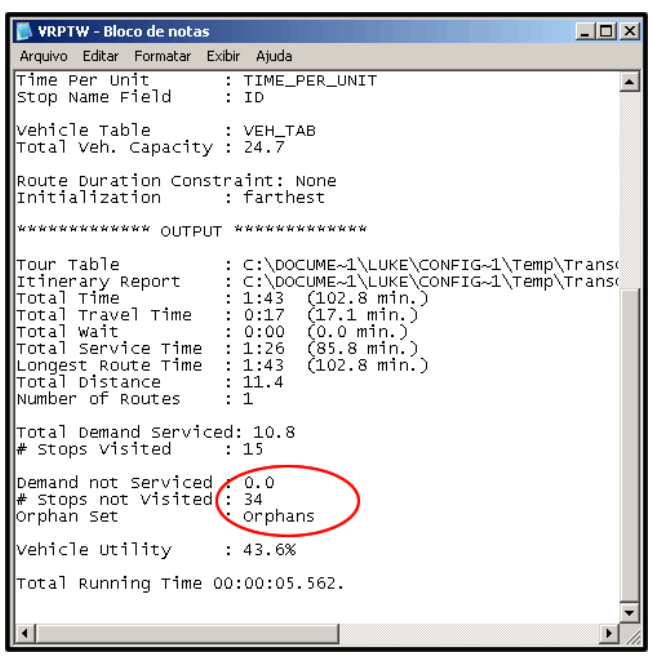

FIGURA 16. Relatório do procedimento com os pontos órfãos indicados 


\subsubsection{Rotina Arc Routing}

Para se atravessar todos os links em uma rede direcionada exatamente uma vez e retornar ao ponto de partida, todo nó deve ter o mesmo número de ligações. A rotina de cobertura de vias certifica-se se esta condição é satisfeita ao encontrar o mínimo acréscimo de links não servidos (deadhead links) e o correspondente nó de depósito. Esta rede aumentada é construída ao resolver o problema de transporte de Hitchcock e, em conseqüência, contém um conjunto de ligações de deadhead que minimiza esse custo e, conseqüentemente, o custo total (EISELT, GENDEAU e LAPORTE. 1995).

O procedimento então une ligações dentro e fora de cada nó da rede aumentada. Se a rede contém penalidades de conversão, um algoritmo é usado para encontrar o mais eficiente pareamento de ligações. Caso contrário, o pareamento é arbitrário. O processo de pareamento resulta na criação de pequenos roteiros. A seguir, os pequenos roteiros são unidos por alguns nós de união para formar um roteiro completo. Se a rede contém penalidades de conversões, o conjunto de nós aos quais os roteiros pequenos são unidos é escolhido em um caminho para impor pelos menos um aumento nas penalidades de conversões. Caso contrário eles são escolhidos arbitrariamente (CALIPER, 1996).

As Tabelas 7, 8 e 9 identificam os campos a serem preenchidos na camada de linhas e nós.

Tabela 7. Campos a serem preenchidos na base de dados da camada dos links servidos pela coleta (camada de linhas)

\begin{tabular}{lll}
\hline Campo & Tipo & Conteúdo \\
\hline ID & Inteiro & Um número que unicamente identifica a elemento da linha \\
\hline Dir & Inteiro & $\begin{array}{l}\text { Um número que indica se a elemento é mão única ou mão } \\
\text { dupla }\end{array}$ \\
\hline Cost* & Real & $\begin{array}{l}\text { O custo de atravessar a ligação sem fornecer serviço (o custo } \\
\text { de deadhead) }\end{array}$ \\
\hline Service Flag* & Inteiro & $\begin{array}{l}\text { Um número que identifica as ligações nas quais o serviço é } \\
\text { necessário, ou que aloca uma ligação a um território }\end{array}$ \\
\hline
\end{tabular}

Fonte: adaptado de Caliper (1996)

O campo DIR, que indica o sentido dos links, deve ser preenchido com “0”, que indica que a rua é de mão dupla, "1", que indica que o sentido do fluxo coincide com a 
direção topológica do link e “-1”, que indica que o sentido de fluxo não coincide com a direção topológica do link.

Freqüentemente existem diferenças nas características ou requisitos do serviço nos dois lados de uma rua. Por exemplo, o número de casas a serem servidas pode ser diferente de um lado da rua ao do outro lado. Para representar estas diferenças, a camada de linhas deve incluir dois campos para cada variável de interesse, um indicando o valor aplicável na direção topológica frontal ao longo de cada ligação, e a outra contendo o valor aplicável na direção topológica reversa ao longo de cada ligação. O campo SERVICE_AB indica o requisito de serviço na direção frontal ao longo da rua e o campo SERVICE_BA indica o requisito de serviço na direção reversa ao longo da rua.

Este campo, também pode ser usado para dividir uma camada de linhas em partes (por exemplo, regiões ou territórios), em que cada uma será roteirizada separadamente. Para isso basta usar valores diferentes para o preenchimento deste campo (código de serviço).

Tabela 8. Campos opcionais a serem preenchidos na base de dados da camada dos links servidos pela coleta (camada de linhas)

\begin{tabular}{lll}
\hline Campo & Tipo & Conteúdo \\
\hline Depot* & Inteiro & O ID do depósito que serve à ligação \\
\hline Passes* & Inteiro & $\begin{array}{l}\text { O número de passagens que são necessários para servir à } \\
\text { ligação, onde zero ou um valor errado indica que uma única } \\
\text { passagem é requerida }\end{array}$ \\
\hline Service Load* & Real & A quantidade de trabalho necessária a servir a ligação \\
\hline Deadhead Load* & Real & $\begin{array}{l}\text { A quantidade de trabalho necessária para viajar a ligação sem } \\
\text { fornecer serviço }\end{array}$ \\
\hline Name & inteiro ou caractere & É usado para identificar a rua no relatório de itinerário \\
\hline
\end{tabular}

Fonte: adaptado de Caliper (1996)

Tabela 9. Campos a serem preenchidos na base de dados da camada de pontos que localizam os depósitos (camada de pontos)

\begin{tabular}{lll}
\hline Campo & Tipo & Conteúdo \\
\hline ID & Inteiro & Um número que unicamente identifica a camada de pontos \\
\hline
\end{tabular}

Fonte: adaptado de Caliper (1996) 
A Figura 17 mostra a base de dados da camada de links e a Figura 18 apresenta a caixa de diálogo da rotina de roteirização em arco.

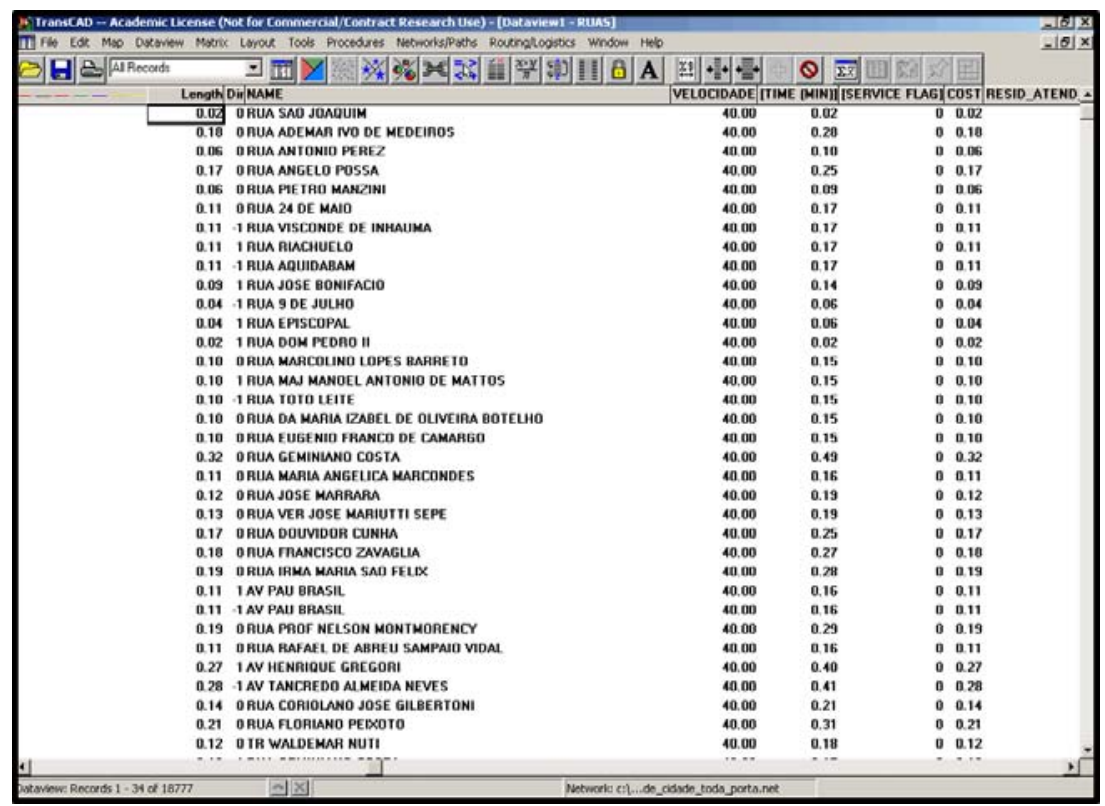

FIGURA 17. Base de dados da camada de links preparada para a execução de rotina de roteirização em arco
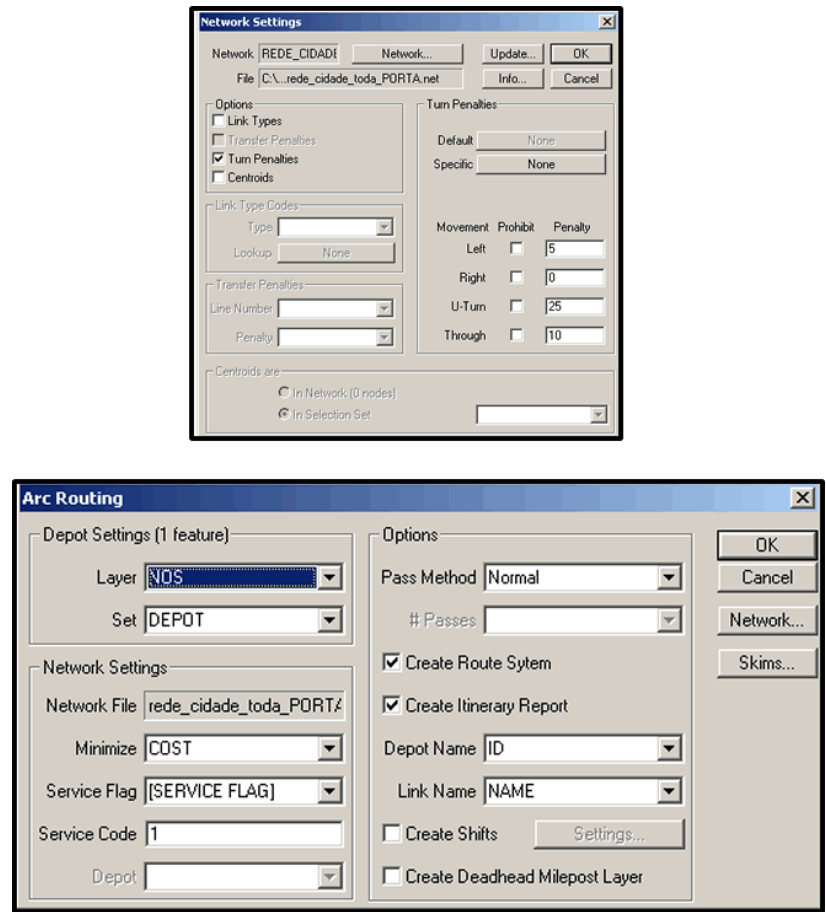

FIGURA 18. Caixa de diálogo da rotina de roteirização em arco (abaixo) e caixa de diálogo com as penalidades impostas aos movimentos do veículo na rede de transportes (acima) 
O procedimento de cobertura de vias mostra um arquivo de relatório, arpw.rep, o qual lista os arquivos de entrada e as configurações que foram usadas e fornece informações resumidas sobre as rotas de veículos resultantes.

O procedimento pode também produzir os seguintes arquivos de saída (ilustrados na Figura 19):

- Um arquivo texto contendo o itinerário de cada veículo;

- Um sistema de rota mostrando as rotas como uma camada em um mapa.

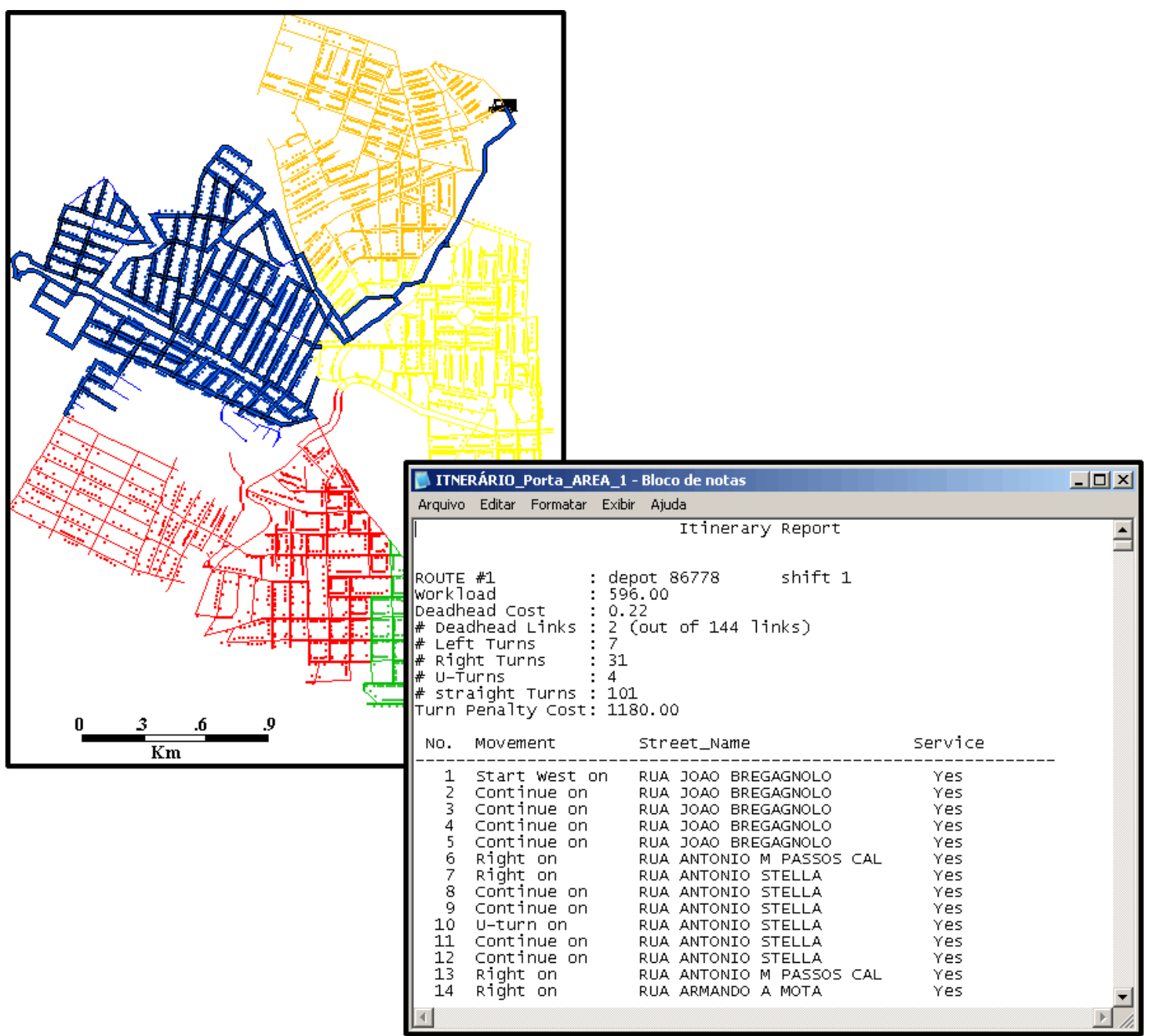

FIGURA 19. Resultados da rotina de roteirização em arco: rota mostrada como uma camada do mapa e relatório com itinerário

O relatório de itinerário contém as direções completas para cada rota, listando os links que são percorridos e identificando aquelas nas quais existe serviço e aquelas nas 
quais ocorrem passagens por links sem serviço (deadheading). O relatório usa os nomes ou IDs dos depósitos e ruas.

O sistema de rotas criado pelo procedimento de cobertura de vias contém uma rota para cada depósito. O software automaticamente calcula as seguintes estatísticas resumidas para cada rota:

- $\quad$ o custo de deadheading;

- O número de ligações, e o número de ligações em deadheading;

- A soma de todas as penalidades de cruzamento (se penalidades de cruzamento existem na rede);

- O número de viradas por tipo (esquerda, direita etc.).

Quando, na roteirização, a carga do veículo for completada, o procedimento simplesmente interrompe a rota no link em que a carga está completa e inicia a nova rota a partir deste ponto. Para definir a distância real define-se o caminho mínimo entre o ponto em que a rota foi interrompida e a garagem e entre a garagem e o ponto em que a rota irá iniciar. A distância obtida será adicionada à distância total percorrida pelo veículo. A Figura 20 ilustra este procedimento.

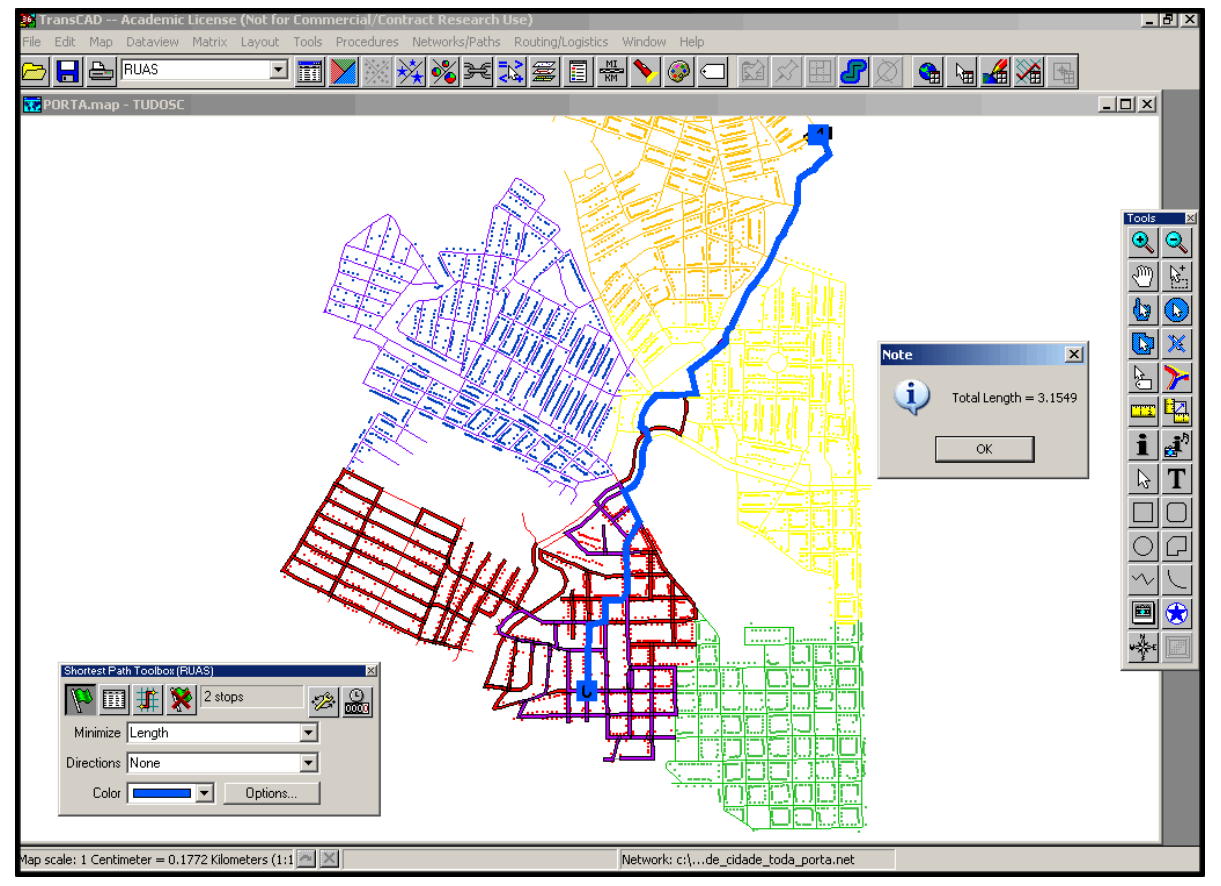

FIGURA 20. Determinação da distância entre o ponto de fim/início das rotas até a garagem 
Uma descrição passo a passo da preparação da base de dados e utilização das rotinas do software é apresentada no apêndice A, ao final desta dissertação.

\subsection{CUSTOS DE TRANSPORTES NA COLETA DE RESÍDUOS}

Os custos dos diferentes sistemas foram analisados. Neste trabalho não foram levados em conta outros custos envolvidos em um projeto de coleta seletiva como campanhas educacionais e de conscientização da população, apenas foram analisados os custos da operação de coleta. $\mathrm{O}$ cálculo, assim como seus parâmetros, foram baseados em planilhas como as elaboradas pela Fundação Getulio Vargas - FGV, para o Sindicato das Empresas de Limpeza Urbana - SELUR (SELUR, 2001), planilhas fornecidas em Economia e Transporte (2005) e planilhas de custo da Associação Nacional do Transporte de Cargas - NTC (NTC, 2001). O custo total será estimado em função do tipo de coleta, da quilometragem percorrida e da quantidade de mão-de-obra utilizada.

Os itens que fazem parte desse custo são descritos a seguir:

\subsubsection{Custos operacionais}

Os custos operacionais foram divididos em custos fixos mensais e custos variáveis por quilômetro. Os custos fixos são aqueles que independem do volume da “produção", enquanto que os custos variáveis são função deste volume.

O custo operacional fixo é dividido em: custo da mão de obra, custos de remuneração de capital, licenciamento, seguro, entre outros. Os custos operacionais variáveis são: custo de manutenção, pneus, câmaras, recapagens, combustível e óleos lubrificantes.

\subsubsection{Custos operacionais fixos}

- Custo da mão-de-obra

O custo da mão-de-obra é calculado levando-se em conta salários, encargos, vales refeição, cesta e transporte, assistência médica e insalubridade. No caso da coleta seletiva efetuada por meio de cooperativas (como na cidade de São Carlos), os custos da mão de obra, principalmente o custo dos catadores é coberto pelo rateio da venda do 
material reciclável. Neste trabalho todos os trabalhadores serão considerados no custo de mão-de-obra. $\mathrm{O}$ cálculo deste custo é dado pela fórmula a seguir:

Para o salário do motorista:

$S M+(S M x E N C)$

Com:

SM - Salário básico motorista (média em R\$);

ENC - Encargos sociais sobre salários.

Para o salário dos catadores:

$[S C+(S C x E N C)] \times N C A T$

Com:

SC - Salário básico do catador (média em R\$);

ENC - Encargos sociais sobre salários;

NCAT - Número de catadores.

Para o salário de oficina:

$[(S M E C+(S M E C x E N C)] / N M E C$

Com:

SMEC - Salário de mecânico (média em R\$);

NMEC - Quantidade de veículos atendidos por mecânico;

ENC - Encargos sociais sobre salários.

Além do gasto com salários e encargos, também existem os gastos com uniformes, que é considerado fixo. No gasto com uniformes leva-se em conta todo o 
consumo anual de uniforme pela equipe, que depois é dividido por 12 meses, para a obtenção do custo mensal.

- Custo de licenciamento e seguros dos veículos

São os custos com as principais taxas que um veículo deve pagar para rodar legalmente: IPVA, seguro obrigatório e licenciamento, e o custo de seguro contra incêndio, danos materiais e danos materiais contra terceiros. O cálculo será feito como segue:

Para o licenciamento:

$(D P V A T+I P V A+L I C) / 12$ meses

Com:

DPVAT - Valor do seguro obrigatório - DPVAT (R\$);

IPVA - Valor imposto sobre veículos - IPVA (R\$);

LIC - Taxa para licenciamento $(\mathrm{R} \$)$.

Para o seguro do casco:

$[(V V x C O E F+V A P) x I O F] / 12$ meses

Com:

$V V$ - Valor do veículo (R\$);

COEF - Coeficiente sobre importância segurada;

VAP - Valor da apólice (R\$);

IOF - Imposto sobre operações financeiras - IOF. 
Para o Seguro de Responsabilidade Civil Facultativo:

$(\mathrm{SRCFxIOF)/12} \mathrm{meses}$

Sendo que:

$S R C F$ - valor do seguro para prêmio de danos materiais;

IOF - Imposto sobre operações financeiras - IOF

- Custo de manutenção dos contêineres

O custo de manutenção dos contêineres é variável, de acordo com a sua utilização, onde a variável determinante seria a tonelagem utilizada. Como essa análise leva em conta a quilometragem rodada como variável, optou-se por incluir o custo de manutenção dos contêineres como custo fixo, representando então uma taxa mensal de gasto. Esta hipótese é válida uma vez que, para o dimensionamento do número de contêineres por localidade, levou-se em consideração o total preenchimento destes, tendo, portanto, um desgaste constante mensal (contêineres sempre preenchidos e esvaziados semanalmente). Para tanto tomou-se uma porcentagem do valor do novo como taxa de manutenção, valor este que é dividido pela vida útil do contêiner, em meses, para a obtenção do custo mensal:

$\{[(N C B x V C B)+(N C A x V C A)] x T M A\} / V U C$

Com:

NCB - Número de contêineres de baixa capacidade;

VCB - Valor do contêiner de baixa capacidade (R\$);

NCA - Número de contêineres de alta capacidade;

VCA - Valor do contêiner de alta capacidade;

TMA - Taxa de manutenção anual (\% do novo);

VUC - Vida útil do contêiner (em meses). 


\subsubsection{Custos operacionais variáveis}

- Custo de manutenção

Representa o gasto médio mensal com peças e mão de obra de oficina. Não se considera, porém, gastos com pneus e óleo de motor, pois estes possuem um item específico. Seu cálculo é dado a seguir:

$\{V V-[N P x(V P+V C)]-V E\} \times T M M / K M$

Com:

$V$ - Valor do veículo (R\$);

$N P$ - Quantidade de pneus;

$V P$ - Valor do pneu (R\$);

VC - Valor da câmara $(\mathrm{R} \$)$;

$V E$ - Valor do estepe (R\$);

TMM - Taxa mensal de peças e material de manutenção;

$K M$ - Quilometragem mensal de referência $(\mathrm{km})$.

- Custos de pneus e câmaras

O custo dos pneus representa o gasto com rodagem e a quilometragem alcançada pela carcaça, de nova até o seu sucateamento, passando pelo número de recapagens economicamente viáveis em cada operação. É dado pela fórmula:

$\{[(V P+V C) x N P]+(N R x V R x N P)\} / V U P$

$V P$ - Valor do pneu (R\$);

VC - Valor da câmara (R\$);

$V R$-Valor da recauchutagem $(\mathrm{R} \$)$; 
$N P$ - Quantidade de pneus;

VUP - Vida útil total do pneu $(\mathrm{km})$;

$N R$ - Número de recauchutagens.

- Consumo de combustível

O custo do consumo de combustível é representado pelo preço de um litro de combustível e pelo consumo médio $(\mathrm{km} / \mathrm{l})$ que o veículo faz. O valor, em $\mathrm{R} \$$ por $\mathrm{km}$, é dado pela divisão do preço de um litro pela média do consumo.

- Lubrificação e lavagens

Os gastos com lubrificação incluem a lubrificação do motor, das transmissões, dos comandos hidráulicos e filtros. O seu cálculo se resume em dividir o gasto com os litros de óleo consumidos na troca, mais os litros que são necessários para a reposição entre as trocas, pelo intervalo de quilômetros entre trocas. Para o cálculo dos gastos com lavagem estimou-se um número adequado de lavagens por mês e dividiu-se o gasto com estas lavagens pela média de quilometragem rodada pelos veículos durante um mês:

Para o lubrificante:

$\{P O C x[(C O C+R O C) / I T O C]\}+[(P O C D x C O C D) / I T O C D]$

Com:

POC - Preço do óleo de cárter por litro (R\$);

COC - Capacidade de óleo de cárter (litros);

$R O C$ - Reposição óleo de cárter até a próxima troca (litros);

ITOC - Intervalo de troca de óleo de cárter $(\mathrm{km})$;

POCD - Preço do óleo de câmbio e diferencial (R \$/litro);

COCD - Capacidade do câmbio e do diferencial (litros); 
ITOCD - Intervalo entre trocas câmbio e diferencial $(\mathrm{km})$.

Para a lavagem e lubrificação:

$(C L / I L)$

Com:

$C L$ - Custo de uma lavagem/engraxamento $(\mathrm{R} \$)$;

$I L$ - Intervalo entre duas lavagens $(\mathrm{km})$.

\subsubsection{Custos de capital}

Os custos de capital são os custos de depreciação dos bens e remuneração do capital investido. Os custos de depreciação incluem a depreciação dos veículos de coleta e dos coletores (no caso do sistema de coleta por PEVs). O cálculo é feito pela seguinte expressão:

$\{(T R V / V U V) x\{V V-[(V P+V C) x N P]\}\}+[(T R E / V U E) x V E]+$

$+[(T C B / V U C B) x N C B x V C B]+[((T C A / V U C A) x N C A x V U C A]$

Sendo que:

$V V$ - Valor do veículo (R\$);

$N P$ - Quantidade de pneus por veículo (R\$);

$V P$ - Valor do pneu $(\mathrm{R} \$)$;

VC - Valor da câmara (R\$);

$T R V$ - Taxa de reposição do veículo;

VUV - Vida útil do veículo (meses);

VE - Valor da carroceria;

TRE - Taxa de reposição da carroceria; 
VUE - Vida útil da carroceria (meses);

NCB - Número de contêineres de baixa capacidade;

$V C B$ - Valor do contêiner de baixa capacidade $(\mathrm{R} \$)$;

TCB - Taxa de reposição dos contêineres de baixa capacidade;

VUCB - Vida útil dos contêineres de baixa capacidade (meses);

NCA - Número de contêineres de alta capacidade;

VCA - Valor do contêiner de alta capacidade;

TCA - Taxa de reposição dos contêineres de alta capacidade;

VUCA - Vida útil dos contêineres de alta capacidade (meses).

Pela existência de um custo de oportunidade, é que se inclui o custo de remuneração de capital, pois o investimento feito pressupõe um retorno ou remuneração mínima do capital investido. Investir em um projeto significa perder a oportunidade de realizar outros menos arriscados. A remuneração é dada pela fórmula:

$[V T A+V R P+V R E+(N C B x V T B)+(N C A x V T A)] / 12$ meses

Com:

VV - Valor do veículo;

$T R$ - Taxa de remuneração do capital (anual);

VTA - Valor total anual (VVxTR);

TRP - Taxa de remuneração de peças (anual);

$V R P$ - Valor anual da remuneração de peças;

VE - Valor da carroceria; 
VRE - Valor anual da remuneração da carroceria (VExTR);

NCB - Número de conteineres de baixa capacidade;

VCB - Valor do conteiner de baixa capacidade;

$V T B$ - Valor total anual por conteiner $(V C B C x T R)$;

NCA - Número de conteineres de alta capacidade;

VCA - Valor do conteiner de alta capacidade;

$V T A$ - Valor total anual por conteiner de alta capacidade (VCACxTR).

\subsubsection{Custos administrativos}

Normalmente são calculados como uma porcentagem dos custos operacionais, destinando-se a cobrir as seguintes despesas: honorários, salários e ordenados, taxas, água, luz, telefone, entre outras despesas geradas na administração do serviço de coleta seletiva. 


\section{APLICAÇÃO DO MÉTODO}

Para a aplicação do método descrito no capítulo anterior algumas hipóteses foram assumidas, devido à falta de dados mais precisos para a entrada no modelo. Estas hipóteses são descritas abaixo:

- A taxa de geração por residência e a composição dos resíduos sólidos gerados não variam entre as propriedades residenciais de diferentes tamanhos;

- Os pontos no mapa considerados como residências não possuem diferenciação socioeconômica entre si como: prédios de apartamentos, residências geminadas, número de cômodos (que poderiam indicar a quantidade de pessoas que vivem no imóvel), e finalmente o tipo de uso do imóvel (residencial, comercial ou industrial);

- O tempo de esvaziamento dos contêineres ou de carregamento/descarregamento dos veículos, que poderia indicar o rendimento de cada sistema, não foi levado em consideração, apenas a distância percorrida.

A variável tempo de operação, que é o tempo gasto pelo sistema de coleta em cada turno, englobando as operações de deslocamento até o local de coleta, tempo de carregamento do veículo coletor, deslocamento até o depósito/garagem e esvaziamento do veículo coletor, mostrou-se de difícil mensuração para operações de coleta seletiva.

No caso dos sistemas porta-a-porta e híbrido, o resíduo reciclável fica guardado dentro das residências até o momento da coleta, quando os catadores solicitam aos moradores que entreguem o material. O tempo gasto entre a solicitação e a entrega varia muito de morador para morador. O sistema de coleta por PEVs, varia de acordo com o tipo de contêiner que pode variar de volume e o tipo de operação de esvaziamento, ambas variáveis que incidem sobre o tempo de esvaziamento.

\subsection{DELIMITAÇÃO DA ÁREA A SER ESTUDADA}

Localizada na região central do estado de São Paulo, São Carlos apresenta as características de uma cidade de médio porte, com população de 192.998 habitantes, segundo o último censo estatístico do IBGE, em 2000 (IBGE, 2000b). 
No município de São Carlos existem três programas de coleta seletiva, o primeiro deles organizado por iniciativa da Universidade Federal de São Carlos, que iniciou a sua implantação em 1994 (CUNHA, L., 1995 e TEIXEIRA e ZANIN, 1995), o segundo, o programa municipal, implantado por meio de uma iniciativa do governo local desde 2003 (THIEMERMAM, 2004), e o terceiro o programa de redução e reciclagem de resíduos dos campi da USP, chamado USP RECICLA.

Dados referentes à área onde a coleta seletiva municipal foi implantada foram obtidos junto a Secretaria de Desenvolvimento Sustentável do Município de São Carlos, que é responsável pela coordenação das cooperativas que atuam no programa de coleta seletiva municipal. A coleta seletiva praticada no município é executada em três áreas distintas, administradas por três cooperativas: Cooletiva, Coopervida e Ecoativa.

Para a execução das simulações de trajeto dos veículos deste estudo de caso, foi escolhida a área de uma destas cooperativas, cujas características geométricas não são muito uniformes, tendo-se assim uma boa representatividade da cidade toda. Essa área é constituída pelos seguintes bairros da cidade de São Carlos: Jd. São Carlos; Jd. Bethânia; Pq. Sta. Mônica; Jd. Paraíso; Jd. Lutfalla; Solar dos Engenheiros; Pq. Arnold Schimdt; Chácara Casalle; Cidade Jardim; Sta. Paula; Jd. Centenário; Pq. Sta. Marta; Jd. Bandeirantes; Nova Sta. Paula; Jd. Hikare; Jd. Paulistano; Pq. Delta e Vila Pq. Industrial. A área é mostrada na Figura 21. 

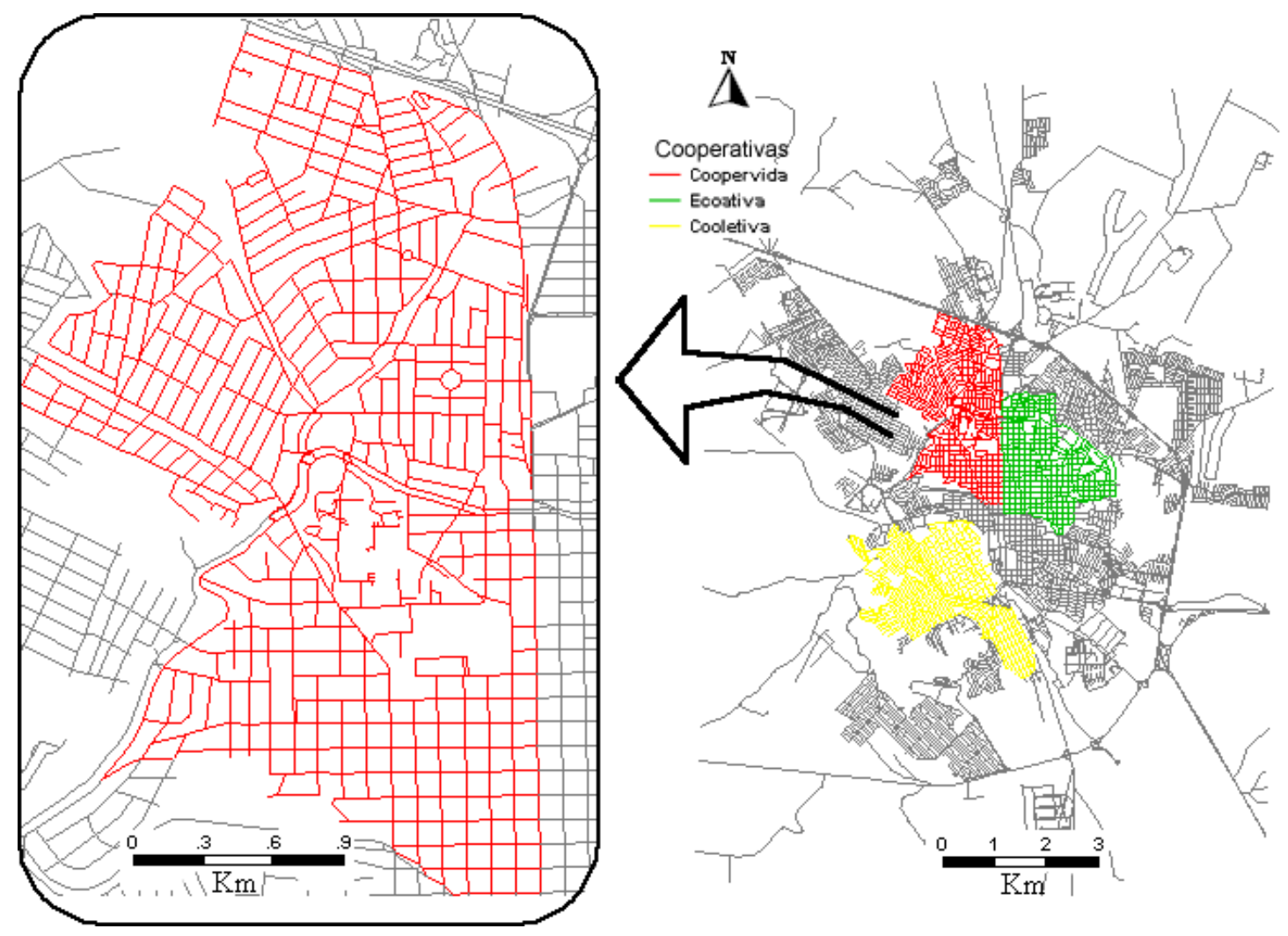

FIGURA 21. Área escolhida para as simulações de coleta (em vermelho) e áreas em que as cooperativas de coleta seletiva atuam (em amarelo, verde e vermelho) na cidade de São Carlos.

\subsubsection{Determinação da demanda residencial aproximada de São Carlos}

Para a determinação da produção diária de resíduos recicláveis por residência, a ser utilizada como demanda para este estudo, foi necessária a utilização de dados obtidos em estudos anteriores. Segundo Gomes e Povinelli (1991) "Os dados obtidos na caracterização de uma cidade podem ser comparados com os de outra localidade, ou até mesmo servir como base para comunidades onde ainda não se tenha realizado esse serviço. É importante salientar que a utilização da composição física de outra cidade só é válida quando as populações e as próprias cidades possuírem características muito semelhantes. Ainda assim, é aconselhável que só se utilizem estes dados em uma fase preliminar, partindo-se posteriormente para a caracterização do lixo da cidade e somente depois, de posse destes resultados, é que se deve dar continuidade ao projeto".

O estudo descrito em Zanin et al. (2002) foi realizada no município de São Carlos, em um bairro de classe média e média alta, situado na região central da cidade, que apresenta infra-estrutura básica como água encanada, energia elétrica, coleta regular de lixo e asfalto. Nesse bairro existem escolas públicas e particulares desde a educação 
infantil até o ensino médio, um hospital, praças e comércio com lojas e supermercados. A média domiciliar obtida neste estudo foi de $564 \mathrm{~g} / \mathrm{hab}$.dia de resíduos descartados e 102,9 g/hab.dia de resíduos recicláveis descartados, e está bem abaixo dos valores geralmente referidos como média global da cidade (pesagem do que chega ao aterro incluindo residências e também supermercados, lojas etc - dividida pelo número de habitantes).

Para o "veículo tipo" utilizado nesta pesquisa, um caminhão com carroceria adaptada de dimensões $4,7 \mathrm{~m} \times 2,5 \mathrm{~m} \times 2,1 \mathrm{~m}$, o peso médio da carga, quando este estava completamente carregado, era de $2.500 \mathrm{~kg}$ (THIEMERMAM, 2004), e como a quantidade média de recicláveis gerados por habitante daquela região foi de 102,9 $\mathrm{g} /$ hab.dia, tem-se que a densidade deste tipo de carga pode ser assim aproximada:

$$
\text { Densidade }=2.500 \mathrm{~kg} \div(4,7 \mathrm{~m} \times 2,5 \mathrm{~m} \times 2,1 \mathrm{~m})=101,3 \mathrm{~kg} / \mathrm{m}^{3}
$$

O número médio de pessoas residentes por domicílio residencial na cidade de São Carlos é de 3,32 (IBGE, 2000b), e a freqüência de coleta definida para este estudo é semanal, portanto, a quantidade de materiais recicláveis a ser coletada em cada domicílio residencial da cidade de São Carlos pode ser assim descrita:

$$
(0,1029 \mathrm{~kg} / \mathrm{hab} . \text { dia } \times 3,32 \mathrm{hab} \times 7 \text { dias }) / 101,3 \mathrm{~kg} / \mathrm{m}^{3}=0,023607 \mathrm{~m}^{3}
$$

\subsubsection{Definição dos cenários a serem analisados}

A implantação de um programa de coleta seletiva sofre algumas variações na demanda visto que depende diretamente do envolvimento da população atendida, que participa da primeira etapa do processo: a separação na fonte geradora.

A variação na participação da população nestes tipos de programa pode ser influenciada por alguns fatores como: campanhas educacionais para a informação e motivação da população, incentivos e/ou taxas atribuídas pelo poder público, políticas públicas para o desenvolvimento desse tipo de serviço.

Para a definição dos cenários a serem analisados foi considerado como a demanda máxima a ser recolhida a demanda atual da cidade em estudo (participação 
efetiva da população no programa), representada pelo cenário $100 \%$, e mais quatro cenários com $20 \%, 40 \%, 60 \%$ e $80 \%$ da demanda máxima, conforme a Tabela 10 , a seguir:

\section{Tabela 10. Cenários analisados}

\begin{tabular}{c|c|c|c} 
Cenário & $\begin{array}{c}\text { Sistema } \\
\text { de coleta }\end{array}$ & $\begin{array}{c}\text { Contribuição por domicílio } \\
\text { (em \% da demanda máx.) }\end{array}$ & $\begin{array}{c}\text { Volume de recicláveis } \\
\text { por domicílio }\left(\mathbf{m}^{\mathbf{3}} \mathbf{)}\right.\end{array}$ \\
\hline PEV20 & PEV & $20 \%$ & 0,0047214 \\
PEV40 & PEV & $40 \%$ & 0,0094428 \\
PEV60 & PEV & $60 \%$ & 0,0141642 \\
PEV80 & PEV & $80 \%$ & 0,0188856 \\
PEV100 & PEV & $100 \%$ & 0,0236070 \\
POR20 & Porta & $20 \%$ & 0,0047214 \\
POR40 & Porta & $40 \%$ & 0,0094428 \\
POR60 & Porta & $60 \%$ & 0,0141642 \\
POR80 & Porta & $80 \%$ & 0,0188856 \\
POR100 & Porta & $100 \%$ & 0,0236070 \\
HIB20 & Híbrido & $20 \%$ & 0,0047214 \\
HIB40 & Híbrido & $40 \%$ & 0,0094428 \\
HIB60 & Híbrido & $60 \%$ & 0,0141642 \\
HIB80 & Híbrido & $80 \%$ & 0,0188856 \\
HIB100 & Híbrido & $100 \%$ & 0,0236070
\end{tabular}

A quantidade de catadores utilizada em cada sistema varia. Para o sistema Portaa-Porta são necessários quatro catadores, visto que o veículo coletor passa no local onde o material a ser coletado está, sendo então necessário dois catadores sobre o veículo, acondicionando o resíduo coletado e dois catadores, para que recolham o material nos dois lados do meio fio.

Para o sistema por PEVs, são necessários três catadores: um catador para acondicionar a carga e dois para esvaziar os contêineres. A operação de esvaziamento dos contêineres, que pode ser automatizada, foi considerada como manual, com dois catadores içando o material do contêiner para o interior do veículo. O tempo de esvaziamento dos contêineres não foi considerado nesse estudo, uma vez que a variável considerada foi a distância percorrida pelo veículo coletor.

Para o sistema Híbrido, são necessários oito catadores, dois sobre o veículo para o acondicionamento da carga e seis catadores nas ruas, cobrindo as ruas adjacentes ao 
percurso do veículo. Esse número é o número observado no sistema já implantado na área em estudo (THIEMERMAN, 2004).

\subsubsection{Parâmetros de custo utilizados}

As Tabelas 11, 12 e 13 mostram os parâmetros inicialmente utilizados nesta análise para a determinação dos custos, assim como suas referências:

Tabela 11. Parâmetros de custo: custos fixos de capital

\begin{tabular}{|c|c|c|c|}
\hline \multicolumn{4}{|c|}{ Custos Fixos } \\
\hline \multirow{29}{*}{ 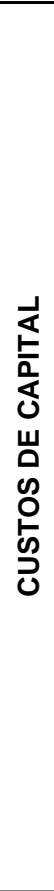 } & VEÍCULOS & & \\
\hline & Depreciação do capital investido & & \\
\hline & Valor do veículo novo (IVECO - DAILY CHASSI 70-12) & & R\$ 59.500,00 ECONOMIA \& TRANSPORTE (2005) \\
\hline & Valor residual do veículo & $20 \%$ & $11.900,00$ NTC (2001) \\
\hline & Vida útil & meses & 60 NTC (2001) \\
\hline & Remuneração do Capital & & \\
\hline & \begin{tabular}{|l|} 
Taxa de juros \\
\end{tabular} & anual & $12 \%$ NTC (2001) \\
\hline & $\begin{array}{l}\text { \% do novo a ser remunerada como investimento em } \\
\text { peças de reposição }\end{array}$ & anual & $1 \%$ NTC (2001) \\
\hline & VEICULOS - EQUIPAMENTOS & & \\
\hline & Depreciação do capital investido & & \\
\hline & Valor do novo (MADEIRA ABERTA) & & 5.000,00 ECONOMIA \& TRANSPORTE (2005) \\
\hline & Valor residual da carroceria & & $5 \%$ NTC (2001) \\
\hline & Vida útil & meses & 60 NTC (2001) \\
\hline & Remuneração do Capital & & \\
\hline & \begin{tabular}{|l|} 
Taxa de juros \\
\end{tabular} & anual & $12 \%$ NTC (2001) \\
\hline & CONTEINERES DE BAIXA CAPACIDADE (200L a 400L) & & \\
\hline & Depreciação do capital investido & & \\
\hline & Valor do conteiner novo (investimento inicial) & & 500,00 \\
\hline & Valor residual do conteiner & & 5\% GOULART (2003) \\
\hline & Vida útil & meses & 60 GOULART (2003) \\
\hline & Remuneração do Capital & & \\
\hline & Taxa de juros & anual & 12\% ECONOMIA \& TRANSPORTE (2005) \\
\hline & CONTEINERES DE ALTA CAPACIDADE (1200L a 1600L & & \\
\hline & \begin{tabular}{|l|} 
Depreciação do capital investido \\
\end{tabular} & & \\
\hline & Valor do conteiner novo (investimento inicial) & & $2.000,00$ \\
\hline & Valor residual do conteiner & & 5\% GOULART (2003) \\
\hline & Vida útil & meses & 60 GOULART (2003) \\
\hline & Remuneração do Capital & & \\
\hline & Taxa de juros & anual & 12\% ECONOMIA \& TRANSPORTE (2005) \\
\hline
\end{tabular}

Tabela 12. Parâmetros de custo: custos fixos operacionais

\begin{tabular}{|c|c|c|}
\hline \multicolumn{3}{|c|}{ Custos Fixos } \\
\hline \multirow{14}{*}{ 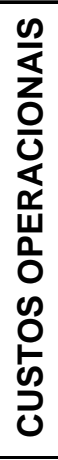 } & \multicolumn{2}{|l|}{ Salários+Benefícios e encargos } \\
\hline & Catadores (Sal. Méd.: 300,00; VT.:4,00x25dias; VR.:4,00x25dias) & 500,00 SELUR (2001) \\
\hline & Motorista (Sal. Méd.: 644,00; VT.:4,00x25dias; VR.:4,00x25dias) & 844,00 ECONOMIA \& TRANSPORTE (2005) \\
\hline & Os encargos sociais aplicados & $79,81 \%$ SELUR (2001) \\
\hline & \multicolumn{2}{|l|}{ Uniformes } \\
\hline & $1 / 12$ dos valores gastos anuais (por funcionário) & 5,10 THIEMERMAM (2004) \\
\hline & \multicolumn{2}{|l|}{\begin{tabular}{|l|} 
Licenciamento e Seguro \\
\end{tabular}} \\
\hline & Seguro obrigatório em R $\$$ /ano & 66,43 ECONOMIA \& TRANSPORTE (2005) \\
\hline & \multirow{2}{*}{\begin{tabular}{|l|} 
IPVA \\
Taxa de Licenciamento \\
\end{tabular}} & $1.315,40$ NTC (2001) \\
\hline & & 10,20 NTC (2001) \\
\hline & Imposto s/ Operações Financeiras & $1,07 \%$ NTC (2001) \\
\hline & \begin{tabular}{|l|} 
Custo da apólice \\
Coef. s/ importância sequrada
\end{tabular} & 60,00 NTC (2001) \\
\hline & Coef. s/ importância segurada & 0,0570 NTC (2001) \\
\hline & S.R.C.F Prêmio de DM(R\$ 50 mil) e DP(R\$ 100 mil) & $1.064,49$ NTC (2001) \\
\hline
\end{tabular}


Tabela 13. Parâmetros de custo: custos variáveis

\begin{tabular}{|c|c|c|c|}
\hline \multicolumn{4}{|c|}{ Custos Variáveis } \\
\hline \multirow{27}{*}{$\begin{array}{l}\frac{n}{4} \\
\frac{Z}{0} \\
\frac{0}{U} \\
\frac{\alpha}{\alpha} \\
\frac{1}{0} \\
0\end{array}$} & Manutenção de veículos & & \\
\hline & Salário do mecânico - média & $\mathrm{R} \$$ & 840,76 NTC (2001) \\
\hline & Quantidade de veículos atendidos p/ mecânico & QTD & 5 NTC (2001) \\
\hline & Taxas s/ peças, acessórios e mat. manutenção & & 1\% NTC (2001) \\
\hline & Manutenção dos conteiners (PEVs) & & \\
\hline & $\%$ do custo de investmento do conteiner por ano & & $35 \%$ GOULART (2003) \\
\hline & Custos de Pneus e Câmaras & & \\
\hline & Valor do Estepe - veículo & $\mathrm{R} \$$ & 669,27 ECONOMIA \& TRANSPORTE (2005) \\
\hline & Valor do Pneu - veículo 195/75 R16 & $\mathrm{R} \$$ & 669,27 ECONOMIA \& TRANSPORTE (2005) \\
\hline & Valor da Câmara - veículo & $\mathrm{R} \$$ & 0 NTC (2001) \\
\hline & Valor da Recauchutagem a frio - veículo & $\mathrm{R} \$$ & 177,90 ECONOMIA \& TRANSPORTE (2005) \\
\hline & Quantidade de pneus por veículo & QTD & 4 NTC (2001) \\
\hline & Vida útil do pneu com uma recapagem & $\mathrm{km}$ & 70.000 NTC (2001) \\
\hline & Numero de recapagens & QTD & 2 NTC (2001) \\
\hline & Consumo de Combustível & & \\
\hline & Preço do combustível - litro & $\mathrm{R} \$$ & 1,68 ECONOMIA \& TRANSPORTE (2005) \\
\hline & Rendimento do combustível & km/litro & 7,50 NTC (2001) \\
\hline & Lubrificação e Lavagens & & \\
\hline & Preço do óleo de cárter - litro & $\mathrm{R} \$$ & 5,70 ECONOMIA \& TRANSPORTE (2005) \\
\hline & Capacidade de óleo do cárter & litros & 7,00 NTC (2001) \\
\hline & Reposição até a próxima troca & litros & 1,50 NTC (2001) \\
\hline & Troca de óleo do cárter & $\mathrm{km}$ & 30.000 \\
\hline & Preço do óleo de câmbio/diferencial - litro & $\mathrm{R} \$$ & 6,95 ECONOMIA \& TRANSPORTE (2005) \\
\hline & Capacidade de óleo caixa do diferencial & litros & 2,90 NTC (2001) \\
\hline & Troca de óleo do diferencial & $\mathrm{km}$ & 120.000 NTC (2001) \\
\hline & Periodicidade de lavagem do veículo & $\mathrm{km}$ & 2.000 NTC (2001) \\
\hline & Lavagem (água, luz, xampu, desinfetante e mão de obra) & $\mathrm{R} \$ /$ por & 72,00 ECONOMIA \& TRANSPORTE (2005) \\
\hline
\end{tabular}

Tabela 14. Parâmetros de custo: custos administrativos

\begin{tabular}{|c|c|c|}
\hline ֻّ & $15 \%$ do valor dos custos operacionais & SELUR (2001) \\
\hline
\end{tabular}

\subsection{APLICAÇÃO DAS ROTINAS DO SOFTWARE}

Após a preparação da base de dados e aplicação das rotinas de localização dos pontos de coleta para os três sistemas na área de estudos, foram obtidos os seguintes mapas, conforme mostrado nas Figuras 22, 23 e 24: 


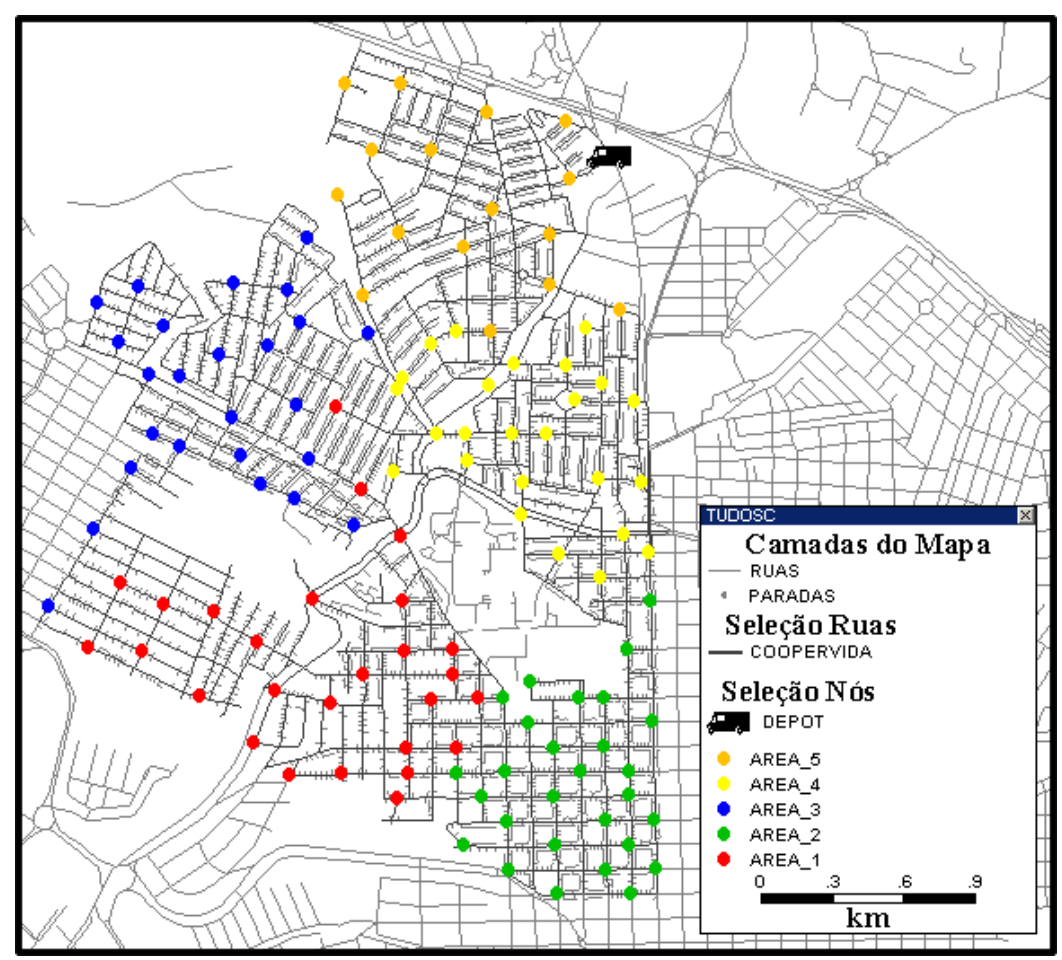

FIGURA 22. Mapa para o sistema por PEVs - seleção da área de estudo dividida em áreas menores e os pontos indicando os PEVs separados em pequenas áreas

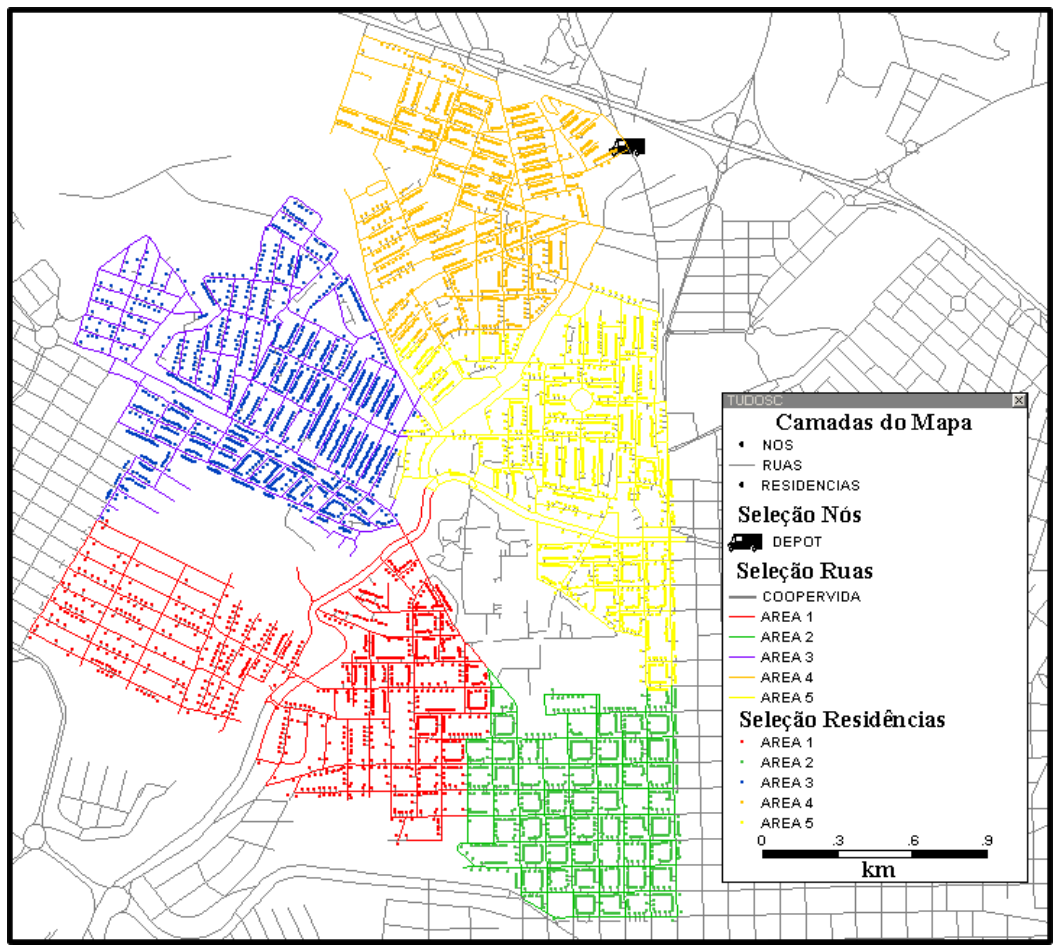

FIGURA 23. Mapa para o sistema Porta a Porta - seleção da área de estudo separada em áreas menores e os pontos indicando as residências atendidas por cada área 


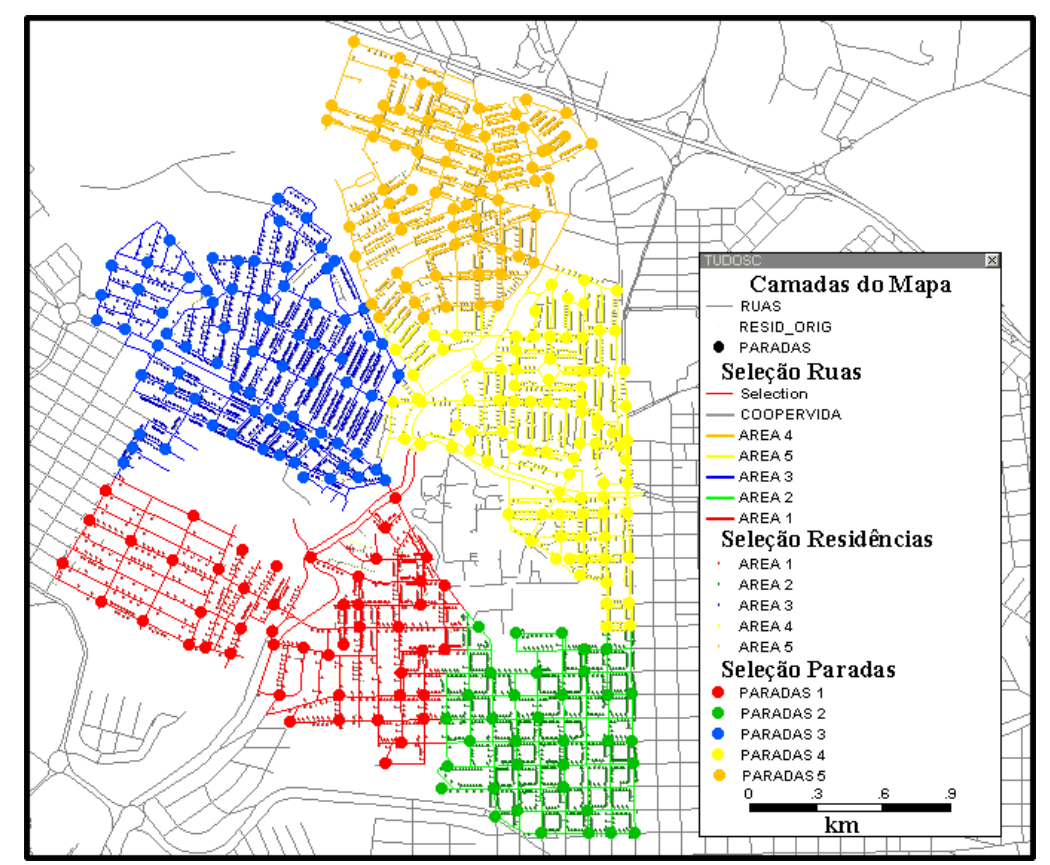

FIGURA 24. Mapa para o sistema Híbrido - seleção da área de estudo como pontos indicando as residências atendidas por cada área e os pontos de parada para cada área

\subsection{PLANILHAS DE CUSTO PARA CADA CENÁRIO}

Para o cálculo do custo de cada cenário foram confeccionadas as planilhas de custo com os parâmetros descritos na seção 4.1.4 deste capítulo, conforme mostrado nas tabelas $15,16,17 \mathrm{e} 18$.

Tabela 15. Dados de entrada na planilha de custos

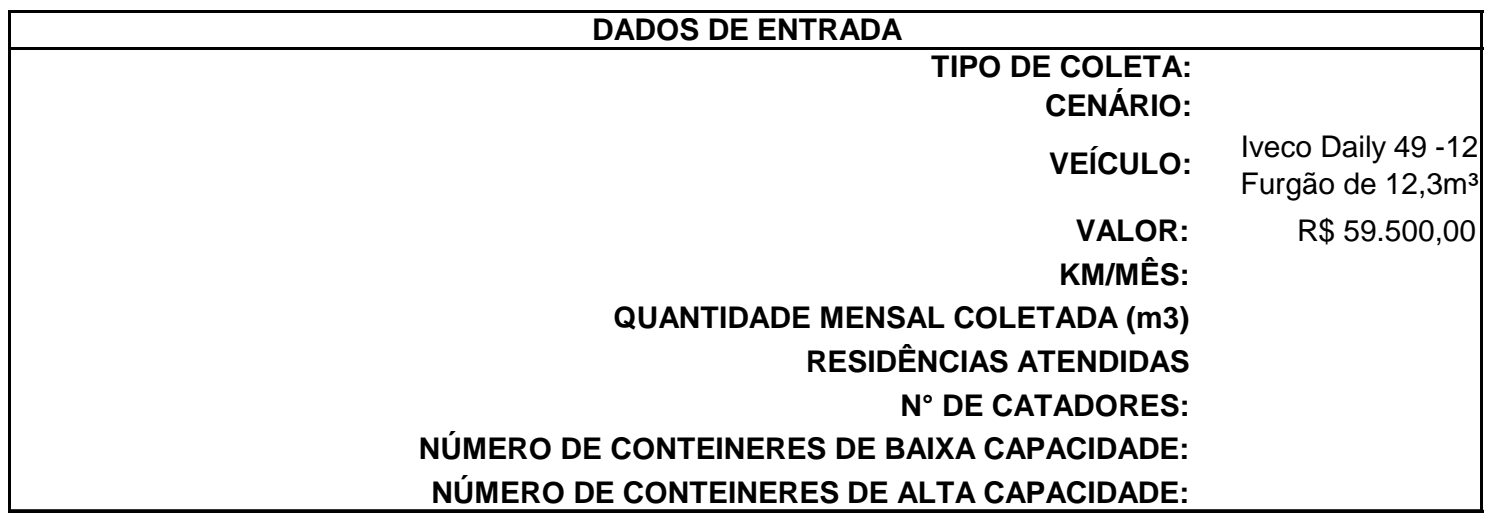


Tabela 16. Planilha de cálculo dos custos fixos

\begin{tabular}{|c|c|}
\hline \multicolumn{2}{|l|}{ CÁLCULO } \\
\hline CUSTOS FIXOS: $(a+b+c+d+e+f+g)$ & $3.116,85$ \\
\hline a - Remuneração de capital & 694,58 \\
\hline b - Salário do motorista & $1.157,98$ \\
\hline \multicolumn{2}{|l|}{ c - Salário dos catadores } \\
\hline d - Salário de oficina & 302,35 \\
\hline e - Uniformes & 5,10 \\
\hline f - Reposição do veículo & 836,81 \\
\hline g - Licenciamento & 116,00 \\
\hline h- Seguro do casco do veículo & 3,08 \\
\hline i- Seguro de responsabilidade civil facultativa & 0,95 \\
\hline \multicolumn{2}{|l|}{ j - Manutenção dos conteineres } \\
\hline \multicolumn{2}{|l|}{ a - Remuneração do capital: } \\
\hline$((V T A+V R P+V R E+(N C B x V T B)+(N C A x V T A)) / 12$ meses $)$ & 694,58 \\
\hline VV - Valor do veículo (R\$) & $59.500,00$ \\
\hline TR - Taxa de remuneração do capital (anual) & $12 \%$ \\
\hline VTA - Valor total anual (VVxTR) (R\$) & $7.140,00$ \\
\hline TRP - Taxa de remuneração de peças (anual) & $1 \%$ \\
\hline VRP - Valor anual da remuneração de peças $(R \$)$ & 595,00 \\
\hline VE - Valor da carroceria & 5000,00 \\
\hline VRE - Valor anual da remuneração da carroceria (VExTR) & 600,00 \\
\hline \multicolumn{2}{|l|}{ NCB - Número de conteineres de baixa capacidade } \\
\hline$V C B$ - Valor do conteiner de baixa capacidade $(\mathrm{R} \$)$ & 500,00 \\
\hline VTB - Valor total anual por conteiner (VCBxTR) (R\$) & 60,00 \\
\hline \multicolumn{2}{|l|}{ NCA - Número de conteineres de alta capacidade } \\
\hline VCA - Valor do conteiner de alta capacidade & 2000,00 \\
\hline VTA - Valor total anual por conteiner (VCAxTR) (R\$) & 240,00 \\
\hline b - Salário do motorista: (SM+(SMxENC)) & $1.157,98$ \\
\hline SM - Salário básico (média em R\$) & 644,00 \\
\hline ENC - Encargos sociais sobre salários & $79,81 \%$ \\
\hline \multicolumn{2}{|l|}{ c - Salário dos catadores: $((S C+(S C x E N C)) x N C A T)$} \\
\hline SC - Salário básico (média em R\$) & 400,00 \\
\hline ENC - Encargos sociais sobre salários & $79,81 \%$ \\
\hline \multicolumn{2}{|l|}{ NCAT - Número de catadores } \\
\hline d - Salário de oficina: (SMEC+(SMECXENC)/NMEC & 302,35 \\
\hline SMEC - Salário de mecânico (média em R\$) & 840,76 \\
\hline NMEC - Quantidade de veículos atendidos por mecânico & 5 \\
\hline ENC - Encargos sociais sobre salários & $79,81 \%$ \\
\hline e - Uniformes: (UNxNF) & 5,10 \\
\hline UN - Custo mensal com uniformes por funcionário & 5,1 \\
\hline NF - Número de funcionários & 1 \\
\hline
\end{tabular}




\section{Tabela 16 Planilha de cálculo dos custos fixos (cont.)}

\begin{tabular}{|c|c|}
\hline $\mid \begin{array}{l}\text { f - Depreciação: } \\
((T R V / V U V) \times((V V-((V P+V C) \times N P)))+((T R E / V U E) \times V E)+\end{array}$ & \\
\hline$+((T C B / V U C B) \times N C B \times V C B)+((T C A / V U C A) \times N C A x V U C A)$ & 836,81 \\
\hline VV - Valor do veículo $(\mathrm{R} \$)$ & $59.500,00$ \\
\hline$N P$ - Quantidade de pneus por veículo (R\$) & 4 \\
\hline$V P$ - Valor do pneu $(\mathrm{R} \$)$ & 669,27 \\
\hline VC - Valor da câmara (R\$) & \\
\hline TRV - Taxa de reposição do veículo & $80 \%$ \\
\hline VUV - Vida útil do veículo (meses) & 60 \\
\hline VE - Valor da carroceria & $5.000,00$ \\
\hline TRE - Taxa de reposição da carroceria & $95 \%$ \\
\hline VUE - Vida útil da carroceria (meses) & 60 \\
\hline NCB - Número de conteineres de baixa capacidade & \\
\hline$V C B$ - Valor do conteiner de baixa capacidade $(\mathrm{R} \$)$ & 500,00 \\
\hline$T C B$ - Taxa de reposição dos conteineres de baixa capacidade & $95 \%$ \\
\hline VUCB - Vida útil dos conteineres de baixa capacidade (meses) & 60 \\
\hline NCA - Número de conteineres de alta capacidade & \\
\hline VCA - Valor do conteiner de alta capacidade & $2.000,00$ \\
\hline TCA - Taxa de reposição dos conteineres de alta capacidade & $95 \%$ \\
\hline VUCA - Vida útil dos conteineres de alta capacidade (meses) & 60 \\
\hline g - Licenciamento: (DPVAT+IPVA+LIC)/12 meses & 116,00 \\
\hline DPVAT - DPVAT (R\$) & 66,43 \\
\hline IPVA - I.P.V.A (R\$) & $1.315,40$ \\
\hline LIC - Taxa para licenciamento $(\mathrm{R} \$)$ & 10,20 \\
\hline h - Seguro do casco : (VVxCOEF+VAP)xIOF/12 meses & 3,08 \\
\hline VV- Valor do veículo $(\mathrm{R} \$)$ & $59.500,00$ \\
\hline COEF - Coeficiente sobre importância segurada & 0,057 \\
\hline VAP - Valor da apólice (R\$) & 60,00 \\
\hline IOF - IOF & 0,0107 \\
\hline i - Seguro de Responsabilidade Civil Facultativo: (SRCFxIOF)/12 meses & 0,95 \\
\hline SRCF-SRCF prêmio danos materiais & $1.064,49$ \\
\hline IOF - Imposto sobre Operações Financeiras - IOF & 0,0107 \\
\hline j - Manutenção de conteineres: ((NCBxVCB)+(NCAxVCA))xTMA)/VUC & \\
\hline NCB - Número de conteineres de baixa capacidade & \\
\hline$V C B$ - Valor do conteiner de baixa capacidade $(R \$)$ & 500,00 \\
\hline NCA - Número de conteineres de alta capacidade & \\
\hline VCA - Valor do conteiner de alta capacidade & $2.000,00$ \\
\hline TMA - Taxa de manutenção anual (\% do novo) & $35 \%$ \\
\hline VUC - Vida util do conteiner & 60 \\
\hline
\end{tabular}


Tabela 17. Cálculo dos custos variáveis

\begin{tabular}{|c|c|}
\hline CUSTOS VARIÁVEIS: $(a+b+c+d+e)$ & 0,4429 \\
\hline a - Peças, acessórios e materiais de manutenção & 0,1404 \\
\hline b - Combustíveis & 0,2237 \\
\hline c-Lubrificantes & 0,0018 \\
\hline d - Lavagem e lubrificação & 0,0360 \\
\hline e - Pneus & 0,0410 \\
\hline \multicolumn{2}{|l|}{ Cálculo } \\
\hline \multicolumn{2}{|l|}{ a - Peças, acessórios e material de manutenção de veículos: } \\
\hline & 0,1404 \\
\hline VV - Valor do veículo (R\$) & $59.500,00$ \\
\hline NP - Quantidade de pneus & 4 \\
\hline VP - Valor do pneu (R\$) & 669,27 \\
\hline \multicolumn{2}{|l|}{ VC - Valor da câmara (R\$) } \\
\hline VE - Valor do estepe (R\$) & 669,27 \\
\hline TMM - Taxa mensal peças e material de manutenção & $1 \%$ \\
\hline$K M$ - Quilometragem mensal de referência $(\mathrm{km})$ & 4.000 \\
\hline b - Combustível: (COMB/REND) & 0,2237 \\
\hline COMB -Preço do combustível por litro (R\$) & 1,678 \\
\hline REND - Rendimento (km/litro) & 7,5 \\
\hline c - Lubrificante: $(P O C x(C O C+R O C) / I T O C)+(P O C D x C O C D / I T O C D)$ & 0,0018 \\
\hline$P O C$ - Preço do óleo de cárter por litro (R\$) & 5,7 \\
\hline COC - Capacidade de óleo de cárter (litros) & 7,000 \\
\hline ROC - Reposição óleo de cárter até a próxima troca (litros) & 1,500 \\
\hline ITOC - Intervalo de troca de óleo de cárter (km) & 30.000 \\
\hline$P O C D$ - Preço do óleo de câmbio e diferencial ( $\mathrm{R} \$ /$ litro) & 6,95 \\
\hline COCD - Capacidade do câmbio e do diferencial (litros) & 2,90 \\
\hline ITOCD - Intervalo entre trocas câmbio e diferencial (km) & 120.000 \\
\hline d - Lavagem e lubrificação: (CL/IL) & 0,0360 \\
\hline$C L$ - Custo de uma lavagem/engraxamento (R\$) & 72,00 \\
\hline IL - Intervalo entre duas lavagens $(\mathrm{km})$ & 2.000 \\
\hline e - Pneus, câmaras e recapagens: $(((V P+V C) \times N P)+N R \times V R \times N P) / V U P$ & 0,0410 \\
\hline VP - Valor do pneu (R\$) & 669,27 \\
\hline \multicolumn{2}{|l|}{ VC - Valor da câmara (R\$) } \\
\hline$V R$-Valor da recauchutagem $(\mathrm{R} \$)$ & 177,90 \\
\hline NP - Quantidade de pneus & 4 \\
\hline VUP - Vida útil total do pneu $(\mathrm{km})$ & 100.000 \\
\hline NR - Número de recauchutagens & 2 \\
\hline
\end{tabular}

Tabela 18. Cálculo dos custos administrativos 
Tabela 19. Cálculo do custo total, por quilômetro, por metro cúbico coletado e por residência atendida

CUSTO MENSAL TOTAL

CUSTO TOTAL POR QUILÔMETRO (R\$/km)

CUSTO TOTAL POR METRO CUBICO COLETADO (R\$/m3)

CUSTO MENSAL POR RESIDÊNCIA ATENDIDA

\subsection{PROBLEMAS OBSERVADOS}

Durante as simulações executadas com o software TransCAD, alguns problemas foram observados, principalmente na execução da rotina arc routing. Dessa forma, os problemas encontrados serão relatados a seguir:

- Para a execução da Rotina Transportation Problem, uma matriz de custos deveria ser criada. No mapa da área em estudo, os nós simbolizando as residências e os nós simbolizando as esquinas (ou os pontos nas ruas) estão em camadas diferentes. O procedimento de criação da matriz de custos não permite que, quando os nós estão em camadas diferentes, as distâncias sejam calculadas pela rede de transporte, somente pelas distâncias em linha reta multiplicada por um valor que as aproxima das distâncias em rede (opção straight lines);

- Para a definição das residências atendidas pelos links, primeiramente foram definidas quantas residências eram atendidas pelos pontos da camada de ruas (nós da camada de links). Para que fossem definidas quantas residências seriam atendidas pelos links, e posterior definição da demanda de cada link, foi necessário agregar os valores observados na camada de pontos para a camada de linhas (com comando Fill - agregate) como a menor banda possível para que o número mais exato de residências atendidas fosse conferido aos links. Para a execução desse procedimento, algumas tentativas foram realizadas até que o número de residências atendidas pelo link fosse muito próximo à metade do número de residências atendidas pelos dois nós que definem o link;

- Para a execução da rotina Arc Routing, o procedimento considera duas passagens em cada link em que o serviço é solicitado. Para resolver esse problema deve-se preparar os dados de maneira que suporte o "serpenteamento", com algumas restrições como: as ligações nas quais o "serpenteamento" ocorrerá 
e as direções nas quais estas ligações serão atravessadas quando o serviço ocorrer;

- Para indicar que ambos os lados da rua devem ser servidos numa única passagem, deve-se ajustar o campo da bandeira de serviço (service flag da camada de links) tal que ele iguale o código de serviço somente na direção na qual o serviço ocorrerá. O problema encontrado foi definir em qual direção o veículo deveria passar. Para tanto, primeiramente definiu-se a passagem no sentido favorável à topologia do link. Após a execução da rotina, verificou-se em quais links havia mais de uma passagem em sentidos opostos, selecionou-se tais links e definia-se a passagem no sentido inverso à topologia do link, para posteriormente se executar a rotina e fazer nova análise. 
Após a aplicação do método proposto os resultados obtidos foram divididos em:

- Resultados das rotinas de roteirização aplicadas para cada sistema: com a quilometragem percorrida por sistema, a quantidade de resíduo coletada, a quantidade de residências atendidas e a quantidade de contêineres utilizados para o sistema por PEVs;

- Os custos de cada cenário que serão analisados em termos de: custo total mensal por sistema, custo mensal por residência atendida, custo por quilômetro percorrido e custo por metro cúbico coletado;

- E, por fim, serão analisados os custos do sistema por PEVs referentes à variações nas configurações de contêineres utilizados;

\subsection{RESULTADOS DAS ROTINAS DE ROTEAMENTO}

Nesta seção são mostradas graficamente as rotas definidas pelas rotinas de roteamento executadas. As planilhas com os resultados obtidos a partir destas rotinas, para cada uma das 5 áreas de coleta diária, foram apresentadas no Apêndice B, ao final desta dissertação.

\subsubsection{Sistema por PEVs}

Após a execução das rotinas do sistema por PEVs para os cinco cenários, variando-se a demanda, foram obtidos os seguintes resultados. Tabela 20. Resultados das rotinas de roteirização para as variações da
demanda propostas para o sistema por PEVs

\begin{tabular}{|c|c|c|c|c|c|}
\hline Cenário & $\begin{array}{c}\text { Distância semanal } \\
\text { percorrida } \\
(\mathrm{km})\end{array}$ & $\begin{array}{l}\text { Residências } \\
\text { atendidas }\end{array}$ & $\begin{array}{c}\text { Demanda } \\
\text { coletada } \\
\left(\mathrm{m}^{3}\right)\end{array}$ & $\begin{array}{c}\text { Contêineres de } \\
\text { alta capacidade } \\
\left(1,6 \mathrm{~m}^{3}\right)\end{array}$ & $\begin{array}{l}\text { Contêineres de baixa } \\
\text { capacidade }\left(0,36 \mathrm{~m}^{3}\right)\end{array}$ \\
\hline PEV20 & 55,00 & 6113 & 28,94 & 0 & 144 \\
\hline PEV40 & 55,00 & 6113 & 57,63 & 1 & 213 \\
\hline PEV60 & 55,00 & 6113 & 86,57 & 8 & 261 \\
\hline PEV80 & 66,70 & 6113 & 115,50 & 20 & 288 \\
\hline PEV100 & 76,70 & 6113 & 144,25 & 44 & 265 \\
\hline
\end{tabular}

Como observado na tabela 20 e nas planilhas 1, 2, 3, 4 e 5 do apêndice B, para os cenários PEV20, PEV40 e PEV60 não houve variação na distância percorrida pelo veículo de coleta. Para as quantidades de demanda destes cenários, a capacidade 
máxima do veículo não foi atingida para nenhuma das cinco áreas de coleta semanais, não havendo assim a necessidade de uma segunda viagem. Para o cenário PEV80, nas áreas 1, 3 e 5, também não houve a necessidade de uma segunda viagem, assim como na área 5, para o cenário PEV100. As rotas destes cenários em cada área são mostradas nas Figuras 25, 26, 27, 28 e 29.

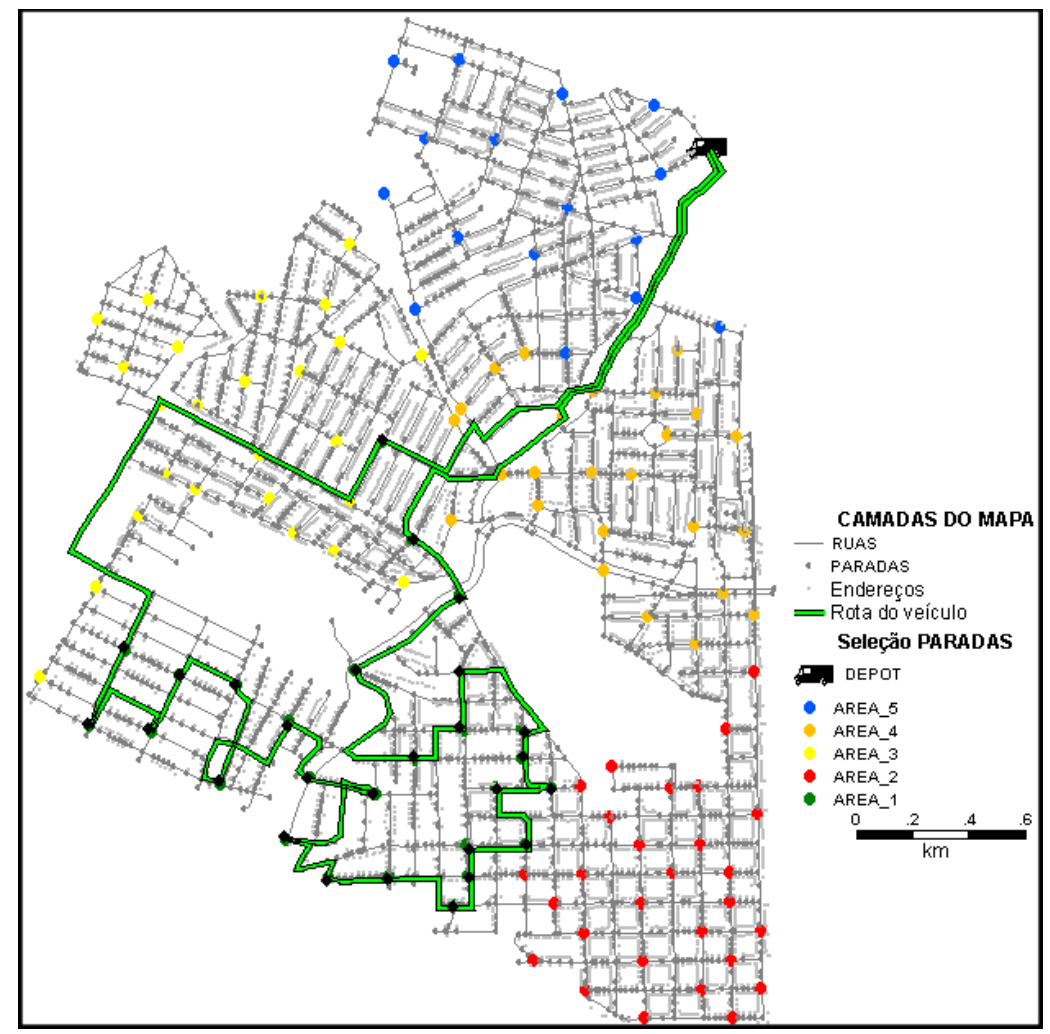

FIGURA 25. Rota do veículo de coleta na área 1 para os cenários PEV20, PEV40, PEV60 e PEV80 


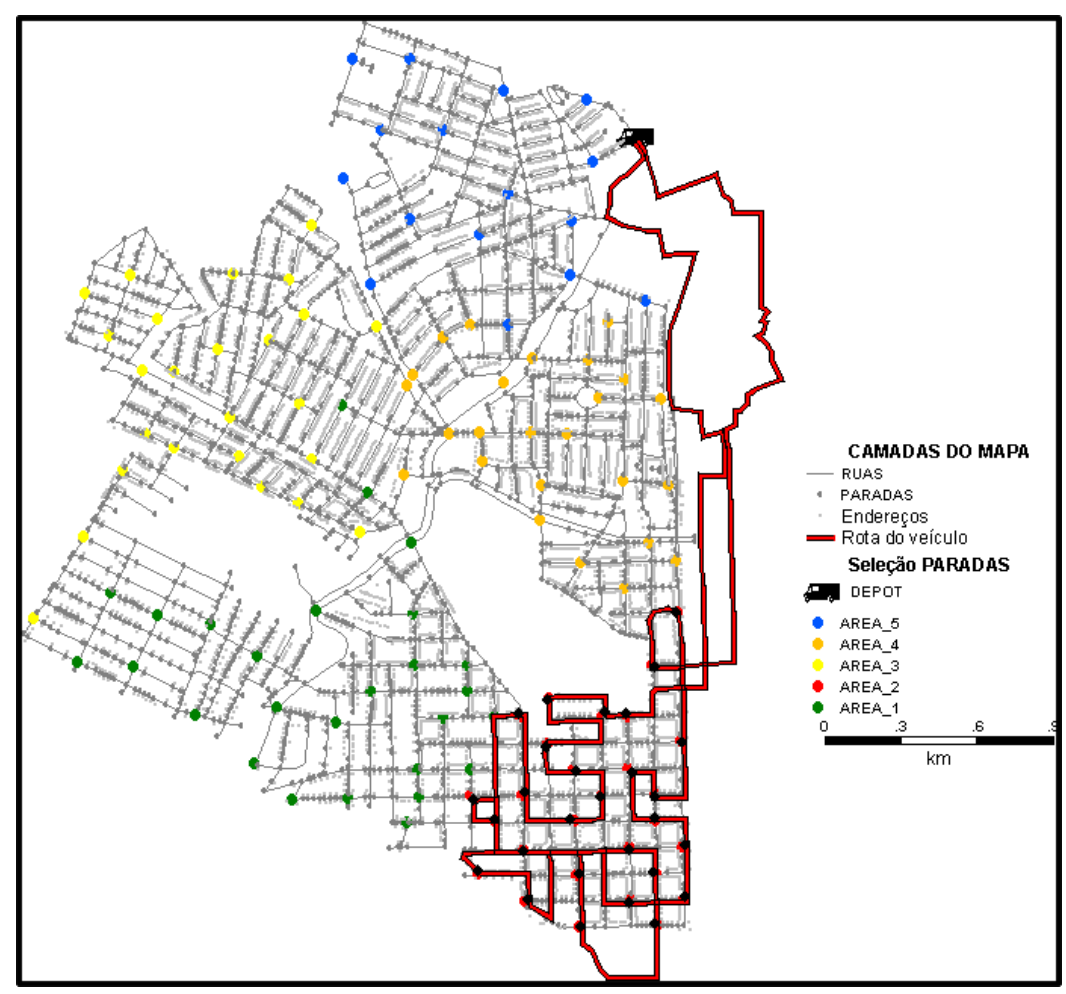

FIGURA 26. Rota do veículo de coleta na área 2 para os cenários PEV20, PEV40 e PEV60

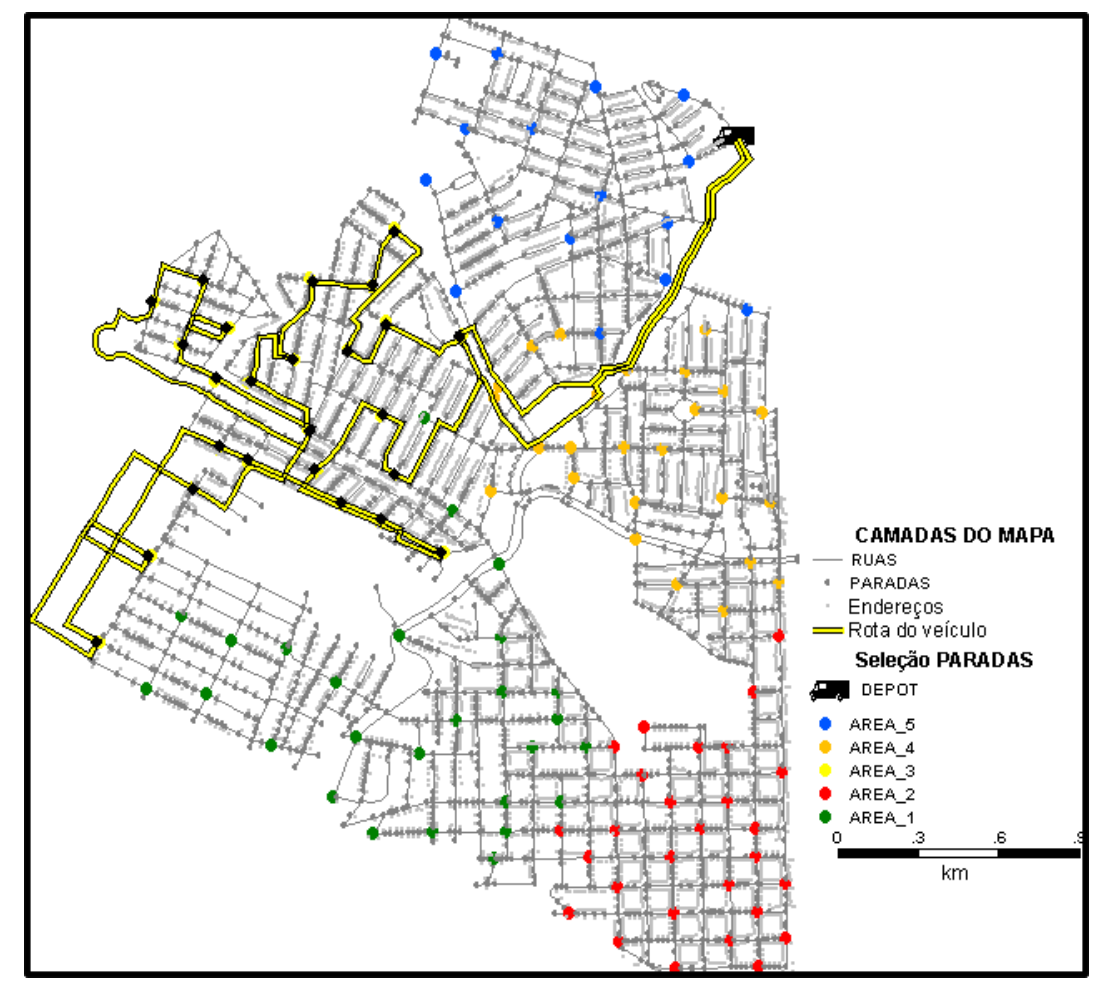

FIGURA 27. Rota do veículo de coleta na área 3 para os cenários PEV20, PEV40, PEV60 e PEV80 


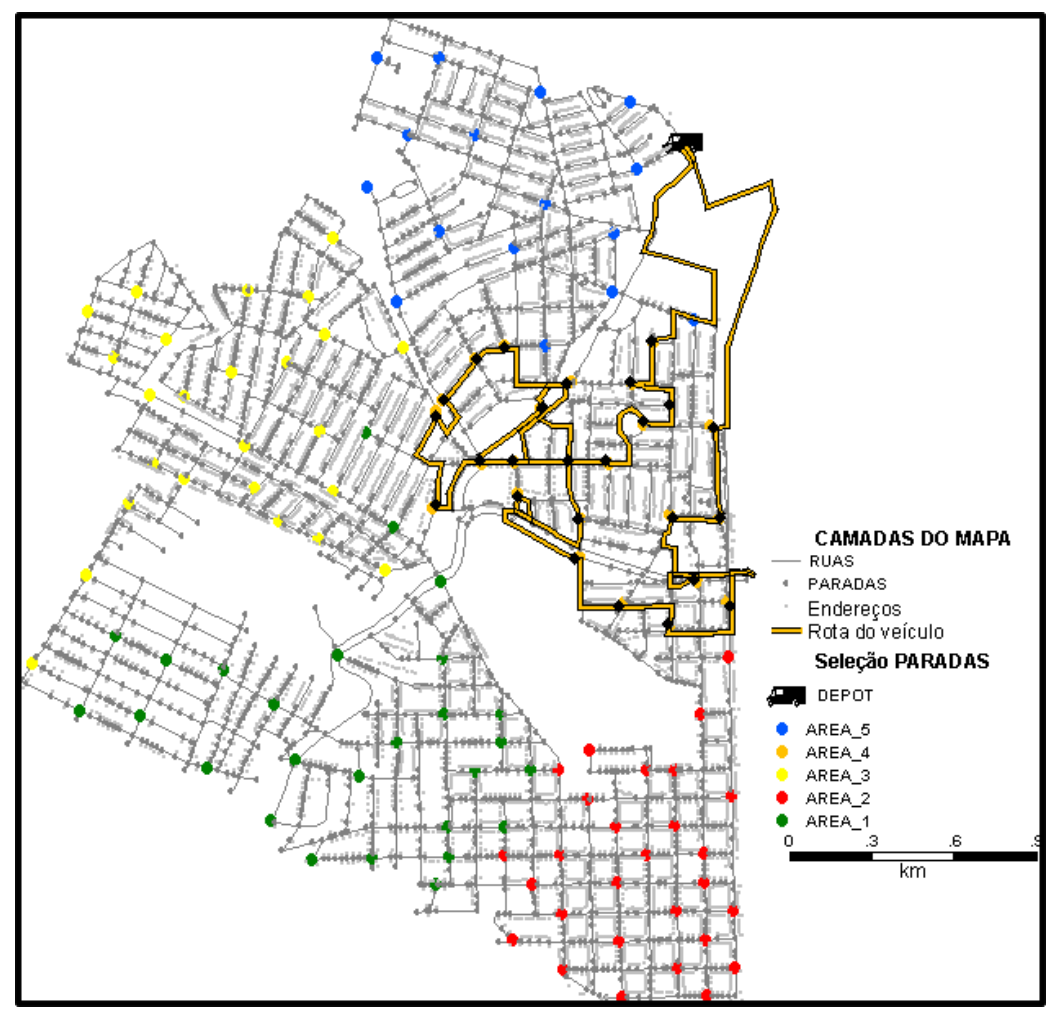

FIGURA 28. Rota do veículo de coleta na área 4 para os cenários PEV20, PEV40 e PEV60

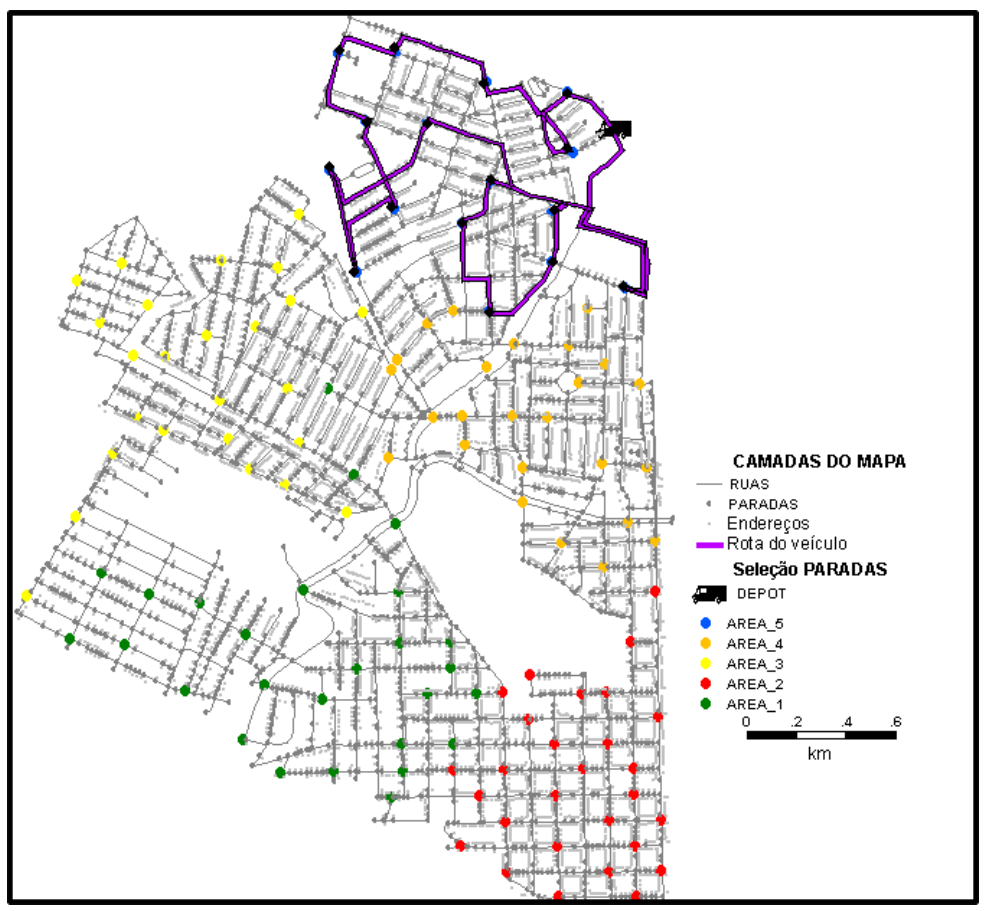

FIGURA 29. Rota do veículo de coleta na área 5 para os cenários PEV20, PEV40, PEV60, PEV80 e PEV100 
Para o cenário PEV80 houve a necessidade de uma segunda viagem nas áreas 2 e 4, cujas rotas são mostradas nas figuras 30 e 31 .

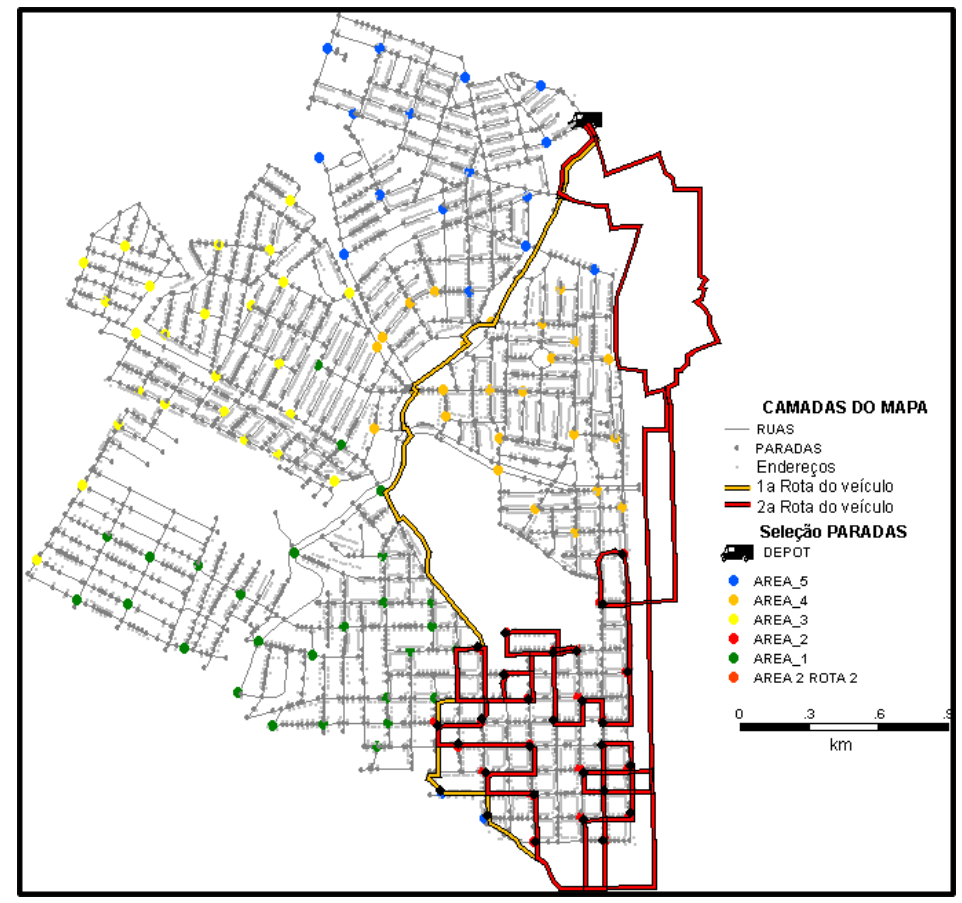

FIGURA 30. Rotas do veículo de coleta na área 2 para o cenário PEV80

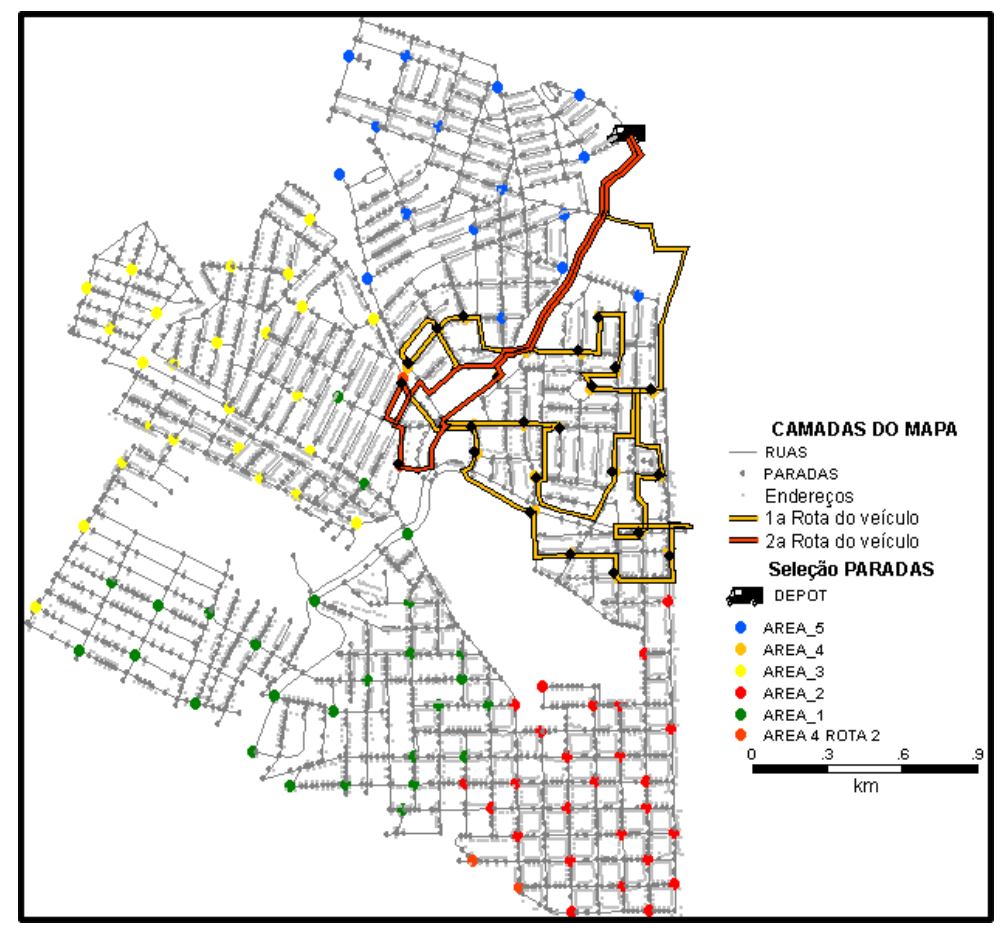

FIGURA 31. Rotas do veículo de coleta na área 4 para o cenário PEV80 
Para o cenário PEV100 houve a necessidade de uma segunda viagem nas áreas 1, 2, 3 e 4, cujas rotas são mostradas nas figuras 32, 33, 34 e 35.

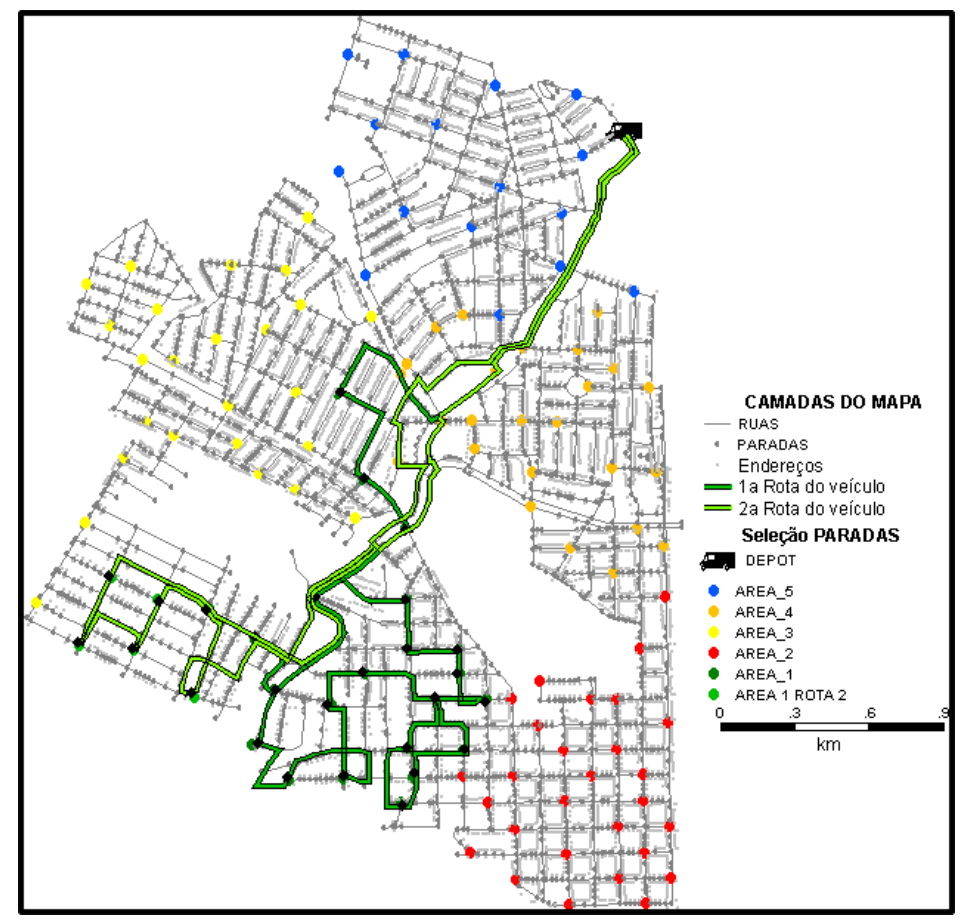

FIGURA 32. Rotas do veículo de coleta na área 1 para o cenário PEV100

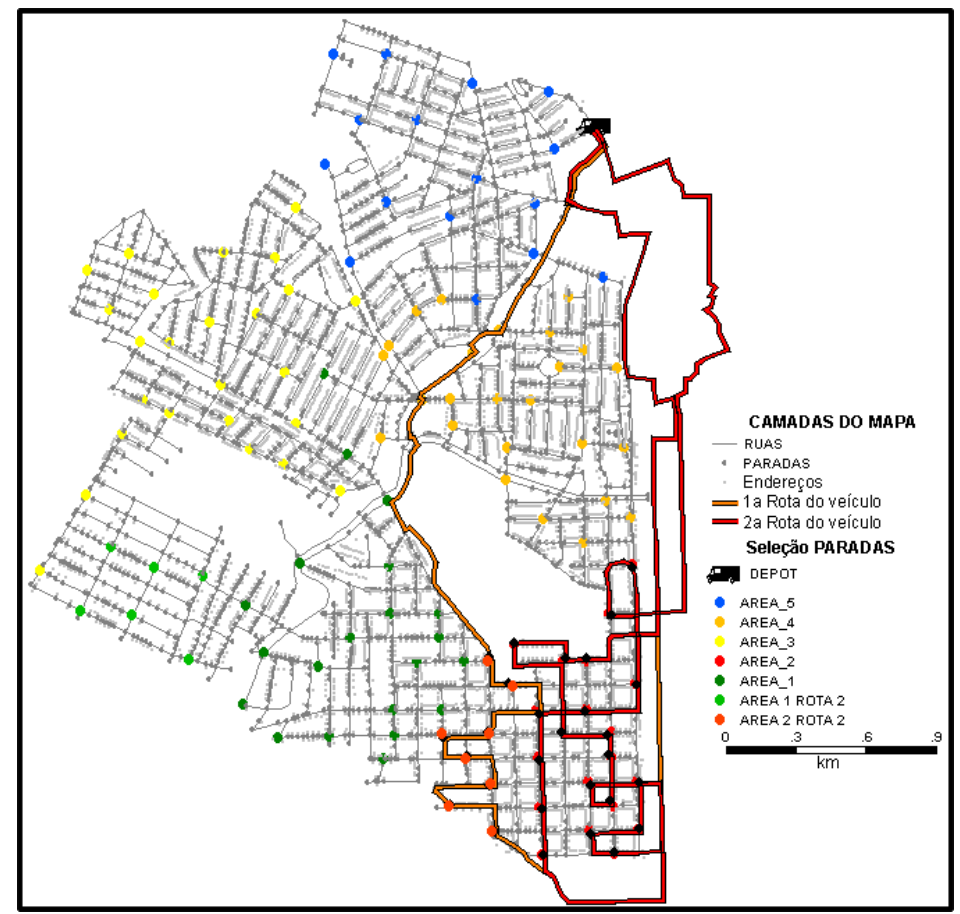

FIGURA 33. Rotas do veículo de coleta na área 2 para o cenário PEV100 


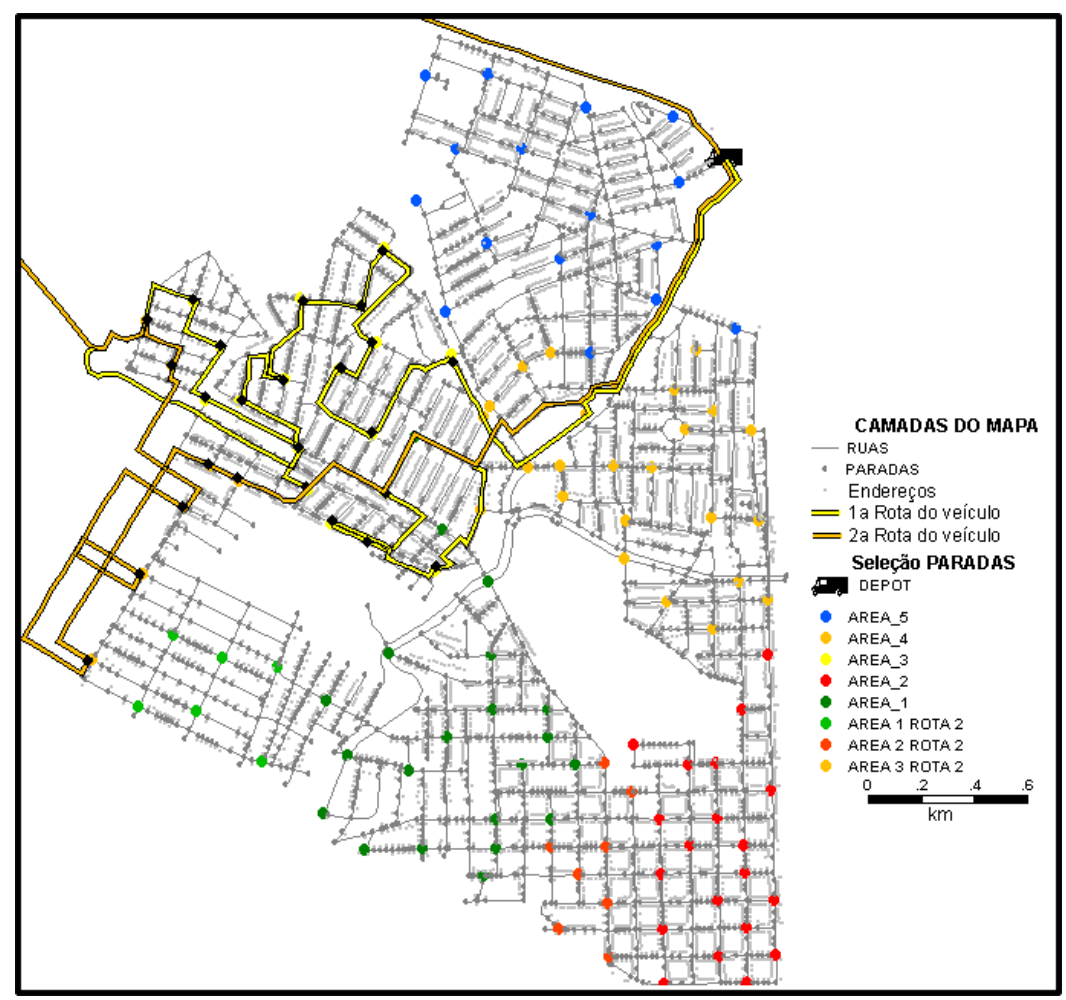

FIGURA 34. Rotas do veículo de coleta na área 3 para o cenário PEV100

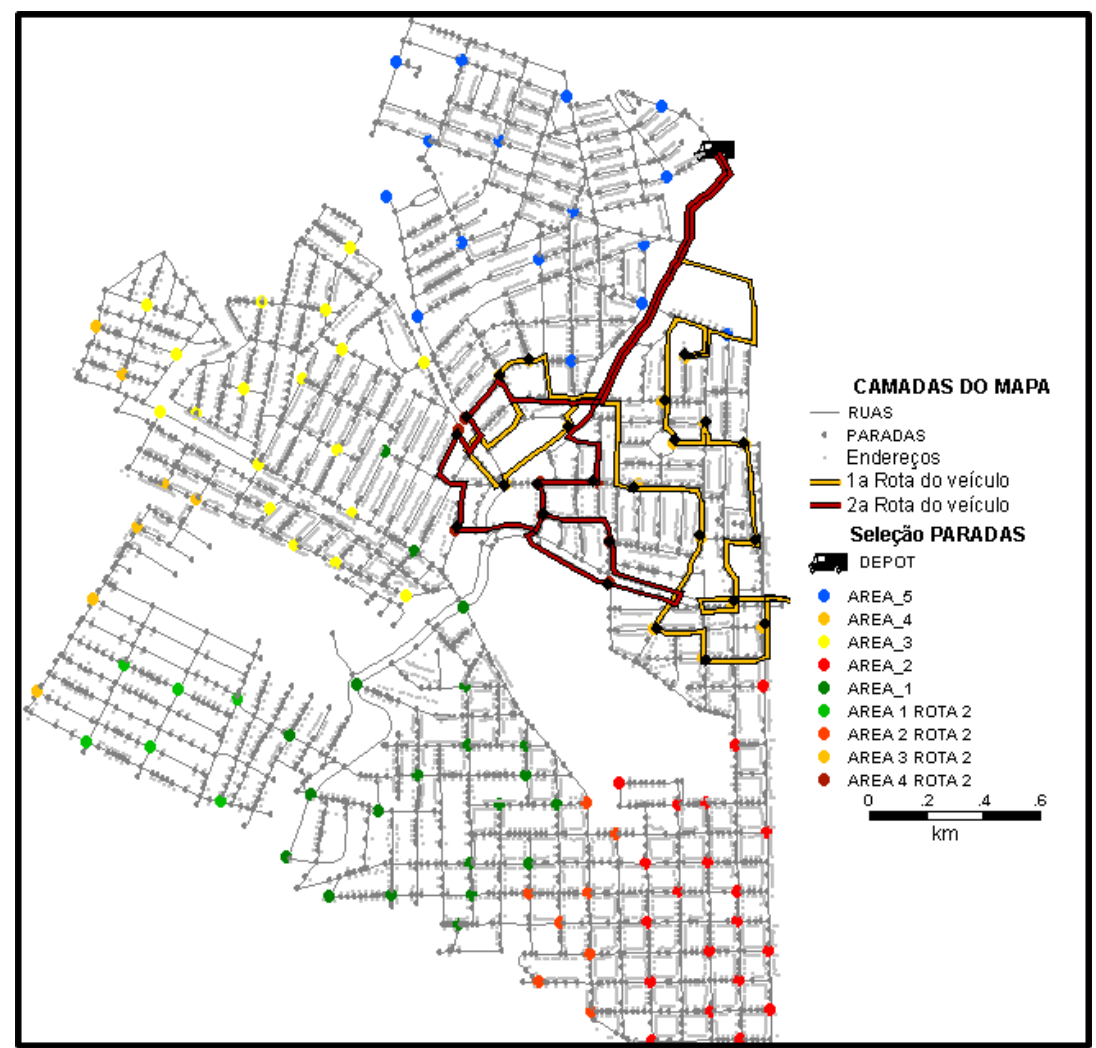

FIGURA 35. Rotas do veículo de coleta na área 4 para o cenário PEV100 
Conforme observado nas figuras 30,31, 32, 33, 34 e 35, foi necessária a segunda viagem do veículo coletor apenas para alguns cenários. Nota-se que, para os cenários com pouca demanda $(20 \%, 40 \%$ e $60 \%$ da demanda máxima), o critério de divisão das áreas diárias de coleta está "super-dimensionando" o uso do veículo coletor.

Nesta análise, por considerar a demanda máxima a meta a ser obtida pelo programa de coleta e as demandas intermediárias os degraus necessários para processo de familiarização da população ao programa, o processo de agrupamento e divisão em áreas menores não foi repetido para cada variação de demanda. Foi realizado apenas um agrupamento, utilizando-se a demanda máxima dividida em cinco para a obtenção das áreas de coleta diárias.

Portanto, caso fosse desejável otimizar o sistema para os cenários de demanda reduzida, poderia ser racionalizado o uso do veículo, redividindo a área de estudo, tentando sempre coincidir a quantidade demandada da área com a capacidade do veículo.

\subsubsection{Sistema Porta-a-Porta}

O sistema Porta-a-Porta, pela sua própria característica, foi o sistema que teve a maior distância semanal percorrida, conforme demonstrado na Tabela 21.

\section{Tabela 21. Resultados das rotinas de roteirização para as variações da demanda propostas para o sistema Porta-a-Porta}

\begin{tabular}{|c|c|c|c|c|c|}
\hline Cenário & $\begin{array}{c}\text { Distância semanal } \\
\text { percorrida } \\
(\mathrm{km})\end{array}$ & $\begin{array}{l}\text { Residências } \\
\text { atendidas }\end{array}$ & $\begin{array}{c}\text { Demanda } \\
\text { coletada } \\
\left(\mathrm{m}^{3}\right)\end{array}$ & $\begin{array}{c}\text { Contêineres de } \\
\text { alta capacidade } \\
\left(1,6 \mathrm{~m}^{3}\right)\end{array}$ & $\begin{array}{l}\text { Contêineres de baixa } \\
\text { capacidade }\left(0,36 \mathrm{~m}^{3}\right)\end{array}$ \\
\hline POR20 & 159,20 & 6622 & 31,30 & 0 & 0 \\
\hline POR40 & 159,20 & 6622 & 62,60 & 0 & 0 \\
\hline POR60 & 159,20 & 6622 & 93,91 & 0 & 0 \\
\hline POR80 & 170,02 & 6622 & 125,20 & 0 & 0 \\
\hline POR100 & 175,11 & 6622 & 142,97 & 0 & 0 \\
\hline
\end{tabular}

Assim, da mesma maneira que para os cenários do sistema por PEVs, para os cenários POR20, POR40 e POR60 não houve variação na distância percorrida pelo veículo de coleta, conforme observado na tabela 22 e nas planilhas $6,7,8,9$ e 10 do apêndice B pois para estas quantidades de demanda a capacidade máxima do veículo não foi atingida, não havendo assim a necessidade de uma segunda viagem. Para o cenário POR80, nas áreas 1 e 2, e para o cenário POR100 na área 1, também não houve 
a necessidade de uma segunda viagem. As rotas para estes cenários são mostradas nas figuras $36,37,38,39$ e 40 .

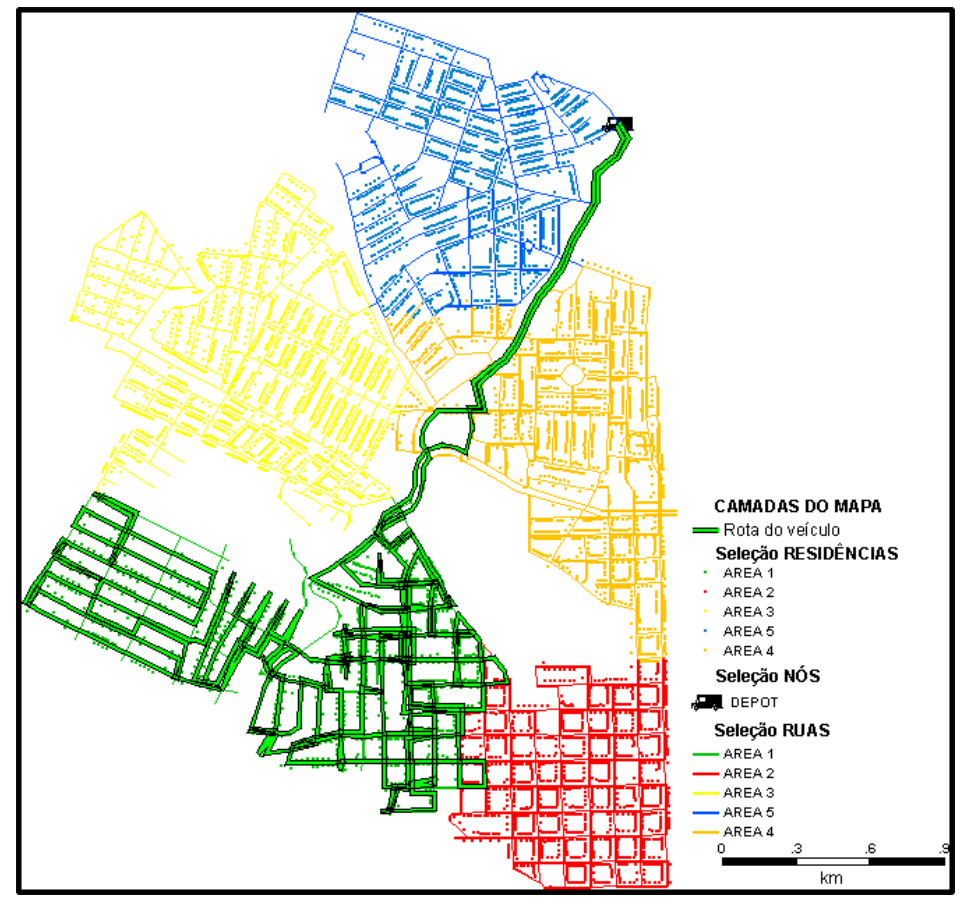

FIGURA 36. Rota do veículo de coleta na área 1 para os cenários POR20, POR40, POR60, POR80 e POR100

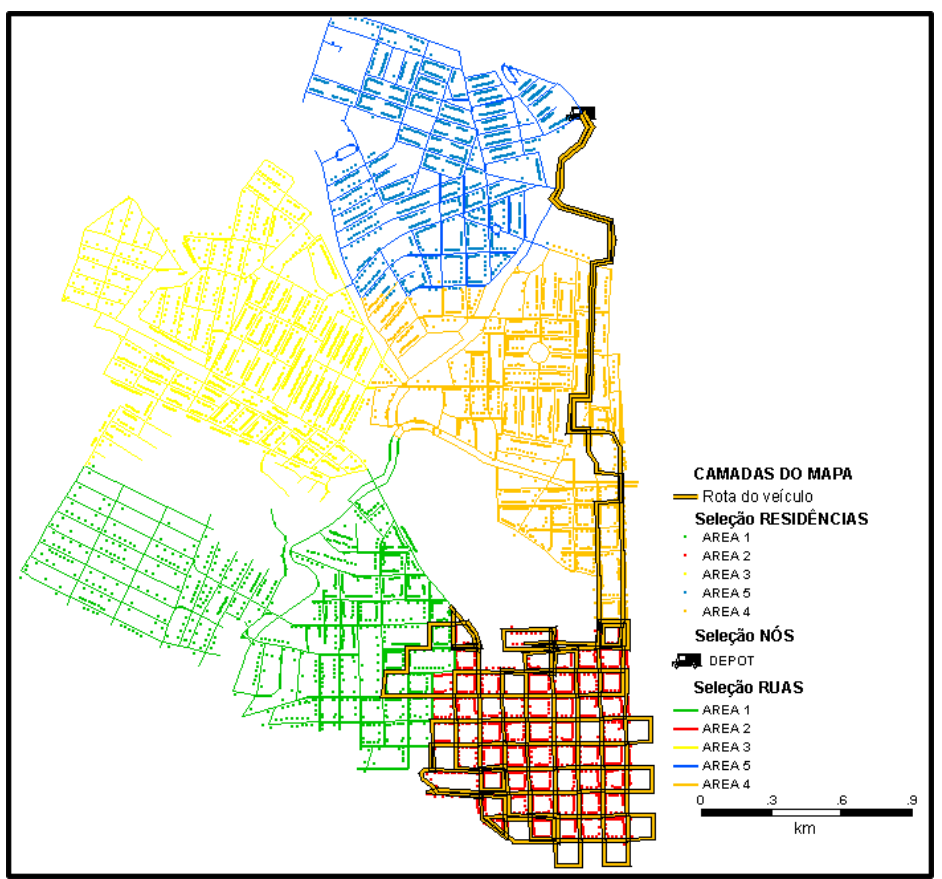

FIGURA 37. Rota do veículo de coleta na área 2 para os cenários POR20, POR40, POR60 e POR80 


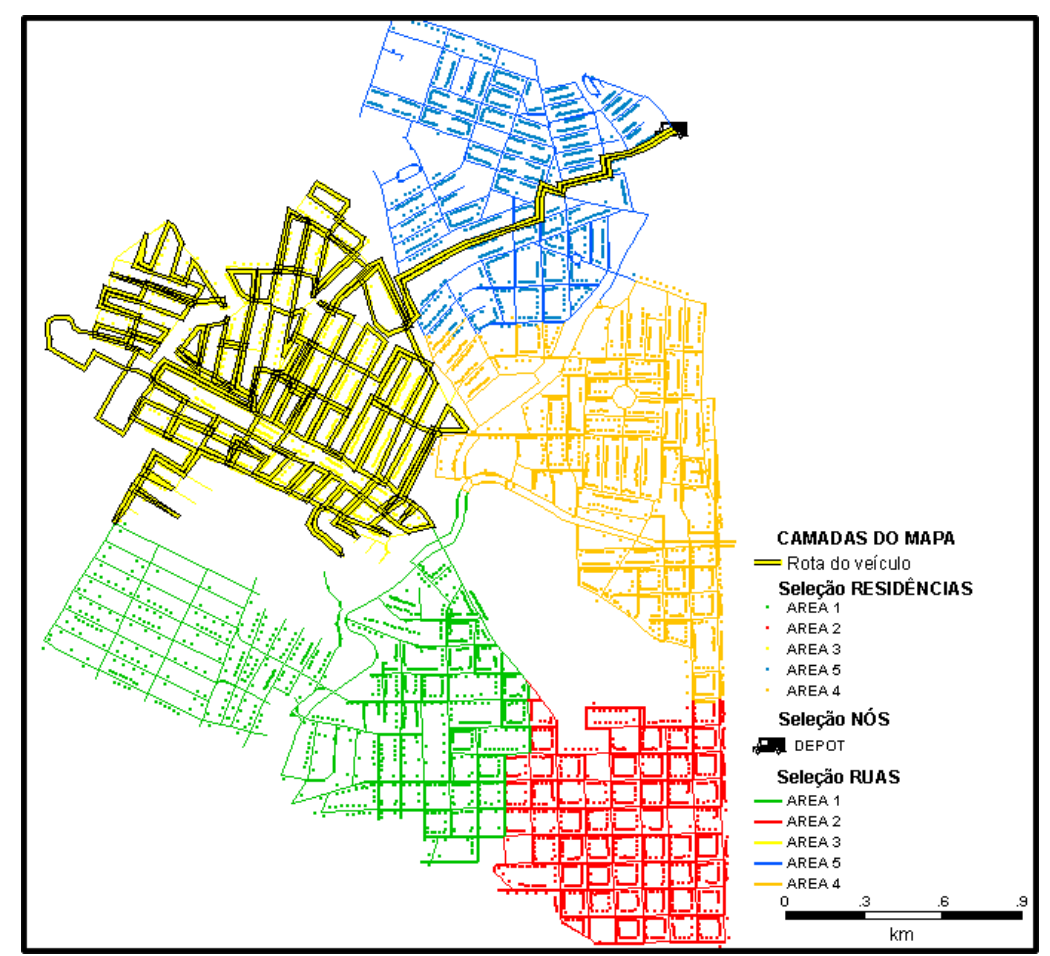

FIGURA 38. Rota do veículo de coleta na área 3 para os cenários POR20, POR40 e POR60

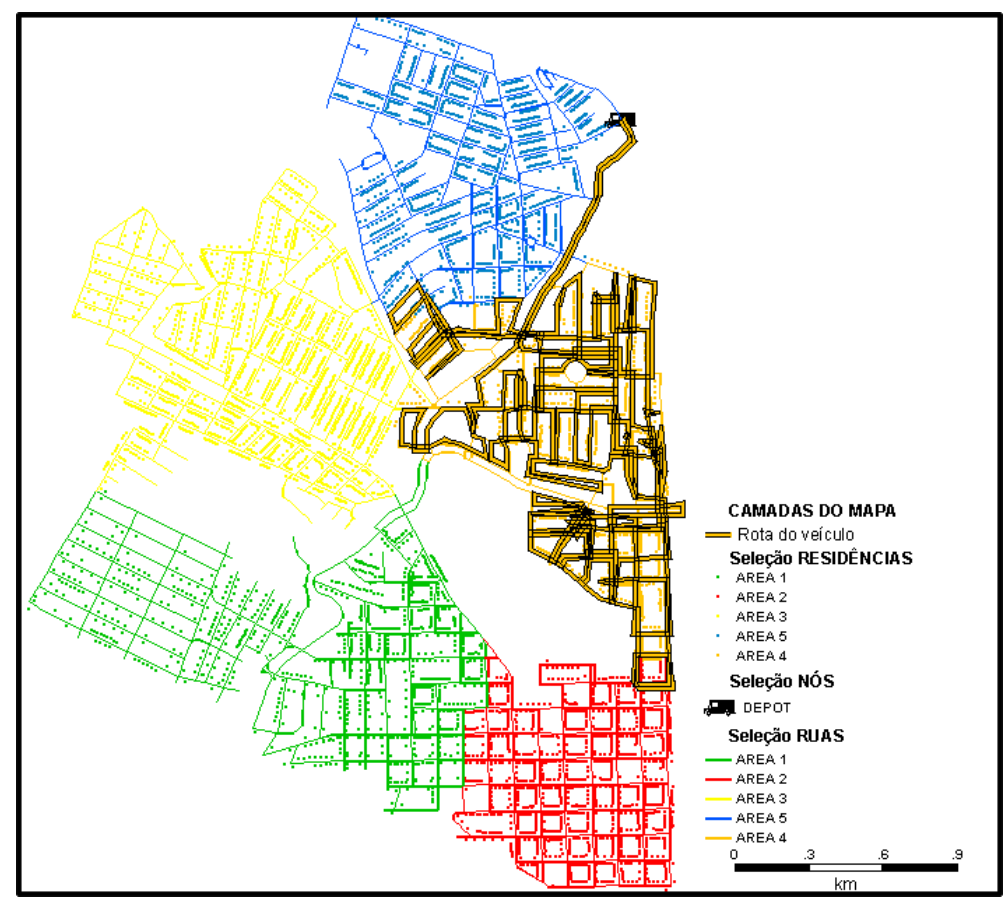

FIGURA 39. Rota do veículo de coleta na área 4 para os cenários POR20, POR40 e POR60 


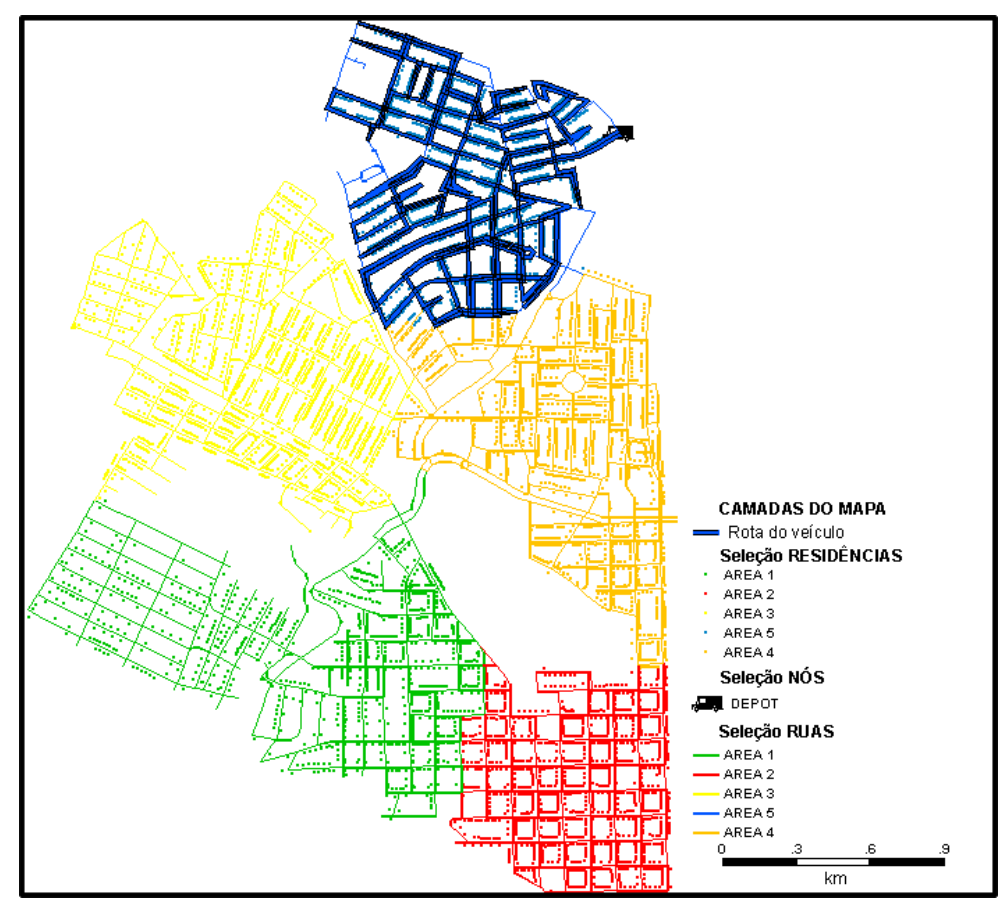

FIGURA 40. Rota do veículo de coleta na área 5 para os cenários POR20, POR40 e POR60

Para o cenário POR80 houve a necessidade de uma segunda viagem nas áreas 3, 4 e 5, cujas rotas são mostradas nas figuras 41,42 e 43.

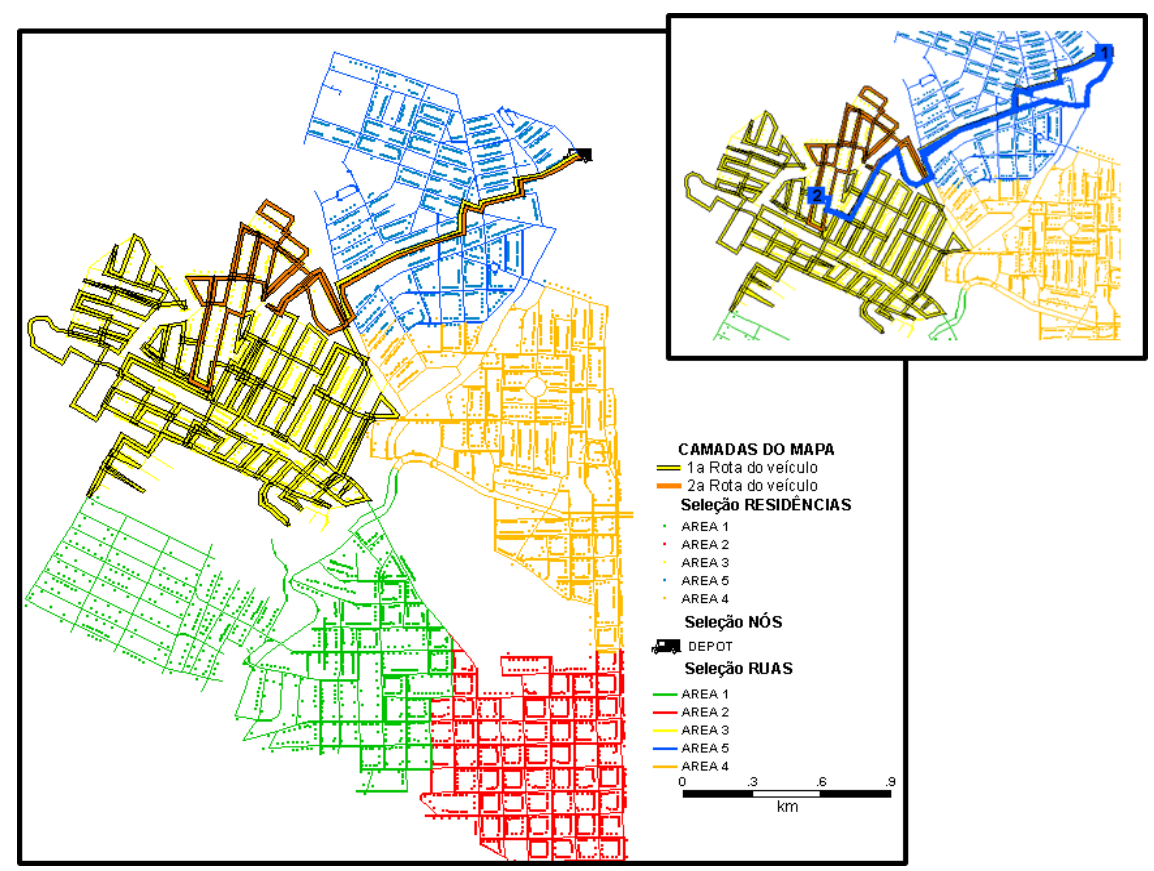

FIGURA 41. Rotas do veículo de coleta na área 3 para o cenário POR80. No detalhe o caminho mínimo entre o fím da $1^{\mathrm{a}}$ rota - depósito - início da $2^{\mathrm{a}}$ rota 


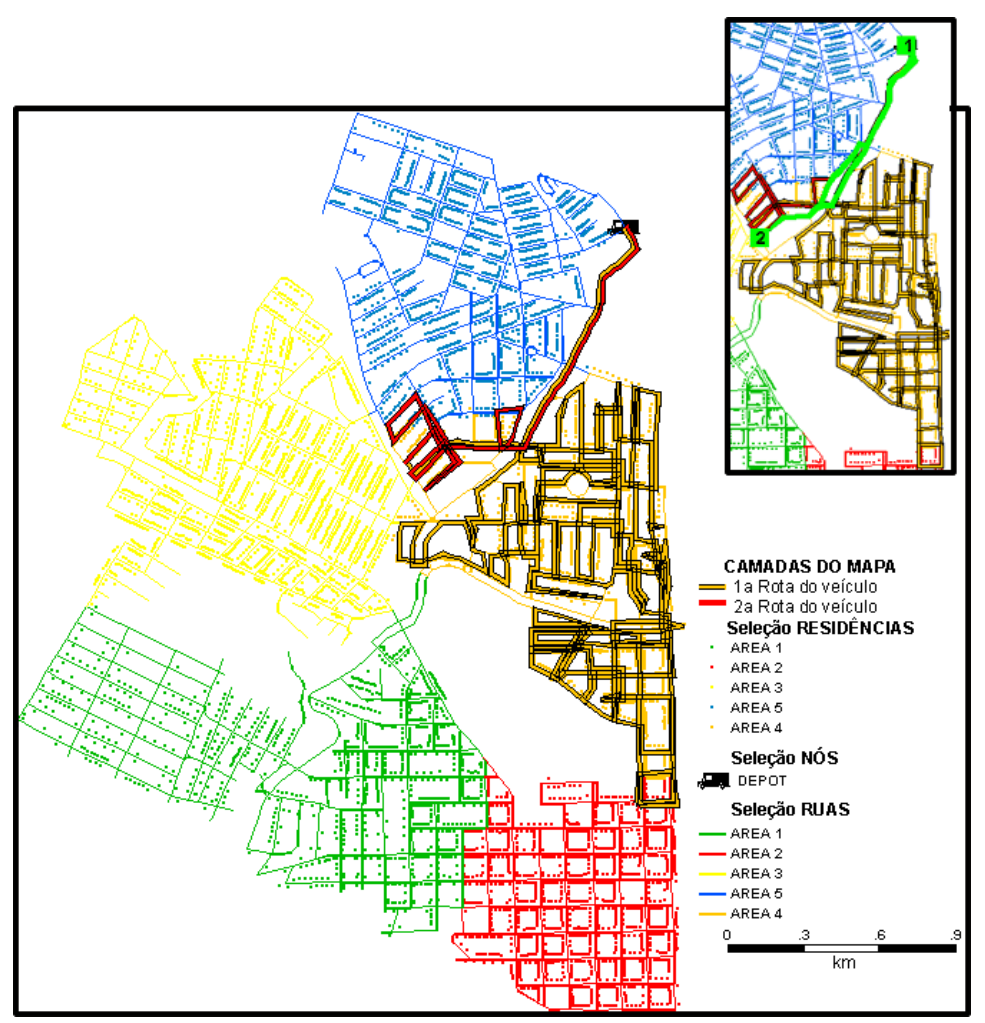

FIGURA 42. Rotas do veículo de coleta na área 4 para o cenário POR80. No detalhe o caminho mínimo entre o fim da $1^{\mathrm{a}}$ rota - depósito - início da $2^{\mathrm{a}}$ rota

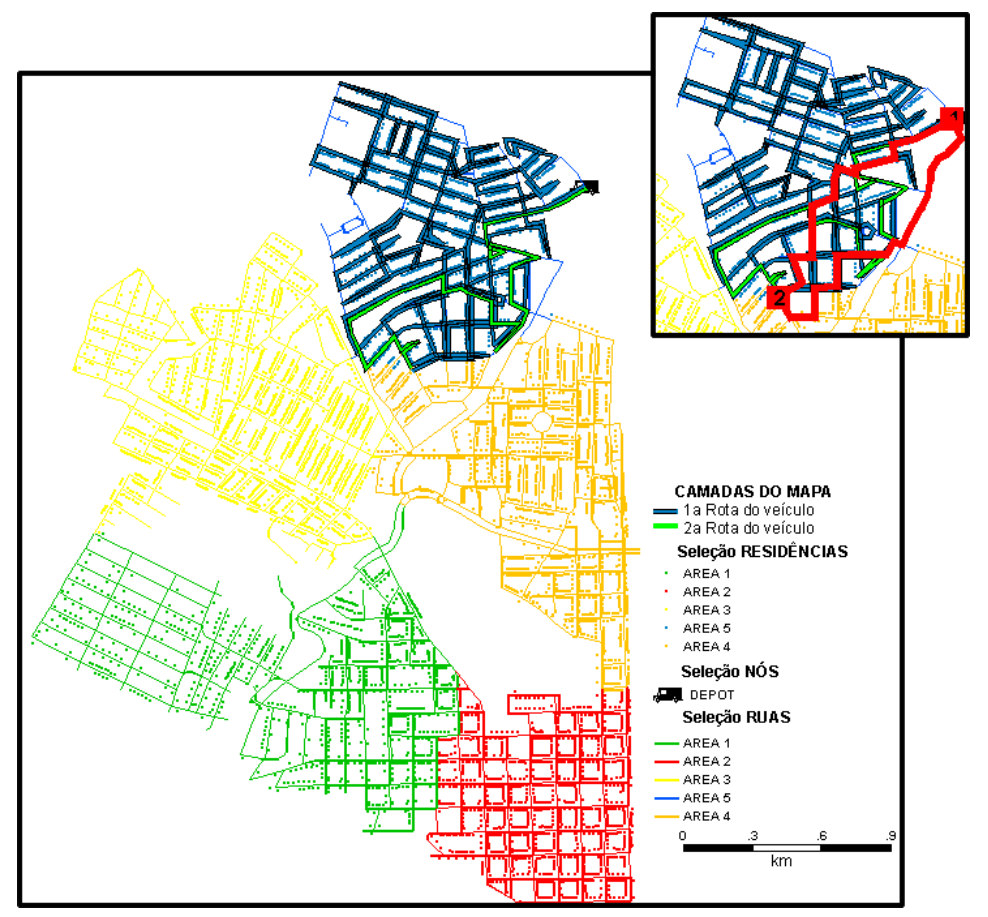

FIGURA 43. Rotas do veículo de coleta na área 5 para o cenário POR80. No detalhe o caminho mínimo entre o fim da $1^{\mathrm{a}}$ rota - depósito - início da $2^{\mathrm{a}}$ rota 
Para o cenário POR100, nas áreas 2, 3, 4 e 5 houve a necessidade de uma segunda viagem, cujas rotas são mostradas nas figuras 44, 45, 46 e 47.

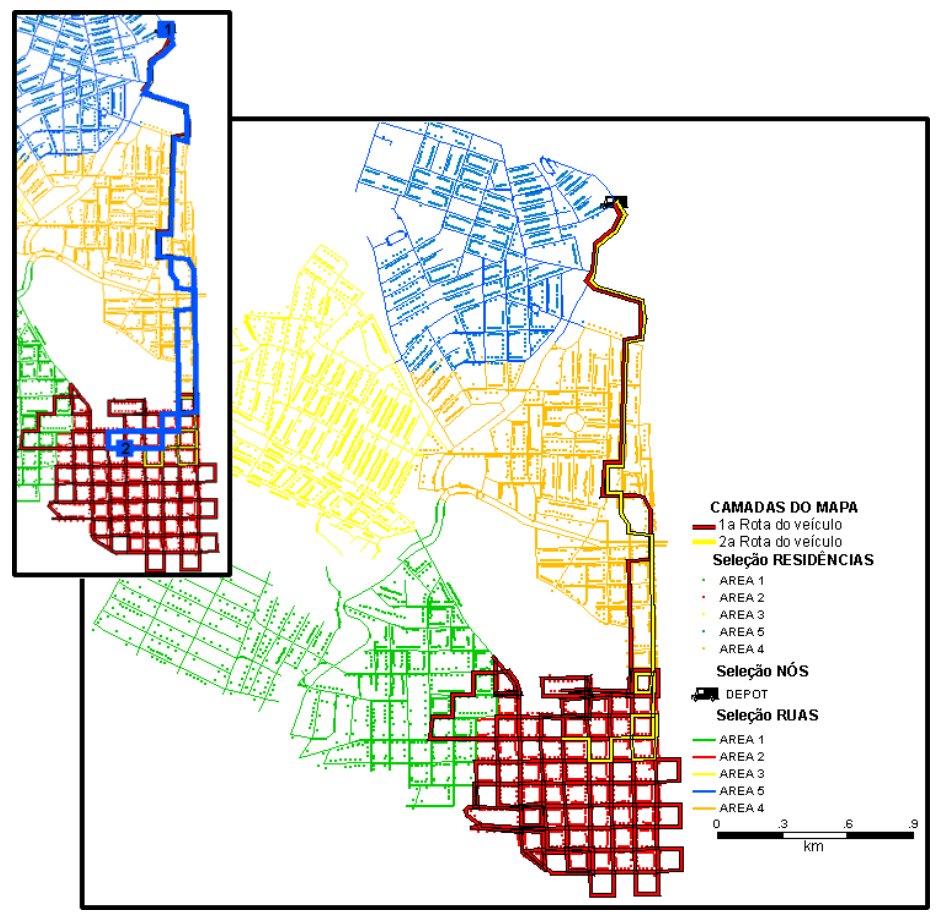

FIGURA 44. Rotas do veículo de coleta na área 2 para o cenário POR100. No detalhe o caminho mínimo entre o fim da $1^{\mathrm{a}}$ rota - depósito - início da $2^{\mathrm{a}}$ rota

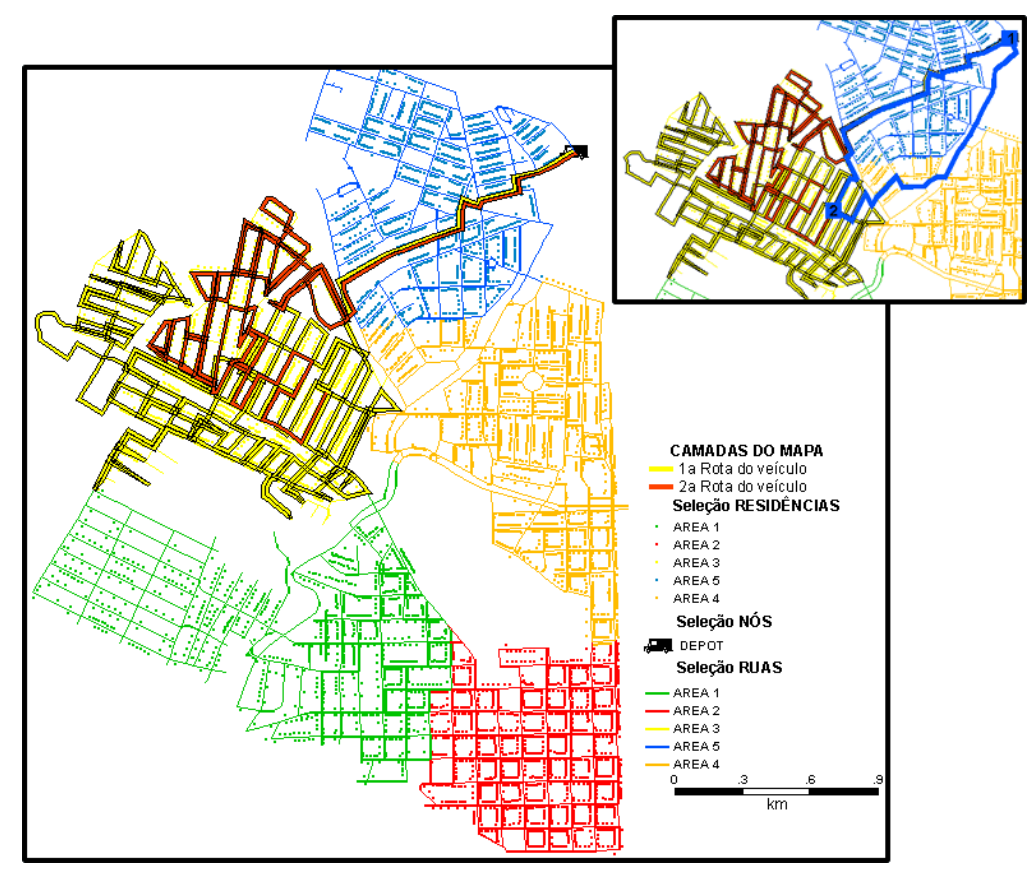

FIGURA 45. Rotas do veículo de coleta na área 3 para o cenário POR100. No detalhe o caminho mínimo entre o fim da $1^{\mathrm{a}}$ rota - depósito - início da $2^{\mathrm{a}}$ rota 


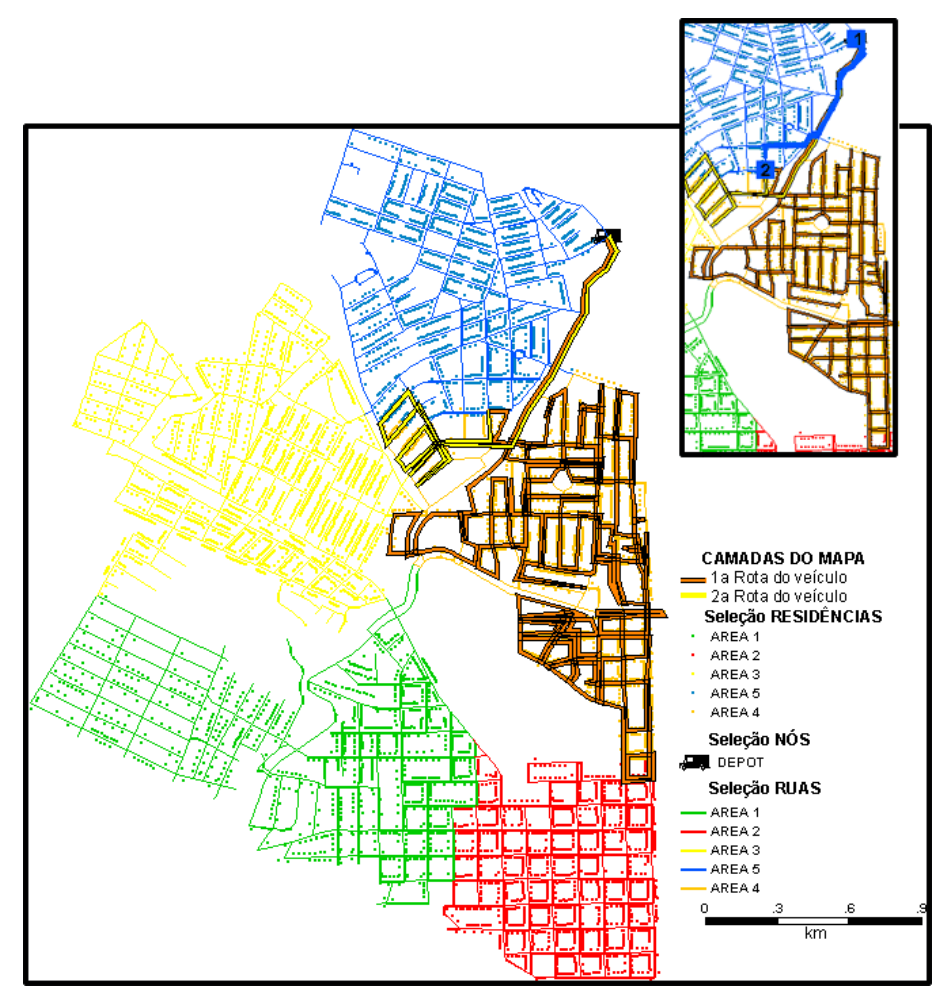

FIGURA 46. Rotas do veículo de coleta na área 4 para o cenário POR100. No detalhe o caminho mínimo entre o fim da $1^{\mathrm{a}}$ rota - depósito - início da $2^{\mathrm{a}}$ rota

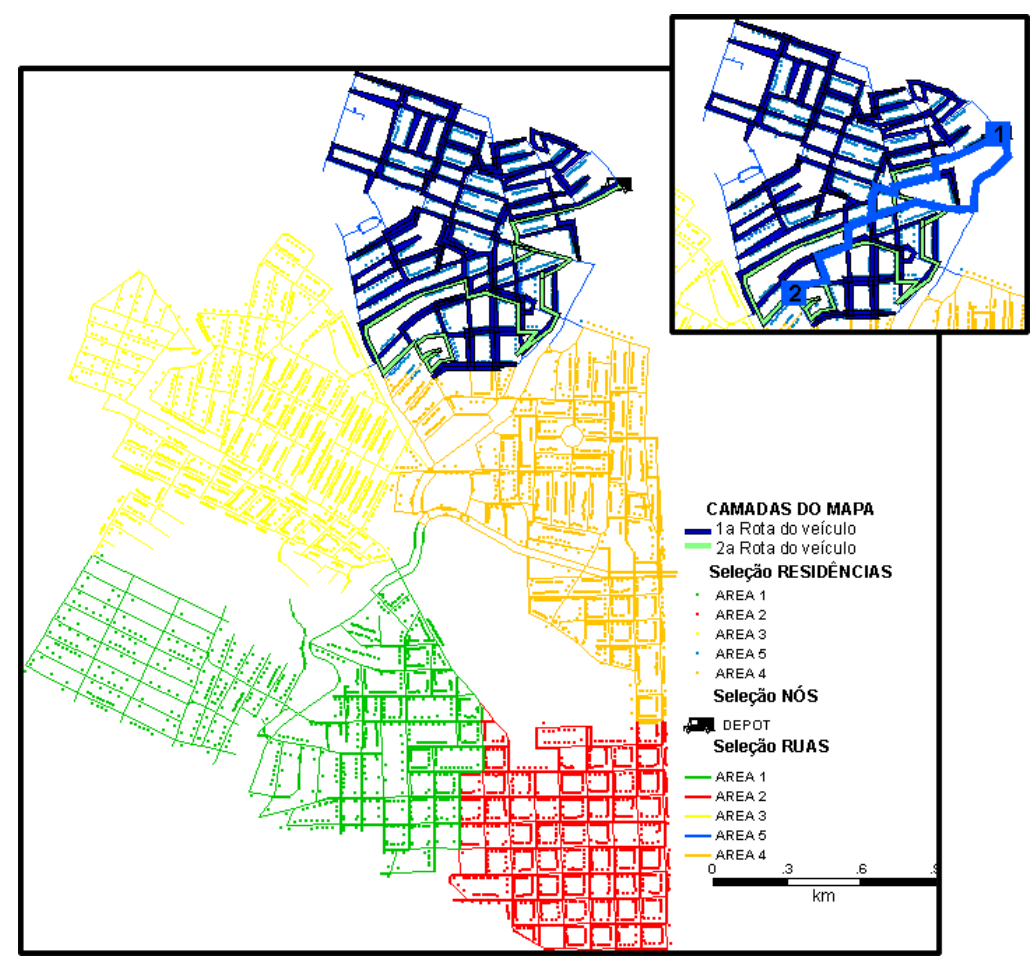

FIGURA 47. Rotas do veículo de coleta na área 5 para o cenário POR100. No detalhe o caminho mínimo entre o fim da $1^{\mathrm{a}}$ rota - depósito - início da $2^{\mathrm{a}}$ rota 
Para o sistema Porta-a-Porta, mais uma vez foi notado o "super dimensionamento" do sistema para os cenários com as menores demandas. A divisão das áreas de coleta para cada cenário poderia ser uma alternativa para a definição da área mais adequada para uma demanda pré-determinada.

Mesmo para este sistema, onde o veículo tradicionalmente anda mais, obteve-se uma baixa quilometragem semanal $(175 \mathrm{~km})$, para o cenário de maior demanda. Isto mostra que, devido às características desta área de estudo, o desgaste do veículo e os custos decorrentes da quilometragem percorrida serão reduzidos.

\subsubsection{Sistema Híbrido}

No sistema Híbrido, a distância percorrida pelo veículo coletor teve valor aproximadamente intermediário entre os dois sistemas analisados anteriormente, conforme mostrado na Tabela 22.

Tabela 22. Resultados das rotinas de roteirização para as variações da demanda propostas para o sistema Híbrido

\begin{tabular}{|c|c|c|c|c|c|}
\hline Cenário & $\begin{array}{c}\text { Distância semanal } \\
\text { percorrida } \\
(\mathrm{km}) \\
\end{array}$ & $\begin{array}{c}\text { Residências } \\
\text { atendidas }\end{array}$ & $\begin{array}{c}\text { Demanda } \\
\text { coletada } \\
\left(\mathrm{m}^{3}\right) \\
\end{array}$ & $\begin{array}{c}\text { Contêineres de } \\
\text { alta capacidade } \\
\left(1,6 \mathrm{~m}^{3}\right)\end{array}$ & $\begin{array}{l}\text { Contêineres de baixa } \\
\text { capacidade }\left(0,36 \mathrm{~m}^{3}\right)\end{array}$ \\
\hline HIB20 & 70,40 & 6470 & 30,60 & 0 & 0 \\
\hline HIB40 & 70,40 & 6470 & 61,10 & 0 & 0 \\
\hline HIB60 & 70,40 & 6470 & 91,50 & 0 & 0 \\
\hline HIB80 & 88,00 & 6470 & 121,90 & 0 & 0 \\
\hline HIB100 & 98,90 & 6470 & 152,80 & 0 & 0 \\
\hline
\end{tabular}

Assim, de modo similar aos cenários dos sistemas por PEVs e Porta-a-Porta, para os cenários HIB20, HIB40 e HIB60 não houve variação na distância percorrida pelo veículo de coleta, conforme observado na tabela 23 e nas planilhas $11,12,13,14$ e 15 do apêndice B pois, para estas quantidades de demanda a capacidade máxima do veículo não foi atingida, não havendo assim a necessidade de uma segunda viagem. Para o cenário HIB80, nas áreas 1 e 2, e para o cenário HIB100 na área 1, também não houve a necessidade de uma segunda viagem. As rotas para estes cenários são mostradas nas figuras 48, 49, 50, 51 e 52 . 


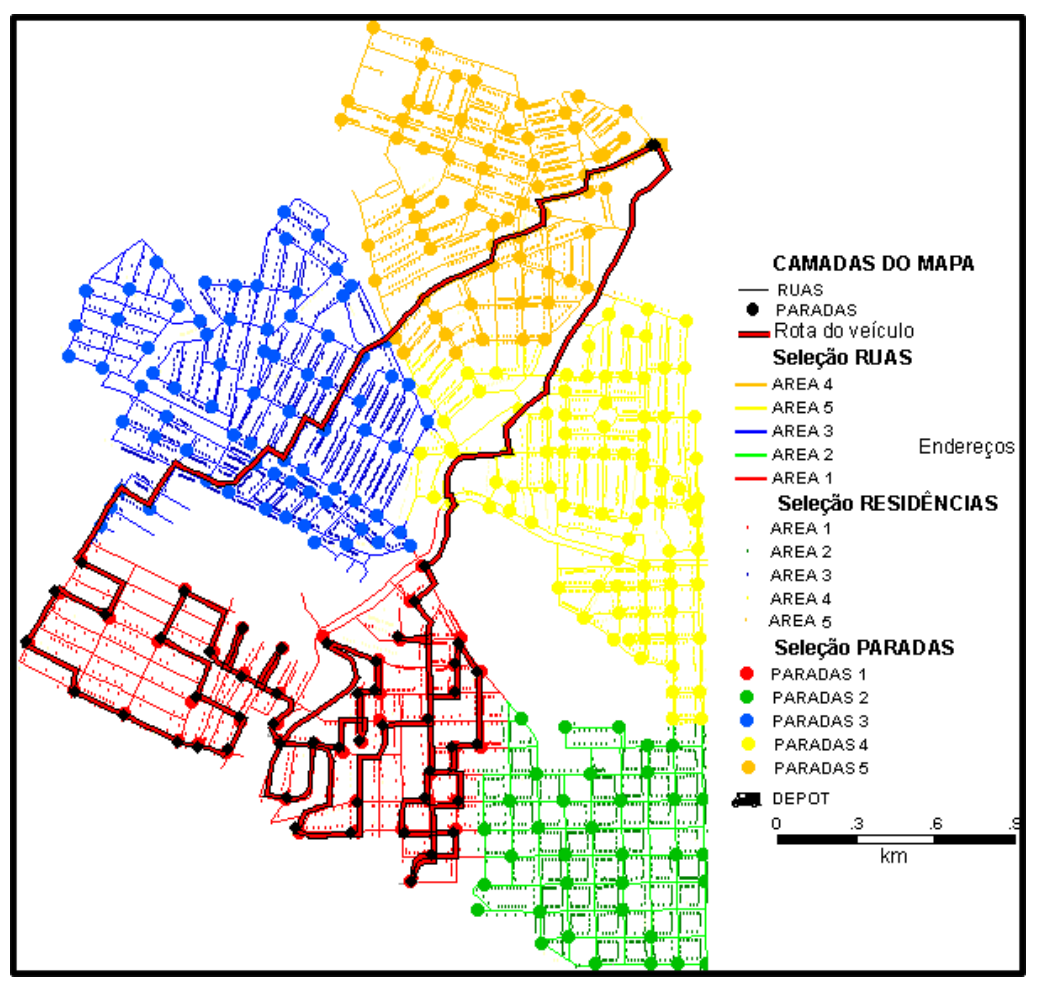

FIGURA 48. Rota do veículo de coleta na área 1 para o cenários HIB20, HIB40, HIB60, HIB80 e HIB100

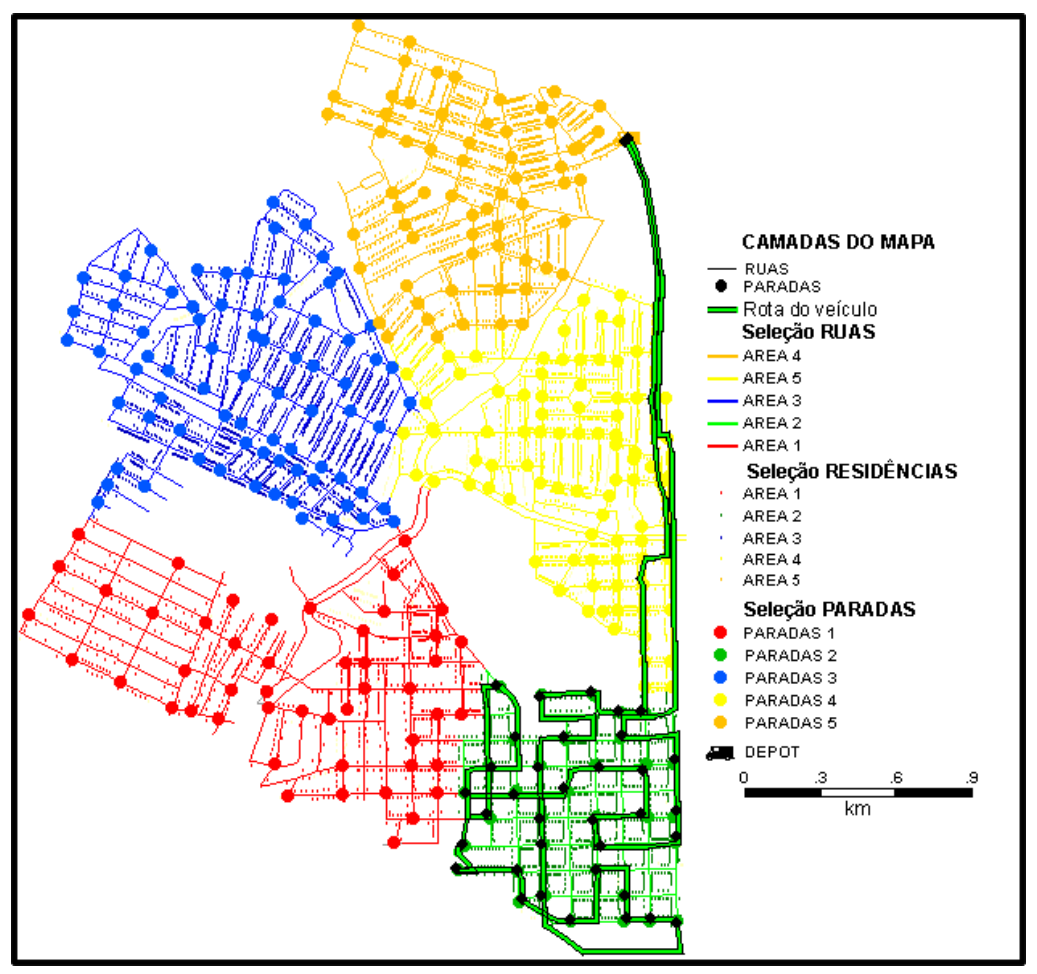

FIGURA 49. Rota do veículo de coleta na área 2 para o cenários HIB20, HIB40, HIB60 e HIB80 


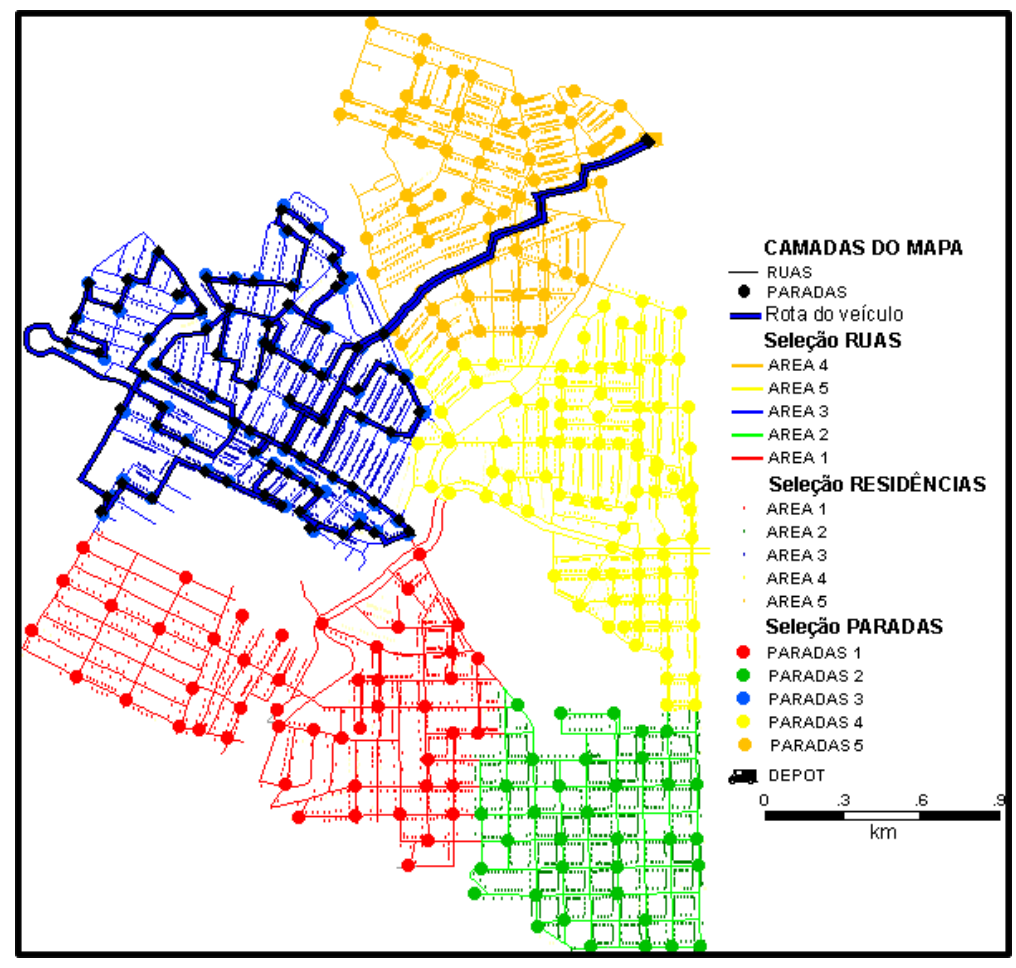

FIGURA 50. Rota do veículo de coleta na área 3 para o cenários HIB20, HIB40 e HIB60

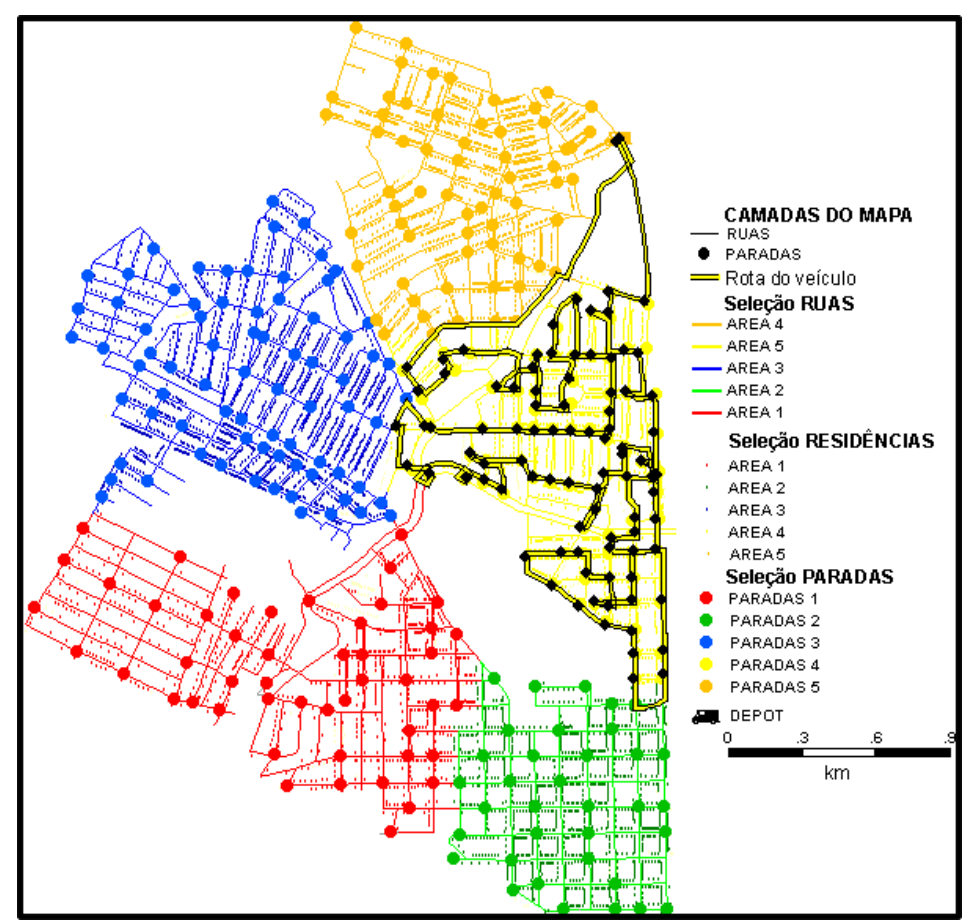

FIGURA 51. Rota do veículo de coleta na área 4 para o cenários HIB20, HIB40 e HIB60 


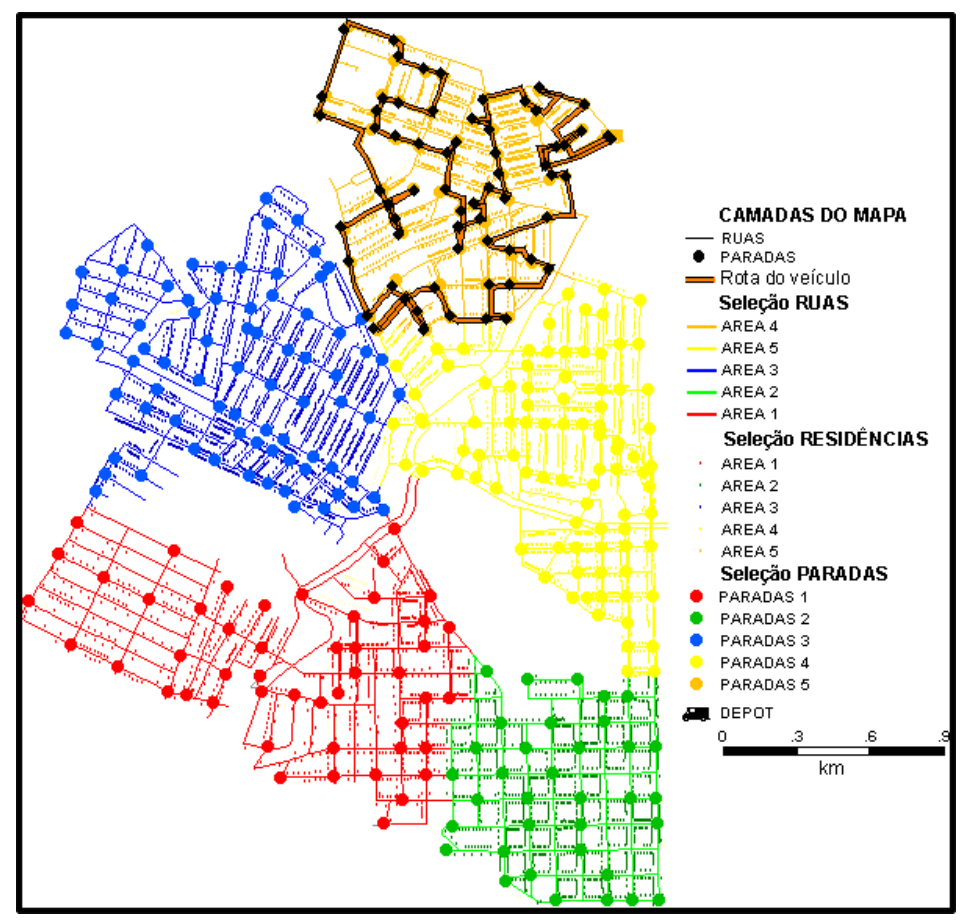

FIGURA 52. Rota do veículo de coleta na área 5 para o cenários HIB20, HIB40 e HIB60

Para o cenário HIB80 houve a necessidade de uma segunda viagem nas áreas 3 , 4 e 5 , cujas rotas são mostradas nas figuras 53,54 e 55.

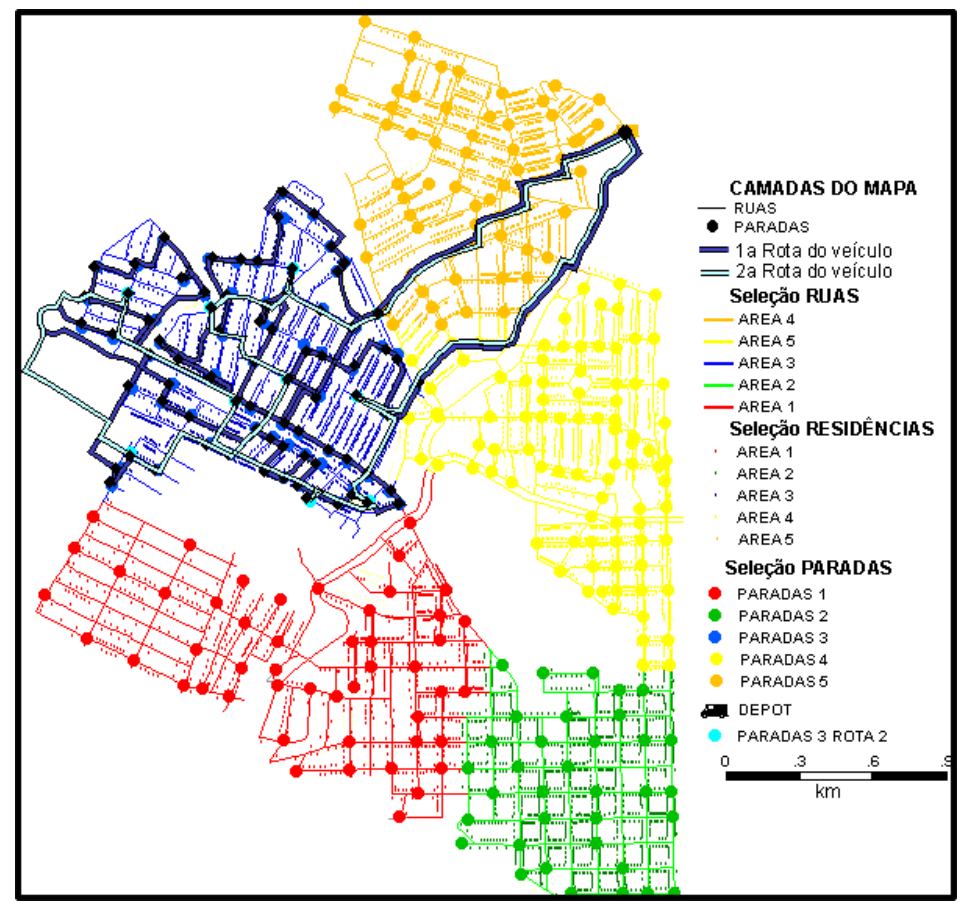

FIGURA 53. Rotas do veículo de coleta na área 3 para o cenário HIB80 


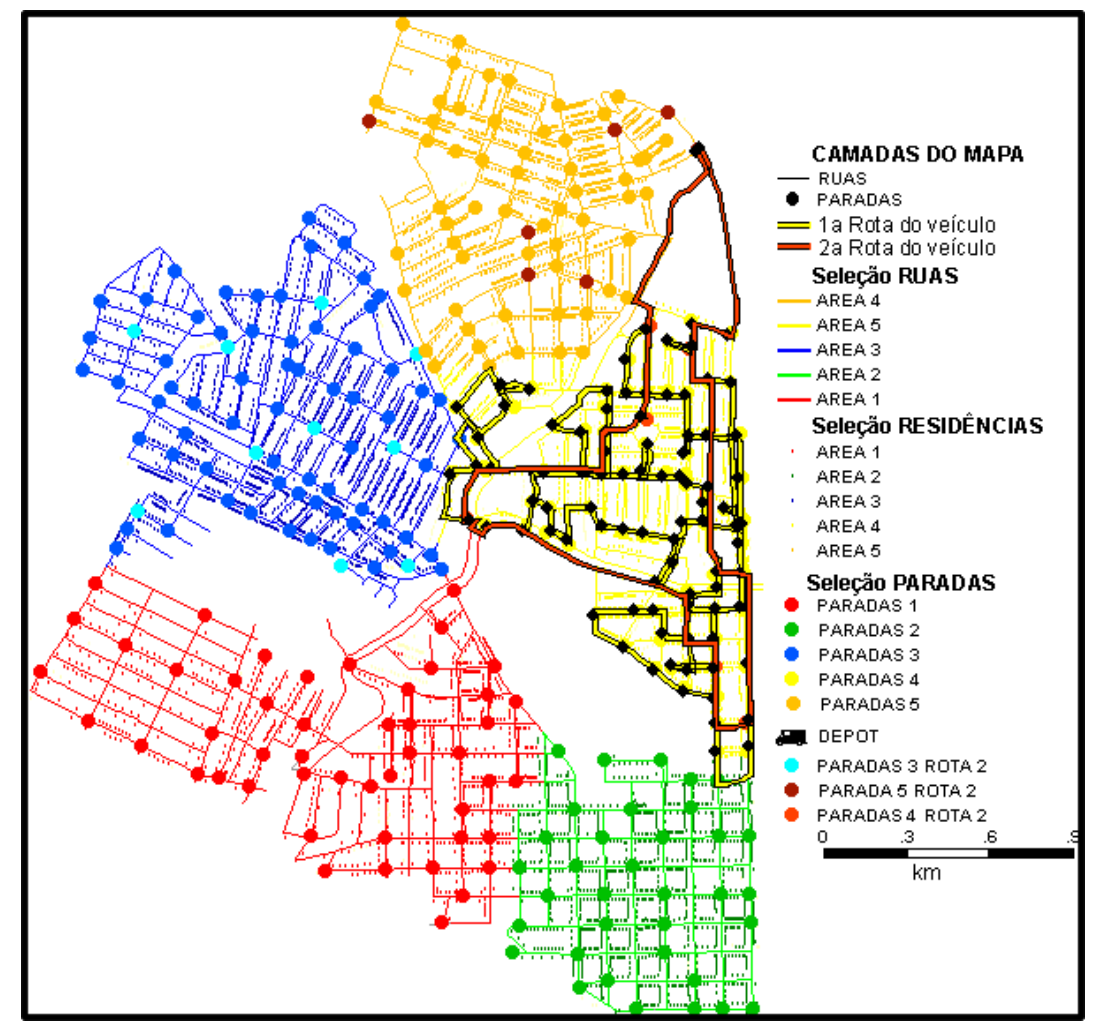

FIGURA 54. Rotas do veículo de coleta na área 4 para o cenário HIB80

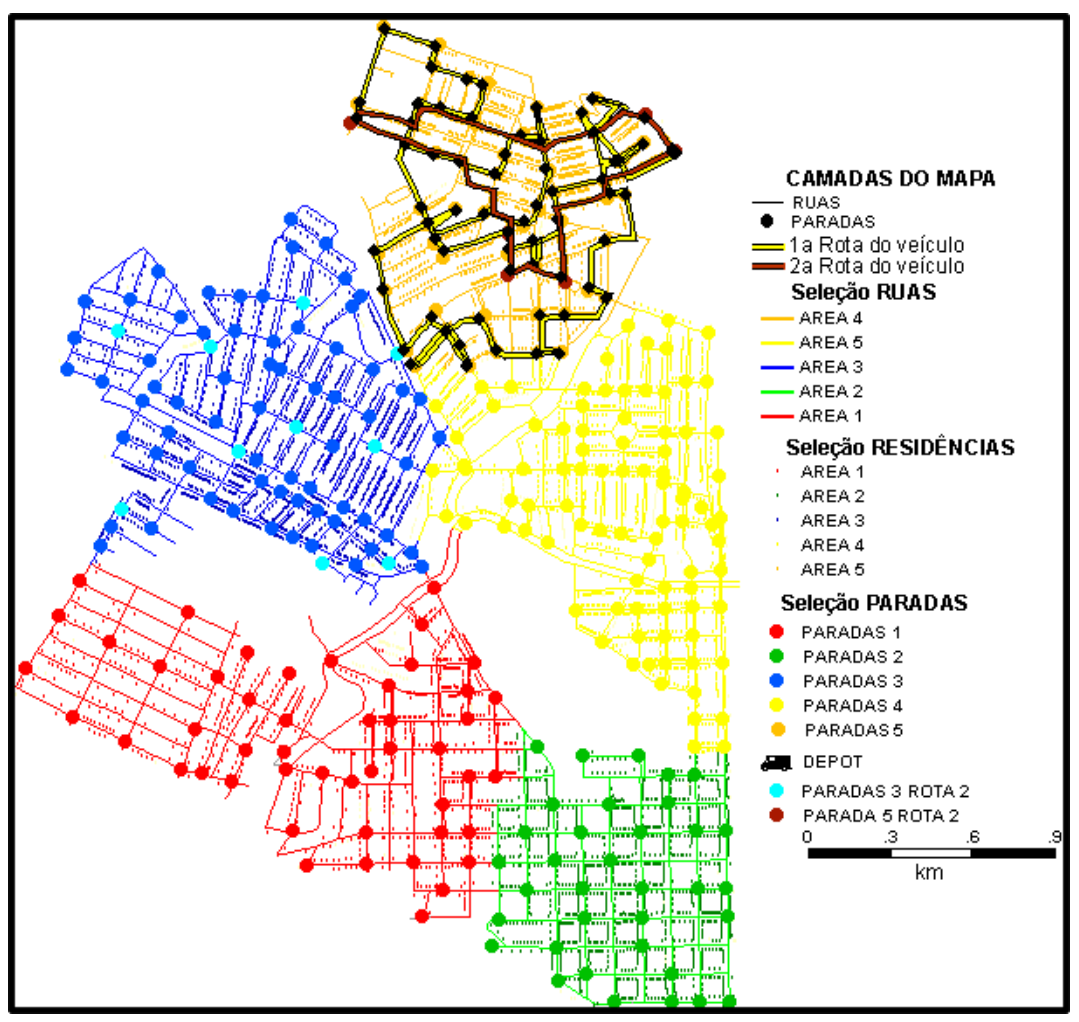

FIGURA 55. Rotas do veículo de coleta na área 5 para o cenário HIB80 
Para o cenário HIB100, houve a necessidade da segunda viagem nas áreas 2, 3, 4 e 5, cujas rotas são mostradas nas figuras $56,57,58$ e 59 .

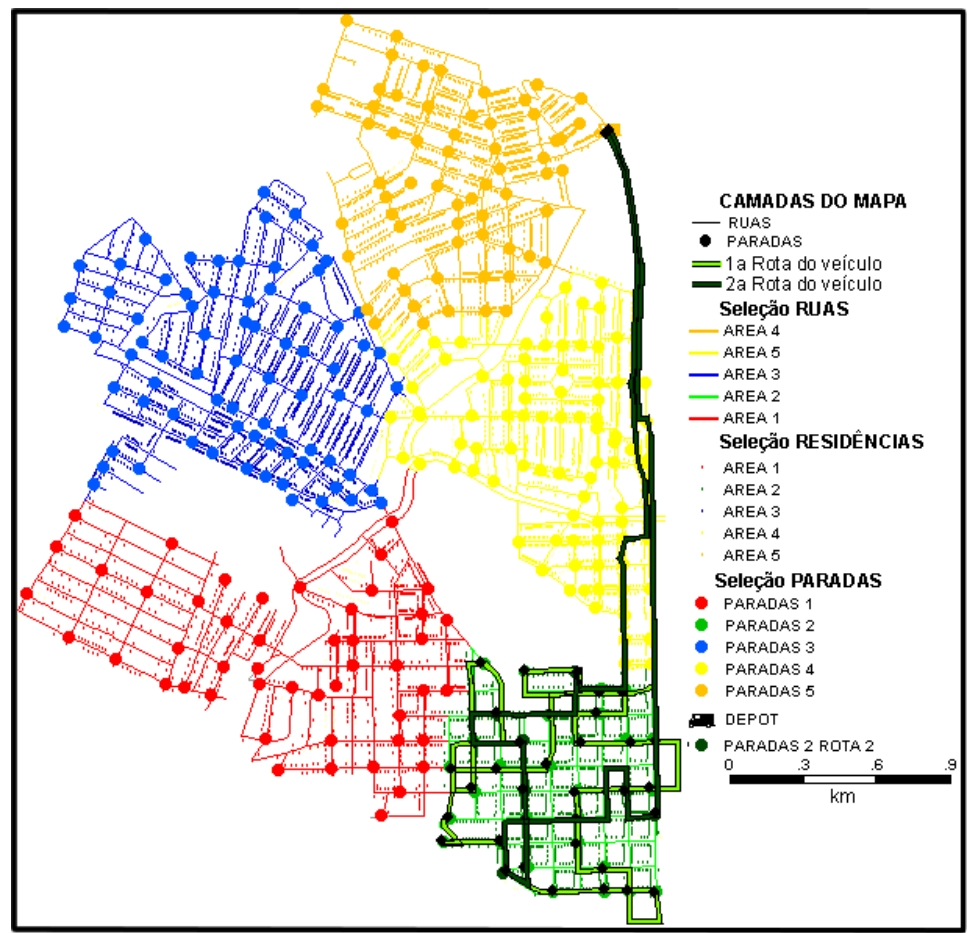

FIGURA 56. Rotas do veículo de coleta na área 2 para o cenário HIB100

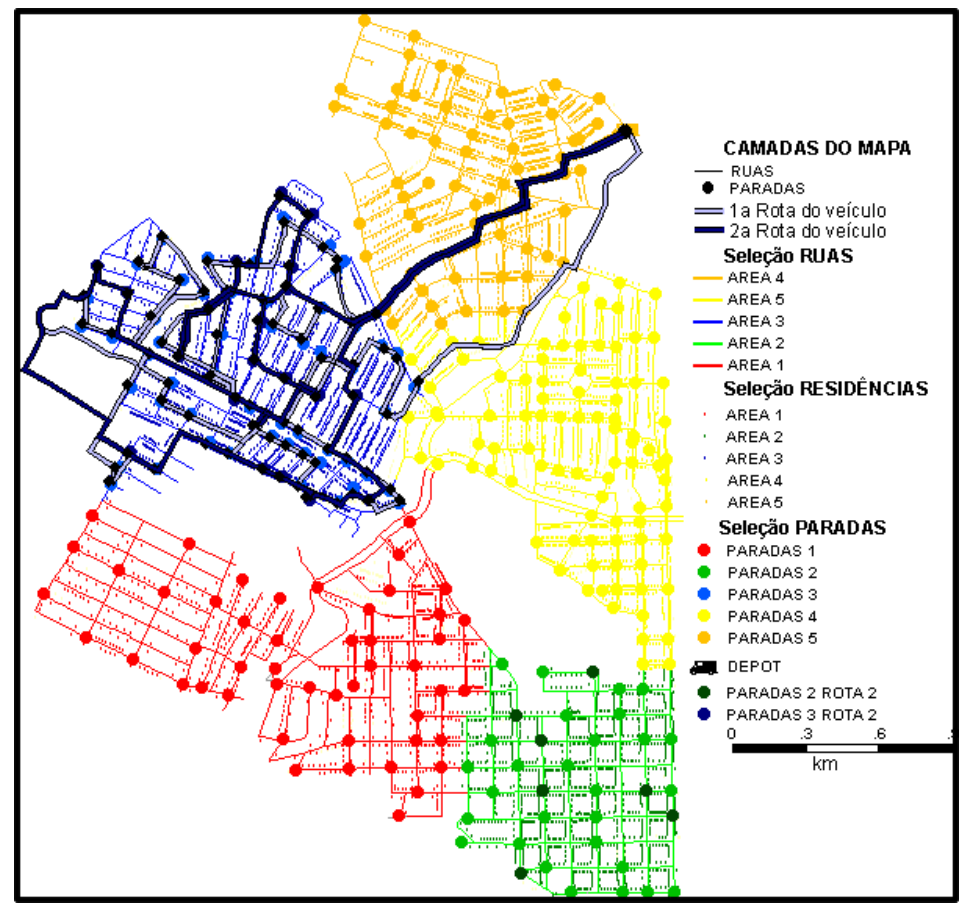

FIGURA 57. Rotas do veículo de coleta na área 3 para o cenário HIB100 


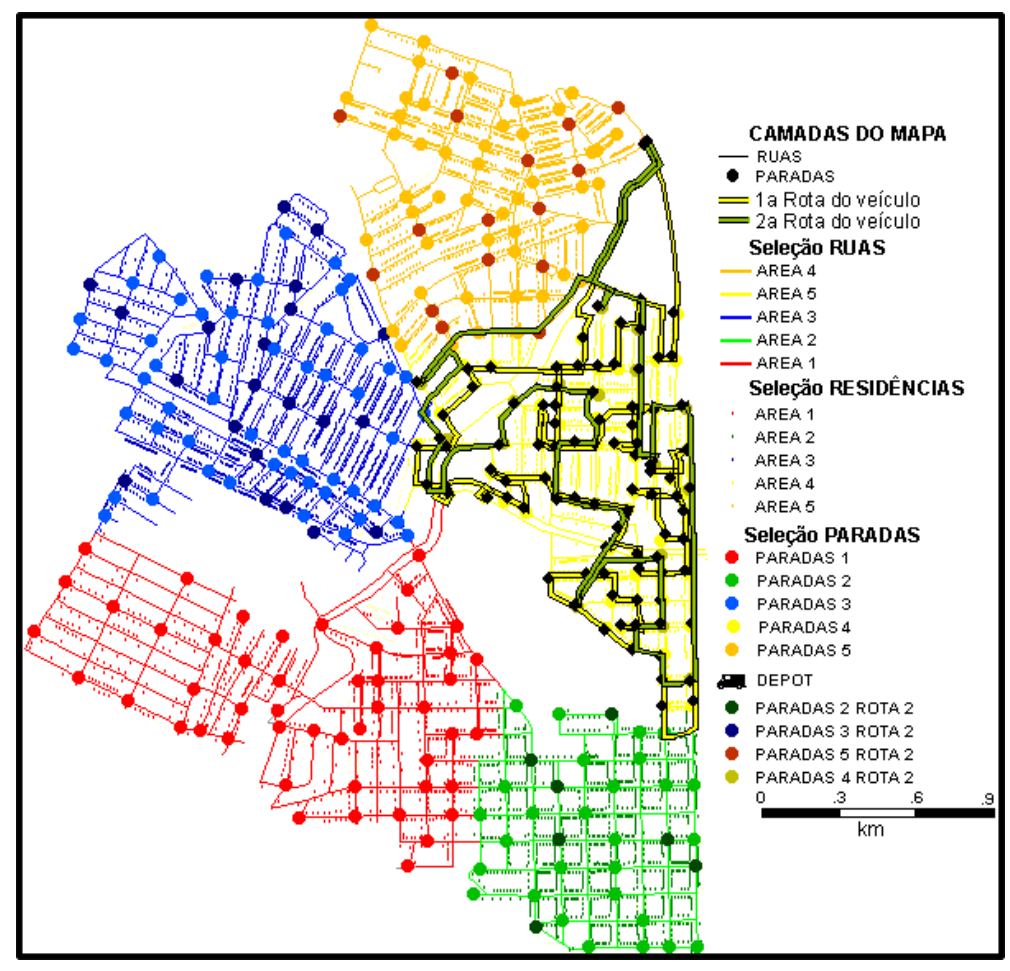

FIGURA 58. Rotas do veículo de coleta na área 4 para o cenário HIB100

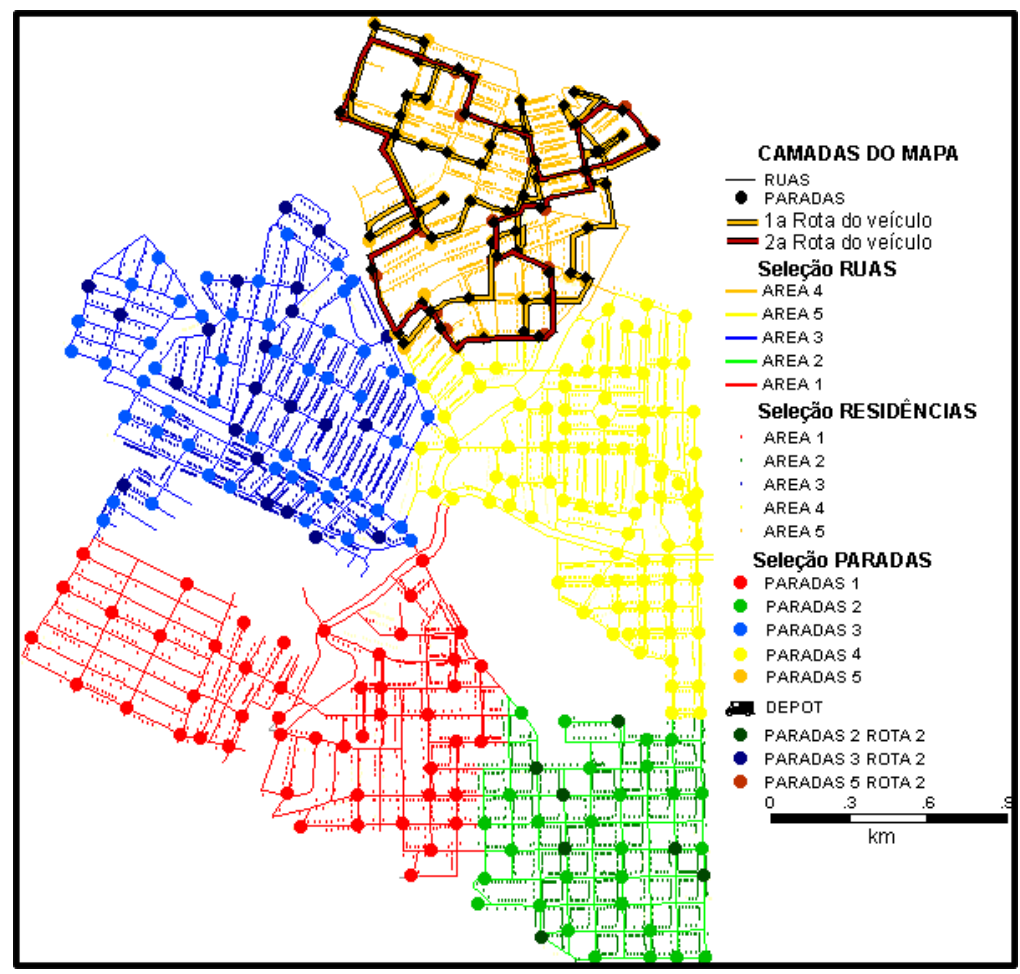

FIGURA 59. Rotas do veículo de coleta na área 5 para o cenário HIB100 
Para o sistema Híbrido, a questão do "super dimensionamento" do sistema, para os cenários com demandas menores, fica mais complexa devido ao aumento de mais uma condicionante, que é a limitação física dos catadores, que fazem todo o percurso caminhando. A divisão proposta, com a demanda máxima como variável, forneceu 5 áreas com características bem próximas das áreas onde esse tipo de coleta efetivamente ocorre, mostrando, portanto, que esta configuração é possível. Para áreas onde a demanda esteja mais "pulverizada" e, assim, obrigando que a área de coleta seja maior, alternativas como o uso de carrinhos ou utilização de pontos de acúmulo devem ser previstas, sempre tentando aproveitar ao máximo o veículo de coleta e reduzir ao máximo a distância caminhada pelos catadores.

\subsection{OS CUSTOS DE CADA CENÁRIO}

Após a obtenção das distâncias percorridas pelo veículo em cada sistema nos diferentes cenários, foram utilizadas as planilhas de cálculo dos custos para cada um destes cenários.

Para complementar esta análise, alguns parâmetros de custo foram alterados e os resultados destas variações foram verificados e comentados. Desta maneira, parâmetros como vida útil, taxas de manutenção e encargos sobre salários tiveram suas variações analisadas.

As planilhas mostrando os parâmetros para cada análise foram apresentadas no Apêndice C.

\subsubsection{Custos de acordo com os parâmetros inicialmente propostos}

Para os parâmetros inicialmente definidos no capítulo 4 deste trabalho foram apresentados os custos para os cenários propostos, mostrados nas Figuras 60, 61, 62, 63 e 64. 


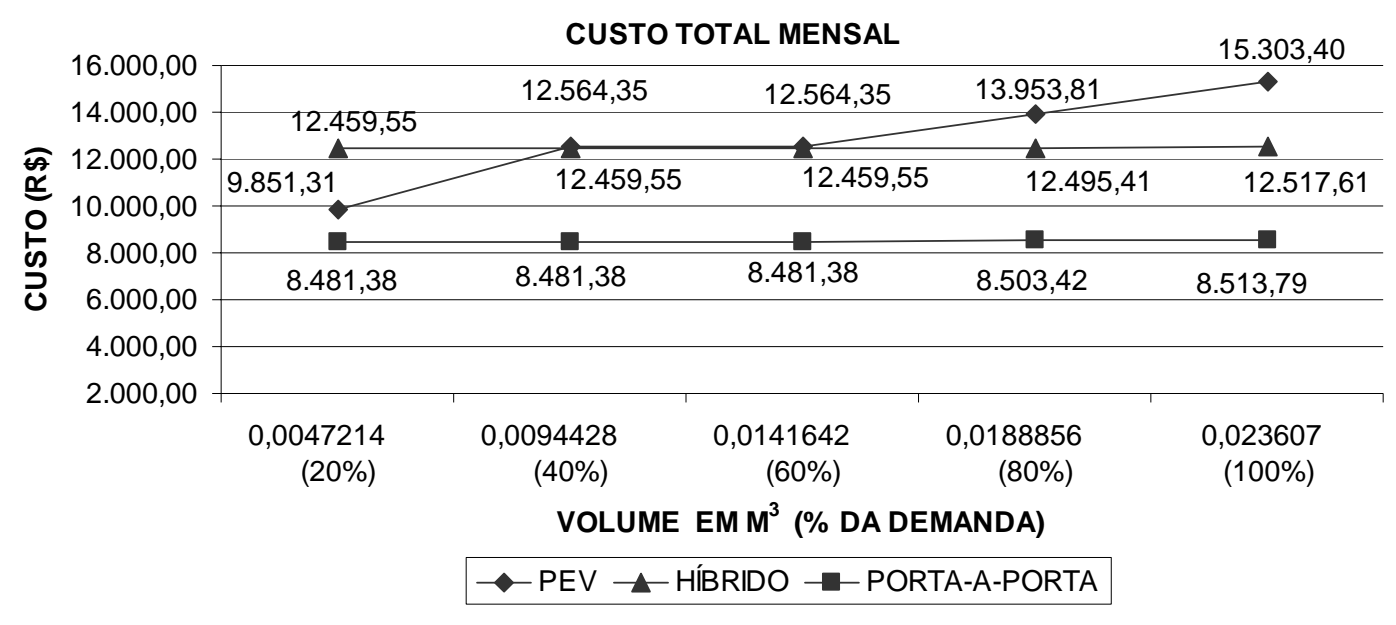

FIGURA 60. Custo total mensal dos 3 sistemas de coleta, para os cenários propostos, de acordo com os parâmetros de custo definidos inicialmente

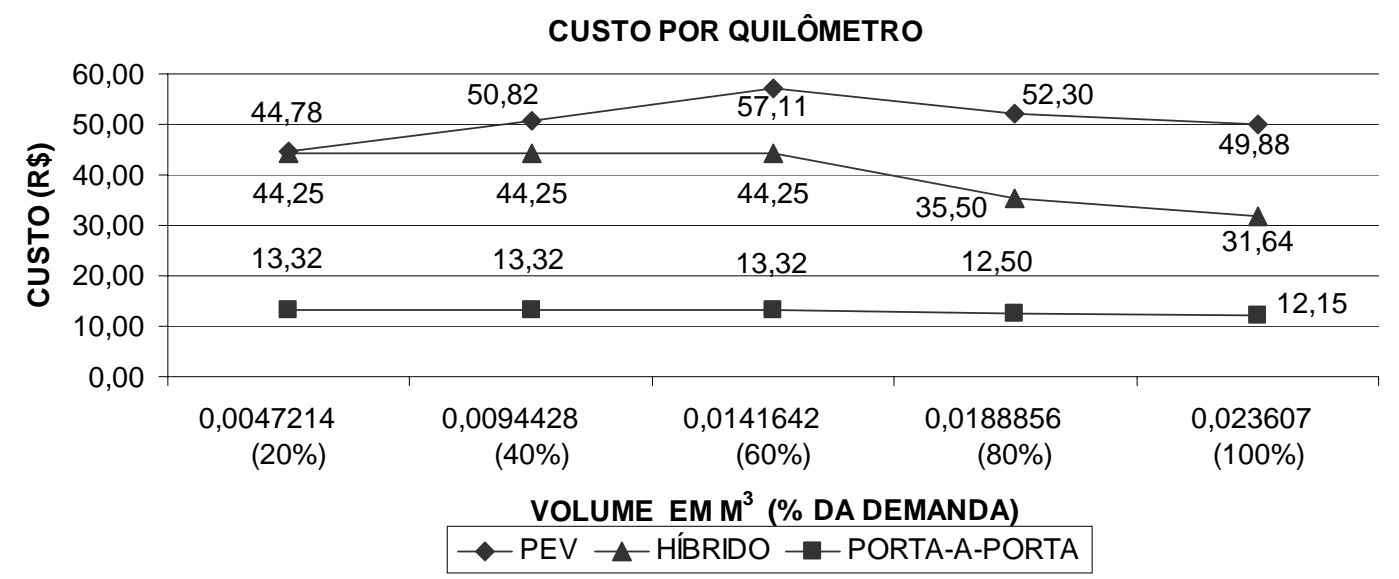

FIGURA 61. Custo por quilômetro percorrido dos 3 sistemas de coleta, para os cenários propostos, de acordo com os parâmetros de custo definidos inicialmente

Para este tipo de comparação (sistemas com grande variação na distância percorrida) a comparação do custo por quilômetro é uma ferramenta que demonstra a eficiência de cada sistema. Pelas características dos sistemas estudados a quilometragem percorrida vai ser sempre maior no sistema Porta-a-Porta cujo custo, como mostrado na Figura 61, foi sempre menor que o custo dos outros sistemas, mostrando que nesta análise este sistema é o mais eficiente. 


\section{Componentes dos custos de cada cenário}

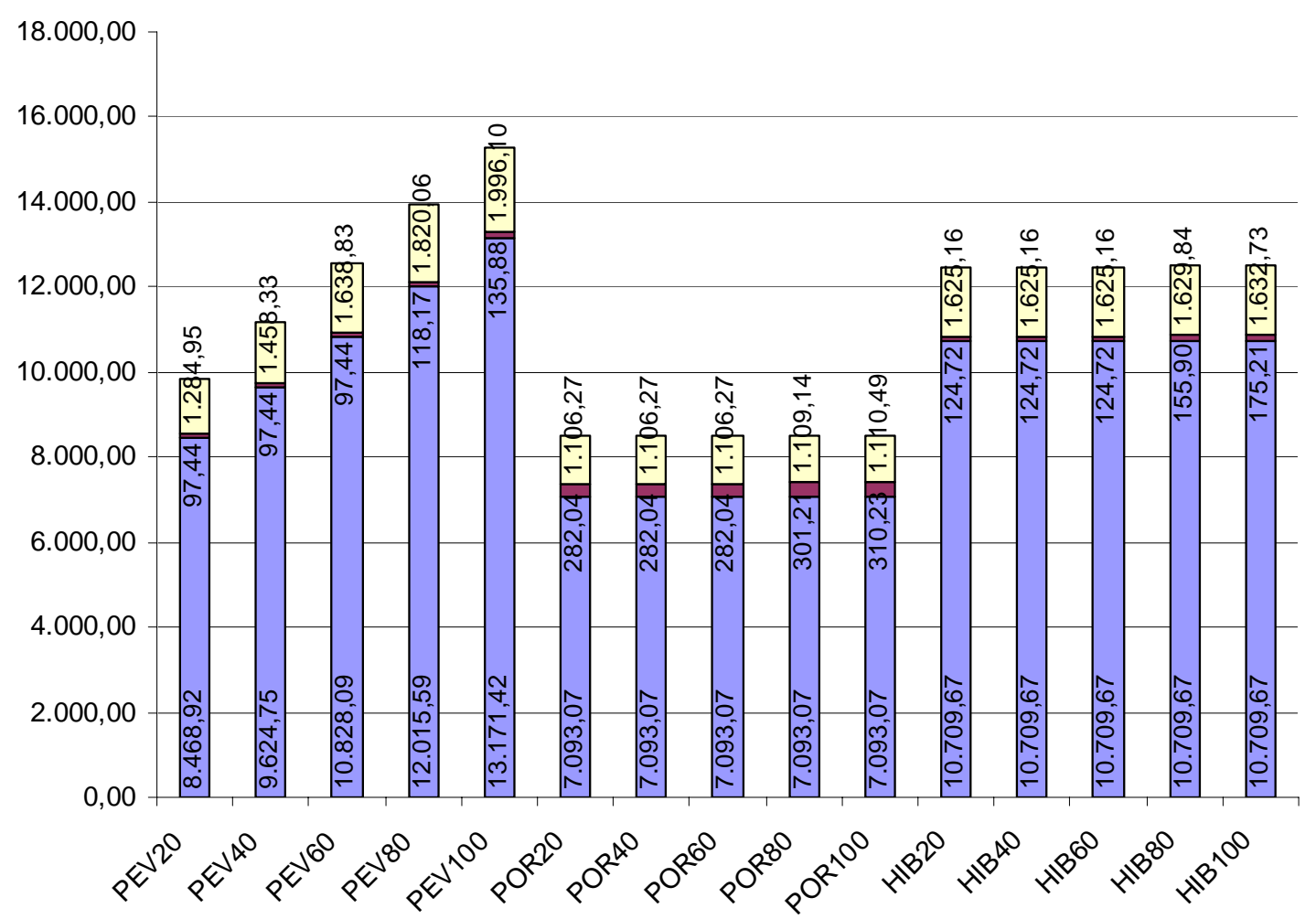

$\square$ Custos Fixos $\square$ Custos Variáveis $\square$ Custos Administrativos

FIGURA 62. Composição dos custos de cada sistema

Uma característica observada no gráfico apresentado na Figura 62, é que os custos variáveis, aqueles que variam com a quilometragem percorrida, não representam nem $5 \%$ do custo fixo (1\% para o sistema por PEVs, 4\% para o sistema Porta-a-Porta e de 1 a $2 \%$ para o sistema híbrido). Isto pode ser explicado por algumas características da área em estudo:

- Por se tratar de uma cidade de médio porte, as localizações da garagem e da central de triagem são bem próximas à área de coleta, reduzindo a distância de viagem destes locais até a região da coleta. Além disso, para este tipo de coleta não existe a necessidade do "depósito" ser localizado distante dos centros residenciais urbanos, como no caso da coleta regular de resíduos sólidos domésticos. 
- O aspecto temporal não foi analisado na roteirização dos veículos de coleta. Esta variável poderia aumentar o rendimento de alguns sistemas, e com isso aumentar a área de cobertura e a distância mensal percorrida.

Nota-se, portanto, que o custo fixo do sistema por PEVs é sempre maior que o custo total do sistema Porta-a-Porta, assim como para o sistema Híbrido, que não varia de um cenário para outro, pois não existe variação na frota ou na equipe.

Como as rotinas de agrupamento das residências atendidas utilizadas pelo SIG-T apresentaram pequenas variações no número total de residências atendidas por cada sistema, foi necessário comparar os custos por residência (Figura 64) e custo por metro cúbico coletado (Figura 63).

A princípio, no cenário de menor demanda, nota-se que o sistema de maior custo por metro cúbico foi o sistema Híbrido. Isso ocorre, pois o custo de implantação deste sistema é alto, devido, principalmente ao custo de mão de obra. Nota-se que o custo do sistema por PEVs varia bastante, mas com o aumento da demanda tende a ser duas vezes maior que o sistema de menor custo. Este sistema tem seu custo aumentado gradualmente em proporção quase que direta com o aumento da demanda, pois, os custos de capital representam a maior parcela do custo total deste sistema, principalmente, devido ao capital investido na aquisição de contêineres.

Para efeito desta análise, as demonstrações de custos por residência atendida e por metro cúbico coletado são as mais reais, uma vez que o número de residências e consequentemente a quantidade de resíduo reciclável recolhida variou de um sistema para o outro. 


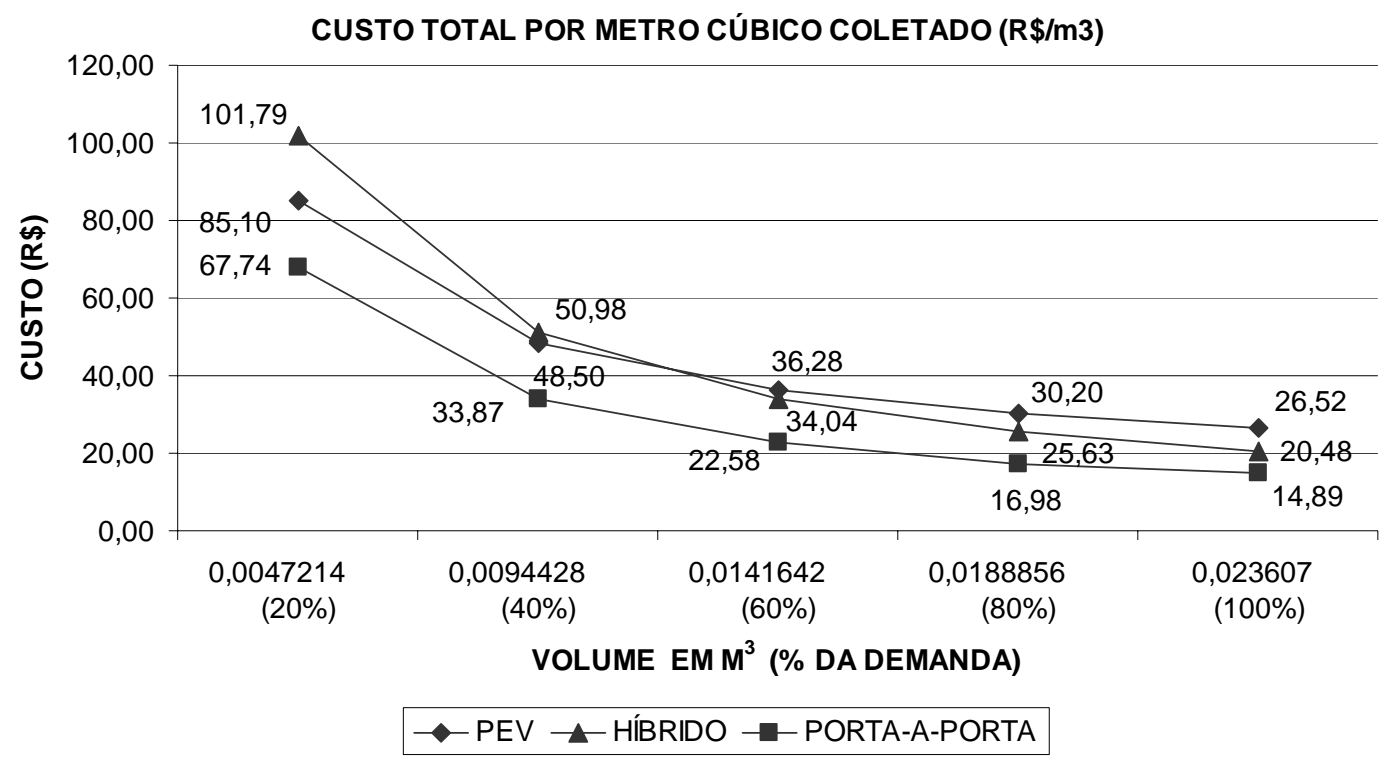

FIGURA 63. Custo por metro cúbico coletado dos 3 sistemas de coleta, para os cenários propostos, de acordo com os parâmetros de custo definidos inicialmente

CUSTO POR RESIDÊNCIA ATENDIDA

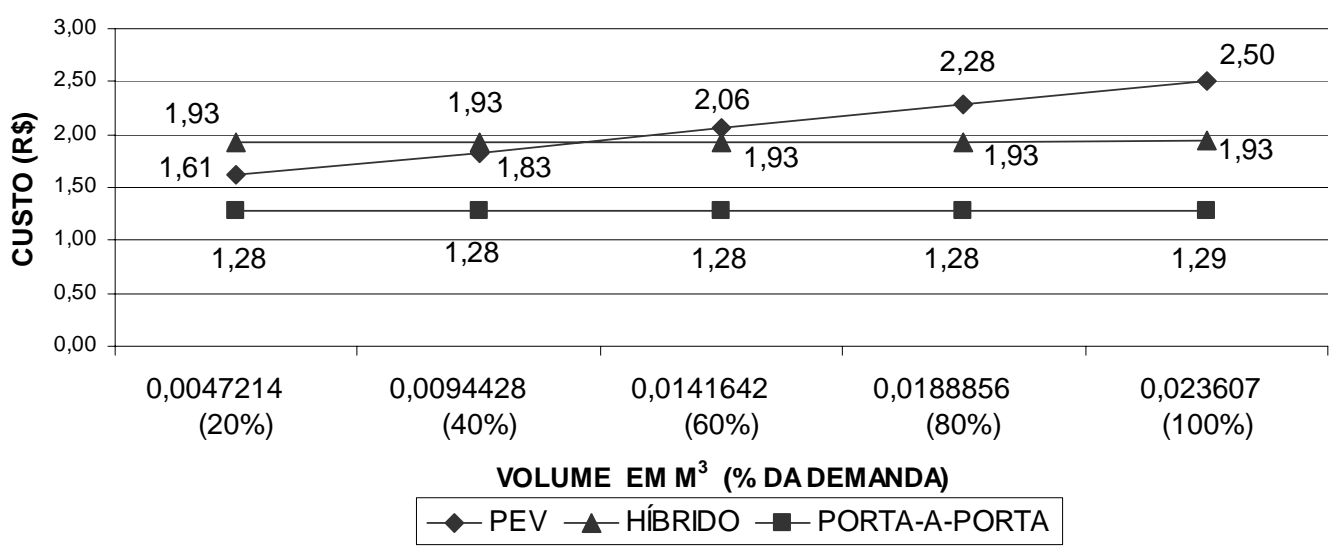

FIGURA 64. Custo por residência atendida dos 3 sistemas de coleta, para os cenários propostos, de acordo com os parâmetros de custo definidos inicialmente

Na Figura 65 é apresentado o volume coletado por quilômetro rodado, que representa a produtividade em termos de transporte de cada sistema. No sistema por PEVs, cuja quilometragem mensal percorrida foi a menor e a quantidade coletada é praticamente a mesma que nos outros sistemas, o rendimento é sempre maior se comparado com os outros sistemas, mesmo que este sistema apresente os mais elevados custos. 


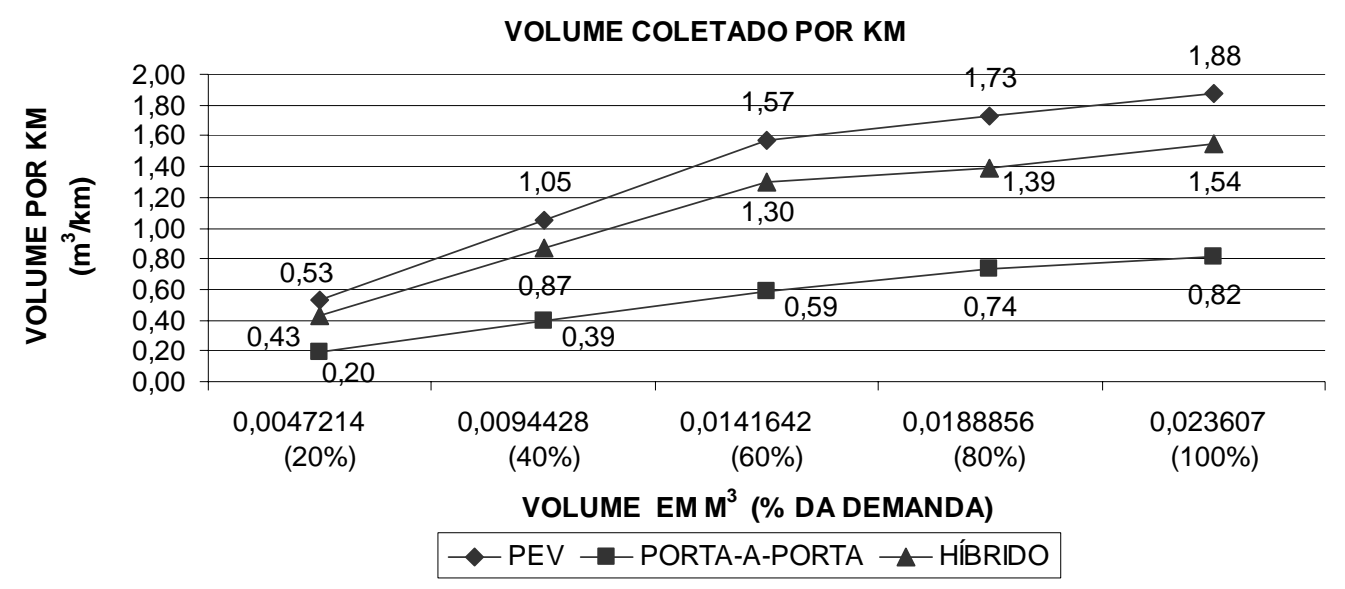

FIGURA 65. Volume coletado por quilômetro percorrido nos 3 sistemas de coleta, para os cenários propostos

É feita a seguir uma análise dos custos que compõem estes sistemas, na tentativa de apresentar alternativas aos parâmetros de custos apresentados inicialmente, de modo que se possa estender este estudo a um número maior de cenários.

\section{Composição dos custos operacionais fixos de cada sistema}

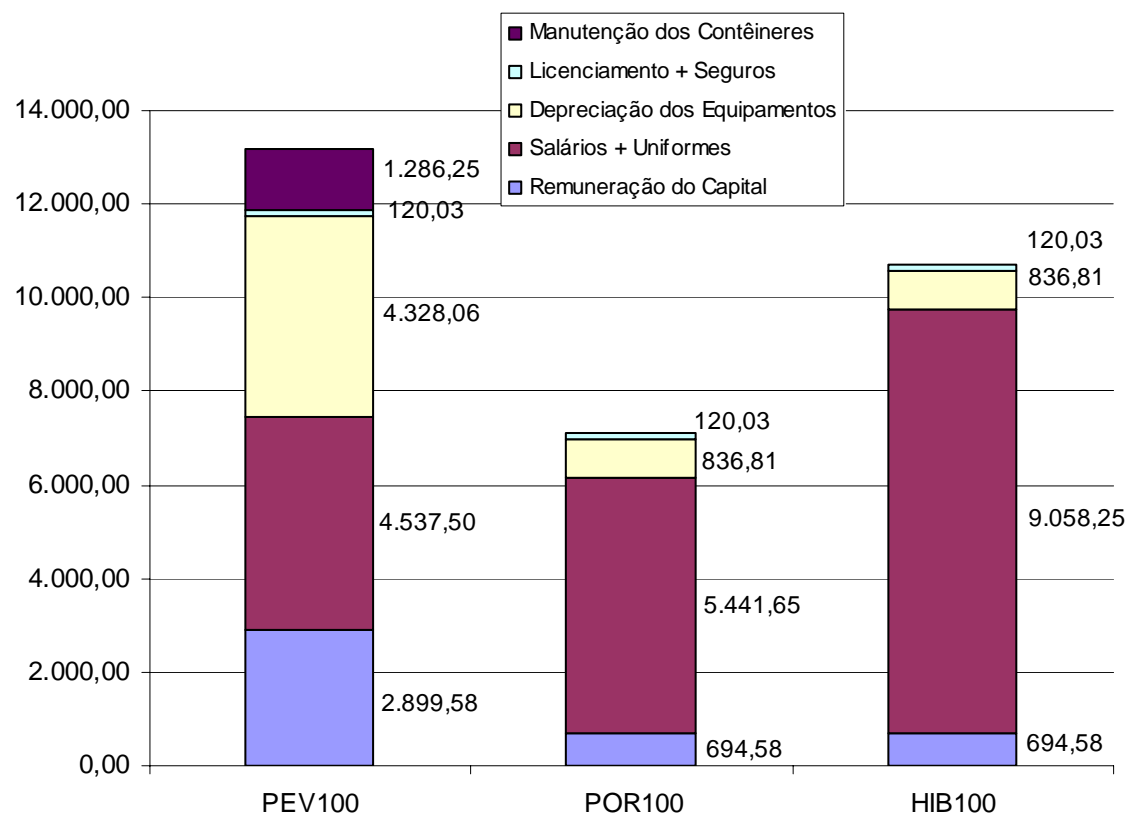

FIGURA 66. Composição dos custos operacionais fixos de cada sistema com os parâmetros de custo propostos inicialmente e com demanda máxima $(100 \%)$ 
Como mostrado na Figura 66, para o sistema por PEVs, a maior parcela do custo é composta pelo custo de capital (depreciação dos equipamentos e remuneração do capital investido). Para o sistema Híbrido a maior parcela de seus custos é composta pelos custos de mão de obra.

\subsubsection{Custos com os parâmetros vida útil dos insumos depreciáveis aumentados (120 meses)}

Para reduzir os custos de capital e com isso tornar o sistema por PEVs mais competitivo, foram modificados os parâmetros que influenciam diretamente sobre este tipo de custo.

Conforme explicitado em Naruo (2003):

"Na análise de custos da coleta, foi verificado que os parâmetros de manutenção como sendo de $85 \%$ do valor dos veículos de coleta em uma vida útil de 60 meses, indicada pela SELUR (2001), não condizia com a realidade do nosso estudo de caso. Bem como a adoção do valor residual, considerado de $22 \%$, dentro desta mesma vida útil. Esta conclusão foi tirada, sabendo-se que estes parâmetros foram estimados com base em dados de empresas que trabalham em grandes centros urbanos, ou seja, com 2 a 3 turnos de trabalho por dia. E, as pequenas cidades deste estudo de caso podem chegar a não completar uma jornada para a coleta dos resíduos. Assim, como a manutenção e o valor residual do equipamento são função do tempo de trabalho do equipamento, para simplificação, foi adotada uma vida útil de 120 meses, o dobro do indicado pela SELUR (2001), mantendo-se os parâmetros de manutenção e valor residual dos veículos." (NARUO, 2003).

Alterando o parâmetro de vida útil dos insumos depreciáveis, foram obtidos os custos para cenários propostos, que são mostrados nas Figuras 67, 68, 69 e 70. 
CUSTO TOTAL MENSAL

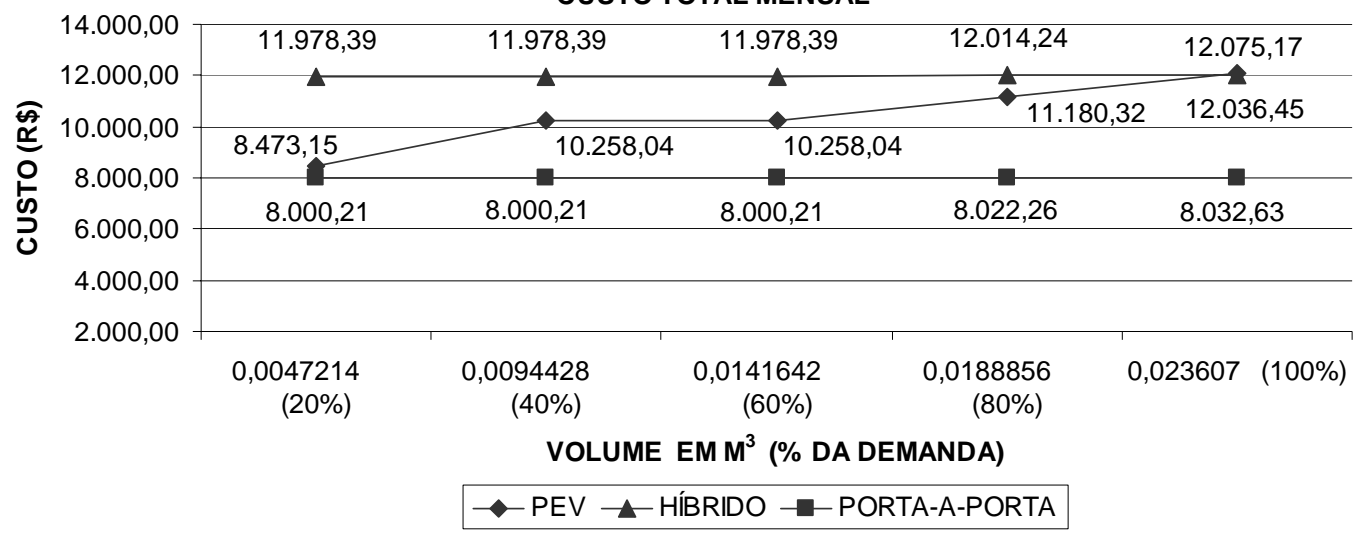

FIGURA 67. Custo total mensal dos 3 sistemas de coleta, para os cenários propostos com o parâmetro de vida útil aumentado

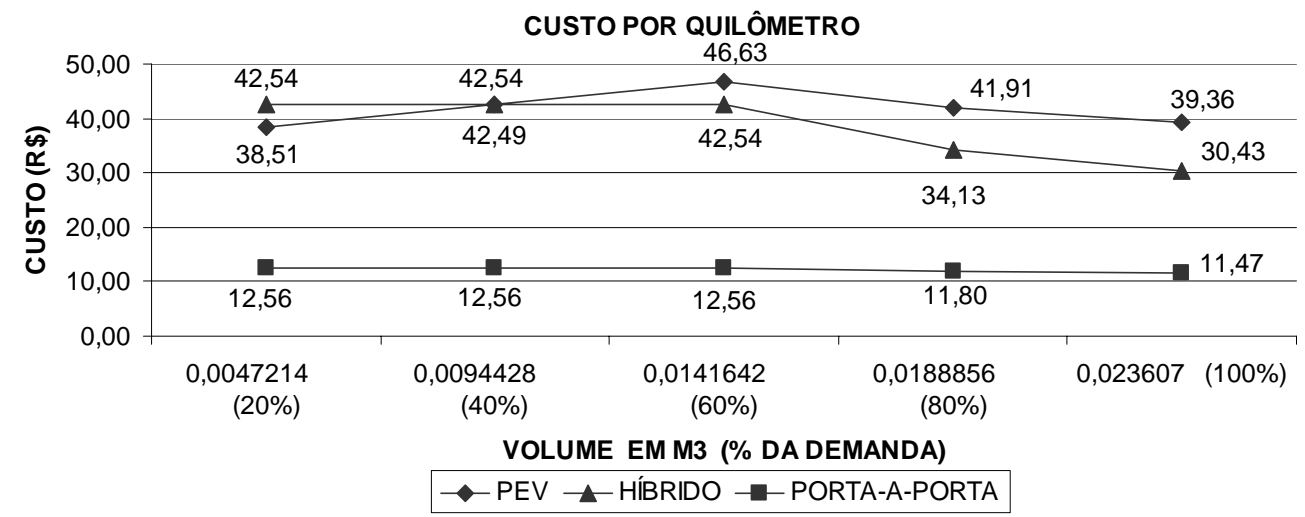

FIGURA 68. Custo por quilômetro percorrido dos 3 sistemas de coleta, para os cenários propostos com o parâmetro de vida útil aumentado

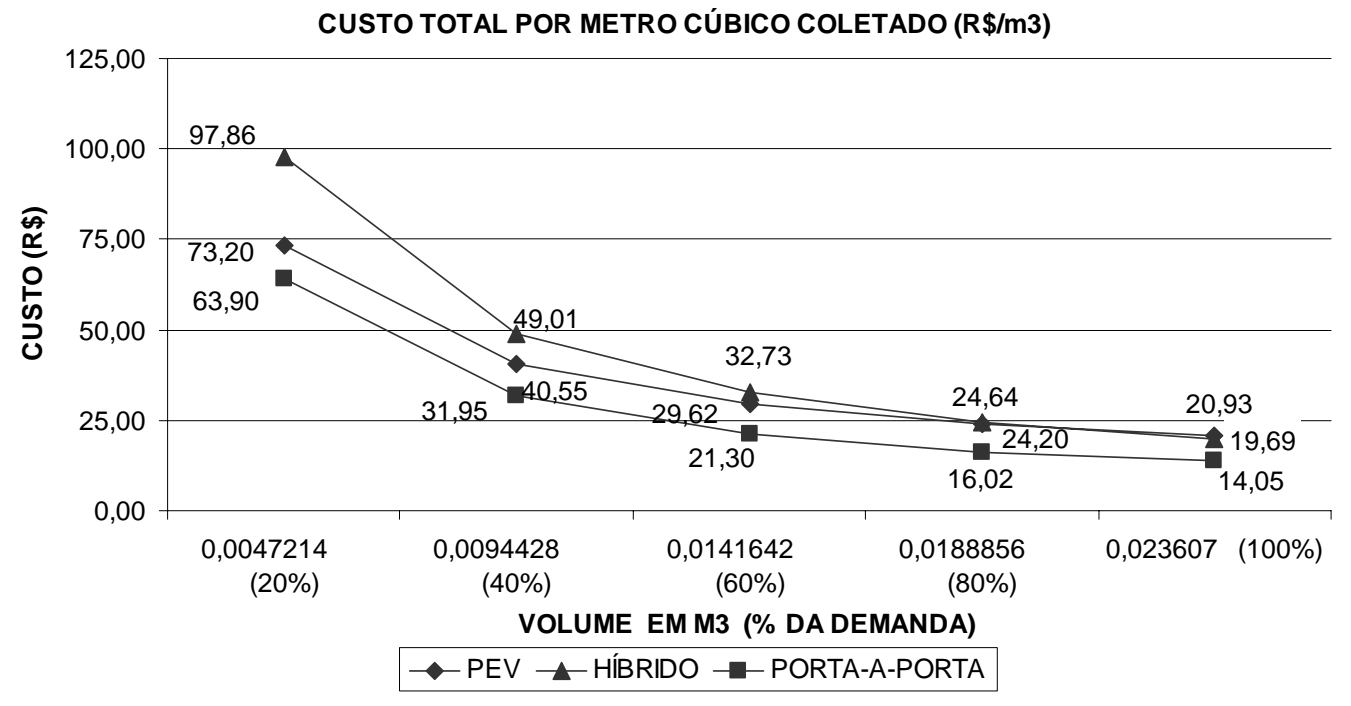

FIGURA 69. Custo por metro cúbico coletado dos 3 sistemas de coleta, para os cenários propostos com o parâmetro de vida útil aumentado 


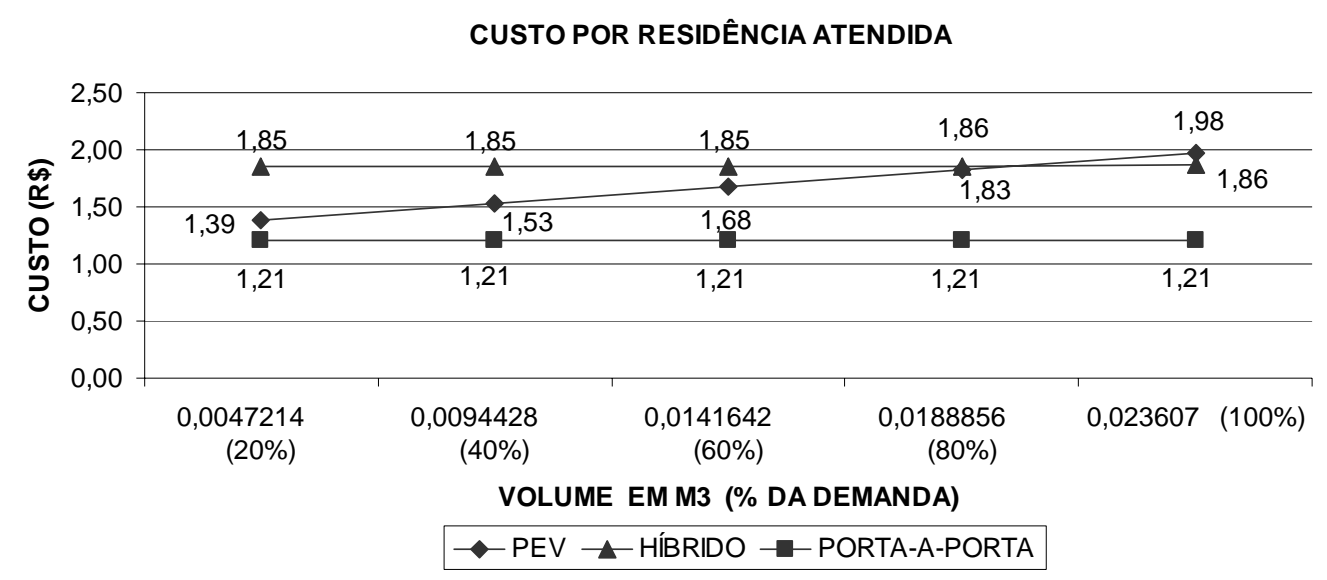

FIGURA 70. Custo por residência atendida dos 3 sistemas de coleta, para os cenários propostos com o parâmetro de vida útil aumentado

Os custos em todos os sistemas tiveram redução. Como se pode notar, a alternativa de coleta por PEVs mostrou-se mais competitiva, tendo inclusive custos menores que a alternativa do sistema Híbrido.

\subsubsection{Custos com os parâmetros da vida útil dos insumos depreciáveis aumentados (120 meses) e parâmetro da taxa de remuneração do capital investido diminuída pela metade (crédito mais barato)}

Ainda com a intenção de reduzir o custo de capital, adotou-se a redução da taxa de remuneração de capital, que tradicionalmente é considerada em $12 \%$ ao ano para análise de viabilidade de sistemas de transportes. O cenário foi visualizado de maneira que políticas públicas facilitassem a implantação de coleta seletiva nos municípios, que teriam então acesso a crédito mais barato. $\mathrm{O}$ valor utilizado foi de $6 \%$ ao ano. Os custos para este cenário são mostrado nas Figuras 71, 72, 73 e 74. 


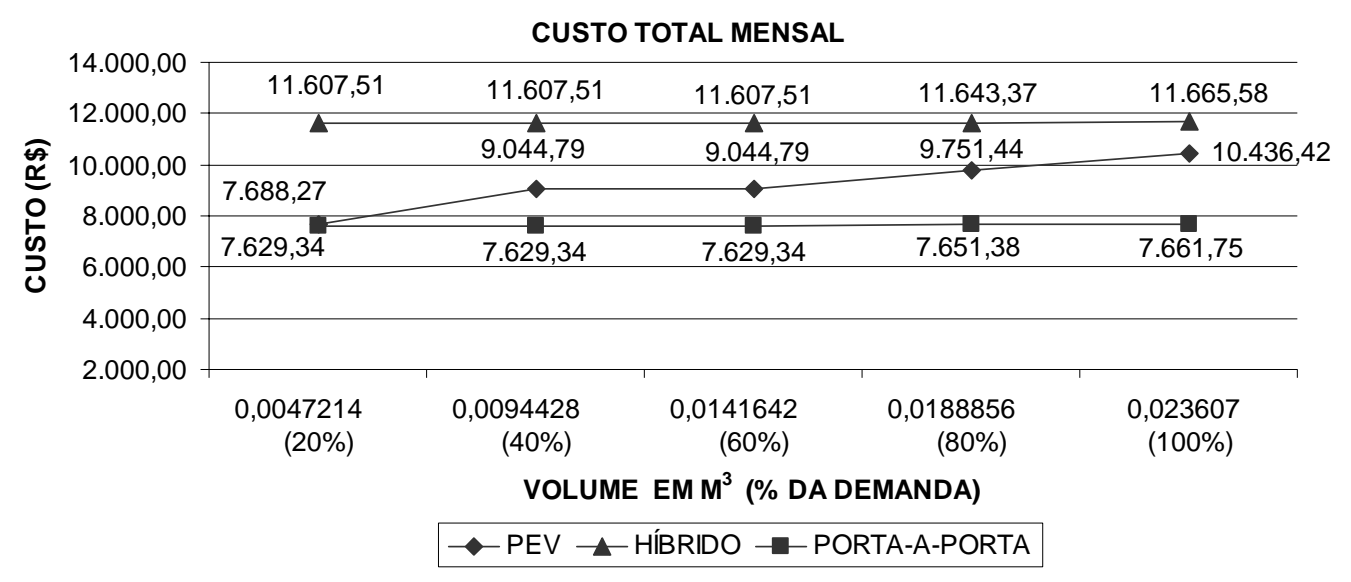

FIGURA 71. Custo total mensal dos 3 sistemas de coleta, para os cenários propostos com o parâmetro de vida útil aumentado e taxa de remuneração reduzida

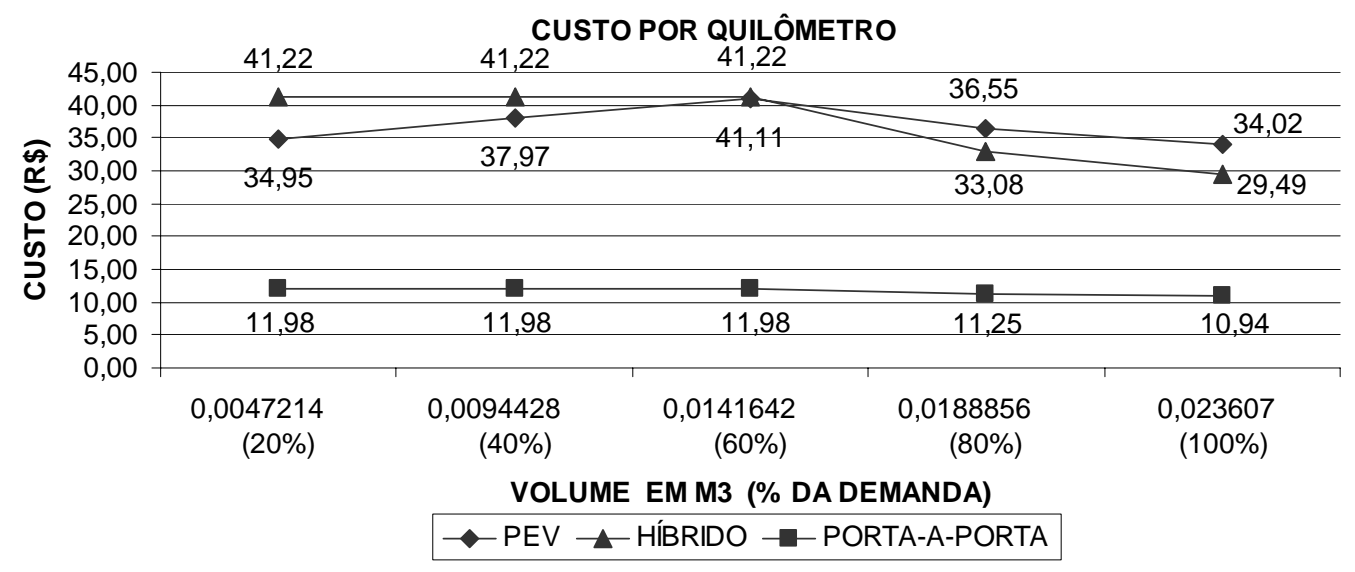

FIGURA 72. Custo por quilômetro percorrido dos 3 sistemas de coleta, para os cenários propostos com o parâmetro de vida útil aumentado e taxa de remuneração reduzida

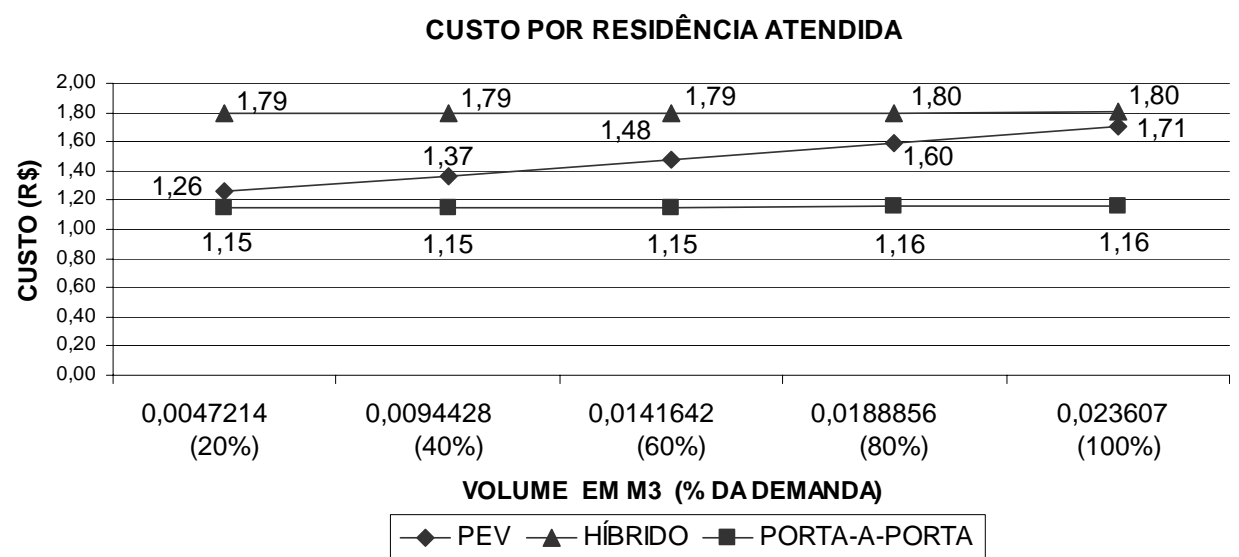

FIGURA 73. Custo por residência atendida dos 3 sistemas de coleta, para os cenários propostos com o parâmetro de vida útil aumentado e taxa de remuneração reduzida 


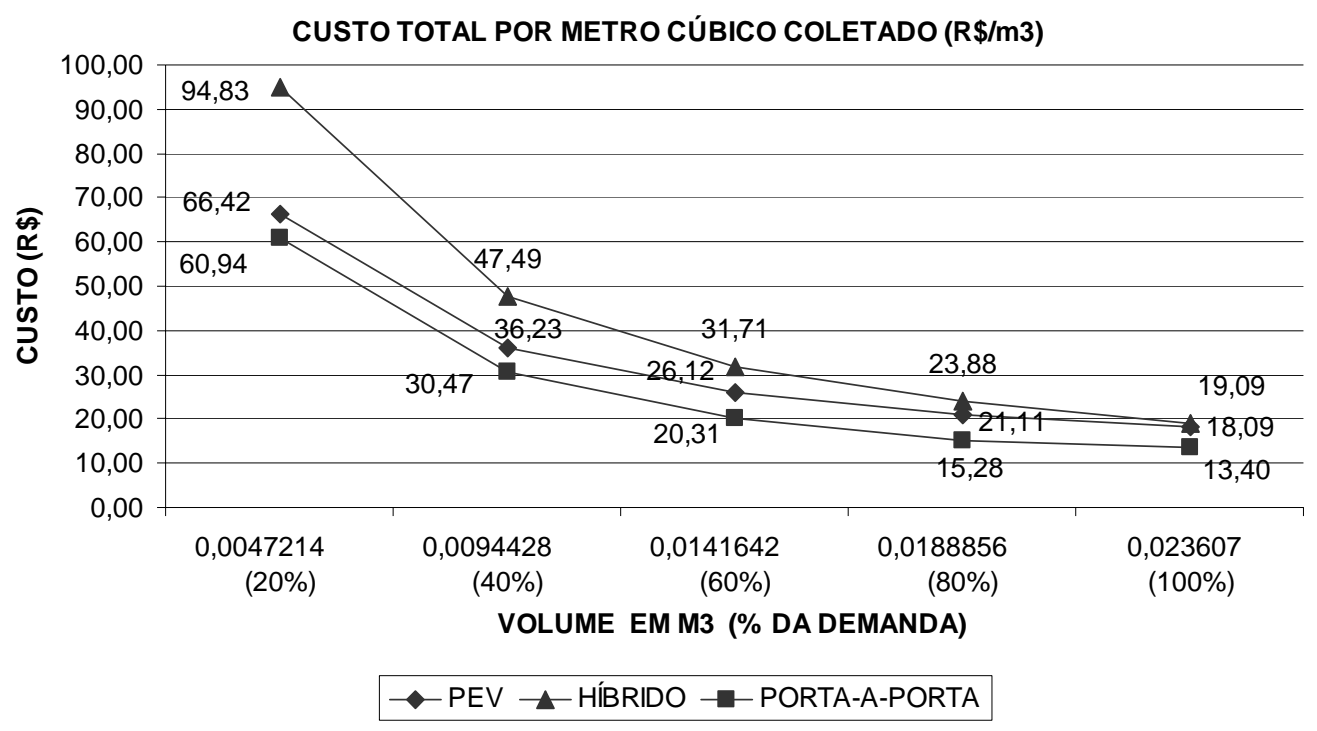

FIGURA 74. Custo por metro cúbico coletado dos 3 sistemas de coleta, para os cenários propostos com o parâmetro de vida útil aumentado e taxa de remuneração reduzida

Neste cenário, como era de se esperar, houve uma redução nos custos totais dos três sistemas. Mais uma vez o sistema por PEVs teve seu custo reduzido se mostrando uma opção bastante competitiva neste cenário. Isto pode ser notado na Figura 74, onde a curva dos custos por metro cúbico coletado do sistema por PEV se aproxima bastante da curva do sistema Porta-a-Porta, a de menor custo entre os 3 sistemas.

\subsubsection{Custos com os parâmetros da vida útil dos insumos depreciáveis aumentados (120 meses), parâmetro da taxa de remuneração do capital investido diminuída pela metade (crédito mais barato) e sem considerar encargos sobre a mão-de-obra (cooperativa)}

Como visto na Figura 66, a maior parcela do custo do sistema Híbrido é formada pelo custo de mão de obra. Para reduzir este custo e assim melhorar a competitividade deste sistema, foi analisada a situação em que o sistema de coleta seletiva fosse gerido por cooperativas. Segundo Thiemermam (2004), nas cooperativas existentes no município de São Carlos, o rendimento médio mensal dos catadores é de R\$ 400,00. Então, para este cenário, o salário médio dos catadores é fixado em $\mathrm{R} \$ 400,00$, e será considerada a inexistência de encargos sobre a mão-de-obra. 
Alterando o parâmetro de vida útil dos insumos depreciáveis, diminuindo a taxa de juros do capital investido e excluindo os encargos sobre a mão-de-obra, foram obtidos os custos para cenários propostos mostrados nas Figuras 75, 76,77 e 78.

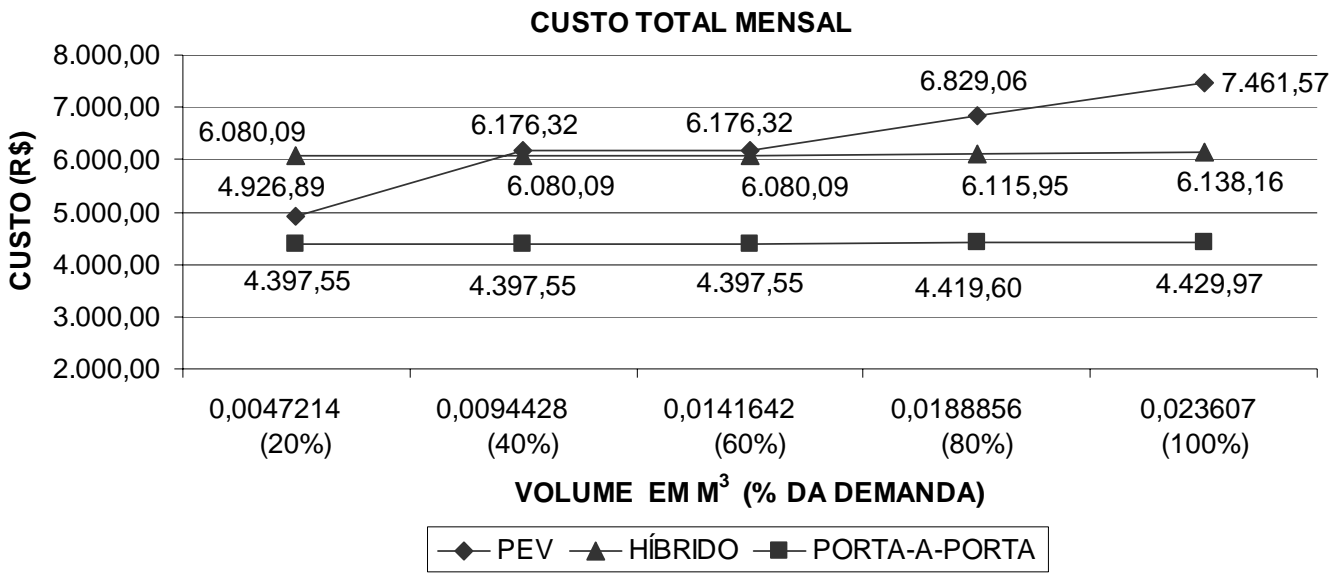

FIGURA 75. Custo total mensal dos 3 sistemas de coleta, para os cenários propostos com o parâmetro de vida útil aumentado, taxa de remuneração reduzida e sem encargos sobre a mão-de-obra

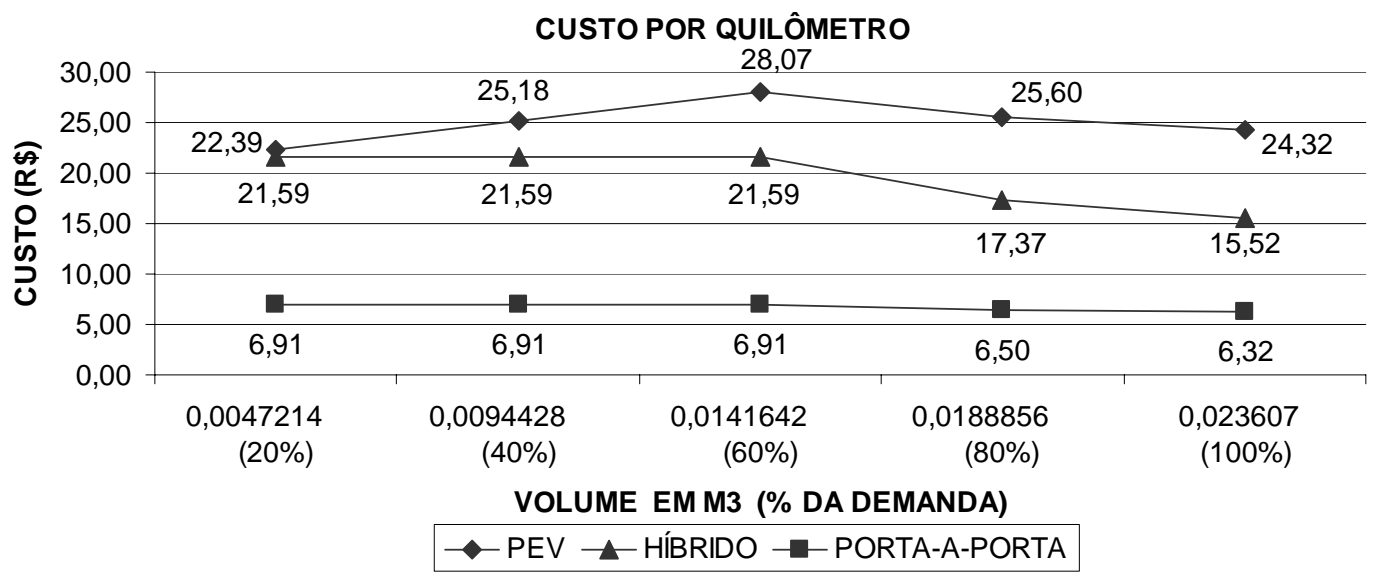

FIGURA 76. Custo por quilômetro percorrido dos 3 sistemas de coleta, para os cenários propostos com o parâmetro de vida útil aumentado, taxa de remuneração reduzida e sem encargos sobre a mão-de-obra 


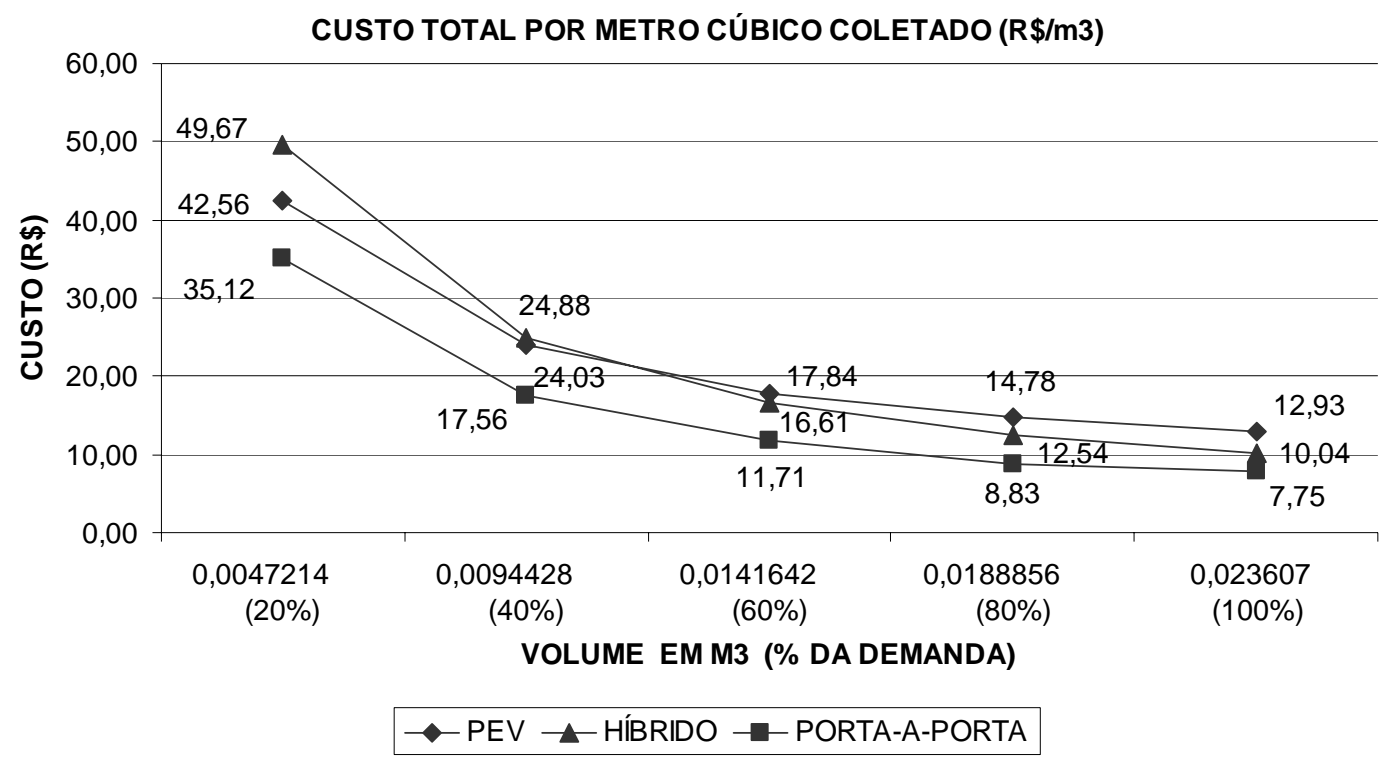

FIGURA 77. Custo por metro cúbico coletado dos 3 sistemas de coleta, para os cenários propostos com o parâmetro de vida útil aumentado e de taxa de remuneração reduzido e sem encargos sobre a mão-de-obra

CUSTO POR RESIDÊNCIA ATENDIDA

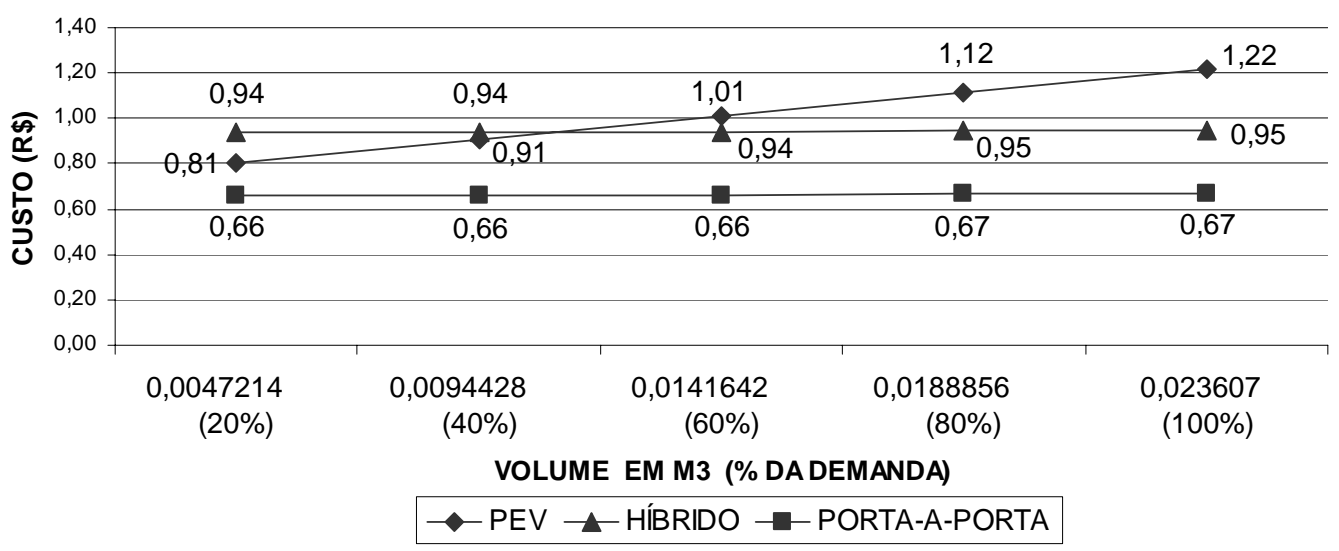

FIGURA 78. Custo por residência atendida dos 3 sistemas de coleta, para os cenários propostos com o parâmetro de vida útil aumentado, taxa de remuneração reduzida e sem encargos sobre a mão-de-obra

Neste cenário, o custo do sistema Híbrido mostrou-se mais competitivo que o custo do sistema por PEVs, mas mesmo assim o custo do sistema Porta-a-Porta mostrase como melhor opção.Na situação idealizada nesta seção, obteve-se os menores custos em todos os sistemas. 
Assim, algumas outras variações podem ser exploradas de modo que o cenário proposto se encaixe o mais precisamente possível dentro da realidade do local em estudo.

\subsection{COMPARAÇÃO DOS CUSTOS DO SISTEMA POR PEVS PARA ALGUMAS VARIAÇÕES NOS TIPOS DE CONTÊINERES UTILIZADOS}

Uma das complexidades do sistema por PEVs é a grande variação de combinações de contêineres de diferentes materiais e custos. Visto que os custos de capital para este sistema representam parcela considerável dos custos totais, faz-se necessária uma análise mais meticulosa de algumas configurações de contêineres disponíveis no mercado.

A análise realizada neste estudo variou a capacidade, o material e o tipo dos contêineres, para que com isso, pudesse ser analisado o comportamento do custo deste sistema para as novas configurações. As configurações escolhidas para a análise podem ser observadas na Tabela 23. Alguns tipos de contêineres comerciais (e os tipos utilizados nestas configurações) são mostrados no Anexo A.

Tabela 23. Capacidades, custos e configurações previstas para diferentes tipos de contêineres

\begin{tabular}{|c|c|c|c|c|c|c|c|c|}
\hline \multirow{2}{*}{ Fornecedor } & \multirow{2}{*}{ Material } & \multirow{2}{*}{$\begin{array}{c}\text { Capacidade } \\
\text { (I) }\end{array}$} & \multirow{2}{*}{$\begin{array}{c}\text { Custo } \\
\text { (R\$) }\end{array}$} & \multirow{2}{*}{$\begin{array}{c}\text { Custol } \\
\text { Litro } \\
\text { (R\$/l) } \\
\end{array}$} & \multicolumn{4}{|c|}{ Configurações } \\
\hline & & & & & C1 & $\mathrm{C2}$ & C3 & C4 \\
\hline \multirow{6}{*}{ Arte da Fibra } & Fibra de Vidro & 750 & $\mathrm{R} \$ 860,00$ & $\mathrm{R} \$ 1,15$ & & & & \\
\hline & Fibra de Vidro & 900 & $\mathrm{R} \$ 1.080,00$ & $\mathrm{R} \$ 1,20$ & & & & \\
\hline & \begin{tabular}{|l} 
Fibra de Vidro \\
\end{tabular} & 1300 & $\mathrm{R} \$ 1.290,00$ & $\mathrm{R} \$ 0,99$ & & & & \\
\hline & Fibra de Vidro & 1500 & $\mathrm{R} \$ 1.390,00$ & $\mathrm{R} \$ 0,93$ & & & & \\
\hline & Fibra de Vidro & 1800 & $\mathrm{R} \$ 1.740,00$ & $\mathrm{R} \$ 0,97$ & & & & \\
\hline & Fibra de Vidro & 2600 & $\mathrm{R} \$ 2.390,00$ & $\mathrm{R} \$ 0,92$ & & & & \\
\hline \multirow{3}{*}{ Brazil Virgo } & PEAD & 120 & $\mathrm{R} \$ 195,00$ & $\mathrm{R} \$ 1,63$ & & & & \\
\hline & PEAD & 240 & $\mathrm{R} \$ 245,00$ & $\mathrm{R} \$ 1,02$ & & & & \\
\hline & PEAD & 360 & $\mathrm{R} \$ 540,00$ & $\mathrm{R} \$ 1,50$ & & & & \\
\hline Terrabras & Aço & 1200 & $\mathrm{R} \$ 980,00$ & $\mathrm{R} \$ 0,82$ & & & & \\
\hline \multirow{2}{*}{ Dix Higiene } & Polipropileno & 240 & $\mathrm{R} \$ 272,00$ & $\mathrm{R} \$ 1,13$ & & & & \\
\hline & PEAD & 1000 & $\mathrm{R} \$ 1.320,00$ & $\mathrm{R} \$ 1,32$ & & & & \\
\hline \multirow{4}{*}{ Orion Clean } & PEAD & 1000 & $\mathrm{R} \$ 1.677,02$ & $\mathrm{R} \$ 1,68$ & & & & \\
\hline & PEAD & 1200 & $\mathrm{R} \$ 1.702,70$ & $\mathrm{R} \$ 1,42$ & & & & \\
\hline & PEAD & 1200 & $\mathrm{R} \$ 1.398,65$ & $\mathrm{R} \$ 1,17$ & & & & \\
\hline & PEAD & 2500 & $\mathrm{R} \$ 3.333,78$ & $\mathrm{R} \$ 1,33$ & & & & \\
\hline \multirow{3}{*}{ Conishi } & Aço & 1200 & $\mathrm{R} \$ 1.766,40$ & $\mathrm{R} \$ 1,47$ & & & & \\
\hline & Aço & 1600 & $\mathrm{R} \$ 2.342,40$ & $\mathrm{R} \$ 1,46$ & & & & \\
\hline & Tambor em chapa de aço & 200 & $\mathrm{R} \$ 60,00$ & $\mathrm{R} \$ 0,30$ & & & & \\
\hline
\end{tabular}

Configurações de Contêineres

\begin{tabular}{|c|l}
\hline C1 & Contêineres de todas as capacidades comerciais \\
\hline C2 & Contêineres com capacidades bem distintas e com menor relação custo por litro \\
\hline C3 & Todos os contêineres de mesmo material \\
\hline C4 & Somente conêiner com a melhor relação custo por litro (tambores)
\end{tabular}


Os critérios utilizados para a determinação destas configurações, foram:

- Para a configuração $\mathrm{C} 1$ : utilização de todos os tamanhos comerciais, na tentativa de reduzir o "super dimensionamento" do sistema, fazendo com que a capacidade instalada seja bem próxima à demanda a ser coletada;

- Para a configuração C2: utilização de contêineres de tamanhos bem distintos e com boa relação custo/beneficio (aqui definida pela relação: custo de aquisição por quantidade coletável, ou simplesmente custo/volume);

- Para a configuração C3: padronização do material utilizado em cada contêiner. Para isto foram escolhidos todos os contêineres de um mesmo fabricante e que tivessem boa relação custo/volume;

- Para a configuração C4: utilização de apenas um contêiner - aquele que tivesse a menor relação custo/volume (tambores de 200 litros).

Para cada configuração, e com a demanda em cada PEV para cada cenário, fica definido o número de contêineres para cada situação, conforme a planilha a seguir, na Tabela 24. 
ปีత్ర

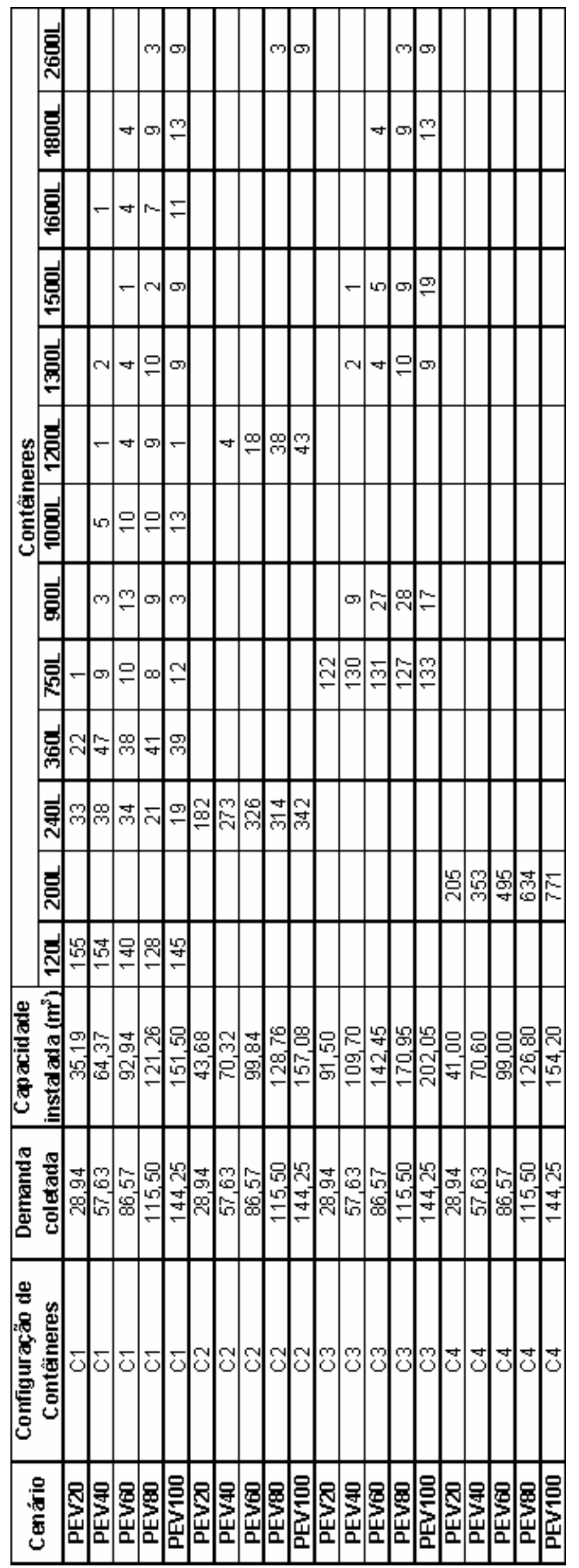


As planilhas com os resultados das combinações dos contêineres para cada cenário, são mostradas no Apêndice D ao final desta dissertação.

Para cada cenário e configuração de contêineres, e com os parâmetros de custo propostos inicialmente para a análise (apresentado no Capitulo 4), foram obtidos os custos de cada configuração, conforme é mostrado na Tabela 25 e nas Figuras 79, 80, 81 e 82.

Tabela 25. Custos de cada combinação de contêineres

\begin{tabular}{|c|c|c|c|c|c|}
\hline $\begin{array}{c}\text { Combinação } \\
\text { de } \\
\text { Contêineres }\end{array}$ & CENÁRIO & $\begin{array}{c}\text { CUSTO MENSAL } \\
\text { TOTAL }\end{array}$ & $\begin{array}{l}\text { CUSTO POR } \\
\text { QUILÔMETRO } \\
(\mathrm{R} \$ / \mathrm{km})\end{array}$ & $\begin{array}{c}\text { CUSTO POR } \\
\text { METRO CUBICO } \\
\text { COLETADO } \\
(\mathrm{R} \$ / \mathrm{m} 3)\end{array}$ & $\begin{array}{l}\text { CUSTO MENSAL } \\
\text { POR RESIDÊNCIA } \\
\text { ATENDIDA }\end{array}$ \\
\hline \multirow{5}{*}{ C1 } & PEV20 & $9.088,38$ & 41,31 & 78,51 & 1,49 \\
\hline & PEV40 & $10.356,05$ & 47,07 & 44,92 & 1,69 \\
\hline & PEV60 & $11.555,17$ & 52,52 & 33,37 & 1,89 \\
\hline & PEV80 & $12.561,57$ & 47,08 & 27,19 & 2,05 \\
\hline & PEV100 & $13.817,67$ & 45,04 & 23,95 & 2,26 \\
\hline \multirow{5}{*}{$\mathrm{C} 2$} & PEV20 & $8.853,13$ & 40,24 & 76,48 & 1,45 \\
\hline & PEV40 & $9.807,79$ & 44,58 & 42,55 & 1,60 \\
\hline & PEV60 & $10.780,30$ & 49,00 & 31,13 & 1,76 \\
\hline & PEV80 & $11.671,95$ & 43,75 & 25,26 & 1,91 \\
\hline & PEV100 & $12.642,79$ & 41,21 & 21,91 & 2,07 \\
\hline \multirow{5}{*}{ C3 } & PEV20 & $11.050,15$ & 50,23 & 95,46 & 1,81 \\
\hline & PEV40 & $11.799,24$ & 53,63 & 51,19 & 1,93 \\
\hline & PEV60 & $12.148,79$ & 55,22 & 35,08 & 1,99 \\
\hline & PEV80 & $14.088,56$ & 52,81 & 30,49 & 2,30 \\
\hline & PEV100 & $15.099,10$ & 49,21 & 26,17 & 2,47 \\
\hline \multirow{5}{*}{ C4 } & PEV20 & $7.677,24$ & 34,90 & 66,32 & 1,26 \\
\hline & PEV40 & $8.000,62$ & 36,37 & 34,71 & 1,31 \\
\hline & PEV60 & $8.310,89$ & 37,78 & 24,00 & 1,36 \\
\hline & PEV80 & $8.638,44$ & 32,38 & 18,70 & 1,41 \\
\hline & PEV100 & $8.958,16$ & 29,20 & 15,53 & 1,47 \\
\hline
\end{tabular}

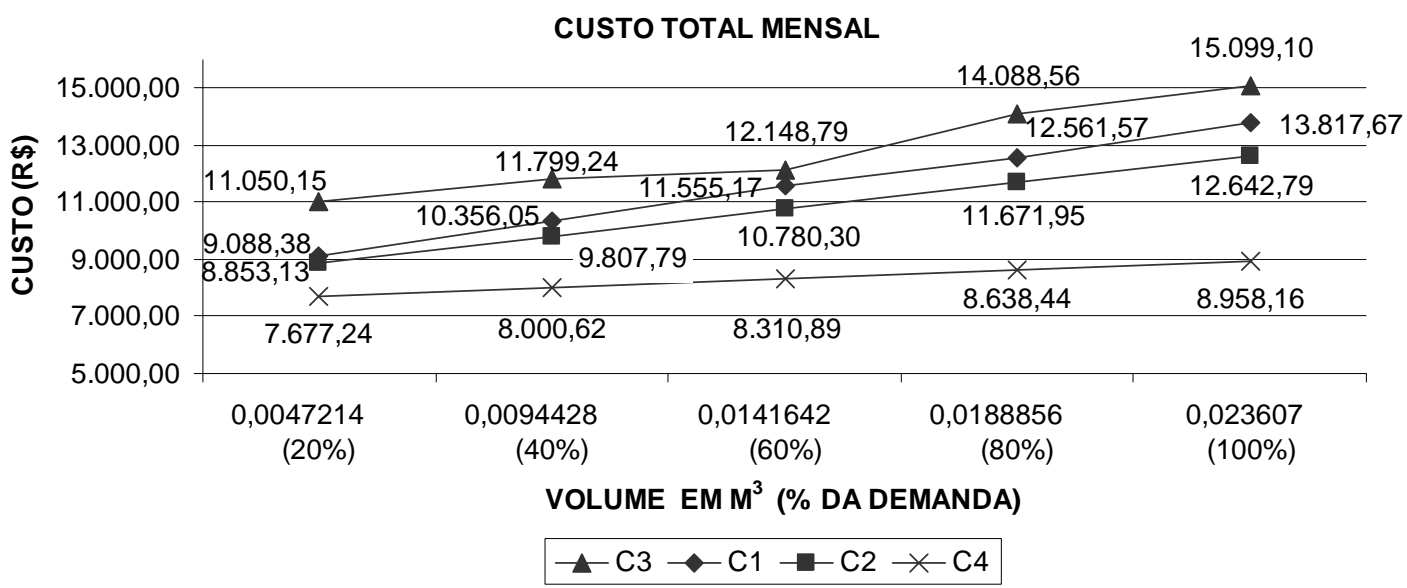

FIGURA 79. Custo total mensal para cada uma das configurações de contêineres 
CUSTO POR QUILÔMETRO

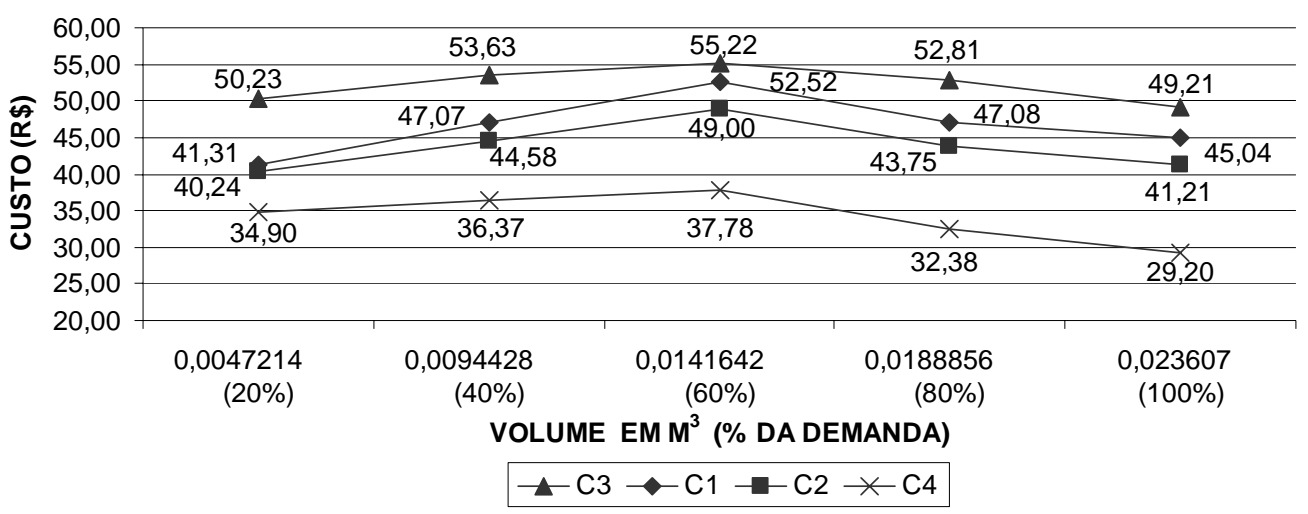

FIGURA 80. Custo por quilômetro para cada uma das configurações de contêineres

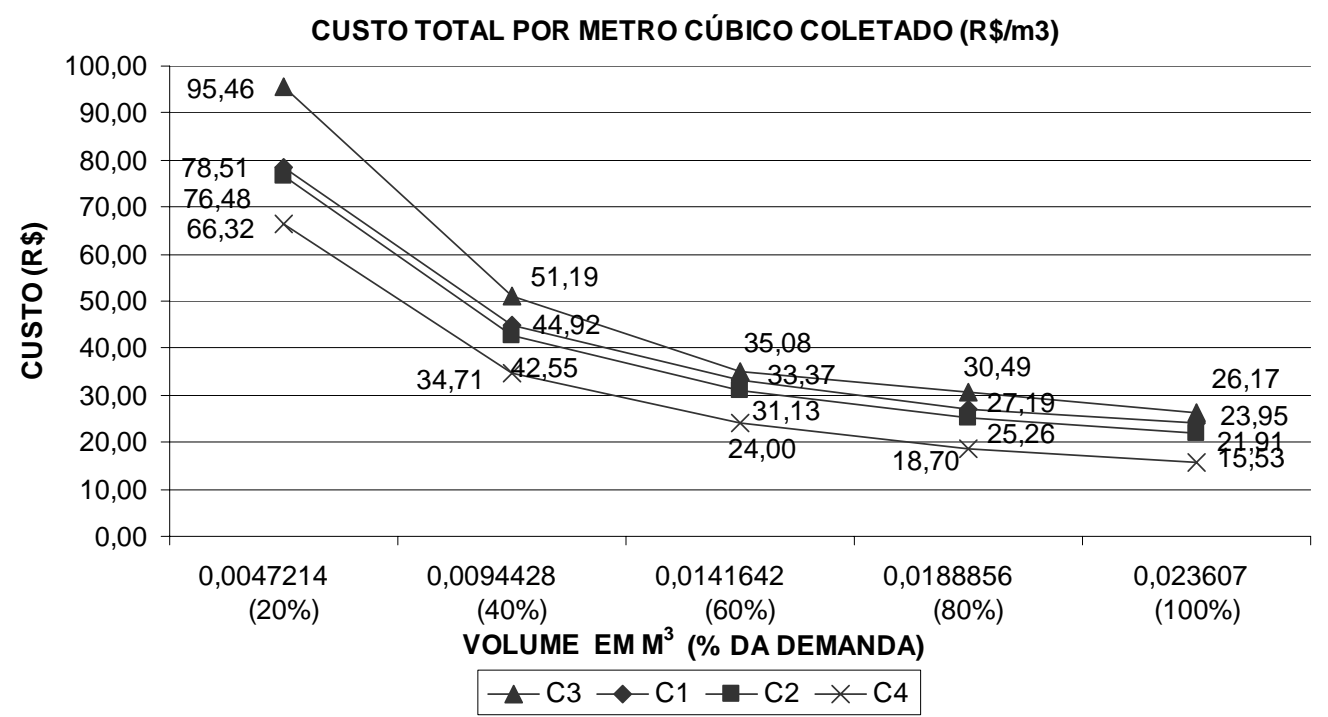

FIGURA 81. Custo por metro cúbico coletado para cada uma das configurações de contêineres

CUSTO POR RESIDÊNCIA ATENDIDA

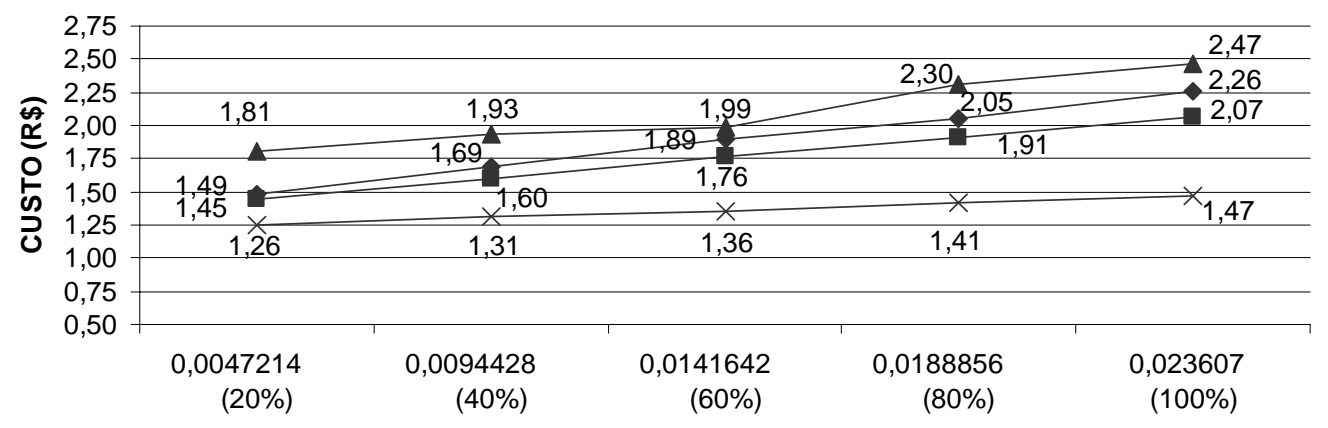

VOLUME EM M ${ }^{3}$ (\% DA DEMANDA)

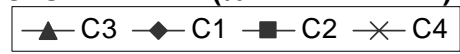

FIGURA 82. Custo por residência atendida pelo sistema para cada uma das configurações de contêineres 
Para cada configuração analisada ocorreram algumas variações nos custos. $\mathrm{Na}$ configuração $\mathrm{C} 1$, apesar da sua capacidade instalada ser a que mais se aproximou da demanda a ser coletada em todos os cenários, esta configuração não se mostrou muito econômica, principalmente porque os contêineres de pequenas dimensões, muito utilizados nesta configuração, apresentam altas relações custo/volume.

A configuração C2 mostrou um bom desempenho, usando apenas contêineres com boas relações custo/volume e de tamanhos distintos, apesar de ter a capacidade instalada bem acima da demanda a ser coletada, principalmente para os cenários de menor demanda. Se nesta configuração houvesse mais contêineres de diferentes tamanhos, oferecendo mais flexibilidade às combinações, o seu custo seria ainda menor.

A configuração C3 foi a que teve a maior capacidade instalada em relação à demanda dentre as 4 configurações. $O$ seu custo foi maior, principalmente pela alta relação custo/volume de seu contêiner de menor dimensão (750L), cuja capacidade é um pouco exagerada para os cenários de menor demanda.

A configuração C4, que era composta apenas por tambores de 200L, foi a de melhor desempenho devido à relação custo/volume. Essa configuração, apesar de apresentar bons resultados é hipotética, pois para alguns pontos (que são localizados em esquinas da cidade) seria necessário mais de 15 contêineres deste tipo. Além disso, este tipo de contêiner (tambor) é totalmente aberto, facilitando a ação de ladrões.

Pode-se notar que os valores do sistema por PEVs podem ser mais competitivos em relação aos outros sistemas estudados, conforme mostram a Tabela 26 e as Figuras 83, 8485 e 86, que comparam estas configurações com os outros sistemas, para os parâmetros de custo propostos inicialmente para a análise e mostrados no Capitulo 4. 
Tabela 26. Custos de todos os sistemas e de cada combinação de contêineres

\begin{tabular}{|c|c|c|c|c|c|}
\hline $\begin{array}{c}\text { Combinação } \\
\text { de } \\
\text { Contêineres }\end{array}$ & CENÁRIO & $\begin{array}{c}\text { CUSTO MENSAL } \\
\text { TOTAL }\end{array}$ & $\begin{array}{c}\text { CUSTO POR } \\
\text { QUILÔMETRO } \\
\text { (R\$/km) }\end{array}$ & $\begin{array}{l}\text { CUSTO POR } \\
\text { METRO CUBICO } \\
\text { COLETADO } \\
(\mathrm{R} \$ / \mathrm{m} 3)\end{array}$ & $\begin{array}{l}\text { CUSTO MENSAL } \\
\text { POR RESIDÊNCIA } \\
\text { ATENDIDA }\end{array}$ \\
\hline \multirow{5}{*}{ PEV - C1 } & PEV20 & $9.088,38$ & 41,31 & 78,51 & 1,49 \\
\hline & PEV40 & $10.356,05$ & 47,07 & 44,92 & 1,69 \\
\hline & PEV60 & $11.555,17$ & 52,52 & 33,37 & 1,89 \\
\hline & PEV80 & $12.561,57$ & 47,08 & 27,19 & 2,05 \\
\hline & PEV100 & $13.817,67$ & 45,04 & 23,95 & 2,26 \\
\hline \multirow{5}{*}{ PEV - C2 } & PEV20 & $8.853,13$ & 40,24 & 76,48 & 1,45 \\
\hline & PEV40 & $9.807,79$ & 44,58 & 42,55 & 1,60 \\
\hline & PEV60 & $10.780,30$ & 49,00 & 31,13 & 1,76 \\
\hline & PEV80 & $11.671,95$ & 43,75 & 25,26 & 1,91 \\
\hline & PEV100 & $12.642,79$ & 41,21 & 21,91 & 2,07 \\
\hline \multirow{5}{*}{ PEV - C3 } & PEV20 & $11.050,15$ & 50,23 & 95,46 & 1,81 \\
\hline & PEV40 & $11.799,24$ & 53,63 & 51,19 & 1,93 \\
\hline & PEV60 & $12.148,79$ & 55,22 & 35,08 & 1,99 \\
\hline & PEV80 & $14.088,56$ & 52,81 & 30,49 & 2,30 \\
\hline & PEV100 & $15.099,10$ & 49,21 & 26,17 & 2,47 \\
\hline \multirow{5}{*}{ PEV - C4 } & PEV20 & $7.677,24$ & 34,90 & 66,32 & 1,26 \\
\hline & PEV40 & $8.000,62$ & 36,37 & 34,71 & 1,31 \\
\hline & PEV60 & $8.310,89$ & 37,78 & 24,00 & 1,36 \\
\hline & PEV80 & $8.638,44$ & 32,38 & 18,70 & 1,41 \\
\hline & PEV100 & $8.958,16$ & 29,20 & 15,53 & 1,47 \\
\hline \multirow{5}{*}{$\begin{array}{l}\text { PORTA-A- } \\
\text { PORTA }\end{array}$} & POR20 & $8.481,38$ & 13,32 & 67,74 & 1,28 \\
\hline & POR40 & $8.481,38$ & 13,32 & 33,87 & 1,28 \\
\hline & POR60 & $8.481,38$ & 13,32 & 22,58 & 1,28 \\
\hline & POR80 & $8.503,42$ & 12,50 & 16,98 & 1,28 \\
\hline & POR100 & $8.513,79$ & 12,15 & 14,89 & 1,29 \\
\hline \multirow{5}{*}{ HÍBRIDO } & HIB20 & $12.459,55$ & 44,25 & 101,79 & 1,93 \\
\hline & HIB40 & $12.459,55$ & 44,25 & 50,98 & 1,93 \\
\hline & HIB60 & $12.459,55$ & 44,25 & 34,04 & 1,93 \\
\hline & HIB80 & $12.495,41$ & 35,50 & 25,63 & 1,93 \\
\hline & HIB100 & $12.517,61$ & 31,64 & 20,48 & 1,93 \\
\hline
\end{tabular}

CUSTO TOTAL MENSAL

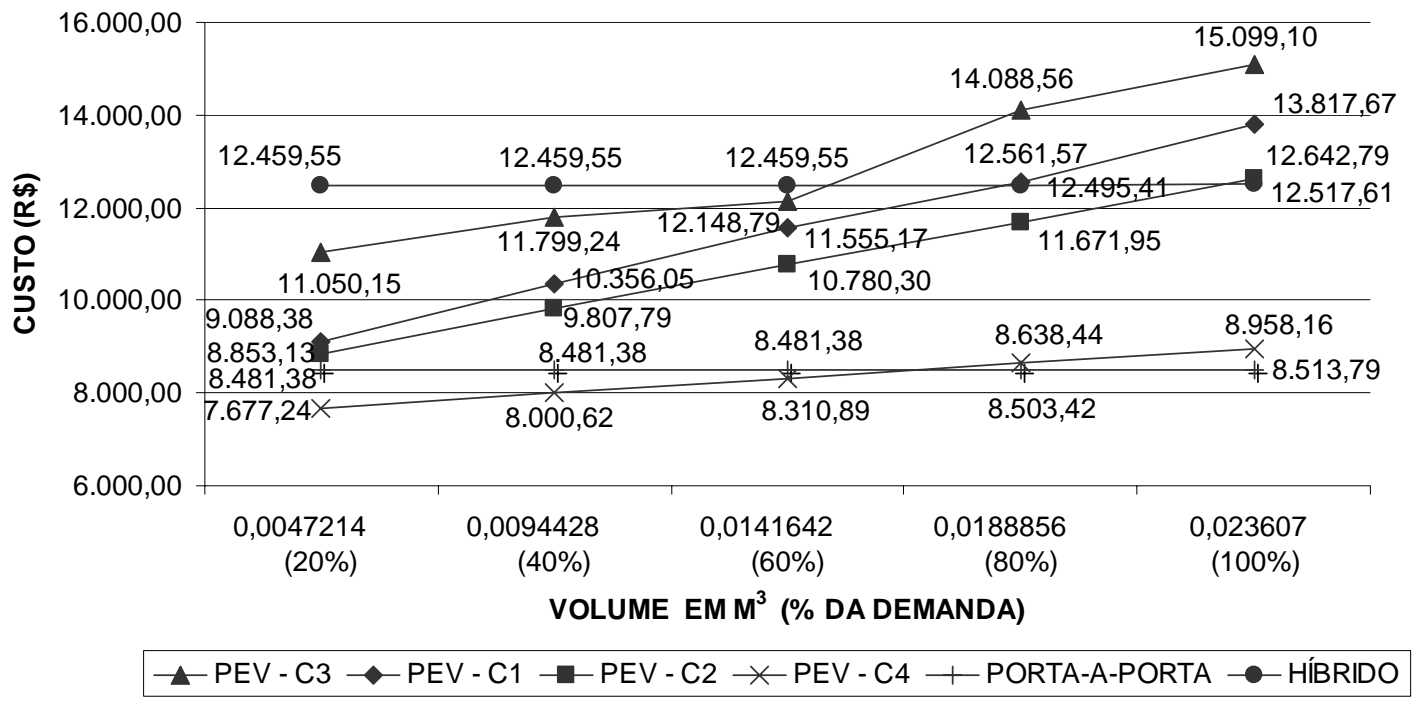

FIGURA 83. Custo total mensal de cada cenário dos 3 sistemas com as variações nas configurações dos contêineres do sistema PEV 


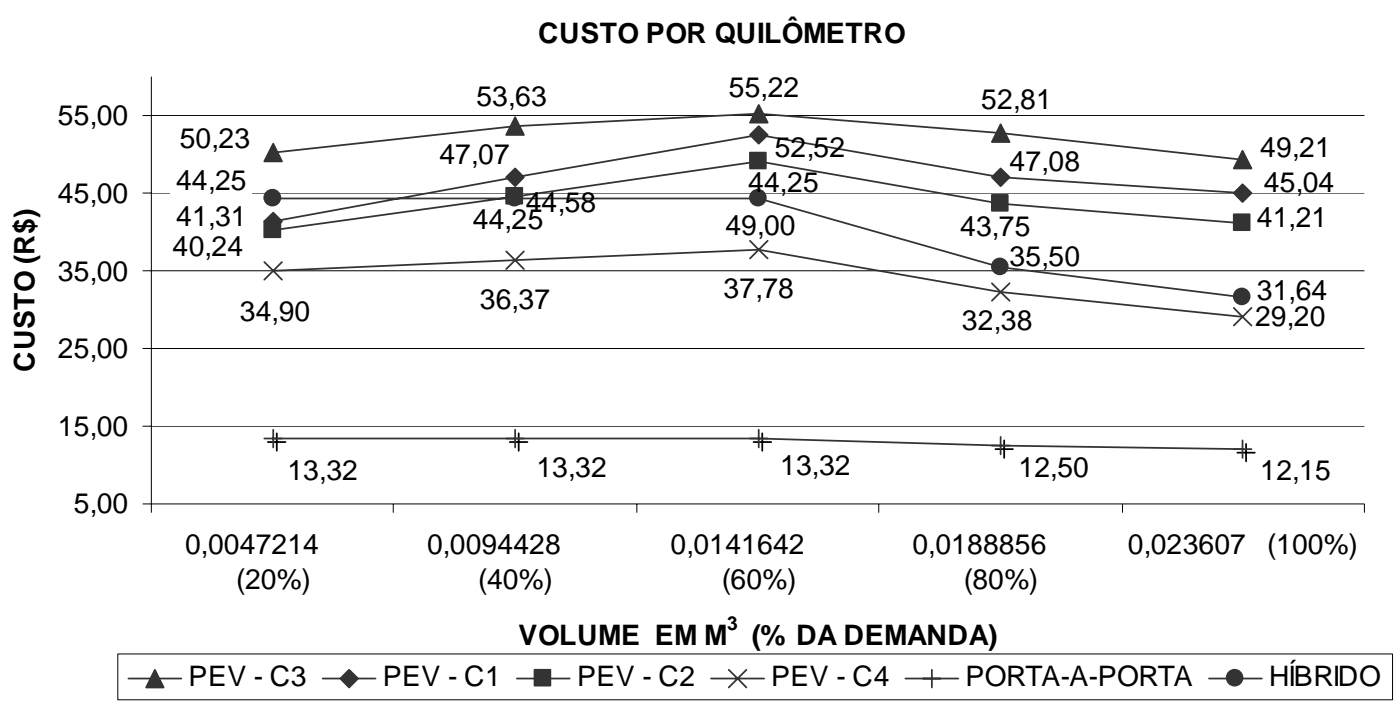

FIGURA 84. Custo por quilômetro de cada cenário dos 3 sistemas com as variações nas configurações dos contêineres do sistema PEV

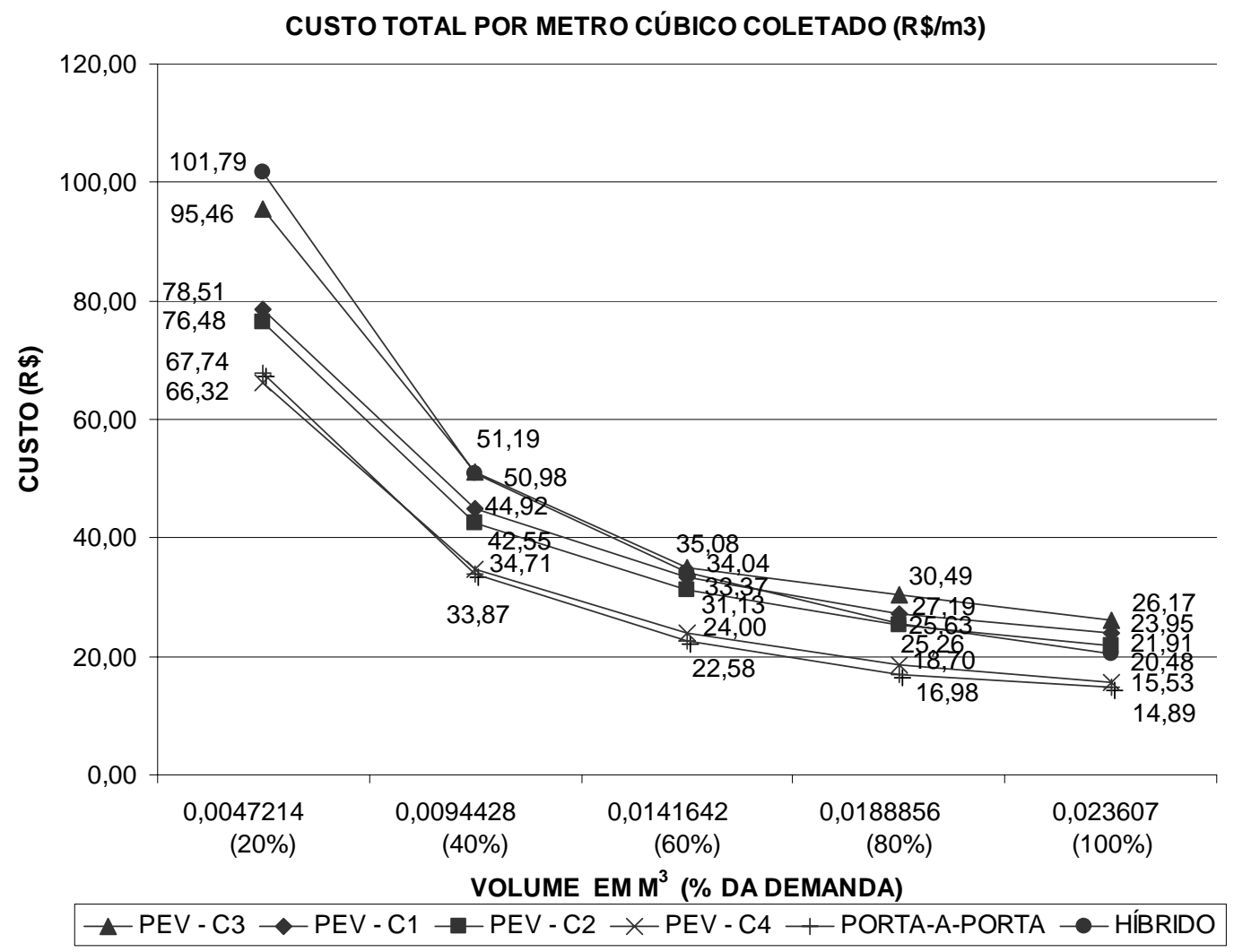

FIGURA 85. Custo por metro cúbico coletado de cada cenário dos 3 sistemas com as variações nas configurações dos contêineres do sistema PEV 


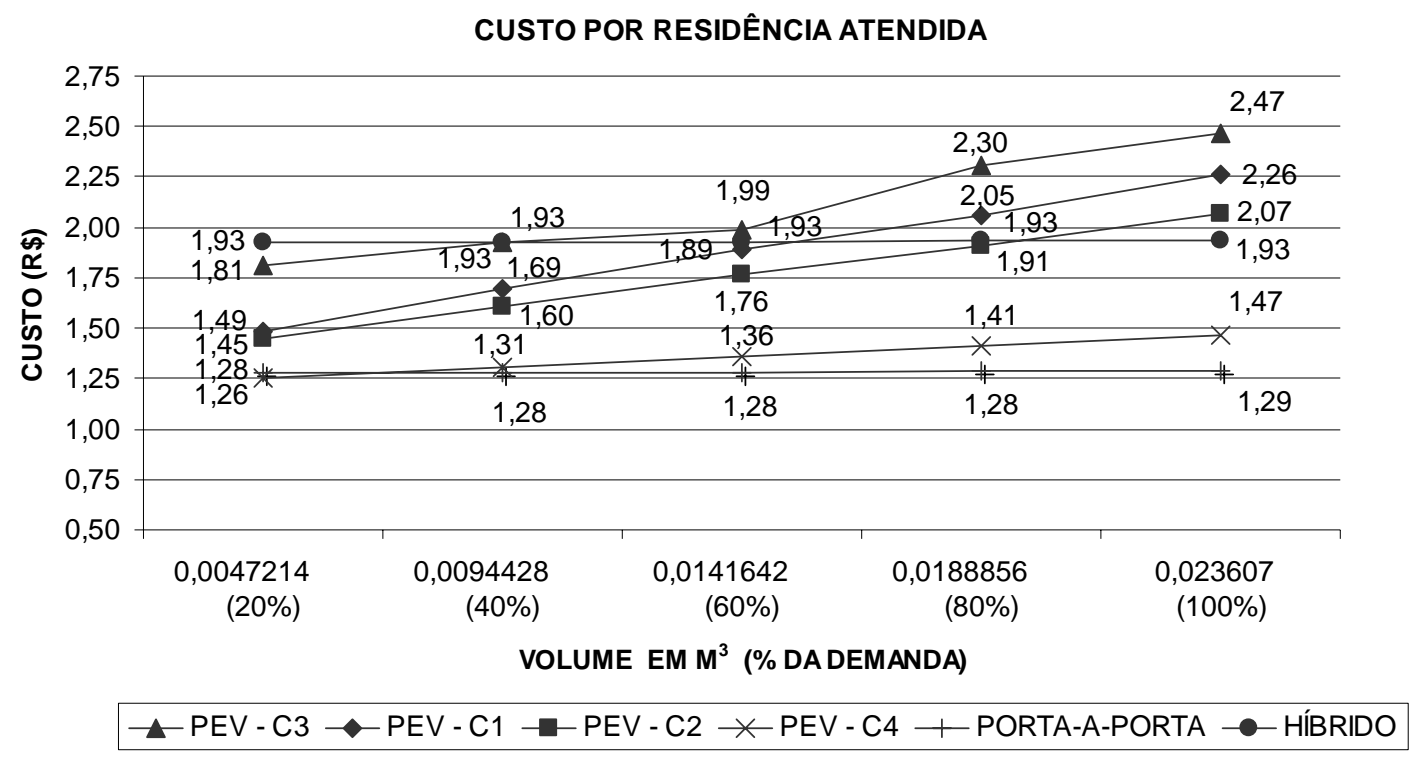

FIGURA 86. Custo por residência atendida de cada cenário dos 3 sistemas com as variações nas configurações dos contêineres do sistema PEV

Observa-se que o sistema PEV com a configuração de contêineres C4 mostrouse bastante competitivo, mesmo que os custos sejam determinados com os parâmetros de custo mais desfavoráveis a este tipo de sistema, conforme discutido na seção anterior.

A configuração C2 que é um pouco mais viável que a configuração C4, obteve um resultado satisfatório, com valores competitivos com o sistema Híbrido. Uma $5^{\text {a }}$ configuração, mesclando os tipos de contêineres apresentados nas configurações C4 e $\mathrm{C} 2$ poderia propiciar resultados bastante interessantes.

A aplicação de diferentes parâmetros para estas configurações também podem modificar o entendimento e a configuração do melhor sistema para a área em estudo. 


\section{CONCLUSÕES E RECOMENDAÇÕES}

Após a aplicação do método proposto conclui-se que o melhor método de coleta sempre estará intimamente ligado às características do local em que será implantado. De maneira geral, não se pode afirmar que exista um método de coleta que seja melhor do que qualquer outro.

Comparando os três sistemas, observou-se que para a área e para as condições apresentadas neste estudo, o sistema Porta-a-Porta é o mais eficaz.

Observa-se, porém, que cada sistema tem uma característica favorável que deve ser explorada quando se deseja determinar o sistema mais adequado para cada situação. O sistema Híbrido, por exemplo, tem a particularidade de envolver mais trabalhadores na operação de coleta, o que torna o "custo extra" deste contingente justificável em épocas de desemprego ou em situações em que se devam inserir no mercado de trabalho formal trabalhadores irregulares, como os catadores de lixo em lixões (como aconteceu no caso da coleta seletiva da cidade de São Carlos).

O sistema por PEVs pode ser o mais eficaz caso o custo da mão-de-obra seja mais elevado. Neste trabalho, este sistema teve algumas de suas complexidades exploradas, como a grande variação nos valores de seus custos com a simples modificação dos tipos de contêineres utilizados.

O sistema Porta-a-Porta, que tem seu ponto fraco na maior distância percorrida pelo veículo coletor, mostrou-se eficiente em uma cidade de pequeno porte, onde as distâncias entre o depósito e a área de coleta, assim como as distâncias percorridas pelo veículo na operação de coleta não são muito expressivas.

Ao início deste trabalho, as variáveis adotadas como medida de comparação dos sistemas foram: a distância percorrida e a quantidade de mão-de-obra e equipamentos utilizados por cada sistema. Nota-se que, para que esta análise fosse mais abrangente, a variável tempo de coleta poderia ser incluída, para que com isso fosse determinado o tempo ocioso do veículo e o tempo gasto em operações de carga e descarga. O principal motivo para esta variável não ter sido incluída neste trabalho foi a grande dificuldade 
para a correta mensuração desta nos sistemas de coleta estudados, que em sua maioria ainda estão em fases de implantação, com padrões de operação ainda sendo definidos.

Surge aí uma recomendação para o aprimoramento deste trabalho: uma criteriosa mensuração do tempo de operação de cada fase destes sistemas e a inclusão da variável tempo nas rotinas de roteirização. Opções como modificações na jornada de trabalho, hora extra incluída nos salários e métodos mais eficientes de carga e descarga do veículo coletor poderiam ser exploradas.

Outro aspecto não explorado por este trabalho foi a variação na capacidade do veículo coletor, onde o agrupamento das áreas de coleta seria determinado pela demanda a ser coletada e pela capacidade do veículo.

Com relação aos custos de implantação de cada sistema, que é uma variável capaz de definir o tipo de coleta a ser implantado, o sistema mais dispendioso foi o sistema por PEVs, devido ao custo de aquisição dos contêineres, que aumentam proporcionalmente com o aumento da demanda. Para demandas mais elevadas, os sistemas Híbrido e Porta-a-Porta possuem custos de implantação mais enxutos. Note-se que esta análise não levou em conta os custos de implantação de centrais de triagem e sua manutenção.

Para uma análise mais profunda sobre os tipos de centrais de triagem mais adequados, uma discussão sobre a maneira de coletar o resíduo reciclável (separado ou todo junto) deve ser aprofundada, incluindo veículos diferenciados, assim como os contêineres apropriados.

E, finalmente, estender esta análise para outros tipos de resíduos gerados no meio urbano como resíduos de demolição e construção e resíduos facilmente degradáveis.

Além dos custos de transporte apresentados neste trabalho, existem outros custos que são difíceis de quantificar, mas que, sem dúvida devem ser incluídos em análises mais abrangentes sobre a implantação completa de um sistema de coleta seletiva. São eles: 
- Custos educacionais para a promoção do sistema, como campanhas educativas pelas várias mídias, que devem ter sua abragência definida por questões culturais, e socioeconômicas da população a ser atendida;

- Custos ambientais, tanto aqueles relacionados com a poluição efetivamente gerada pela implantação deste sistema (poluição do ar por gases produzidos pelos veículos, poluição gerada pelos panfletos educativos), assim como as economias ambientais geradas por essa iniciativa;

- Custos economizados com o aumento de vida útil dos aterros.

A ferramenta SIG mostrou sua eficiência nesse tipo de análise, onde dados espaciais são parte fundamental do problema. Teve êxito no auxilio à delimitação do problema e resolução de suas variáveis, seja em problemas de localização de instalações, agrupamento de regiões e roteamento de veículos.

Porém, a aplicação deste método em um caso real deve ser realizada com muito critério, pois a adoção de alguns parâmetros pode modificar completamente o resultado final. É importante que a qualidade da informação seja sempre verificada.

E, finalmente, a hipótese proposta neste trabalho, de que o método proposto seria capaz de comparar diferentes sistemas de coleta seletiva de resíduos sólidos domésticos é válida, com a obtenção de resultados efetivos que claramente conduzem a análise a uma decisão.

Fica, portanto, como recomendação para trabalhos futuros, a inserção de parâmetros ambientais, que contemplem não somente o processo de coleta em si, mas o ciclo de vida dos materiais a serem reciclados, para que se consiga responder à seguinte pergunta: a coleta seletiva deve ser encorajada como solução ambiental ou apenas contextualizada como um processo para preencher a lacuna de um problema muito maior que engloba os padrões atuais de consumo e de produção de bens? 


\section{REFERÊNCIAS BIBLIOGRÁFICAS}

AGENDA21 (1992). Agenda 21, disponível em: <http://www.mma.gov.br/ port/se/agen21>, acesso em 28/05/2004.

AGUIAR, E. M. (1993). Racionalização da operação de sistemas de coleta e transporte de resíduos sólidos domiciliares para cidades de pequeno e médio porte. São Paulo. 91p. Tese (Doutorado). Universidade de São Paulo.

ASSOCIAÇÃO BRASILEIRA DE NORMAS TÉCNICAS - ABNT (1985). NBR 8849. Apresentação de projetos de Aterros Controlados.

------, (1990). NBR 11175. Incineração de resíduos sólidos perigosos.

------, (1992). NBR 8419. Apresentação de projetos de Aterros Sanitários.

------, (1993). NBR 12980. Coleta, varrição e acondicionamento de resíduos sólidos urbanos - Terminologia.

------, (1996). NBR 13591. Compostagem.

------, (2004a). NBR 10004. Resíduos sólidos - Classificação.

------, (2004b). NBR 10005. Procedimento para a obtenção de extrato lixiviado de resíduos sólidos.

------, (2004c). NBR 10006. Procedimentos para a obtenção de extrato solubilizado de resíduos sólidos.

------, (2004d). NBR 10007. Amostragem de resíduos sólidos.

ASSOCIAÇÃO NACIONAL DO TRANSPORTE DE CARGAS - NTC (2001). Manual de Cálculo de Custos e Formação de Preços do Transporte Rodoviário de Cargas. 61p. São Paulo-SP.

BELTON, V., CROWE, D.V., MATTHEWS, R., SCOTT, S., (1994). A survey of public attitudes to recycling in Glasgow (U.K.). Waste Management and Research. v. 12, p.351-667. 
BRASIL - Política nacional de resíduos sólidos, (2004). Disponível em $<$ http://www.lixo.com.br/substilucianozica.doc>, acesso em 25/05/2004.

BRASILEIRO, L. A. (2004). Análise do roteamento de veículos na coleta de resíduos domésticos, comerciais e de serviços de saúde. Ilha Solteira. 94p. Tese (LivreDocência) - Faculdade de Engenharia de Ilha Solteira, Universidade Estadual Paulista.

BUTLER, J., HOOPER, P., (2000). Factors determining the post-consumer waste recycling burden. Journal of Environmental Planning and Management, v. 43, n 3, p.407-432.

CALIPER, (1996). TransCAD: transportation GIS software. Routing and Logistics with TransCAD. Caliper Corporation, Version 3.0 for use with Microsoft Windows.

CAMPOS, R. de (1994). Proposta de sistematização e reavaliação do processo de gerenciamento de serviços de coleta seletiva de resíduos sólidos domiciliares. São Carlos. 104p. Dissertação (Mestrado). Escola de Engenharia de São Carlos, Universidade de São Paulo.

CEMPRE - Compromisso Empresarial para a Reciclagem (2004). Pesquisa Ciclosoft 2004. Disponível em: <http://www.cempre.org.br>, acesso em 28/07/2004.

CIWMB (2002). Curbside recycling, the next generation: a model for local government recycling and waste reduction. California Integrated Waste Management Board. Disponível em: <http://www.ciwmb.ca.gov/LGLibrary/Innovations/Curbside/>, acesso em 16/06/2005.

CLARK,G., WRIGHT, J. (1964). Scheduling of Vehicles from a Central Depot to a Number of Delivery Points. Operations Research, v. 12, p.568-861.

CUNHA, L. C. (1995). A importância da coleta seletiva e sua implantação na UFSCAR. Trabalho de graduação.

CUNHA, V., CAIXETA FILHO, J. V. (2002) Gerenciamento da coleta de resíduos sólidos urbanos: estruturação e aplicação de modelo não-linear de programação por metas. Gestão \& Produção, v.9, n.2, p.143-161. 
DELUQUI, K. K. (1998); Roteirização para veículos de coleta de resíduos sólidos domiciliares utilizando um Sistema de Informação Geográfica - SIG. São Carlos. 222p. Dissertação (Mestrado) - Escola de Engenharia de São Carlos, Universidade de São Paulo.

ECONOMIA \& TRANSPORTE (2005). Planilhas de Custos. Disponível em: $<$ Www.economiaetransporte.com.br>, acesso em: 14/03/ 2005.

EISELT, H. A., GENDEAU, M.,LAPORTE, G. (1995). Arc Routing Problems, Part I: The Chinese Postman Problem. Operations Research, v.43, n.2, p. 231-242.

EIGENHEER, E. M. (1999) Coleta Seletiva no Brasil. In: Eigenheer, E. M.: Coleta Seletiva de Lixo, Rio de Janeiro, p.42-47.

GALVÃO, R. D., BARROS, J. F. N., FERREIRA, V. J. M. F. F., HENRIQUES, H. B. S. (1997). Roteamento de veículos com base em sistemas de informação geográfica. Gestão e Produção, v.4, n.2, p. 159-173.

GOMES, L. P. e POVINELLI, J., (1991). Caracterização Física dos Resíduos Sólidos Urbanos da Cidade de São Carlos-Sp. Estudos tecnológicos, engenharia 9 e 10, v. 14, p.91-106.

GOULART, A. (2003). Comparison of deep collection system with traditional systems. Tampere - Finlândia. 112 p. Dissertação (Msc). Tampere. University of Technology. Disponível em: $\quad<$ http://www.tut.fi/units/ymp/bio/reports/Comparison_of_Deep CollectionSystem_with_TraditionalSystems.pdf>, acesso em 20/10/2005.

INSTITUTO BRASILEIRO DE GEOGRAFIA E ESTATÍSTICA - IBGE, (2000a). Pesquisa Nacional de Saneamento Básico. Disponível em: <http://www.ibge.gov.br>, acesso em 16/07/2004.

------, (2000b). Censo Demográfico 2000, Cidades@. Disponível em: <www.ibge.gov.br>, acesso em: 13/02/2005.

JUNKES, M. B. (2002). Procedimentos para aproveitamento de resíduos sólidos urbanos em municípios de pequeno porte. Dissertação (Mestrado) - Florianópolis-SC. 116p. Disponível em: <teses.eps.ufsc.br/defesa/pdf/9349.pdf>, acesso em 16/06/05. 
LEITE, W. C. A. (1997). Estudo da gestão de resíduos sólidos: uma proposta de modelo tomando a unidade de gerenciamento de recursos hídricos (UGRHI - 5) como referência. São Carlos. 270p. Tese (Doutorado) - Escola de Engenharia de São Carlos, Universidade de São Paulo.

LIMA, R. S. (2003). Bases para uma metodologia de apoio à decisão para serviços de educação e saúde sob a ótica dos transportes. São Carlos. 200p. Tese (Doutorado). Escola de Engenharia de São Carlos, Universidade de São Paulo.

MACHADO, G. E. (1995). Estudo comparativo de custos da coleta seletiva e regular de resíduos sólidos urbanos no bairro balneário do município de Florianópolis, SC. Florianópolis-SC. 130p. Dissertação (Mestrado). Universidade Federal de Santa Catarina.

MANCINI, P. J. P. (1999) Uma avaliação do sistema de coleta informal de resíduos sólidos recicláveis no município de São Carlos-SP. São Carlos. 150p. Dissertação (Mestrado). Escola de Engenharia de São Carlos, Universidade de São Paulo.

NARUO, M. K. (2003). O Estudo do Consórcio entre Municípios de Pequeno Porte para Disposição Final de Resíduos Sólidos Urbanos Utilizando Sistema de Informações Geográficas. São Carlos. 286p. Dissertação (Mestrado) - Escola de Engenharia de São Carlos, Universidade de São Paulo.

NOVAES, A. G. (1989). Sistemas Logísticos: transporte, armazenagem e distribuição física de produtos. São Paulo. Edgard Blücher.

OLIVEIRA, L. B., REIS, L. E., (2002). Custos externos da coleta de resíduos sólidos urbanos. In: Congresso Brasileiro de Energia, 9., 2002, Rio de Janeiro. Anais do IX Congresso Brasileiro de Energia. Rio de Janeiro: COPPE, 2002. v. 1. p. 144-151.

RESOL - Gerenciamento integrado do lixo (2004a). Disponível em: $<$ www.resol.com.br>, acesso em: 31/06/2004.

RESOL - Legislação brasileira sobre resíduos sólidos, (2004b). Disponível em: <www.resol.com.br>, acesso em: 25/05/2004. 
RIBEIRO, T. F., LIMA, S. C. (2000). Coleta seletiva de lixo domiciliar - estudo de casos. Caminhos de Geografia - Revista On Line, Programa de Pós-Graduação Em Geografia, n.1, v. 2. p. 50-69.

SALTORATO, P. (1998); O roteamento de veículos: uma avaliação sobre sua introdução na coleta de resíduos sólidos urbanos. São Carlos. 111p. Dissertação (Mestrado) - Escola de Engenharia de São Carlos, Universidade de São Paulo.

SANTOS, C. M. dos (1999); Viabilização de softwares comerciais na roteirização de veículos de serviços de entregas, visando a geração de respostas rápidas e eficientes. São Carlos. Tese (Mestrado). 139p. Escola de Engenharia de São Carlos, Universidade de São Paulo.

SARKIS, L. F. P. G. (2000). Resíduos de serviços de saúde em cidades de médio porte: caracterização de sistemas de coleta e aplicação de um Sistema de Informação Geográfica na roteirização de veículos de coleta e transporte. São Carlos. 215p. Dissertação (Mestrado) - Escola de Engenharia de São Carlos, Universidade de São Paulo.

SCHALCH, V; LEITE, W. C. A., FERNANDES JR, J.L., CASTRO, M.C.A.A. (2001). Apostila do curso de "Gerenciamento de Resíduos Sólidos" do Programa de Pósgraduação em Hidráulica e Saneamento: agosto-dez. 2001 (Apostila). 169p. Escola de Engenharia de São Carlos, Universidade de São Paulo.

SILVA, A. N. R. ; MELO, J. J. O. ; BRONDINO, N. C. M. (1997). Apostila: Uma introdução ao planejamento de transportes com Sistemas de Informação Geográfica. São Carlos. 74p. Escola de Engenharia de São Carlos - Universidade de São Paulo.

SINDICATO DAS EMPRESAS DE LIMPEZA URBANA NO ESTADO DE SÃO PAULO - SELUR (2001). Estudo das Planilhas de Custo dos Serviços de Limpeza Pública. São Paulo. Elaboração: FGV - USP.

TANSKANEN, J. H. (2000). Strategic planning of municipal solid waste management. Resources, Conservation and Recycling. v.30, p. 111-133. 
TANSKANEN, J. H., KAILA, J. (2001). Comparision of methods used in the collection of source-separated household waste. Waste Management and Research. v.19, p 486 497.

TCHOBANOGLOUS, G. (1977). Solid wastes: engineering principles and management Issues. Tokyo: McGraw-Hill.

TEIXEIRA, B. A. N., ZANIN, M. (1995). A implantação da coleta seletiva de resíduos sólidos na universidade federal de São Carlos-SP: aspectos relevantes do projeto e avaliação preliminar. In: $18^{\circ}$ Congresso Brasileiro de Engenharia Ambiental.

THIEMERMAM, F (2004). Coordenadora do programa de coleta seletiva da cidade de São Carlos, Comunicação Pessoal, São Carlos.

TORRES, P. L. G, DI'AZA, B. A., TORRES, A, R.(2003). Some comparative factors regarding recycling collection systems in regions of the USA and Europe. Journal of Environmental Management, v. 69, p.129-138.

VALEO, C., BAETZ, B. W., TSANIS, I. K. (1998). Location of recylcing depots with GIS. Journal of Urban Planning and Development. v 124, n. 2.p. 93 - 99.

YELLOW (1970). A Computational Modification to the Savings Method of Vehicle Sheduling. Operations Research Quaterlly, n.21, p.281-283.

ZANIN, M., LOGAREZZI, A., TEIXEIRA, B., NORDI, N. (2002). Relatório da fase 1. A gestão da cadeia da reciclagem dos resíduos sólidos urbanos domiciliares: contribuição para formulação de Políticas Públicas. Universidade Federal de São Carlos/3R Núcleo de reciclagem de resíduos. Processo FAPESP no 00/13727-6. 
APÊNDICE A

Descrição passo-a-passo da preparação da base de dados e execução das rotinas de transportes no software TransCAD, versão 3.6 


\section{PREPARAÇÃO DA BASE DE DADOS:}

1. Abrir em um mapa o arquivos correspondente às ruas da área de estudo (arquivo de linhas e nós) e aos endereços das residências da área de estudo (arquivo de nós).

2. Selecionar no novo mapa os links da área de estudo (seleção AREA DE ESTUDO) e exportar esta seleção como uma camada geográfica (com o comando EXPORT).

3. Fazer uma seleção por localização dos nós (esquinas) da área escolhida partir do comando SELECT BY LOCATION (within $0.001 \mathrm{~km}$ ) e criar a seleção ESQUINAS.

4. Na camada (layer) dos endereços, fazer a seleção de residências atendidas pela área escolhida a partir do comando SELECT BY LOCATION (within $0.03 \mathrm{~km}$ ) e criar a seleção RESIDÊNCIAS.

5. Fazer a conexão dos nós de residências aos links mais próximos a partir da ferramenta CONNECT, preenchida a opção nearest link.

6. Refazer a seleção da área, a partir do comando SELECT BY LOCATION (within $0.001 \mathrm{~km}$ ) relacionando-a com a camada da seleção exportada AREA DE ESTUDO.

7. Fazer a seleção dos nós adicionados ao sistema de linhas pelo comando CONNECT (nós de ligação das residências às ruas) a partir do comando SELECT BY LOCATION (within $0.001 \mathrm{~km}$ ) e criar a seleção RESIDENCIAS+ESQUINAS.

8. Exportar a seleção RESIDENCIAS+ESQUINAS (com o comando EXPORT) com o nome de PARADAS e abri-la neste mapa como uma nova camada.

9. Para determinar as residências atendidas por cada ponto de ligação residência-rua, primeiramente executa-se a rotina COST MATRIX preenchendo straight lines, minimizando a distância, com o campo depots sendo os pontos que podem servir às residências (PEVs ou pontos das ruas em que o veículo coletor passará ou pontos a serem agrupados pela demanda), e o campo stops os pontos que indicam as residências. Esta matriz só será usada para a determinação do número de residências atendidas por cada ponto.

10. Para alocar as residências a esses pontos, utiliza-se a rotina TRANSPORTATION PROBLEM, com o campo source sendo os pontos que servirão as residências e o campo sinks os pontos que indicam as residências. O campo quantity é preenchido 
pela demanda, que deve obrigatoriamente ser igual a 1 para os pontos que indicam as residências, e um número suficientemente grande para os pontos que servirão as residências. Este procedimento fornece um arquivo tipo DBF com os sources (fornecedores), os sinks (clientes) alocados a cada source e o fluxo entre eles (neste caso sempre igual a 1). Este arquivo deve ser exportado como um dataview que depois será juntado com o dataview de pontos do mapa (join pelos IDs dos pontos e sources) e preenche-se o campo RESID_ATEND_PEV com a os valores do campo flow acumulado por cada source. Fazer isto para os sistemas Porta-a-Porta (RESID_ATEND_POR) e Híbrido (RESID_ATEND_HIB).

11. Fazer este procedimento para o sistema PEV, usando como source os pontos selecionados como PEVs, para o sistema Híbrido usando como source os pontos representando as esquinas e para o sistema Porta-a-Porta os pontos representando as esquinas e as residências na rua.

12. Criar a seleção DEPOT na camada PARADAS e na camada de nós da camada de ruas selecionar o ponto a ser usado como depósito.

13. Na tabela de dados (dataview) a camada de ruas da área de estudo (camada de links) adicionar os campos: VELOCIDADE (KM/H), TEMPO(MIM) (dado pela fórmula (LENGTH/ VELOCIDADE)*60, inserido com o comando FILL), SERVICE_AB, SERVICE_BA RESID_ATEND_LINK e DEMANDA_LINK.

14. Na camada PARADAS (camada de pontos exportada), adicionar os campos: DEMANDA_PEV, DEMANDA_POR, DEMANDA_HIB, FIXED TIME, TIME PER UNIT, OPEN TIME, CLOSE TIME.

15. Preencher os campos DEMANDA_PEV, DEMANDA_POR e DEMANDA_HIB com o comando FILL formula e a fórmula com o campo de residências atendidas pelo ponto (RESID_ATEND_PEV, RESID_ATEND_POR ou RESID_ATEND_HIB) multiplicado pela demanda de cada residência.

16. Criar a rede de transporte (comando CREATE NETWORK), que deve incluir todos os nós da camada de ruas da área em estudo. Na criação da rede, devem ser habilitados os seguintes campos da camada de links: TIME(MIM), SERVICE_AB, SERVICE_BA, DEMANDA_LINK e LENGTH.

17. Criar a tabela de veículos VEH_TAB como um arquivo DBase file com os campos: DEPOT_ID, COST, TYPE, CAPACITY e NUM_VEHS. 


\section{ROTEIRIZAÇÃO DO SISTEMA DE PEVS:}

1. Criar a matriz de custos (comando COST MATRIX) a partir das distâncias em rede, minimizando a distância, e escolhendo em depot settings a camada de nós (da camada PARADAS) e a seleção RESIDENCIAS+ESQUINAS. Em stop settings escolher a camada de nós (da camada PARADAS) e a seleção RESIDENCIAS+ESQUINAS.

2. Para se localizar os PEVs de maneira que fiquem a pelo menos $250 \mathrm{~m}$ dos pontos que representam as residências nas ruas (seleção RESIDENCIAS) utiliza-se o comando FACILITY LOCATION, com a opção as many as needed, e minimize highest cost $\leq 0,250 \mathrm{~km}$. Os depots sendo a camada de nós (da camada PARADAS) e a seleção ESQUINAS e os stops sendo a camada de nós (da camada PARADAS) e a seleção RESIDENCIAS+ESQUINAS. Esse comando fornecerá a seleção New Facilities, que será renomeada para PEVs.

3. Para ter certeza que todas as residências serão atendidas pela condição acima, na camada RESIDENCIAS, cria-se a seleção RESIDENCIAS ATENDIDAS, e com o comando SELECT BY LOCATION, baseado na seleção PEVs da camada PARADAS (com o critério de seleção within $0,250 \mathrm{~km}$ ), tem se a visualização das residências não atendidas pela condição. Depois, adiciona-se novos pontos na seleção de PEVs para que todas as residências sejam atendidas pela condição préestabelecida.

4. Abrir a tabela de veículos (VEH_TAB).

5. Para a divisão da área escolhida em 5 áreas menores, representando os 5 dias úteis da semana, utiliza-se o comando CLUSTERING:

5.1. Abrir a matriz de custos.

5.2. No comando CLUSTERING, escolher em features to cluster a camada de nós (camada PARADAS) e a seleção PEVs, fixar o número de clusters iguais a 5, e definir a capacidade de cada cluster como o um quinto do número de residências. Para feature size selecionar campo RESID_ATEND_PEV da camada de nós. 
5.3. Desfazer a joined view formada pelo procedimento e formar a joined view (com os parâmetros from PARADAS,ID to Clusters, ID1). Nessa tabela criar seleções para cada dia da semana (cinco seleções) com o comando SELECT BY CONDITION usando a fórmula: seed $=I D$ da semente para cada um dos IDs das sementes;

6. Utilizar a rotina VEHICLE ROUTING:

6.1. Criar uma matriz de roteirização (comando ROUTING MATRIX) para cada uma das áreas escolhidas: minimizando a distância, e escolhendo em depot settings a camada de nós (da camada de links) e em stop settings a camada de nós (da camada de links).

6.2. Executar a rotina utilizando na aba stops o layer de PARADAS e a seleção da área escolhida e na aba depot o layer de PARADAS e a seleção DEPOT.

\section{ROTEIRIZAÇÃO PORTA A PORTA}

1. Criar a matriz de custos (comando COST MATRIX) a partir das distâncias em rede, minimizando a distância, e escolhendo em depot settings a camada de nós (da camada PARADAS) e a seleção RESIDENCIAS+ESQUINAS. Em stop settings escolher a camada de nós (da camada PARADAS) e a seleção RESIDENCIAS+ESQUINAS.

2. Para a divisão da área escolhida em 5 áreas menores, representando os 5 dias úteis da semana, utiliza-se com o comando CLUSTERING:

2.1. Abrir a matriz de custos.

2.2. No comando CLUSTERING, escolher em features to cluster a camada de nós (camada PARADAS) e a seleção RESIDENCIAS+ESQUINAS, fixar o número de clusters iguais a 5, e definir a capacidade de cada cluster como o um quinto do número de residências. Para feature size selecionar o campo RESID_ATEND_POR da camada de nós.

2.3. Desfazer a joined view formada pelo procedimento e formar a joined view (com os parâmetros from PARADAS, ID to Clusters, ID1). Nessa tabela criar seleções para cada dia da semana (cinco seleções) com o comando SELECT BY 
CONDITION usando a fórmula: seed $=I D$ da semente para cada um dos IDs das sementes;

2.4. Utilizando as seleções criadas na camada PARADAS fazer as seleções na camada de links com o comando SELECT BY LOCATION (within $0.2 \mathrm{~km}$ ) criando as seleções AREA $\mathrm{X}$ e depois utilizar o comando COMBINE SELECTION com a opção both entre as seleções AREA de ESTUDO e AREA X para que apenas os links da seleção AREA DE ESTUDO sejam selecionados.

3. Na camada de ruas (da camada exportada AREA DE ESTUDO), criar o campo RESID_ATEND_LINK e preenchê-lo com o comando FILL agregate, com o tamanho da banda de $0,001 \mathrm{~km}$, preenchido com o total do campo RESID_ATEND_POR da camada de PARADAS.

4. Preencher o campo DEMANDA_LINK com o comando FILL formula, com o campo de residências atendidas pelo link (RESID_ATEND_LINK) multiplicado pela demanda de cada residência.

5. Na tabela de dados (dataview) da camada de ruas, preencher para cada seleção os campos: SERVICE_BA com a fórmula que preenche apenas as linhas onde existe demanda nesta direção, que é a direção contra o sentido topológico do link: com o comando FILL formula, ((Dir=-1)*(DEMANDA_LINK/DEMANDA_LINK))*X, onde $\mathrm{X}$ é o número da área $\mathrm{X}$. Para o campo SERVICE_AB preenchê-lo com a fórmula que preenche apenas as linhas onde existe demanda nesta direção, que é a direção a favor do sentido topológico e nas demais linhas (links não direcionados); com o comando: FILL formula, $\left((\operatorname{Dir}>=0) *\left(D E M A N D A \_L I N K / D E M A N D A \_L I N K\right)\right) * X$, onde $\mathrm{X}$ é o número da área $\mathrm{X}$.

6. Atualizar a rede de transportes em NETWORK - settings - update, habilitando links (enable links), e atualizando os custos de todos os campos da camada de ruas.

7. Utilizar a rotina ARC ROUTING para cada área:

7.1. Para o depot escolher a camada de nós da camada de ruas e a seleção DEPOT. Em Network settings, escolher minimizar a distância (minimize length), o campo SERVICE_* para service flag e para o service code escolher o número da área $(\mathrm{X})$. 
7.2. Na opção Skims (resumir dados de campos) escolher os campos: length e a opção all links para se obter a distância percorrida pelos veículos e o campo DEMANDA_LINK com a opção Service and Deadhead Links Separated para se obter a demanda coletada nos links servidos.

7.3. Para dividir as rotas segundo a demanda, deve-se acionar SHIFTs e dividi-las segundo o maximum workload, que deve ser igual ao número correspondente à capacidade do veículo coletor. E o service load deve ser preenchido com o campo DEMANDA_LINK da camada de ruas do mapa.

\section{ROTEIRIZAÇÃO DO SISTEMA HÍBRIDO}

1. Criar a matriz de custos (comando COST MATRIX) a partir das distâncias em rede, minimizando a distância, e escolhendo em depot settings a camada de nós (da camada PARADAS) e a seleção RESIDENCIAS+ESQUINAS. Em stop settings a camada de nós (da camada PARADAS) e a seleção RESIDENCIAS+ESQUINAS.

2. Para a divisão da área escolhida em 5 áreas menores, representando os 5 dias úteis da semana, utiliza-se com o comando CLUSTERING:

2.1. Abrir a matriz de custos.

2.2. No comando CLUSTERING, escolher em features to cluster a camada de nós (camada PARADAS) e a seleção ESQUINAS, fixar o número de clusters iguais a 5, e definir a capacidade de cada cluster como o um quinto do número de residências. Para feature size selecionar campo RESID_ATEND_HIB da camada de nós.

2.3. Desfazer a joined view formada pelo procedimento e formar a joined view (com os parâmetros from PARADAS,ID to Clusters, ID1). Nessa tabela criar seleções para cada dia da semana (cinco seleções) com o comando SELECT BY CONDITION usando a fórmula: seed $=I D$ da semente para cada um dos IDs das sementes;

3. Localizar os pontos fíctícios de parada (pontos que o veículo deve passar obrigatoriamente fazendo com que a área de influência de sua rota cubra toda a área de coleta): 
3.1. Criar a matriz de custo (comando COST MATRIX ) para cada área, partir das distâncias em rede, minimizando a distância, e escolhendo em depot settings a camada PARADAS e a seleção NOS AREA X. Em stop settings escolher a camada PARADAS e a seleção NOS AREA X.

3.2. Para localizar os pontos de parada de maneira que fiquem a pelo menos $400 \mathrm{~m}$ dos pontos que representam as paradas do veículo nas ruas (seleção ESQUINAS) utiliza-se o comando FACILITY LOCATION, com o máximo custo de serviço (representado pela distância) igual a $400 \mathrm{~m}$. Para isso escolhese a opção minimize highest cost $\leq 0,4 \mathrm{~km}$ com o depots sendo a camada PARADAS e a seleção de NOS AREA X e os stops sendo a camada PARADAS e a seleção RESIDENCIAS+ESQUINAS. Caso o número de pontos obtidos (New Facilities) seja igual ao número de esquinas da área, impõe-se que o número máximo de paradas seja igual à metade do número de esquinas da área. Com a obtenção da seleção New Facilities esta será renomeada para PARADAS (AREA) X.

4. Utilizar a rotina VEHICLE ROUTING:

4.1. Criar uma matriz de roteirização com o comando ROUTING MATRIX para cada uma das áreas escolhidas: minimizando a distância, e escolhendo em depot settings a camada PARADAS e a seleção NOS AREA X. Em stop settings a camada PARADAS e a seleção NOS AREA X.

4.2. Executar a rotina utilizando na aba de stops a camada de PARADAS e a seleção da área escolhida e na aba de depots a camada de PARADAS e a seleção DEPOT. 
APÊNDICE B

Planilhas completas com o roteamento do veículo de coleta para os cenários estudados 
Planilha 1.Resultados do roteamento para o cenário PEV20

\begin{tabular}{|c|c|c|c|c|c|c|c|c|c|c|}
\hline Cenário & AREA & $\begin{array}{l}\text { Distância Percorrida } \\
\qquad(\mathrm{km})\end{array}$ & $\begin{array}{c}\text { Demanda em cada PEV } \\
\left(\mathrm{m}^{3}\right)\end{array}$ & \begin{tabular}{|c|} 
Conteiner de \\
Alta \\
Capacidade \\
\end{tabular} & \begin{tabular}{|c} 
Contêiner de \\
Baixa \\
Capacidade
\end{tabular} & AREA & Distância Percorrida (km) & Demanda em cada PEV $\left(\mathrm{m}^{3}\right)$ & \begin{tabular}{|c|} 
Conteiner de \\
Alta \\
Capacidade
\end{tabular} & \begin{tabular}{|c} 
Contêiner de \\
Baixa \\
Capacidade
\end{tabular} \\
\hline \multirow{61}{*}{ PEV20 } & \multirow{22}{*}{1} & \multirow{20}{*}{12,9} & 0,09 & \begin{tabular}{|c|}
0 \\
0
\end{tabular} & 1 & \multirow{21}{*}{3} & \multirow{19}{*}{13,3} & 0,09 & $\begin{array}{c} \\
0\end{array}$ & 1 \\
\hline & & & $\begin{array}{l}0,13 \\
0,11\end{array}$ & $\begin{array}{l}0 \\
0\end{array}$ & 1 & & & $\begin{array}{l}0,04 \\
0,09\end{array}$ & $\begin{array}{l}0 \\
0\end{array}$ & $\begin{array}{l}1 \\
1\end{array}$ \\
\hline & & & 0,08 & 0 & 1 & & & 0,05 & 0 & 1 \\
\hline & & & 0,13 & 0 & 1 & & & 0,21 & 0 & 1 \\
\hline & & & $\begin{array}{l}0,16 \\
0,03\end{array}$ & $\begin{array}{l}0 \\
0\end{array}$ & 1 & & & 0,27 & 0 & 1 \\
\hline & & & 0,05 & 0 & 1 & & & $\begin{array}{l}0,31 \\
0,23\end{array}$ & 0 & $\begin{array}{l}1 \\
1\end{array}$ \\
\hline & & & 0,17 & 0 & 1 & & & 0,31 & 0 & 1 \\
\hline & & & $\begin{array}{l}0,07 \\
0,32\end{array}$ & $\begin{array}{l}0 \\
0\end{array}$ & $\begin{array}{l}1 \\
1\end{array}$ & & & $\begin{array}{l}0,23 \\
0,45\end{array}$ & $\begin{array}{l}0 \\
0\end{array}$ & $\begin{array}{l}1 \\
2\end{array}$ \\
\hline & & & 0,10 & 0 & 1 & & & 0,32 & 0 & 1 \\
\hline & & & 0,10 & 0 & 1 & & & 0,48 & 0 & 2 \\
\hline & & & $\begin{array}{l}0,10 \\
0,17\end{array}$ & 0 & 1 & & & 0,55 & 0 & 2 \\
\hline & & & $\begin{array}{l}0,17 \\
0,12\end{array}$ & $\begin{array}{l}0 \\
0\end{array}$ & $\begin{array}{l}1 \\
1\end{array}$ & & & $\begin{array}{l}0,03 \\
0,13\end{array}$ & $\begin{array}{l}0 \\
0\end{array}$ & $\begin{array}{l}1 \\
1\end{array}$ \\
\hline & & & 0,44 & 0 & 2 & & & 0,11 & 0 & 1 \\
\hline & & & $\begin{array}{l}0,33 \\
0,57\end{array}$ & $\begin{array}{l}0 \\
0\end{array}$ & 1 & & & 0,27 & 0 & 1 \\
\hline & & & 0,27 & $\begin{array}{l}0 \\
0\end{array}$ & $\begin{array}{l}2 \\
1\end{array}$ & & & $\begin{array}{l}0,36 \\
0,23\end{array}$ & $\begin{array}{l}0 \\
0\end{array}$ & $\begin{array}{l}1 \\
1\end{array}$ \\
\hline & & & 0,27 & 0 & 1 & & & 0,27 & 0 & 1 \\
\hline & & & $\begin{array}{l}0,21 \\
0,14\end{array}$ & $\begin{array}{l}0 \\
0\end{array}$ & 1 & & & 0,24 & 0 & 1 \\
\hline & & & 0,14 & 0 & 1 & & & $\begin{array}{l}0,22 \\
0,26\end{array}$ & 0 & 1 \\
\hline & & & 0,38 & 0 & 2 & & & 0,17 & 0 & 1 \\
\hline & & & & 0 & 1 & & \begin{tabular}{|c|} 
TOTAL \\
RESDENCSATDISA
\end{tabular} & 5,92 & 0 & 28 \\
\hline & & TOTAL & $\frac{0,70}{5,52}$ & 0 & 2 & & RESIDENCIAS ATENDIDAS & & 54 & \\
\hline & & ESIDENCIAS ATENDIDA & 5,52 & 0 & 31 & & & 0,22 & 0 & 1 \\
\hline & & & 0,10 & 0 & 1 & & & 0,23 & 0 & 1 \\
\hline & & & 0,20 & 0 & 1 & & & 0,07 & 0 & 1 \\
\hline & & & 0,34 & 0 & 1 & & & 0,16 & 0 & 1 \\
\hline & & & 0,11 & 0 & 1 & & & 0,09 & 0 & 1 \\
\hline & & & 0,12 & $\begin{array}{l}0 \\
0\end{array}$ & 1 & & & $\begin{array}{l}0,39 \\
0,33\end{array}$ & 0 & 2 \\
\hline & & & $\begin{array}{l}0,32 \\
0,10\end{array}$ & 0 & $\begin{array}{l}1 \\
1\end{array}$ & & & $\begin{array}{l}0,33 \\
0,07\end{array}$ & $\begin{array}{l}0 \\
0\end{array}$ & 1 \\
\hline & & & 0,15 & 0 & 1 & & & 0,08 & 0 & $\begin{array}{l}1 \\
1\end{array}$ \\
\hline & & & 0,15 & 0 & 1 & & & 0,14 & 0 & 1 \\
\hline & & & 0,42 & 0 & 2 & & & 0,50 & 0 & 2 \\
\hline & & & 0,33 & 0 & 1 & & 9,2 & 0,53 & 0 & 2 \\
\hline & & & 0,08 & 0 & 1 & 4 & & 0,17 & 0 & 1 \\
\hline & & & 0,23 & 0 & 1 & & & 0,42 & 0 & 2 \\
\hline & & 13,0 & 0,19 & 0 & 1 & & & 0,57 & 0 & 2 \\
\hline & 2 & 13,0 & 0,11 & 0 & 1 & & & 0,33 & 0 & 1 \\
\hline & & & $\begin{array}{l}0,24 \\
0,40\end{array}$ & $\begin{array}{l}0 \\
0\end{array}$ & $\frac{1}{2}$ & & & $\begin{array}{l}0,34 \\
0,13\end{array}$ & 0 & 1 \\
\hline & & & 0,25 & 0 & 1 & & & 0,31 & 0 & 1 \\
\hline & & & 0,27 & 0 & 1 & & & 0,34 & 0 & 1 \\
\hline & & & $\begin{array}{l}0,17 \\
0,24\end{array}$ & $\begin{array}{l}0 \\
0\end{array}$ & 1 & & & $\begin{array}{l}0,28 \\
0,27\end{array}$ & 0 & 1 \\
\hline & & & 0,31 & 0 & $\begin{array}{l}1 \\
1\end{array}$ & & & $\begin{array}{l}0,27 \\
0,08\end{array}$ & 0 & $\begin{array}{l}1 \\
1\end{array}$ \\
\hline & & & 0,14 & 0 & 1 & & & 0,14 & 0 & 1 \\
\hline & & & 0,23 & 0 & 1 & & TOTAL & 6,50 & 0 & 30 \\
\hline & & & 0,04 & 0 & 1 & & RESIDENCIAS ATENDIDAS & & 369 & \\
\hline & & & 0,42 & 0 & 2 & & & 0,31 & 0 & 1 \\
\hline & & & 0,37 & 0 & 2 & & & 0,60 & 0 & 2 \\
\hline & & TOTAL & $\frac{0,35}{6,38}$ & 0 & $\frac{1}{32}$ & & & 0,08 & 0 & 1 \\
\hline & & ESIDENCIAS ATENDIDA & & 343 & & & & 0,84 & 0 & 3 \\
\hline & & & & & & & & 0,15 & 0 & 1 \\
\hline & & & & & & & & 0,02 & 0 & 1 \\
\hline & & & & & & & 6,6 & 0,06 & 0 & 1 \\
\hline & & & & & & 5 & & 0,70 & 0 & 2 \\
\hline & & & & & & & & $\begin{array}{l}0,03 \\
0,20\end{array}$ & 0 & 1 \\
\hline & & & & & & & & 0,15 & 0 & 1 \\
\hline & & & & & & & & 0,54 & 0 & 2 \\
\hline & & & & & & & & 0,43 & 0 & 2 \\
\hline & & & & & & & & 0,01 & 0 & 1 \\
\hline & & & & & & & TOTAL & $\frac{0,39}{4,62}$ & $\frac{0}{0}$ & $\frac{2}{23}$ \\
\hline & & & & & & & RESIDENCIAS ATENDIDAS & & 99 & \\
\hline & & & & & TOT & & & & & \\
\hline & & $\begin{array}{l}\text { Distância Percorrida } \\
55,0\end{array}$ & $\begin{array}{l}\text { Demanda em cada PEV } \\
28,94\end{array}$ & Conteiner de A & Ita Cap. & Contêir & $\begin{array}{l}\text { de Baixa Cap. } \\
144\end{array}$ & $\begin{array}{l}\text { Residências Atendidas } \\
6113\end{array}$ & & \\
\hline
\end{tabular}


Planilha 2. Resultados do roteamento para o cenário PEV40

\begin{tabular}{|c|c|c|c|c|c|c|c|c|c|c|}
\hline Cenário & AREA & $\begin{array}{l}\text { Distância Percorrida } \\
\qquad(\mathrm{km})\end{array}$ & $\begin{array}{c}\text { Demanda em cada PEV } \\
\left(\mathrm{m}^{3}\right)\end{array}$ & \begin{tabular}{c|} 
Conteiner de \\
Alta \\
Capacidade
\end{tabular} & $\begin{array}{c}\begin{array}{c}\text { Contêiner de } \\
\text { Baixa } \\
\text { Capacidade }\end{array} \\
\end{array}$ & AREA & Distância Percorrida (km) & Demanda em cada PEV $\left(\mathrm{m}^{3}\right)$ & \begin{tabular}{|c|} 
Conteiner de \\
Alta \\
Capacidade
\end{tabular} & \begin{tabular}{|c|} 
Contêiner de \\
Baixa \\
Capacidade
\end{tabular} \\
\hline \multirow{60}{*}{ PEV40 } & \multirow{22}{*}{1} & \multirow{20}{*}{12,9} & 0,18 & 0 & \multirow{20}{*}{$\begin{array}{c}\text { Capacidade } \\
1 \\
1 \\
1 \\
1 \\
1 \\
1 \\
1 \\
1 \\
1 \\
1 \\
2 \\
1 \\
1 \\
1 \\
1 \\
1 \\
3 \\
2 \\
4 \\
2 \\
2 \\
2 \\
1 \\
1 \\
3 \\
1 \\
4\end{array}$} & \multirow{20}{*}{3} & \multirow{18}{*}{13,3} & 0,18 & \begin{tabular}{|c|}
0 \\
0
\end{tabular} & \begin{tabular}{|c|}
1 \\
\end{tabular} \\
\hline & & & $\begin{array}{l}0,26 \\
0,22\end{array}$ & $\begin{array}{l}0 \\
0\end{array}$ & & & & $\begin{array}{l}0,08 \\
0,18\end{array}$ & $\begin{array}{l}0 \\
0\end{array}$ & $\begin{array}{l}1 \\
1\end{array}$ \\
\hline & & & 0,16 & 0 & & & & 0,09 & 0 & 1 \\
\hline & & & 0,26 & 0 & & & & 0,42 & 0 & 2 \\
\hline & & & $\begin{array}{l}0,31 \\
0,06\end{array}$ & 0 & & & & 0,55 & 0 & 2 \\
\hline & & & 0,09 & 0 & & & & $\begin{array}{l}0,61 \\
0,45\end{array}$ & 0 & $\begin{array}{l}2 \\
2\end{array}$ \\
\hline & & & 0,35 & 0 & & & & 0,61 & 0 & 2 \\
\hline & & & $\begin{array}{l}0,14 \\
0,63\end{array}$ & $\begin{array}{l}0 \\
0\end{array}$ & & & & $\begin{array}{l}0,46 \\
0,91\end{array}$ & $\begin{array}{l}0 \\
0\end{array}$ & $\begin{array}{l}2 \\
3\end{array}$ \\
\hline & & & 0,21 & 0 & & & & 0,63 & 0 & 2 \\
\hline & & & $\begin{array}{l}0,20 \\
0,21\end{array}$ & $\begin{array}{l}0 \\
0\end{array}$ & & & & 0,95 & 0 & 3 \\
\hline & & & $\begin{array}{l}0,21 \\
0,33\end{array}$ & $\begin{array}{l}0 \\
0\end{array}$ & & & & $\begin{array}{l}1,10 \\
0,07\end{array}$ & $\begin{array}{l}0 \\
0\end{array}$ & $\begin{array}{l}4 \\
1\end{array}$ \\
\hline & & & 0,24 & 0 & & & & 0,23 & 0 & 1 \\
\hline & & & $\begin{array}{l}0,88 \\
0,66\end{array}$ & $\begin{array}{l}0 \\
0\end{array}$ & & & & 0,22 & 0 & 1 \\
\hline & & & $\begin{array}{l}0,66 \\
1,13\end{array}$ & 0 & & & & $\begin{array}{l}0,54 \\
0,72\end{array}$ & $\begin{array}{l}0 \\
0\end{array}$ & $\begin{array}{l}2 \\
2\end{array}$ \\
\hline & & & 0,55 & 0 & & & & 0,45 & 0 & 2 \\
\hline & & & $\begin{array}{l}0,54 \\
0,42\end{array}$ & $\begin{array}{l}0 \\
0\end{array}$ & & & & 0,54 & 0 & 2 \\
\hline & & & $\begin{array}{l}0,42 \\
0,28\end{array}$ & 0 & & & & $\begin{array}{l}0,47 \\
0,44\end{array}$ & 0 & $\begin{array}{l}2 \\
2\end{array}$ \\
\hline & & & $\begin{array}{l}0,35 \\
0,76\end{array}$ & $\begin{array}{l}0 \\
0\end{array}$ & & & & $\begin{array}{l}0,53 \\
0,35\end{array}$ & $\begin{array}{l}0 \\
0\end{array}$ & $\begin{array}{l}2 \\
1\end{array}$ \\
\hline & & & 0,22 & 0 & & & TOTAL & $\frac{1,35}{11,78}$ & 0 & $\frac{1}{46}$ \\
\hline & & & 1,40 & 0 & & & RESIDENCIAS ATENDIDAS & & $\frac{1}{254}$ & \\
\hline & & \begin{tabular}{|c|} 
TOTAL \\
\end{tabular} & 11,04 & 0 & 42 & \multirow{23}{*}{4} & \multirow{21}{*}{9,2} & 0,43 & 0 & 2 \\
\hline & & ESIDENCIAS ATENDIDA & & 168 & & & & 0,61 & 0 & 2 \\
\hline & \multirow{25}{*}{2} & \multirow{23}{*}{13,0} & 0,20 & 0 & 1 & & & 0,45 & 0 & 2 \\
\hline & & & 0,40 & 0 & 2 & & & 0,13 & 0 & 1 \\
\hline & & & 0,69 & 0 & 2 & & & 0,31 & 0 & 1 \\
\hline & & & $\begin{array}{l}0,23 \\
0,24\end{array}$ & 0 & 1 & & & 0,18 & 0 & 1 \\
\hline & & & $\begin{array}{l}0,24 \\
0,63\end{array}$ & 0 & $\frac{1}{2}$ & & & $\begin{array}{l}0,18 \\
0,66\end{array}$ & $\begin{array}{l}0 \\
0\end{array}$ & 3 \\
\hline & & & 0,21 & 0 & 1 & & & 0,13 & 0 & $\begin{array}{l}2 \\
1\end{array}$ \\
\hline & & & 0,30 & 0 & 1 & & & 0,15 & 0 & 1 \\
\hline & & & 0,29 & 0 & 1 & & & 0,28 & 0 & 1 \\
\hline & & & 0,83 & 0 & 3 & & & 0,99 & 0 & 3 \\
\hline & & & $\begin{array}{l}0,65 \\
0,15\end{array}$ & $\begin{array}{l}0 \\
0\end{array}$ & ${ }_{1}^{2}$ & & & $\begin{array}{l}1,06 \\
0,35\end{array}$ & 0 & 3 \\
\hline & & & 0,45 & 0 & $\frac{1}{2}$ & & & $\begin{array}{l}0,35 \\
0,84\end{array}$ & $\begin{array}{l}0 \\
0\end{array}$ & $\frac{1}{3}$ \\
\hline & & & 0,38 & 0 & 2 & & & 1,13 & 0 & 4 \\
\hline & & & 0,22 & 0 & 1 & & & 0,65 & 0 & 2 \\
\hline & & & 0,47 & 0 & 2 & & & 0,68 & 0 & 2 \\
\hline & & & 0,79 & 0 & 3 & & & 0,26 & 0 & 1 \\
\hline & & & $\begin{array}{l}0,51 \\
0,55\end{array}$ & $\begin{array}{l}0 \\
0\end{array}$ & 2 & & & 0,61 & 0 & 2 \\
\hline & & & 0,33 & 0 & 1 & & & 0,56 & 0 & $\begin{array}{l}2 \\
2\end{array}$ \\
\hline & & & 0,47 & 0 & 2 & & & 0,54 & 0 & 2 \\
\hline & & & 0,61 & 0 & 2 & & & 0,15 & 0 & 1 \\
\hline & & & 0,45 & 0 & 2 & & TOTAL & $\frac{12,20}{12,88}$ & 0 & $\frac{1}{46}$ \\
\hline & & & 0,08 & 0 & 1 & & RESIDENCIAS ATENDIDAS & \multicolumn{3}{|c|}{$\frac{1}{1369}$} \\
\hline & & & 0,84 & 0 & 3 & \multirow{15}{*}{5} & \multirow{13}{*}{6,6} & 0,61 & 0 & 2 \\
\hline & & & 0,74 & 0 & 3 & & & 1,21 & 0 & 4 \\
\hline & & TOTAL & $\frac{, 10}{1268}$ & 0 & $\frac{2}{49}$ & & & & 0 & 1 \\
\hline & & ESIDENCIAS ATENDIDA & & 1343 & & & & 1,68 & 1 & 1 \\
\hline & & & & & & & & 0,30 & 0 & 1 \\
\hline & & & & & & & & 0,05 & 0 & 1 \\
\hline & & & & & & & & $\begin{array}{l}0,11 \\
140\end{array}$ & 0 & 1 \\
\hline & & & & & & & & $\begin{array}{l}1,40 \\
0,06\end{array}$ & 0 & 4 \\
\hline & & & & & & & & 0,40 & 0 & $\frac{1}{2}$ \\
\hline & & & & & & & & 0,29 & 0 & 1 \\
\hline & & & & & & & & 1,08 & 0 & 3 \\
\hline & & & & & & & & 0,86 & 0 & 3 \\
\hline & & & & & & & & 0,03 & 0 & 1 \\
\hline & & & & & & & TOTAL & $\frac{0,17}{9,25}$ & $\frac{0}{1}$ & $\frac{3}{30}$ \\
\hline & & & & & & & RESIDENCIAS ATENDIDA & & 79 & \\
\hline & & & & & $\mathrm{TO}$ & & & & & \\
\hline & & $\begin{array}{l}\text { Distância Percorrida } \\
55,0\end{array}$ & $\begin{array}{c}\text { Demanda em cada PEV } \\
57,63\end{array}$ & Conteiner & $\begin{array}{l}\text { Alta Car } \\
1\end{array}$ & ontêir & $\begin{array}{l}\text { le Baixa Cap. } \\
213\end{array}$ & $\begin{array}{l}\text { Residências Atendidas } \\
6113\end{array}$ & & \\
\hline
\end{tabular}


Planilha 3. Resultados do roteamento para o cenário PEV60

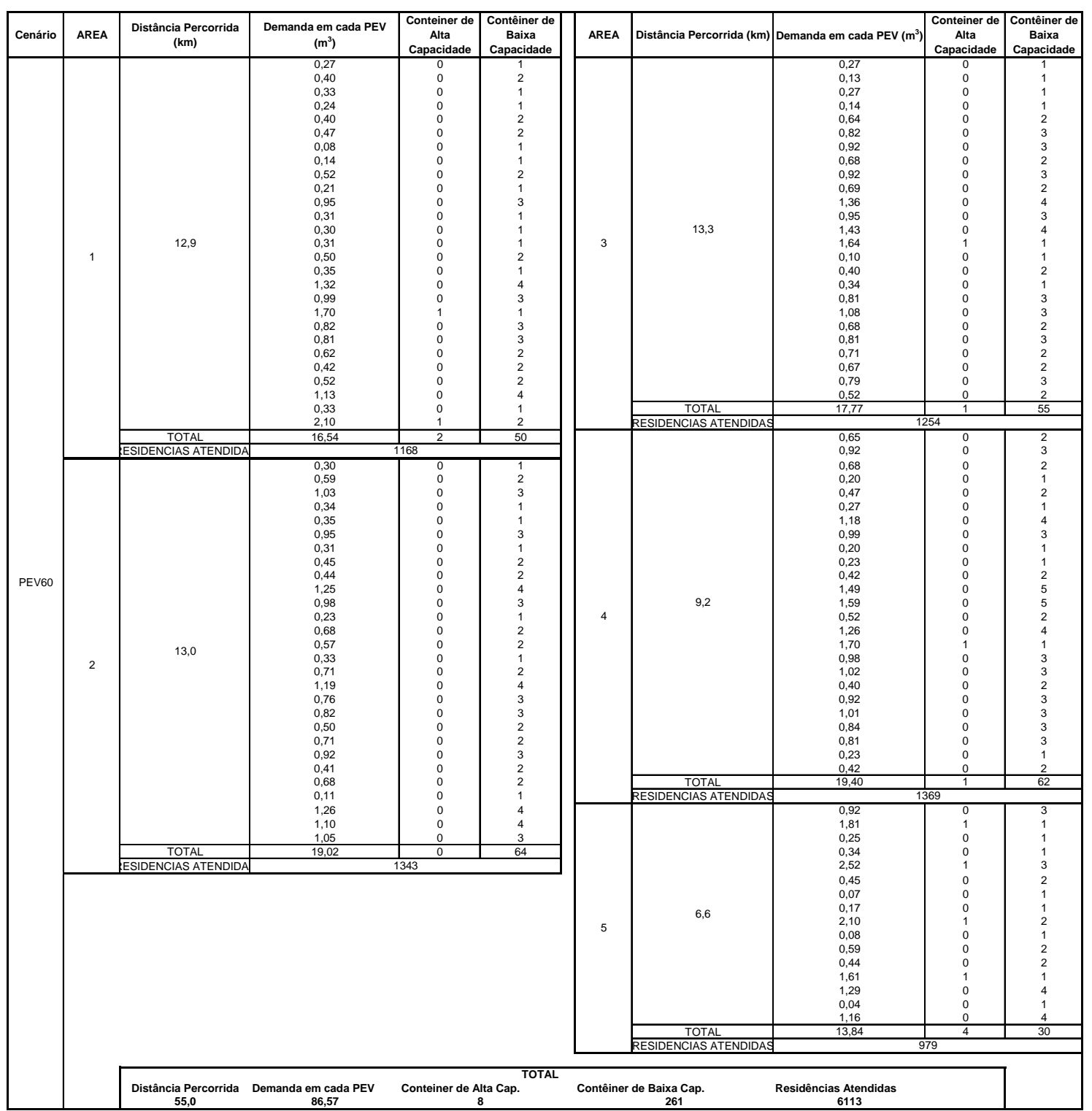


Planilha 4.Resultados do roteamento para o cenário PEV80

\begin{tabular}{|c|c|c|c|c|c|c|c|c|c|c|}
\hline Cenário & AREA & $\begin{array}{c}\text { Distância Percorrida } \\
(\mathrm{km})\end{array}$ & $\begin{array}{c}\text { Demanda em cada PEV } \\
\left(\mathrm{m}^{3}\right)\end{array}$ & \begin{tabular}{|r|}
$\begin{array}{c}\text { Conteiner de } \\
\text { Alta } \\
\text { Capacidade }\end{array}$ \\
\end{tabular} & \begin{tabular}{|c|}
$\begin{array}{c}\text { Contêiner de } \\
\text { Baixa } \\
\text { Capacidade }\end{array}$ \\
\end{tabular} & AREA & Distância Percorrida (km) & Demanda em cada PEV $\left(\mathrm{m}^{3}\right)$ & 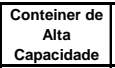 & \begin{tabular}{|c|}
$\begin{array}{c}\text { Contêiner de } \\
\text { Baixa } \\
\text { Capacidade }\end{array}$ \\
\end{tabular} \\
\hline \multirow{64}{*}{ PEV80 } & \multirow{24}{*}{1} & \multirow{22}{*}{12,9} & $\begin{array}{l}0,36 \\
0,53\end{array}$ & $\begin{array}{ll}0 \\
0\end{array}$ & 1 & \multirow{22}{*}{3} & \multirow{21}{*}{13,3} & 0,36 & 0 & 1 \\
\hline & & & 0,53 & 0 & 2 & & & 0,17 & & \\
\hline & & & 0,43 & 0 & 2 & & & 0,36 & 0 & 1 \\
\hline & & & 0,53 & $\begin{array}{l}0 \\
0\end{array}$ & $\begin{array}{l}1 \\
2\end{array}$ & & & $\begin{array}{l}0,19 \\
0,85\end{array}$ & $\begin{array}{l}0 \\
0\end{array}$ & $\begin{array}{l}1 \\
3\end{array}$ \\
\hline & & & 0,62 & 0 & 2 & & & 1,10 & 0 & 4 \\
\hline & & & 0,11 & 0 & 1 & & & 1,23 & 0 & 4 \\
\hline & & & 0,19 & 0 & 1 & & & 0,91 & 0 & 3 \\
\hline & & & $\begin{array}{l}0,70 \\
0,28\end{array}$ & $\begin{array}{l}0 \\
0\end{array}$ & 2 & & & 1,23 & 0 & 4 \\
\hline & & & 1,27 & 0 & 4 & & & $\begin{array}{l}1,93 \\
1,81\end{array}$ & 1 & $\begin{array}{l}3 \\
1\end{array}$ \\
\hline & & & 0,42 & 0 & 2 & & & 1,27 & 0 & 4 \\
\hline & & & 0,40 & 0 & 2 & & & 1,91 & 1 & 1 \\
\hline & & & $\begin{array}{l}0,42 \\
0,66\end{array}$ & 0 & 2 & & & 2,19 & 1 & 2 \\
\hline & & & $\begin{array}{l}0,66 \\
0,47\end{array}$ & $\begin{array}{l}0 \\
0\end{array}$ & $\begin{array}{l}2 \\
2\end{array}$ & & & 0,13 & 0 & 1 \\
\hline & & & $\begin{array}{l}1,76 \\
1,76\end{array}$ & 1 & 1 & & & 0,45 & 0 & 2 \\
\hline & & & 1,32 & 0 & 4 & & & 1,08 & 0 & 3 \\
\hline & & & 2,27 & 1 & 2 & & & 1,44 & 0 & 4 \\
\hline & & & 1,10 & 0 & 4 & & & 0,91 & 0 & 3 \\
\hline & & & $\begin{array}{l}1,08 \\
0,83\end{array}$ & $\begin{array}{l}0 \\
0\end{array}$ & 3 & & & 1,08 & 0 & 3 \\
\hline & & & $\begin{array}{l}0,83 \\
0,57\end{array}$ & 0 & $\begin{array}{l}3 \\
2\end{array}$ & & & $\begin{array}{l}0,94 \\
0,89\end{array}$ & $\begin{array}{l}0 \\
0\end{array}$ & $\begin{array}{l}3 \\
3\end{array}$ \\
\hline & & & 0,70 & 0 & 2 & & & 1,06 & 0 & 3 \\
\hline & & & 1,51 & 0 & 5 & & & $\frac{0,70}{2372}$ & 0 & 2 \\
\hline & & & $\begin{array}{l}0,43 \\
2,80\end{array}$ & 1 & 4 & & $\begin{array}{c}\text { TOTAL } \\
\text { RESIDENCIAS ATENDIDAS }\end{array}$ & 23,72 & 3 & 62 \\
\hline & & TOTAL & $\frac{2,00}{22,08}$ & $\frac{1}{3}$ & 61 & & & 0,87 & 254 & 3 \\
\hline & & ESIDENCIAS ATENDIDA & & 1168 & & & & 1,23 & 0 & 4 \\
\hline & & & $\overline{0,40}$ & 0 & 2 & & & 0,91 & 0 & 3 \\
\hline & & & 0,79 & 0 & 3 & & & 0,26 & 0 & 1 \\
\hline & & & 1,38 & 0 & 4 & & & 0,62 & 0 & 2 \\
\hline & & & 0,45 & 0 & 2 & & & 0,36 & 0 & 1 \\
\hline & & & 0,47 & 0 & 2 & & & 1,60 & 1 & 0 \\
\hline & & & $\begin{array}{l}1,27 \\
0,42\end{array}$ & 0 & 4 & & & 1,32 & 0 & 4 \\
\hline & & & $\begin{array}{l}0,42 \\
0,60\end{array}$ & 0 & 2 & & & 0,26 & 0 & 1 \\
\hline & & & $\begin{array}{l}0,60 \\
0,59\end{array}$ & $\begin{array}{l}0 \\
0\end{array}$ & $\begin{array}{l}2 \\
2\end{array}$ & & & $\begin{array}{l}0,30 \\
0,57\end{array}$ & 0 & 1 \\
\hline & & & 1,66 & 1 & 1 & & & 1,98 & 1 & $\begin{array}{l}2 \\
2\end{array}$ \\
\hline & & & 1,30 & 0 & 4 & & $9,2+3,9=13,1$ & 2,12 & 1 & 2 \\
\hline & & & 0,30 & 0 & 1 & 4 & & 0,70 & 0 & 2 \\
\hline & & & 0,91 & 0 & 3 & & & 1,68 & 1 & 1 \\
\hline & & $13,1+7,7=20,8$ & 0,76 & 0 & 3 & & & 2,27 & 1 & 2 \\
\hline & & $13,1+7,7=20,8$ & 0,43 & 0 & 2 & & & 1,30 & 0 & 4 \\
\hline & 2 & & 0,94 & 0 & 3 & & & 1,36 & 0 & 4 \\
\hline & & & 1,60 & 1 & 0 & & & 0,53 & 0 & 2 \\
\hline & & & 1,02 & 0 & 3 & & & 1,23 & 0 & 4 \\
\hline & & & 1,10 & 0 & 4 & & & 1,34 & 0 & 4 \\
\hline & & & 0,66 & 0 & 2 & & & 1,11 & 0 & 4 \\
\hline & & & 0,94 & $\begin{array}{l}0 \\
0\end{array}$ & 3 & & & 1,08 & 0 & 3 \\
\hline & & & $\begin{array}{l}1,23 \\
0,55\end{array}$ & 0 & 2 & & & $\begin{array}{l}0,30 \\
0,57\end{array}$ & $\begin{array}{l}0 \\
0\end{array}$ & 1 \\
\hline & & & 0,91 & 0 & 3 & & TOTAL & 25,87 & 5 & $\frac{2}{59}$ \\
\hline & & & 0,15 & 0 & 1 & & RESIDENCIAS ATENDIDAS & & 369 & \\
\hline & & & 1,68 & 1 & 1 & & & 1,23 & 0 & 4 \\
\hline & & & 1,47 & 0 & 5 & & & 2,42 & 1 & 3 \\
\hline & & & 1,40 & 0 & 4 & & & 0,34 & 0 & 1 \\
\hline & & TOTAL & 25,38 & 3 & 72 & & & 0,45 & 0 & 2 \\
\hline & & ESIDENCIAS ATENDIDA & & $\frac{1}{1343}$ & & & & 3,36 & 2 & 1 \\
\hline & & & & & & & & 0,60 & 0 & 2 \\
\hline & & & & & & & & $\begin{array}{l}0,09 \\
0,23\end{array}$ & 0 & 1 \\
\hline & & & & & & & 6,6 & $\begin{array}{l}0,23 \\
280\end{array}$ & 0 & 1 \\
\hline & & & & & & 5 & & $\begin{array}{l}2,80 \\
0,11\end{array}$ & ${ }_{0}^{1}$ & $\begin{array}{l}4 \\
1\end{array}$ \\
\hline & & & & & & & & 0,79 & 0 & 3 \\
\hline & & & & & & & & 0,59 & 0 & 2 \\
\hline & & & & & & & & 2,15 & 1 & 2 \\
\hline & & & & & & & & 1,72 & 1 & 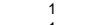 \\
\hline & & & & & & & & $\begin{array}{l}0,06 \\
155\end{array}$ & $\begin{array}{l}0 \\
0\end{array}$ & $\begin{array}{l}1 \\
5\end{array}$ \\
\hline & & & & & & & TOTAL & $\frac{1,059}{18,49}$ & 6 & 34 \\
\hline & & & & & & & RESIDENCIAS ATENDIDAS & & & \\
\hline & & $\begin{array}{l}\text { Distância Percorrida } \\
66.7\end{array}$ & $\begin{array}{l}\text { Demanda em cada PEV } \\
115,54\end{array}$ & Conteiner de A & Ita Cap. & Contêin & r de Baixa Cap. & Residências Atendidas & & \\
\hline
\end{tabular}


Planilha 5.Resultados do roteamento para o cenário PEV100

\begin{tabular}{|c|c|c|c|c|c|c|c|c|c|c|}
\hline Cenário & AREA & $\begin{array}{c}\text { Distância Percorrida } \\
(\mathrm{km})\end{array}$ & $\begin{array}{c}\text { Demanda em cada PEV } \\
\left(\mathrm{m}^{3}\right)\end{array}$ & $\begin{array}{r}\begin{array}{r}\text { Conteiner de } \\
\text { Alta } \\
\text { Capacidade }\end{array} \\
\end{array}$ & \begin{tabular}{|c|}
$\begin{array}{c}\text { Contêiner de } \\
\text { Baixa } \\
\text { Capacidade }\end{array}$ \\
\end{tabular} & AREA & Distância Percorrida (km) & Demanda em cada PEV $\left(\mathrm{m}^{3}\right)$ & 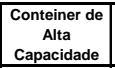 & \begin{tabular}{|c|}
$\begin{array}{c}\text { Contêiner de } \\
\text { Baixa } \\
\text { Capacidade }\end{array}$ \\
\end{tabular} \\
\hline \multirow{66}{*}{ PEV100 } & \multirow{24}{*}{1} & \multirow{22}{*}{$11,1+8,4=19,5$} & 0,45 & 0 & 2 & \multirow{22}{*}{3} & \multirow{21}{*}{$10,5+9,0=19,5$} & 0,45 & 0 & 2 \\
\hline & & & 0,66 & 0 & 2 & & & 0,21 & & \\
\hline & & & 0,54 & 0 & 2 & & & 0,45 & 0 & 2 \\
\hline & & & $\begin{array}{l}0,40 \\
0,66\end{array}$ & $\begin{array}{l}0 \\
0\end{array}$ & $\begin{array}{l}2 \\
2\end{array}$ & & & $\begin{array}{l}0,24 \\
1.06\end{array}$ & $\begin{array}{l}0 \\
0\end{array}$ & $\frac{1}{3}$ \\
\hline & & & 0,78 & 0 & 3 & & & 1,37 & 0 & 4 \\
\hline & & & 0,14 & 0 & 1 & & & 1,53 & 1 & 0 \\
\hline & & & 0,24 & 0 & 1 & & & 1,13 & 0 & 4 \\
\hline & & & $\begin{array}{l}0,87 \\
0,35\end{array}$ & $\begin{array}{l}0 \\
0\end{array}$ & 3 & & & 1,53 & 1 & 0 \\
\hline & & & 1,60 & 1 & 0 & & & $\begin{array}{l}1,16 \\
2,27\end{array}$ & 1 & $\begin{array}{l}4 \\
2\end{array}$ \\
\hline & & & 0,52 & 0 & 2 & & & 1,58 & 1 & 0 \\
\hline & & & 0,50 & 0 & 2 & & & 2,38 & 1 & 3 \\
\hline & & & 0,52 & 0 & 2 & & & 2,74 & 1 & 4 \\
\hline & & & $\begin{array}{l}0,83 \\
0,59\end{array}$ & $\begin{array}{l}0 \\
0\end{array}$ & $\begin{array}{l}3 \\
2\end{array}$ & & & 0,17 & 0 & 1 \\
\hline & & & 2,20 & 1 & 2 & & & 0,57 & 0 & 2 \\
\hline & & & 1,65 & 1 & 1 & & & 1,35 & 0 & 4 \\
\hline & & & 2,83 & 2 & 0 & & & 1,79 & 1 & 1 \\
\hline & & & 1,37 & 0 & 4 & & & 1,13 & 0 & 4 \\
\hline & & & $\begin{array}{l}1,35 \\
1,04\end{array}$ & $\begin{array}{l}0 \\
0\end{array}$ & $\begin{array}{l}4 \\
3\end{array}$ & & & 1,35 & 0 & 4 \\
\hline & & & $\begin{array}{l}1,04 \\
0,71\end{array}$ & 0 & $\begin{array}{l}3 \\
2\end{array}$ & & & $\begin{array}{l}1,18 \\
1,11\end{array}$ & 0 & $\begin{array}{l}4 \\
4\end{array}$ \\
\hline & & & 0,87 & 0 & 3 & & & 1,32 & 0 & 4 \\
\hline & & & 1,89 & 1 & 1 & & & 0,87 & 0 & 3 \\
\hline & & & $\begin{array}{l}0,54 \\
3,49\end{array}$ & $\begin{array}{l}0 \\
2\end{array}$ & $\begin{array}{l}2 \\
1\end{array}$ & & $\begin{array}{c}\text { TOTAL } \\
\text { RESIDENCIAS ATENDIDAS }\end{array}$ & 29,60 & 7 & 63 \\
\hline & & TOTAL & 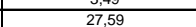 & 8 & 53 & & & 109 & 254 & 4 \\
\hline & & ESIDENCIAS ATENDIDA & & $\frac{1}{1168}$ & & & & $\begin{array}{l}1,09 \\
1,53\end{array}$ & 1 & $\begin{array}{l}4 \\
0\end{array}$ \\
\hline & & & 0,50 & 0 & 2 & & & 1,13 & 0 & 4 \\
\hline & & & 0,99 & 0 & 3 & & & 0,33 & 0 & 1 \\
\hline & & & 1,72 & 1 & 1 & & & 0,78 & 0 & 3 \\
\hline & & & 0,57 & 0 & 2 & & & 0,45 & 0 & 2 \\
\hline & & & 0,59 & 0 & 2 & & & 1,96 & 1 & 1 \\
\hline & & & 1,58 & 1 & 0 & & & 1,65 & 1 & 1 \\
\hline & & & 0,52 & 0 & 2 & & & 0,33 & 0 & 1 \\
\hline & & & 0,76 & 0 & 3 & & & 0,38 & 0 & 2 \\
\hline & & & $\begin{array}{l}0,73 \\
2,08\end{array}$ & 0 & 3 & & & 0,71 & 0 & 2 \\
\hline & & & $\begin{array}{l}2,08 \\
163\end{array}$ & 1 & 2 & & 12 & 2,48 & 1 & 3 \\
\hline & & & $\begin{array}{l}1,63 \\
0,38\end{array}$ & $\begin{array}{l}1 \\
0\end{array}$ & $\frac{1}{2}$ & 4 & $7+5,4=12,4$ & 2,64 & 1 & 3 \\
\hline & & & $\begin{array}{l}1,38 \\
1,13\end{array}$ & 0 & 4 & 4 & & $\begin{array}{l}2,810 \\
2,10\end{array}$ & 1 & $\begin{array}{l}3 \\
2\end{array}$ \\
\hline & & $10,2+8,5=187$ & 0,94 & 0 & 3 & & & 2,83 & 1 & 4 \\
\hline & 2 & $10,2+8,5=18,7$ & 0,54 & 0 & 2 & & & 1,63 & 1 & 1 \\
\hline & 2 & & 1,18 & 0 & 4 & & & 1,70 & 1 & 1 \\
\hline & & & 1,98 & 1 & 2 & & & 0,66 & 0 & 2 \\
\hline & & & 1,27 & 0 & 4 & & & 1,53 & 1 & 0 \\
\hline & & & 1,37 & 0 & 4 & & & 1,68 & 1 & 1 \\
\hline & & & 0,83 & 0 & 3 & & & 1,39 & 0 & 4 \\
\hline & & & 1,18 & 0 & 4 & & & 1,35 & 0 & 4 \\
\hline & & & 1,53 & 1 & 0 & & & 0,38 & 0 & 2 \\
\hline & & & 0,68 & 0 & 2 & & & 0,71 & 0 & 2 \\
\hline & & & 1,13 & 0 & 4 & & TOTAL & 32,29 & 11 & 53 \\
\hline & & & 0,19 & 0 & 1 & & RESIDENCIAS ATENDIDAS & & 369 & \\
\hline & & & 2,10 & 1 & 2 & & & 1,53 & 1 & 0 \\
\hline & & & 1,84 & 1 & 1 & & & 3,02 & 1 & 4 \\
\hline & & & 1,75 & 1 & 1 & & & 0,42 & 0 & 2 \\
\hline & & TOTAL & 31,69 & 9 & 64 & & & 0,57 & 0 & 2 \\
\hline & & ESIDENCIAS ATENDIDA & & $\frac{11343}{1343}$ & & & & 4,20 & 2 & 3 \\
\hline & & & & & & & & 0,76 & 0 & 3 \\
\hline & & & & & & & & $\begin{array}{l}0,12 \\
0,28\end{array}$ & 0 & 1 \\
\hline & & & & & & & 6,6 & 0,28 & 2 & 1 \\
\hline & & & & & & 5 & & $\begin{array}{l}3,49 \\
0,14\end{array}$ & ${ }_{0}^{2}$ & 1 \\
\hline & & & & & & & & 0,99 & 0 & 3 \\
\hline & & & & & & & & 0,73 & 0 & 3 \\
\hline & & & & & & & & 2,69 & 1 & 4 \\
\hline & & & & & & & & 2,15 & 1 & 2 \\
\hline & & & & & & & & 0,07 & 0 & 1 \\
\hline & & & & & & & & $\frac{1,94}{2310}$ & 1 & 1 \\
\hline & & & & & & & TOAAL & 23,10 & 9 & 32 \\
\hline & & & & & & & , & & & \\
\hline & & $\begin{array}{c}\text { Distância Percorrida } \\
76,7\end{array}$ & $\begin{array}{c}\text { Demanda em cada PEV } \\
144,27\end{array}$ & Conteiner de $\mathrm{A}$ & $\begin{array}{l}\text { Ita Cap. } \\
14\end{array}$ & Contêin & $\begin{array}{l}r \text { de Baixa Cap. } \\
265\end{array}$ & $\begin{array}{c}\text { Residências Atendidas } \\
6113\end{array}$ & & \\
\hline
\end{tabular}


Planilha 6. Resultados do roteamento para o cenário POR20

\begin{tabular}{|c|c|c|c|c|}
\hline Cenário & AREA & Distância Percorrida (km) & Demanda na área $\left(\mathrm{m}^{3}\right)$ & Residências atendidas \\
\hline \multirow{6}{*}{ POR20 } & 1 & 37,7 & 4,89 & $103 \varepsilon$ \\
\hline & 2 & 26,0 & 5,70 & 1197 \\
\hline & 3 & 38,34 & 7,16 & 1517 \\
\hline & 4 & 31,42 & 6,60 & 1472 \\
\hline & 5 & 25,79 & 6,95 & $139 \varepsilon$ \\
\hline & TOTAL & 159,20 & 31,30 & 662 \\
\hline
\end{tabular}

Planilha 7.Resultados do roteamento para o cenário POR40

\begin{tabular}{|c|c|c|c|r|}
\hline \multirow{3}{*}{ Cenário } & AREA & Distância Percorrida $(\mathbf{k m})$ & Demanda na área $\left(\mathbf{m}^{\mathbf{3}}\right)$ & Residências atendidas \\
\hline \multirow{4}{*}{ POR40 } & 1 & 37,7 & 9,78 & 1038 \\
\cline { 2 - 5 } & 2 & 25,95 & 11,41 & 1197 \\
\cline { 2 - 5 } & 3 & 38,34 & 14,32 & 1517 \\
\cline { 2 - 5 } & 4 & 31,42 & 13,20 & 1472 \\
\cline { 2 - 5 } & 5 & 25,79 & 13,89 & 1398 \\
\cline { 2 - 5 } & \multicolumn{3}{|c|}{$\mathbf{1 5 9 , 2 0}$} & $\mathbf{2 2 , 6 0}$ \\
\cline { 2 - 5 } & TOTAL & \multicolumn{2}{|c|}{$\mathbf{6 6 2 2}$} \\
\hline
\end{tabular}

Planilha 8. Resultados do roteamento para o cenário POR60

\begin{tabular}{|c|c|c|c|c|}
\hline Cenário & AREA & Distância Percorrida (km) & Demanda na área $\left(\mathrm{m}^{3}\right)$ & Residências atendidas \\
\hline \multirow{6}{*}{ POR60 } & 1 & 37,7 & 14,67 & 1038 \\
\hline & 2 & 25,95 & 17,11 & 1197 \\
\hline & 3 & 38,34 & 21,49 & 1517 \\
\hline & 4 & 31,42 & 19,80 & 1472 \\
\hline & 5 & 25,79 & 20,84 & 1398 \\
\hline & TOTAL & $159,2 \mathrm{C}$ & 93,91 & 6622 \\
\hline
\end{tabular}


Planilha 9. Resultados do roteamento para o cenário POR80

\begin{tabular}{|c|c|c|c|c|c|c|c|c|c|}
\hline \multirow{2}{*}{ Cenário } & \multirow{2}{*}{ AREA } & \multicolumn{4}{|c|}{ Distância Percorrida (km) } & \multicolumn{3}{|c|}{ Demanda na área $\left(\mathrm{m}^{3}\right)$} & \multirow{2}{*}{ Residências atendidas } \\
\hline & & 1 VOLTA & 2 VOLTA & I V DEP & TOTAL & 1 VOLTA & 2 VOLTA & TOTAL & \\
\hline \multirow{6}{*}{ POR80 } & 1 & 37,7 & & & 37,7 & 19,57 & & 19,57 & 1038 \\
\hline & 2 & 25,95 & & & 25,95 & 22,81 & & 22,81 & 1197 \\
\hline & 3 & 29,98 & 8,23 & 5,28 & 43,49 & 24,66 & 3,98 & 28,64 & 1517 \\
\hline & 4 & 27,51 & 3,71 & 2,9324 & 34,1524 & 24,51 & 1,89 & 26,40 & 1472 \\
\hline & 5 & 22,31 & 3,47 & 2,9489 & 28,7289 & 24,87 & 2,91 & 27,78 & 1398 \\
\hline & TOTAL & & & & 170,02 & & & 125,20 & 6622 \\
\hline
\end{tabular}

Planilha 10. Resultados do roteamento para o cenário POR100

\begin{tabular}{|c|c|c|c|c|c|c|c|c|c|}
\hline \multirow{2}{*}{ Cenário } & \multirow{2}{*}{ AREA } & \multicolumn{4}{|c|}{ Distância Percorrida (km) } & \multicolumn{3}{|c|}{ Demanda na área $\left(\mathrm{m}^{3}\right)$} & \multirow{2}{*}{ Residências atendidas } \\
\hline & & 1 VOLTA & 2 VOLTA & I V DEP & TOTAL & 1 VOLTA & 2 VOLTA & TOTAL & \\
\hline \multirow{6}{*}{ POR100 } & 1 & 37,7 & & & 37,7 & 24,46 & & 24,46 & 1038 \\
\hline & 2 & 21,24 & 4,71 & 7,1429 & 33,0929 & 24,29 & 4,23 & 28,52 & 1197 \\
\hline & 3 & 25,07 & 13,14 & 4,021 & 42,231 & 24,57 & 11,24 & 35,81 & 1517 \\
\hline & 4 & 27,49 & 3,93 & 2,1812 & 33,6012 & 24,42 & 1,98 & 26,40 & 1472 \\
\hline & 5 & 21,91 & 3,88 & 2,6956 & 28,4856 & 24,61 & 3,17 & 27,78 & 1398 \\
\hline & TOTAL & & & & 175,11 & & & 142,97 & 6622 \\
\hline
\end{tabular}

Planilha 11. Resultados do roteamento para o cenário HIB20

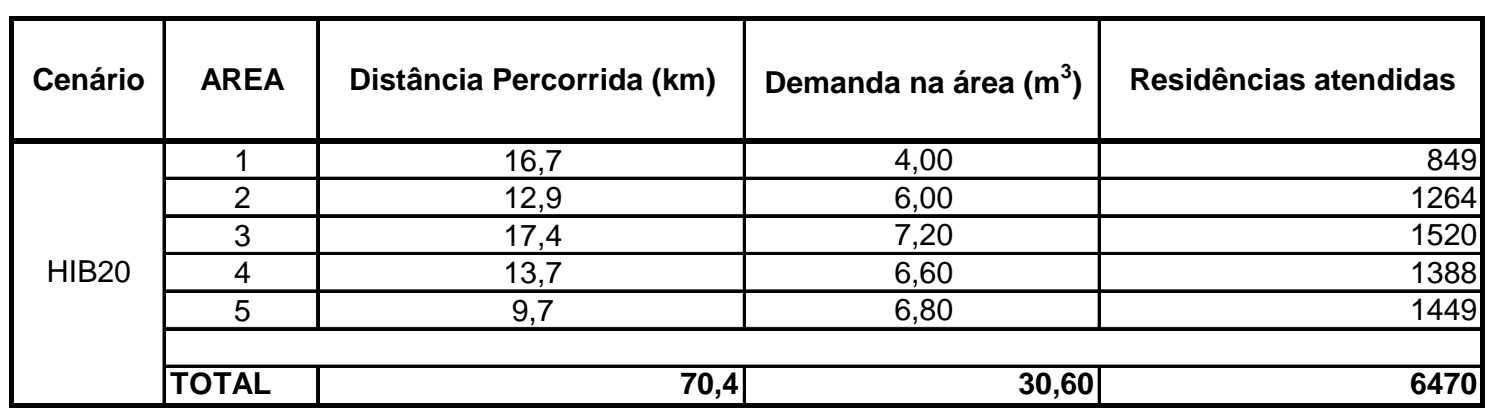


Planilha 12. Resultados do roteamento para o cenário HIB40

\begin{tabular}{|c|c|c|c|c|}
\hline Cenário & AREA & Distância Percorrida (km) & Demanda na área $\left(\mathrm{m}^{3}\right)$ & Residências atendidas \\
\hline \multirow{6}{*}{ HIB40 } & 1 & 16,7 & 8,00 & 849 \\
\hline & 2 & 12,9 & 11,90 & 1264 \\
\hline & 3 & 17,4 & 14,40 & 1520 \\
\hline & 4 & 13,7 & 13,10 & 1388 \\
\hline & 5 & 9,7 & 13,70 & 1449 \\
\hline & TOTAL & 70, & 61,10 & 6470 \\
\hline
\end{tabular}

Planilha 13. Resultados do roteamento para o cenário HIB60

\begin{tabular}{|c|c|c|c|c|}
\hline Cenário & AREA & Distância Percorrida (km) & Demanda na área $\left(\mathrm{m}^{3}\right)$ & Residências atendidas \\
\hline \multirow{6}{*}{ HIB60 } & 1 & 16,7 & 12,00 & 849 \\
\hline & 2 & 12,9 & 17,90 & 1264 \\
\hline & 3 & 17,4 & 21,50 & 1520 \\
\hline & 4 & 13,7 & 19,70 & 1388 \\
\hline & 5 & 9,7 & 20,40 & 1449 \\
\hline & TOTAL & \multicolumn{2}{|r|}{91,50} & 6470 \\
\hline
\end{tabular}

Planilha 14. Resultados do roteamento para o cenário HIB80

\begin{tabular}{|c|c|c|c|c|c|c|}
\hline Cenário & AREA & \multicolumn{2}{|c|}{ Distância Percorrida (km) } & \multicolumn{2}{|c|}{ Demanda na área $\left(\mathrm{m}^{3}\right)$} & Residências atendidas \\
\hline \multirow{6}{*}{ HIB80 } & 1 & 16,7 & 16,7 & 16,00 & 16,00 & 849 \\
\hline & 2 & 12,9 & 12,9 & 23,90 & 23,90 & 1264 \\
\hline & 3 & $16,4+9,4=25,8$ & 25,8 & $24,6+4,1=28,7$ & 28,70 & 1520 \\
\hline & 4 & $13,3+6,1=19,4$ & 19,4 & $24,2+2,0=26,2$ & 26,20 & 1388 \\
\hline & 5 & $9,8+3,4=13,2$ & 13,2 & $24,4+2,7=27,1$ & 27,10 & 1449 \\
\hline & TOTAL & \multicolumn{2}{|r|}{88,00} & & 121,90 & 6470 \\
\hline
\end{tabular}


Planilha 15. Resultados do roteamento para o cenário HIB100

\begin{tabular}{|c|c|c|c|c|c|c|}
\hline Cenário & AREA & \multicolumn{2}{|c|}{ Distância Percorrida (km) } & \multicolumn{2}{|c|}{ Demanda na área $\left(\mathrm{m}^{3}\right)$} & Residências atendidas \\
\hline \multirow{6}{*}{ HIB100 } & 1 & 16,7 & 16,7 & 20,00 & 20,00 & 849 \\
\hline & 2 & $12,3+8,3=20,6$ & 20,6 & $24,1+5,8=29,9$ & 29,90 & 1264 \\
\hline & 3 & $15,4+11=26,4$ & 26,4 & $24,6+11,3=35,9$ & 35,90 & 1520 \\
\hline & 4 & $11,9+8,8=20,7$ & 20,7 & $24,3+8,5=32,8$ & 32,80 & 1388 \\
\hline & 5 & $9,2+5,3=14,5$ & 14,5 & $24,3+9,9=34,2$ & 34,20 & 1449 \\
\hline & TOTAL & \multicolumn{3}{|c|}{98,90} & 152,80 & 6470 \\
\hline
\end{tabular}


Planilhas com os parâmetros para cada análise de custo e uma planilha como exemplo do resultado dos custos para um cenário 
Planilha 16. Parâmetro de custo iniciais, sem alterações

\begin{tabular}{|c|c|c|c|c|}
\hline \multicolumn{5}{|c|}{ Custos Fixos } \\
\hline \multirow{14}{*}{ 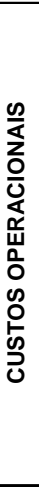 } & \multicolumn{4}{|l|}{ Salários+Benefícios e encargos } \\
\hline & \multicolumn{2}{|l|}{\begin{tabular}{|l|} 
Catadores (Sal. Méd.: 300,$00 ;$ \\
VT. $: 4,00 \times 25$ dias; VR.:4,00×25dias) \\
\end{tabular}} & 500,00 & SELUR (2001) \\
\hline & \multicolumn{2}{|l|}{\begin{tabular}{|l} 
Motorista (Sal. Méd.: 644,$00 ;$ \\
VT. .4, $00 \times 25$ dias; VR.:4,00x25dias)
\end{tabular}} & 844,00 & $\begin{array}{l}\text { ECONOMIA\& TRANSPORTE } \\
(2005)\end{array}$ \\
\hline & \multicolumn{2}{|l|}{ Os encargos sociais aplicados } & $79,81 \%$ & SELUR (2001) \\
\hline & \multicolumn{4}{|l|}{ Uniformes } \\
\hline & \multicolumn{2}{|l|}{\begin{tabular}{|l}
$\begin{array}{l}1 / 12 \text { dos valor } \\
\text { funcionário) }\end{array}$ \\
\end{tabular}} & 5,10 & THIEMERMAM (2004) \\
\hline & \multirow{2}{*}{\multicolumn{2}{|c|}{\begin{tabular}{|l|} 
Licenciamento e Seguro \\
Seguro obrigatório em $R \$ /$ ano
\end{tabular}}} & & \\
\hline & Seguro obrigatório em $\mathrm{R} \$$ /ano & & 66,43 & $\begin{array}{l}\text { ECOONOMIA\& TRANSPORTE } \\
(2005)\end{array}$ \\
\hline & IPVA & $\begin{array}{l}2 \% \text { valor } \\
\text { do novo }\end{array}$ & $1.315,40$ & NTC (2001) \\
\hline & \multicolumn{2}{|l|}{ Taxa de Licenciamento } & 10,20 & NTC (2001) \\
\hline & \multicolumn{2}{|l|}{ Imposto s/ Operações Financeiras } & $1,07 \%$ & NTC (2001) \\
\hline & \multirow{2}{*}{\multicolumn{2}{|c|}{\begin{tabular}{|l|} 
Custo da apólice \\
Coef. s/ importância segurada \\
\end{tabular}}} & 60,00 & NTC (2001) \\
\hline & & & 0,0570 & NTC (2001) \\
\hline & \multicolumn{4}{|l|}{$\begin{array}{l}\text { S.R.C.F Prêmio de } \mathrm{DM}(\mathrm{R} \$ 50 \mathrm{mil}) \mathrm{e} \\
\mathrm{DP}(\mathrm{R} \$ 100 \mathrm{mil})\end{array}$} \\
\hline \multirow{29}{*}{ 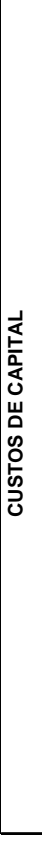 } & \multicolumn{4}{|l|}{ VEÍ́CULOS } \\
\hline & \multicolumn{4}{|l|}{ Depreciação do capital investido } \\
\hline & \multicolumn{2}{|l|}{$\begin{array}{l}\text { Valor do veículo novo (IVECO - DAlLY } \\
\text { CHASSI 70-12) } \\
\end{array}$} & $\mathrm{R} \$ 59.500,00$ & $\begin{array}{l}\text { ECONOMIA \& TRANSPORTE } \\
(2005)\end{array}$ \\
\hline & \begin{tabular}{|l|} 
Valor residual do veículo \\
\end{tabular} & $20 \%$ & $11.900,00$ & NTC (2001) \\
\hline & \begin{tabular}{|l|l} 
Vida útil \\
\end{tabular} & meses & 60 & NTC (2001) \\
\hline & \multicolumn{4}{|l|}{ Remuneração do Capital } \\
\hline & Taxa de juros & anual & $12 \%$ & NTC (2001) \\
\hline & \multirow{2}{*}{\begin{tabular}{|l|} 
\% do novo a ser remunerada como \\
investimento em peças de reposição \\
VEICULOS - EQUIPAMENTOS \\
\end{tabular}} & anual & $1 \%$ & NTC (2001) \\
\hline & & & & \\
\hline & \multicolumn{2}{|l|}{ Depreciação do capital investido } & & \\
\hline & \multicolumn{2}{|l|}{ Valor do novo (MADEIRA ABERTA) } & $5.000,00$ & $\begin{array}{l}\text { ECONOMIA \& TRANSPORTE } \\
(2005)\end{array}$ \\
\hline & \multicolumn{2}{|l|}{\begin{tabular}{|l} 
Valor residual da carroceria \\
\end{tabular}} & $5 \%$ & NTC (2001) \\
\hline & Vida útil & meses & 60 & NTC (2001) \\
\hline & Remuneração do Capital & & & \\
\hline & Taxa de juros & anual & $12 \%$ & NTC (2001) \\
\hline & $\begin{array}{l}\text { CONTEINERES DE BAIXA } \\
\text { CAPACIDADE (360L) }\end{array}$ & & & \\
\hline & Depreciação do capital investido & & & \\
\hline & $\begin{array}{l}\text { Valor do conteiner novo (investimento } \\
\text { inicial) }\end{array}$ & & 500,00 & \\
\hline & \begin{tabular}{|l|} 
Valor residual do conteiner \\
\end{tabular} & & $5 \%$ & $\begin{array}{l}\text { GOULART (2003) } \\
\end{array}$ \\
\hline & \begin{tabular}{|l|l} 
Vida útil \\
\end{tabular} & meses & 60 & $\begin{array}{l}\text { GOULART (2003) } \\
\end{array}$ \\
\hline & Remuneração do Capital & & & \\
\hline & Taxa de juros & anual & $12 \%$ & $\begin{array}{l}\text { ECONOMAA \& TRANSF } \\
(2005)\end{array}$ \\
\hline & $\begin{array}{l}\text { CONTEINERES DE ALTA CAPACIDAL } \\
(1600 \mathrm{~L})\end{array}$ & & & \\
\hline & $\begin{array}{l}\text { Depreciação do capital investido } \\
\end{array}$ & & & \\
\hline & $\begin{array}{l}\text { Valor do conteiner novo (investimento } \\
\text { inicial) }\end{array}$ & & $2.000,00$ & \\
\hline & \begin{tabular}{|l} 
Valor residual do conteiner \\
\end{tabular} & & $5 \%$ & $\begin{array}{l}\text { GOULART (2003) } \\
\text { SORT (203) }\end{array}$ \\
\hline & \begin{tabular}{|l|} 
Vida útil \\
\end{tabular} & meses & 60 & $\begin{array}{l}\text { GOULART (2003) } \\
\end{array}$ \\
\hline & Remuneração do Capital & & & \\
\hline & Taxa de juros & anual & $12 \%$ & $\begin{array}{l}\text { ECONOMMA\& TRAN } \\
(2005)\end{array}$ \\
\hline
\end{tabular}

\begin{tabular}{|c|c|c|c|c|}
\hline \multicolumn{5}{|c|}{ Custos Variáveis } \\
\hline \multirow{26}{*}{ 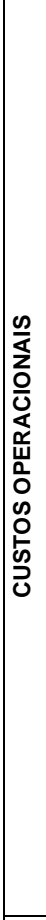 } & \multicolumn{4}{|l|}{ Manutenção de veículos } \\
\hline & Salário do mecânico - média & $\mathrm{R} \$$ & 840,76 & NTC (2001) \\
\hline & $\begin{array}{l}\text { Quantidade de veículos atendidos } \\
\text { p/mecânico }\end{array}$ & QTD & 5 & NTC (2001) \\
\hline & $\begin{array}{l}\begin{array}{l}\text { Taxas s/ peças, acessórios e mat. } \\
\text { manutenção }\end{array} \\
\end{array}$ & & $1 \%$ & NTC (2001) \\
\hline & \multicolumn{4}{|l|}{$\begin{array}{l}\begin{array}{l}\text { Manutenção dos conteiners } \\
\text { (PEVs) }\end{array} \\
\end{array}$} \\
\hline & $\begin{array}{l}\text { \% do custo de investmento do } \\
\text { conteiner por ano }\end{array}$ & & $35 \%$ & GOULART (2003) \\
\hline & \multicolumn{4}{|l|}{ Custos de Pneus e Câmaras } \\
\hline & Valor do Estepe - veículo & $\mathrm{R} \$$ & 669,27 & $\begin{array}{l}\text { ECONOMIA \& TR } \\
\text { (2005) }\end{array}$ \\
\hline & Valor do Pneu - veículo 195/75 R16 & $\mathrm{R} \$$ & 669,27 & $\begin{array}{l}\text { ECONOMIA\& TRANSPORTE } \\
(2005)\end{array}$ \\
\hline & Valor da Câmara - veículo & $\mathrm{R} \$$ & 0 & NTC (2001) \\
\hline & $\begin{array}{l}\begin{array}{l}\text { Valor da Recauchutagem a frio - } \\
\text { veículo }\end{array} \\
\text { (a) }\end{array}$ & $\mathrm{R} \$$ & 177,90 & $\begin{array}{l}\text { ECONOMIA\& TRANSPORTE } \\
(2005)\end{array}$ \\
\hline & Quantidade de pneus por veículo & QTD & 4 & NTC (2001) \\
\hline & $\begin{array}{l}\text { Vida útil do pneu com uma } \\
\text { recapagem }\end{array}$ & $\mathrm{km}$ & 100.000 & $\begin{array}{l}\begin{array}{l}\text { ECONOMA\& TRANSPORTE } \\
(2005)\end{array} \\
\end{array}$ \\
\hline & Numero de recapagens & QTD & 2 & NTC (2001) \\
\hline & $\begin{array}{l}\begin{array}{l}\text { Quilometragem mensal de } \\
\text { referência }\end{array} \\
\text { Consump Complive }\end{array}$ & $\mathrm{km}$ & 4.000 & NTC (2001) \\
\hline & Preço do combustível - litro & $\mathrm{R} \$$ & 1,68 & $\begin{array}{l}\text { ECONOMIA \& TRANSPORTE } \\
(2005)\end{array}$ \\
\hline & \begin{tabular}{|l} 
Rendimento do combustivel \\
\end{tabular} & $\mathrm{km} / \mathrm{itro}$ & 7,50 & NTC (2001) \\
\hline & \multicolumn{4}{|l|}{ Lubrificação e Lavagens } \\
\hline & Capacidade de óleo do cárter & litros & 7,00 & $\frac{(2005)}{\text { NTC (2001) }}$ \\
\hline & Reposição até a próxima troca & litros & 1,50 & NTC (2001) \\
\hline & Troca de óleo do cárter & $\mathrm{km}$ & 30.000 & NTC (2001) \\
\hline & $\begin{array}{l}\text { Preço do óleo de câmbio/diferencial } \\
\text { - litro }\end{array}$ & t & 6,95 & $\begin{array}{l}\text { ECONOMIA \& TRANSPORTE } \\
\text { (2005) }\end{array}$ \\
\hline & $\begin{array}{l}\text { Capacidade de óleo caixa do } \\
\text { diferencial }\end{array}$ & litros & 2,90 & NTC (2001) \\
\hline & $\begin{array}{l}\text { Troca de óleo do diferencial } \\
\end{array}$ & $\mathrm{km}$ & 120.000 & NTC (2001) \\
\hline & $\begin{array}{l}\text { Periodicidade de lavagem do } \\
\text { veículo }\end{array}$ & $\mathrm{km}$ & 2.000 & NTC (2001) \\
\hline & $\begin{array}{l}\text { Lavagem (água, luz, xampu, } \\
\text { desinfetante e mão de obra) }\end{array}$ & $\begin{array}{l}\mathrm{R} \$ / \text { por } \\
\text { lavagem }\end{array}$ & 72,00 & $\begin{array}{l}\text { ECONOMA\& \&RANSPORTE } \\
(2005)\end{array}$ \\
\hline 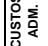 & $15 \%$ do valor dos custos operaciona & & & SELUR (2001) \\
\hline
\end{tabular}


Planilha 17. Planilha de custo para o cenário PEV20, com os parâmetros mostrados na Planilha 16 (parâmetros inicialmente propostos).

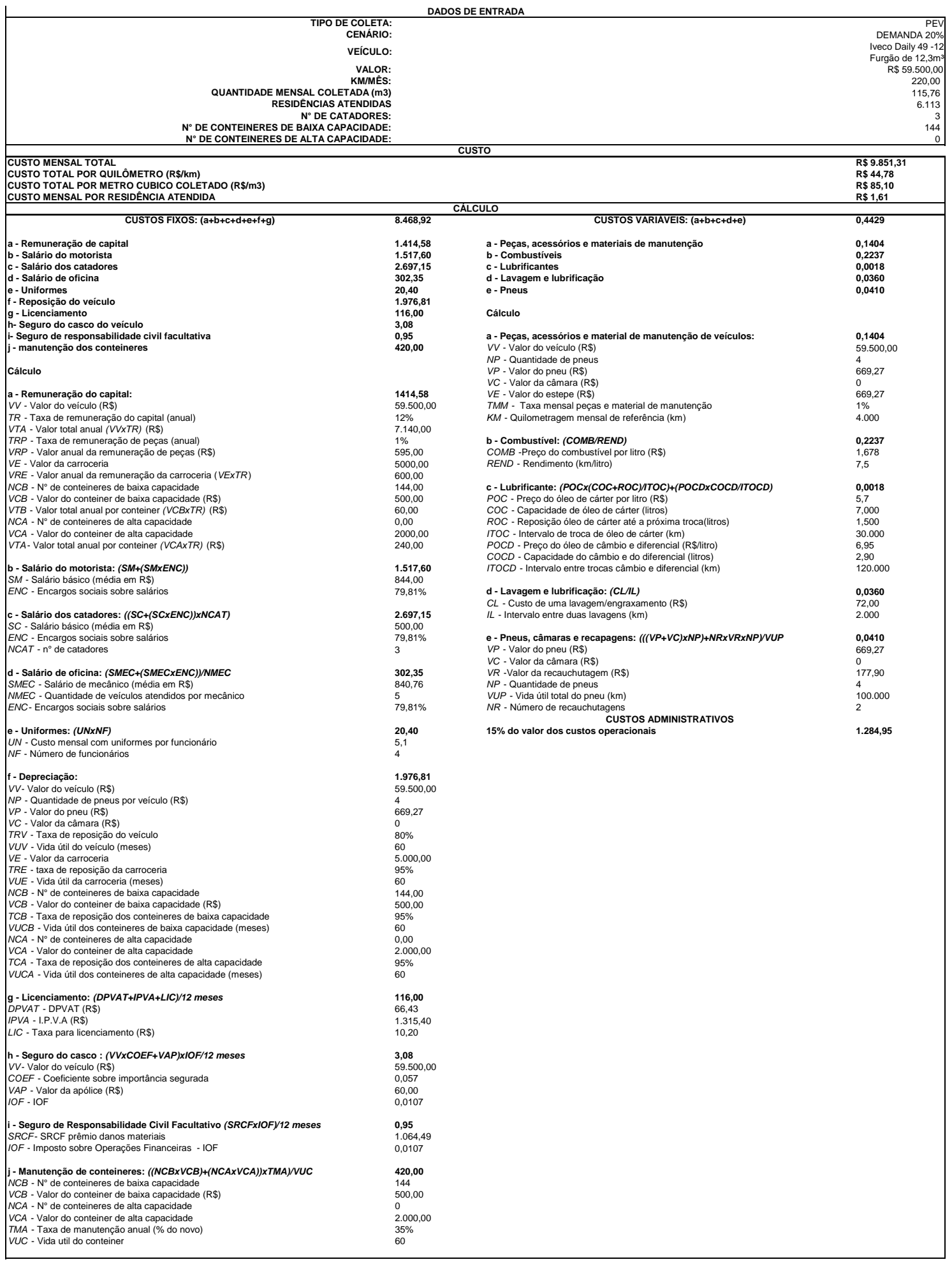


Planilha 18. Parâmetros de custo, com alterações no período de vida útil dos equipamentos.

\begin{tabular}{|c|c|c|c|c|}
\hline \multicolumn{5}{|c|}{ Custos Fixos } \\
\hline \multirow{13}{*}{ 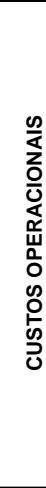 } & \multicolumn{4}{|l|}{ Salários+Benefícios e encargos } \\
\hline & $\begin{array}{l}\text { Catadores (Sal. Méd.: } 300,00 ; \\
\text { VT. }: 4,00 \times 25 \text { dias; VR: } 4,00 \times 25 \text { dias) }\end{array}$ & & 500,00 & SELUR (2001) \\
\hline & $\begin{array}{l}\text { Motorista (Sal. Méd.: 644,00; } \\
\text { VT..4,00×25dias; VR.:4,00×25dias) }\end{array}$ & & 844,00 & ECONOMIA \& TRANSPORTE (2005) \\
\hline & Os encargos sociais aplicados & & $79,81 \%$ & SELUR (2001) \\
\hline & Uniformes & & & \\
\hline & \begin{tabular}{|l|}
$\begin{array}{l}1 / 12 \text { dos valores gastos anuais (po } \\
\text { funcionário) }\end{array}$ \\
\end{tabular} & & 5,10 & THIEMERMAM (2004) \\
\hline & Licenciamento e Seguro & & 8643 & 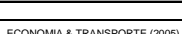 \\
\hline & \begin{tabular}{|l|l|} 
IPVA \\
\end{tabular} & $2 \%$ valor do novo & 131540 & NTC(2001) \\
\hline & Taxa de Licenciamento & & 10,20 & NTC (2001) \\
\hline & Imposto s/ Operaç̄õs Financeiras & I.O.F & $1,07 \%$ & NTC (2001) \\
\hline & Custo da apólice & R\$/ano & 60,00 & NTC (2001) \\
\hline & Coef. s/ importância segurada & & 0,0570 & NTC (2001) \\
\hline & \begin{tabular}{|l|} 
S.R.C.F Prêmio de DM(R $\$ 50$ mil \\
DP(R\$ 100 mil)
\end{tabular} & $\mathrm{R} \$$ /ano & $1.064,49$ & NTC (2001) \\
\hline \multirow{24}{*}{ 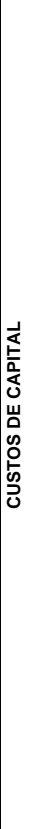 } & Veículos & & & \\
\hline & Depreciação do capital investido & & & \\
\hline & $\begin{array}{l}\text { Valor do veículo novo (IVECO - } \\
\text { DAILY CHASSI 70-12) }\end{array}$ & & $\mathrm{R} \$ 59.500,00$ & ECONOMA \& TRANSPORTE (2005) \\
\hline & Valor residual do veículo & $20 \%$ & $11.900,00$ & NTC (2001) \\
\hline & \begin{tabular}{|l|} 
Vida útil \\
Remuneracão do Capital \\
\end{tabular} & meses & 120 & \\
\hline & Taxa de juros & anual & $12 \%$ & NTC (2001) \\
\hline & $\begin{array}{l}\text { \% do novo a ser remunerada comc } \\
\text { investimento em peças de } \\
\text { reposiçâã }\end{array}$ & anual & $1 \%$ & NTC (2001) \\
\hline & \begin{tabular}{|l|} 
VEICULOS - EQUIPAMENTOS \\
Deprocian
\end{tabular} & & & \\
\hline & Valor do novo (MADEIRA ABERTA & & $5.000,00$ & ECONOMA \& TRANSPORTE (2005) \\
\hline & Valor residual da carroceria & & $5 \%$ & NTC (2001) \\
\hline & Vida útil & meses & 120 & \\
\hline & Remuneração do Capital & & & \\
\hline & \begin{tabular}{|l|} 
Taxa de juros \\
CONTEINERES DE BAIXA \\
CAPACIDADE (360L) \\
\end{tabular} & anual & $12 \%$ & NTC (2001) \\
\hline & Depreciação do capital investido & & & \\
\hline & \begin{tabular}{|l}
$\begin{array}{l}\text { Valor do conteiner novo } \\
\text { (investimento inicial) }\end{array}$ \\
\end{tabular} & & 500,00 & \\
\hline & \begin{tabular}{|l} 
Valor residual do conteiner \\
Vida
\end{tabular} & 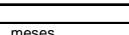 & $5 \%$ & GOULART (2003) \\
\hline & Remuneração do Capital & & & \\
\hline & Taxa de juros & anual & $12 \%$ & ECONOMAQ \& TRANSPORTE (2005) \\
\hline & $\begin{array}{l}\text { CONTEINERES DE ALTA } \\
\text { CAPACIDADE (1600L) }\end{array}$ & & & \\
\hline & Depreciação do capital investido & & & \\
\hline & \begin{tabular}{|l|}
$\begin{array}{l}\text { Valor do conteiner novo } \\
\text { (investimento inicial) }\end{array}$ \\
\end{tabular} & & $2.000,00$ & \\
\hline & $\begin{array}{l}\text { Valor residual do conteiner } \\
\end{array}$ & & $5 \%$ & GOULART (2003) \\
\hline & \begin{tabular}{|l|l|} 
Vida útil \\
Remunerarod
\end{tabular} & meses & 120 & \\
\hline & Taxa de juros & anual & $12 \%$ & ECONOMA \& TRANSPORTE 2005 \\
\hline
\end{tabular}

\begin{tabular}{|c|c|c|c|c|}
\hline \multicolumn{5}{|c|}{ Custos Variáveis } \\
\hline \multirow{27}{*}{ 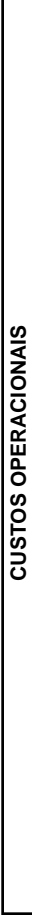 } & \multicolumn{4}{|l|}{ Manutenção de veículos } \\
\hline & Salário do mecânico - média & $\mathrm{R} \$$ & 840,76 & NTC (2001) \\
\hline & $\begin{array}{l}\text { Quantidade de veículos atendidos } \\
\text { p/mecânico }\end{array}$ & QTD & 5 & NTC (2001) \\
\hline & $\begin{array}{l}\text { Taxas s/ peças, acessórios e mat. } \\
\text { manutençẫo }\end{array}$ & & $1 \%$ & NTC (2001) \\
\hline & \begin{tabular}{|l} 
Manutenção dos conteiners \\
(PEVs)
\end{tabular} & & & \\
\hline & $\begin{array}{l}\% \text { do custo de investmento do } \\
\text { conteiner por ano }\end{array}$ & & $35 \%$ & GOULART (2003) \\
\hline & \begin{tabular}{|l} 
Custos de Pneus e Câmaras \\
\end{tabular} & & & 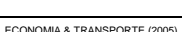 \\
\hline & \begin{tabular}{|l} 
Valor do Estepe - veículo \\
\end{tabular} & $\mathrm{R} \$$ & 669,27 & ECONOMAQ \& TRANSPORTE (2005) \\
\hline & Valor do Pneu - veículo 195/75 R16 & $\mathrm{R} \$$ & 669,27 & ECONOMA \& TRANSPORTE (2005) \\
\hline & Valor da Câmara - veículo & $\mathrm{R} \$$ & 0 & NTC (2001) \\
\hline & $\begin{array}{l}\text { Valor da Recauchutagem a frio - } \\
\text { veículo }\end{array}$ & $\mathrm{R} \$$ & 177,90 & ECONOMA\& \&RANSPORTE (2005) \\
\hline & Quantidade de pneus por veículo & QTD & 4 & NTC (2001) \\
\hline & $\begin{array}{l}\text { Vida útil do pneu com uma } \\
\text { recapagem }\end{array}$ & $\mathrm{km}$ & 100.000 & ECONOMAA \&RANSPORTE (2005) \\
\hline & Numero de recapagens & QTD & 2 & NTC (2001) \\
\hline & $\begin{array}{l}\text { Quilometragem mensal de } \\
\text { referência }\end{array}$ & $\mathrm{km}$ & 4.000 & NTC (2001) \\
\hline & Consumo de Combustivel & & & \\
\hline & Preço do combustivel - litro & $\mathrm{R} \$$ & 1,68 & ECONOMA\& TRANSPORTE (2005) \\
\hline & \begin{tabular}{|l|} 
Rendimento do combustivel \\
Lubrificacăo e Lavagens \\
\end{tabular} & $\mathrm{km} / \mathrm{litro}$ & 7,50 & NTC (2001) \\
\hline & \begin{tabular}{|l|} 
Preço do óleo de cárter - litro \\
\end{tabular} & $\mathrm{R} \$$ & 5,70 & ECONOMA\& TRANSPORTE (2005) \\
\hline & \begin{tabular}{|l|} 
Capacidade de óleo do cárter \\
\end{tabular} & litros & 7,00 & NTC (2001) \\
\hline & Reposição até a próxima troca & litros & 1,50 & NTC (2001) \\
\hline & Troca de óleo do cárter & $\mathrm{km}$ & 30.000 & NTC (2001) \\
\hline & $\begin{array}{l}\text { Preço do óleo de câmbio/diferencial } \\
\text { - litro }\end{array}$ & $\mathrm{R} \$$ & 6,95 & ECONOMA\& TRANSPORTE (2005) \\
\hline & \begin{tabular}{|l|}
$\begin{array}{l}\text { Capacidade de óleo caixa do } \\
\text { diferencial }\end{array}$ \\
\end{tabular} & litros & 2,90 & NTC (2001) \\
\hline & Troca de óleo do diferencial & $\mathrm{km}$ & 120.000 & NTC (2001) \\
\hline & $\begin{array}{l}\begin{array}{l}\text { Periodicidade de lavagem do } \\
\text { veículo }\end{array} \\
\end{array}$ & $\mathrm{km}$ & 2.000 & NTC (2001) \\
\hline & \begin{tabular}{|l|} 
Lavagem (água, luz, xampu, \\
desinfetante e mão de obra)
\end{tabular} & $\mathrm{R} \$$ /por lavagem & 72,00 & ECONOMA\& \&RANSPORTE (2005) \\
\hline 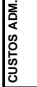 & $15 \%$ do valor dos custos operaciona & & & SELUR (2001) \\
\hline
\end{tabular}


Planilha 19. Parâmetros de custo, com alterações no período de vida útil dos equipamentos e na taxa de remuneração do capital investido.

\begin{tabular}{|c|c|c|c|}
\hline \multicolumn{4}{|c|}{ Custos Fixos } \\
\hline \multirow{13}{*}{ 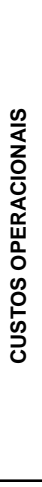 } & \multicolumn{3}{|l|}{ Salários+Benefícios e encargos } \\
\hline & \multicolumn{2}{|l|}{$\begin{array}{l}\text { Catadores (Sal. Méd.: } 300,00 ; \\
\text { VT.:4,00x25dias; VR.:4,00×25dias) }\end{array}$} & SELUR (2001) \\
\hline & \multicolumn{2}{|l|}{$\begin{array}{l}\text { Motorista (Sal. Méd.: 644,00; } \\
\text { VT.:4,00x25dias; VR.:4,00x25dias) }\end{array}$} & ECONOMA \& TRANSPORTE (2005) \\
\hline & \multicolumn{2}{|l|}{ Os encargos sociais aplicados } & SELUR (2001) \\
\hline & \multicolumn{3}{|l|}{ Uniformes } \\
\hline & \multicolumn{2}{|l|}{$\begin{array}{l}\begin{array}{l}1 / 12 \text { dos valores gastos anuais (por } \\
\text { funcionário) }\end{array} \\
\end{array}$} & THIEMERMAM (2004) \\
\hline & \multicolumn{2}{|l|}{\begin{tabular}{|l|} 
Licenciamento e Seguro \\
Seguro obrigatório em $R \$ / a n o$ \\
\end{tabular}} & ECONOMA \& TRANSPORTE (2005) \\
\hline & IPVA & $2 \%$ valor do novo & NTC (2001) \\
\hline & \multicolumn{2}{|l|}{ Taxa de Licenciamento } & NTC (2001) \\
\hline & Imposto s/ Operações Financeiras & I.O.F & NTC (2001) \\
\hline & \begin{tabular}{|l} 
Custo da apólice \\
\end{tabular} & R\$lano & NTC (2001) \\
\hline & Coef. s/ importância segurada & & NTC (2001) \\
\hline & $\begin{array}{l}\text { S.R.C.F Prêmio de DM(R } \$ 50 \text { mil) } \\
\text { DP(R\$ } 100 \text { mil) }\end{array}$ & $\mathrm{R} \$$ /ano & NTC (2001) \\
\hline \multirow{24}{*}{ 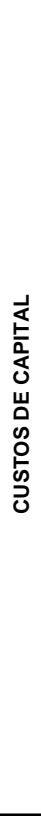 } & \multicolumn{3}{|l|}{ VEículos } \\
\hline & \multicolumn{3}{|l|}{ Depreciação do capital investido } \\
\hline & \multicolumn{2}{|l|}{$\begin{array}{l}\text { Valor do veículo novo (IVECO- } \\
\text { DAlLY CHASSI 70-12) }\end{array}$} & R\$59.500,00 ECONOMA \& TRANSPORTE (2005) \\
\hline & \begin{tabular}{|l} 
Valor residual do veículo \\
\end{tabular} & $20 \%$ & $11.900,00$ NTC (2001) \\
\hline & \multicolumn{3}{|l|}{\begin{tabular}{|l|} 
Vida útil \\
Remuneração do Capital
\end{tabular}} \\
\hline & \multicolumn{3}{|l|}{ Taxa de juros } \\
\hline & \multicolumn{2}{|c|}{$\begin{array}{l}\% \text { do novo a ser remunerada como } \\
\text { investimento em peças de }\end{array}$} & $1 \%$ NTC (2001) \\
\hline & \\
\hline & \multicolumn{3}{|l|}{ Depreciação do capital investido } \\
\hline & \multicolumn{2}{|l|}{ Valor do novo (MADEIRA ABERTA) } & $5.000,00$ ECONOMIA \& TRANSPORTE (2005) \\
\hline & \multicolumn{2}{|l|}{\begin{tabular}{|l} 
Valor residual da carroceria \\
\end{tabular}} & $20 \%$ NTC (2001) \\
\hline & Vida útil & meses & 120 \\
\hline & \multicolumn{3}{|l|}{ Remuneração do Capital } \\
\hline & \begin{tabular}{|l|} 
Taxa de juros \\
CONTEINERES DE BAIXA \\
CAPACIDADE (360L) \\
\end{tabular} & anual & $6 \%$ \\
\hline & Depreciação do capital investido & & \\
\hline & \begin{tabular}{|l|}
$\begin{array}{l}\text { Valor do conteiner novo } \\
\text { (investimento inicial) }\end{array}$ \\
\end{tabular} & & 500,00 \\
\hline & \begin{tabular}{|l|} 
Valor residual do conteiner \\
Vicháti
\end{tabular} & $m e s$ & $20 \%$ GOULART (2003) \\
\hline & $\mid \frac{\mid \text { Vida útil }}{\text { Remuneracão do Capital }}$ & meses & \\
\hline & \begin{tabular}{|l|} 
Taxa de juros \\
CONTEINERES DE ALTA \\
CAPACIDADE (1600L) \\
\end{tabular} & anual & $6 \%$ \\
\hline & Depreciação do capital investido & & \\
\hline & \begin{tabular}{|l|}
$\begin{array}{l}\text { Valor do conteiner novo } \\
\text { (investimento inicial) }\end{array}$ \\
\end{tabular} & & $2.000,00$ \\
\hline & Valor residual do conteiner & & $20 \%$ GOULART (2003) \\
\hline & \begin{tabular}{|l|} 
Vida útil \\
\end{tabular} & meses & 120 GOULART (2003) \\
\hline & \begin{tabular}{|l|} 
Remuneração do Capital \\
Taxa de juros
\end{tabular} & anual & $6 \%$ \\
\hline i & $15 \%$ do valor dos custos operacion & & SELUR (2001) \\
\hline
\end{tabular}

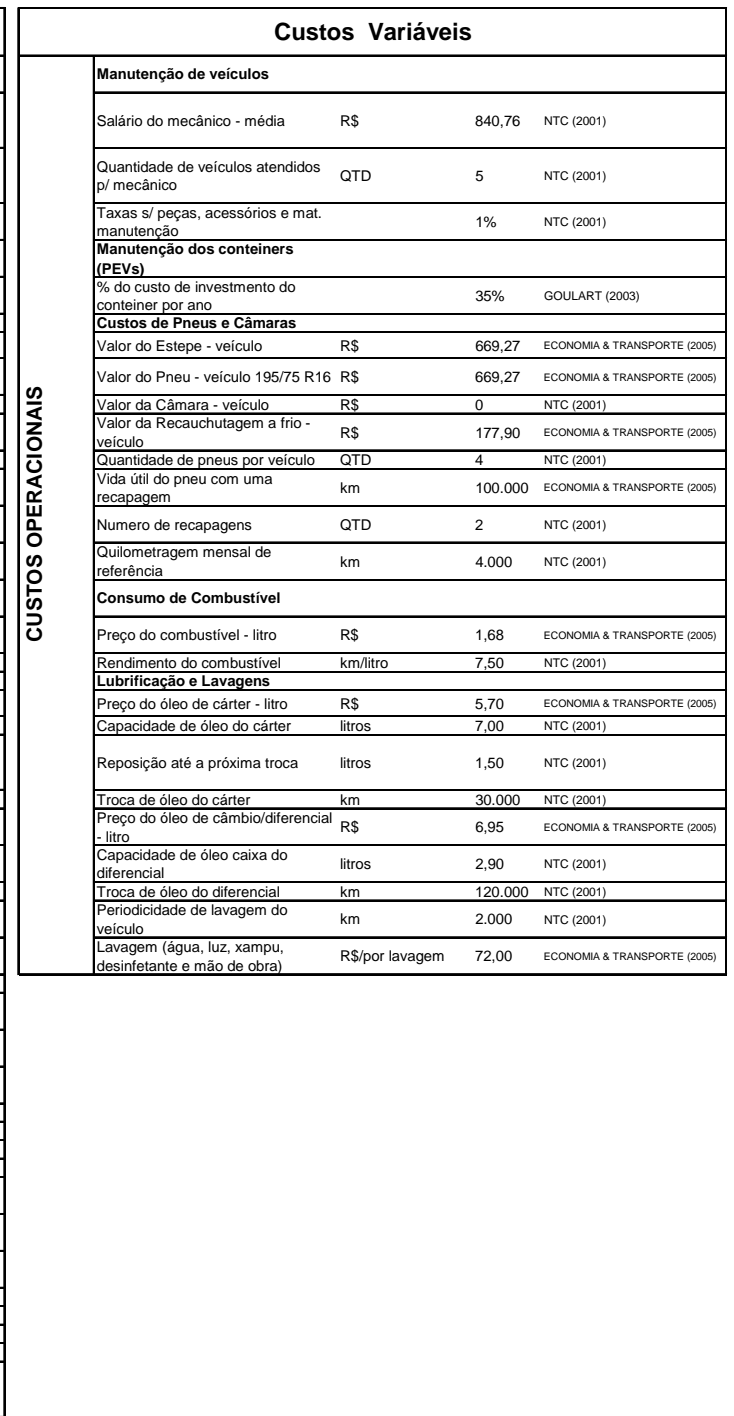


Planilha 20. Parâmetros de custo, com alterações no período de vida útil dos equipamentos, na taxa de remuneração do capital investido e nos encargos sociais e salários.

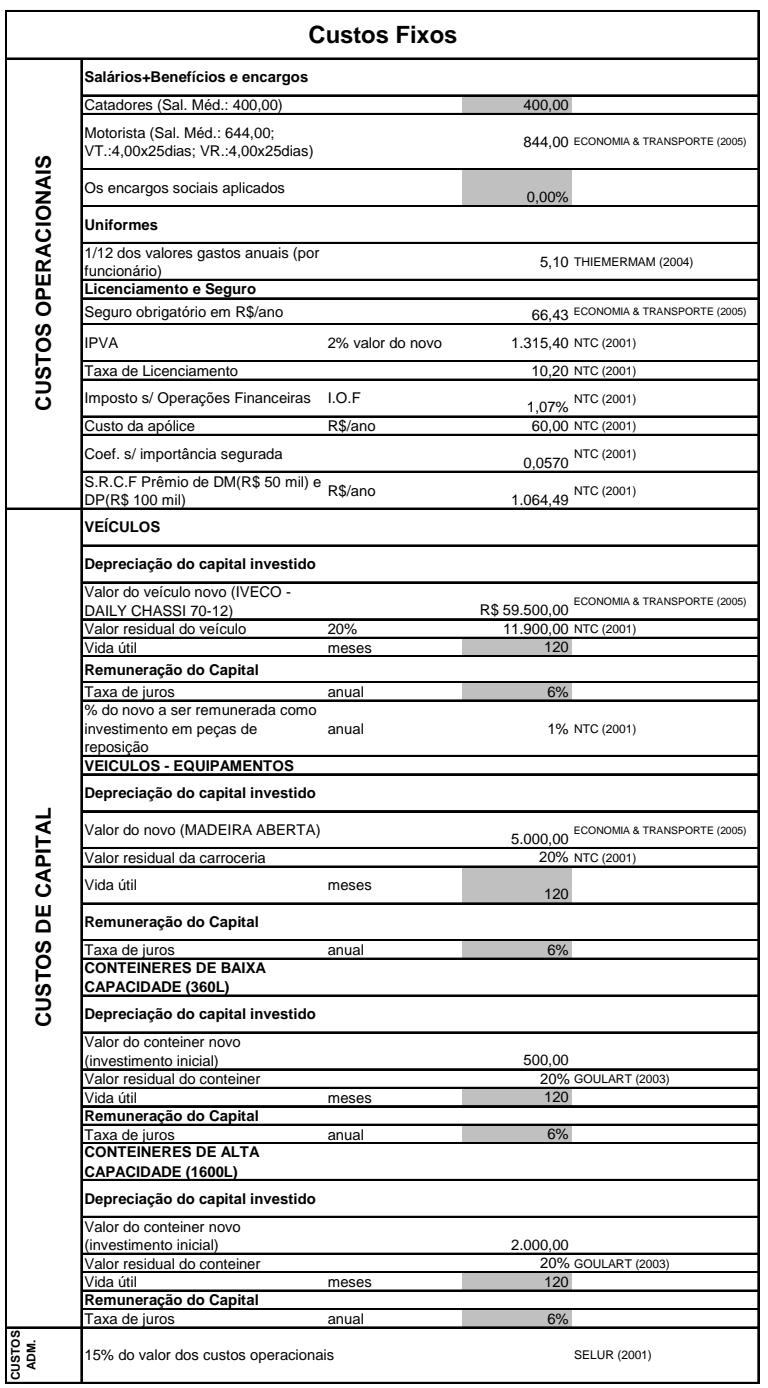

\begin{tabular}{|c|c|c|c|c|}
\hline \multicolumn{5}{|c|}{ Custos Variáveis } \\
\hline \multirow{27}{*}{ 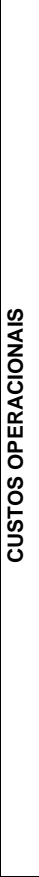 } & Manutenção de veículos & & & \\
\hline & Salário do mecânico - média & $\mathrm{R} \$$ & 840,76 & NTC (2001) \\
\hline & $\begin{array}{l}\text { Quantidade de veículos atendidos } \\
\text { p/mecânico }\end{array}$ & QTD & 5 & NTC (2001) \\
\hline & $\begin{array}{l}\begin{array}{l}\text { Taxas s/ peças, acessórios e mat. } \\
\text { manutenção }\end{array} \\
\end{array}$ & & $1 \%$ & NTC (2001) \\
\hline & $\begin{array}{l}\begin{array}{l}\text { Manutenção dos conteiners } \\
\text { (PEVs) }\end{array} \\
\end{array}$ & & & \\
\hline & $\begin{array}{l}\text { \% do custo de investmento do } \\
\text { conteiner por ano }\end{array}$ & & $35 \%$ & GOULART (2003) \\
\hline & Custos de Pneus e Câmaras & & & \\
\hline & \begin{tabular}{|l|l} 
Valor do Estepe - veículo \\
\end{tabular} & $\mathrm{R} \Phi$ & 669,27 & ECONOMA\& TRANSPORTE (2005) \\
\hline & Valor do Pneu - veículo 195/75 R16 & & 669,27 & ECONOMA \& TRANSPORTE (2005) \\
\hline & \begin{tabular}{|l|} 
Valor da Câmara - veículo \\
\end{tabular} & $\mathrm{R} \$$ & 0 & NTC (2001) \\
\hline & $\begin{array}{l}\text { Valor da Recauchutagem a frio - } \\
\text { veículo }\end{array}$ & $\mathrm{R} \$$ & 177,90 & ECONOMA \& TRANSPORTE (2005) \\
\hline & $\begin{array}{l}\text { Quantidade de pneus por veículo } \\
\text { Quntion }\end{array}$ & QTD & 4 & NTC (2001) \\
\hline & $\begin{array}{l}\text { Vida útil do pneu com uma } \\
\text { recapagem }\end{array}$ & $\mathrm{km}$ & 100.000 & ECONOMA \& TRANSPORTE (2005) \\
\hline & Numero de recapagens & QTD & 2 & NTC (2001) \\
\hline & $\begin{array}{l}\text { Quilometragem mensal de } \\
\text { referência }\end{array}$ & $\mathrm{km}$ & 4.000 & NTC (2001) \\
\hline & Consumo de Combustivel & & & \\
\hline & Preço do combustivel - litro & $\mathrm{R} \$$ & 1,68 & ECONOMA\& TRANSPORTE (2005) \\
\hline & \begin{tabular}{|l|} 
Rendimento do combustivel \\
Lubrificacão e Lavagens \\
\end{tabular} & $\mathrm{km} / \mathrm{litro}$ & 7,50 & NTC (2001) \\
\hline & \begin{tabular}{|l|} 
Preço do óleo de cárter - litro \\
\end{tabular} & $\mathrm{R} \$$ & 5,70 & ECONOMA \& TRANSPORTE (2005) \\
\hline & Capacidade de óleo do cárter & litros & 7,00 & NTC (2001) \\
\hline & Reposição até a próxima troca & litros & 1,50 & NTC (2001) \\
\hline & Troca de óleo do cárter & $\mathrm{km}$ & 30.000 & NTC (2001) \\
\hline & $\begin{array}{l}\begin{array}{l}\text { Preço do óleo de câmbio/diferencial } \\
\text {-litro }\end{array} \\
\end{array}$ & $\mathrm{R} \$$ & 6,95 & ECONOMA\& TRANSPORTE (2005) \\
\hline & \begin{tabular}{|l} 
Capacidade de óleo caixa do \\
differencial
\end{tabular} & litros & 2,90 & NTC (2001) \\
\hline & Troca de óleo do diferencial & $\mathrm{km}$ & 120.000 & NTC (2001) \\
\hline & $\begin{array}{l}\text { Periodicidade de lavagem do } \\
\text { veículo }\end{array}$ & $\mathrm{km}$ & 2.000 & NTC (2001) \\
\hline & $\begin{array}{l}\text { Lavagem (água, luz, xampu, } \\
\text { desinfetante e mão de obra) }\end{array}$ & $\mathrm{R} \$$ /por lavagem & 72,00 & ECONOMA\& \& TRANSPORTE (2005) \\
\hline
\end{tabular}


Planilha 21. Parâmetros de custo, com variações nos tipos de contêineres.

\begin{tabular}{|c|c|c|c|c|}
\hline \multicolumn{5}{|c|}{ Custos Fixos } \\
\hline \multirow{14}{*}{ 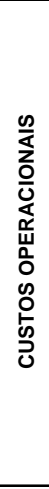 } & \multicolumn{4}{|l|}{ Salários+Benefícios e encargos } \\
\hline & $\begin{array}{l}\text { Catadores (Sal. Méd.: } 300,00 ; \\
\text { VT.:4,00x25dias; VR: } 4,00 \times 25 \text { dias) }\end{array}$ & & 500,00 & SELUR (2001) \\
\hline & $\begin{array}{l}\text { Motorista (Sal. Méd.: } 644,00 ; \\
\text { VT. :4, } 00 \times 25 \text { dias; VR.:4,00x25dias) }\end{array}$ & & 844,00 & ECONOMIA \& TRANSPORTE (2005) \\
\hline & Os encargos sociais aplicados & & $79,81 \%$ & SELUR (2001) \\
\hline & Uniformes & & & \\
\hline & \begin{tabular}{|l}
$1 / 12$ dos valores gastos anuais (po \\
funcionário)
\end{tabular} & & 5,10 & THIEMERMAM (2004) \\
\hline & Licenciamento e Seguro & & & \\
\hline & Seguro obrigatório em $\mathrm{R} \$ /$ ano & & 66,43 & ECONOMIA \& TRANSPORTE (2005) \\
\hline & IPVA & $2 \%$ valor do novo & $1.315,40$ & NTC (2001) \\
\hline & Taxa de Licenciamento & & 10,20 & NTC (2001) \\
\hline & Imposto s/ Operações Financeiras & I.O.F & $1,07 \%$ & NTC (2001) \\
\hline & \begin{tabular}{|l} 
Custo da apólice \\
\end{tabular} & $\mathrm{R} \$$ /ano & 60,00 & NTC (2001) \\
\hline & Coef. s/ importância segurada & & 0,0570 & NTC (2001) \\
\hline & $\begin{array}{l}\text { S.R.C.F Prêmio de DM(R\$ } 50 \text { mil) } \\
\text { DP(R\$ } 100 \text { mil) }\end{array}$ & RS/ano & $1.064,49$ & NTC (2001) \\
\hline \multirow{32}{*}{ 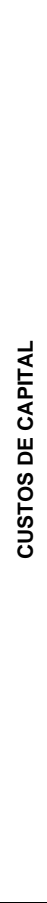 } & \multicolumn{4}{|l|}{ VEículos } \\
\hline & \multicolumn{4}{|l|}{ Depreciação do capital investido } \\
\hline & \begin{tabular}{|l|} 
Valor do veículo novo (IVECO- \\
DAILY CHASSI 70-12)
\end{tabular} & & $\mathrm{R} \$ 59.500,00$ & ECONOMIA \& TRANSPPRTE (2005) \\
\hline & \begin{tabular}{|l|} 
Valor residual do veiculo \\
Vida útil \\
\end{tabular} & $\begin{array}{ll}20 \% \\
\text { meses }\end{array}$ & $\begin{array}{ll}11.900,00 \\
60\end{array}$ & $\frac{\text { NTC (2001) }}{\text { NTC (2001) }}$ \\
\hline & \multicolumn{4}{|l|}{\begin{tabular}{|l|} 
Remuneração do Capital \\
\end{tabular}} \\
\hline & Taxa de juros & anual & $12 \%$ & NTC (2001) \\
\hline & $\begin{array}{l}\text { \% do novo a ser remunerada como } \\
\text { investimento em peças de } \\
\text { reposição }\end{array}$ & anual & $1 \%$ & NTC (2001) \\
\hline & VEICULOS - EQUIPAMENTOS & & & \\
\hline & \multicolumn{4}{|l|}{ Depreciação do capital investido } \\
\hline & Valor do novo (MADEIRA ABERTA & & $5.000,00$ & ECONOMA \& TRANSPORTE (2005) \\
\hline & \begin{tabular}{|l} 
Valor residual da carroceria \\
\end{tabular} & & $5 \%$ & NTC (2001) \\
\hline & Vida útil & meses & 60 & NTC (2001) \\
\hline & \multicolumn{4}{|l|}{ Remuneração do Capital } \\
\hline & \begin{tabular}{|l|} 
Taxa de juros \\
CONTEINERES \\
\end{tabular} & anual & $12 \%$ & NTC (2001) \\
\hline & \multicolumn{4}{|l|}{ Depreciação do capital investido } \\
\hline & \multicolumn{4}{|l|}{\begin{tabular}{|l|}
$\begin{array}{l}\text { Valor do conteiner novo } \\
\text { (investimento inicial) }\end{array}$ \\
\end{tabular}} \\
\hline & $\frac{120 \mathrm{~L}}{200 \mathrm{~L}}$ & & $\frac{195,00}{600}$ & $\begin{array}{l}\text { Brazil Virgo } \\
\text { Canishi }\end{array}$ \\
\hline & $\frac{200 L}{240 L}$ & & $\frac{6,00}{245,00}$ & $\begin{array}{l}\text { Conishi } \\
\text { Brazil Virgo } \\
\end{array}$ \\
\hline & $360 \mathrm{~L}$ & & 540,00 & Brazil Virgo \\
\hline & $750 \mathrm{~L}$ & & 860,00 & Arte da Fibra \\
\hline & & & $1.080,00$ & Arte da Fibra \\
\hline & $1000 \mathrm{~L}$ & & $1.320,00$ & $\begin{array}{l}\text { Dix Higiêne } \\
\text { Torabas }\end{array}$ \\
\hline & $\frac{1200 \mathrm{~L}}{130 \mathrm{~L}}$ & & 980,00 & Terrabras \\
\hline & $\frac{1300 \mathrm{~L}}{1500 \mathrm{~L}}$ & & $\begin{array}{l}1.290,00 \\
1390,00\end{array}$ & $\begin{array}{l}\text { Arte da Fibra } \\
\text { Arte da Fibra }\end{array}$ \\
\hline & $1600 \mathrm{~L}$ & & $2.342,00$ & Conishi \\
\hline & $1800 \mathrm{~L}$ & & $1.740,00$ & Arte da Fibra \\
\hline & & & 2.390 .00 & Arte da Fibra \\
\hline & \begin{tabular}{|l} 
Valor residual do conteiner \\
\end{tabular} & & & GOULART (2003) \\
\hline & \begin{tabular}{|l|} 
Vida útil \\
Remuneracão do Capital \\
\end{tabular} & meses & $\frac{30}{60}$ & GOULART (2003) \\
\hline & Taxa de juros & anual & $12 \%$ & ECONOMIA \& TRANSPORTE (2005) \\
\hline & Remuneração do Capital & & & \\
\hline & Taxa de juros & anual & $12 \%$ & ECONOMIA \& TRANSPORTE (2005) \\
\hline 促 & \multicolumn{3}{|l|}{$15 \%$ do valor dos custos operacionais } & SELUR (2001) \\
\hline
\end{tabular}

\begin{tabular}{|c|c|c|c|c|}
\hline \multicolumn{5}{|c|}{ Custos Variáveis } \\
\hline \multirow{25}{*}{ 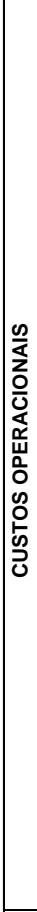 } & \multicolumn{4}{|l|}{ Manutençăo de veículos } \\
\hline & Salário do mecânico - média & $\mathrm{R} \$$ & 840,76 & NTC (2001) \\
\hline & $\begin{array}{l}\text { Quantidade de veículos atendidos } \\
\text { p/mecânico }\end{array}$ & QTD & 5 & NTC (2001) \\
\hline & \begin{tabular}{|l} 
Taxas s/ peças, acessórios e mat. \\
manutenção
\end{tabular} & & $1 \%$ & NTC (2001) \\
\hline & $\begin{array}{l}\% \text { do custo de investmento do } \\
\text { conteiner por ano }\end{array}$ & & $35 \%$ & GOULART (2003) \\
\hline & \begin{tabular}{|l|} 
Custos de Pneus e Câmaras \\
Valor do Estene -
\end{tabular} & $\mathrm{R} \$$ & 669,27 & ECONOMAQ \& TRANSPOPTE (2005) \\
\hline & \begin{tabular}{|l} 
Valor do Estepe - veiculo \\
Valor do Pneu - veículo 195/75 R16
\end{tabular} & $R \$$ & 669,27 & ECONOMA \& TRANSPORTE (2005) \\
\hline & Valor da Câmara - veículo & $\mathrm{R} \$$ & 0 & NTC (2001) \\
\hline & $\begin{array}{l}\text { Valor da Recauchutagem a frio - } \\
\text { veículo }\end{array}$ & $\mathrm{R} \$$ & 177,90 & ECONOMA \& TRANSPORTE (2005) \\
\hline & \begin{tabular}{|l} 
Quantidade de pneus por veículo \\
\end{tabular} & QTD & 4 & NTC (2001) \\
\hline & $\begin{array}{l}\text { Vida útil do pneu com uma } \\
\text { recapagem }\end{array}$ & $\mathrm{km}$ & 100.000 & ECONOMA\& \& TRANSPORTE (2005) \\
\hline & Numero de recapagens & QTD & 2 & NTC (2001) \\
\hline & $\begin{array}{l}\begin{array}{l}\text { Quilometragem mensal de } \\
\text { referência }\end{array} \\
\end{array}$ & $\mathrm{km}$ & 4.000 & NTC (2001) \\
\hline & Consumo de Combustível & & & \\
\hline & Preço do combustivel - litro & $\mathrm{R} \$$ & 1,68 & ECONOMA \& TRANSPORTE (2005) \\
\hline & \begin{tabular}{|l|} 
Rendimento do combustivel \\
Lubrificação e Lavagens \\
\end{tabular} & $\mathrm{km} / \mathrm{litro}$ & 7,50 & NTC (2001) \\
\hline & Preço do óleo de cárter - litro & $\mathrm{R} \$$ & 5,70 & ECONOMIA \& TRANSPORTE (2005) \\
\hline & \begin{tabular}{|l} 
Capacidade de óleo do cárter \\
\end{tabular} & litros & 7,00 & NTC (2001) \\
\hline & Reposição até a próxima troca & litros & 1,50 & NTC (2001) \\
\hline & Troca de óleo do cárter & $\mathrm{km}$ & 30.000 & NTC (2001) \\
\hline & $\begin{array}{l}\text { Preço do óleo de câmbio/diferencial } \\
\text { - litro }\end{array}$ & $R \$$ & 6,95 & ECONOMA \& TRANSPORTE (2005) \\
\hline & $\begin{array}{l}\text { Capacidade de óleo caixa do } \\
\text { diferencial }\end{array}$ & litros & 2,90 & NTC (2001) \\
\hline & 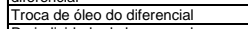 & $\mathrm{km}$ & 120.000 & NTC (2001) \\
\hline & $\begin{array}{l}\begin{array}{l}\text { Periodicidade de lavagem do } \\
\text { veículo }\end{array} \\
\end{array}$ & $\mathrm{km}$ & 2.000 & NTC (2001) \\
\hline & \begin{tabular}{|l} 
Lavagem (água, luz, xampu, \\
desinfetante e mâo de obra)
\end{tabular} & $\mathrm{R} \$ /$ por lavagem & 72,00 & ECONOMA \& TRANSPORTE (2005) \\
\hline 总高 & $15 \%$ do valor dos custos operaciona & & & SELUR (2001) \\
\hline
\end{tabular}


Planilha 22. Planilha de custo para o cenário PEV20 e configuração de contêineres C1, com os parâmetros mostrados na Planilha 16 (parâmetros inicialmente propostos).

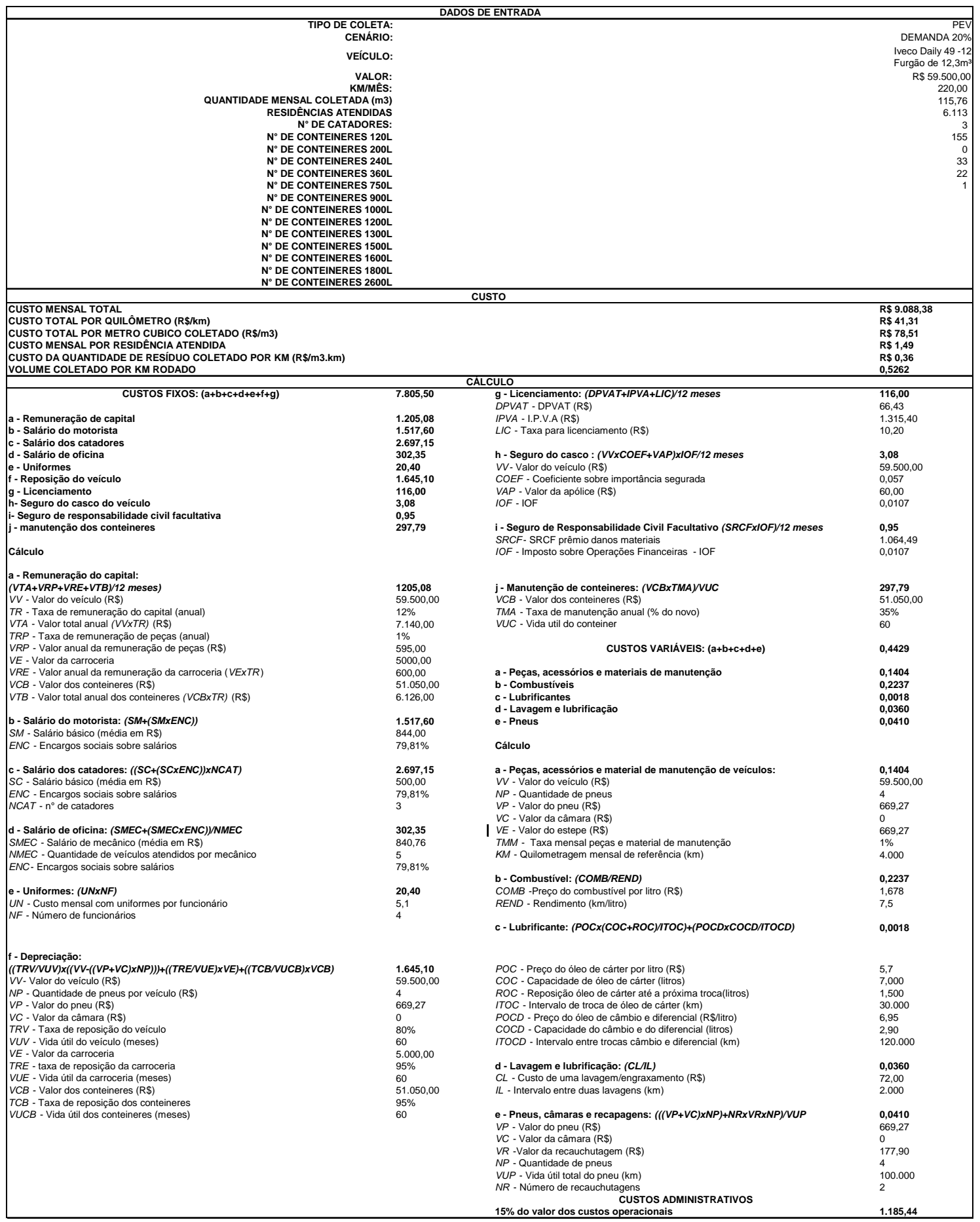


APÊNDICE D

Planilhas com os resultados das combinações dos contêineres para cada cenário 
Planilha 23. Número de contêineres para o cenário PEV20 e configuração C1

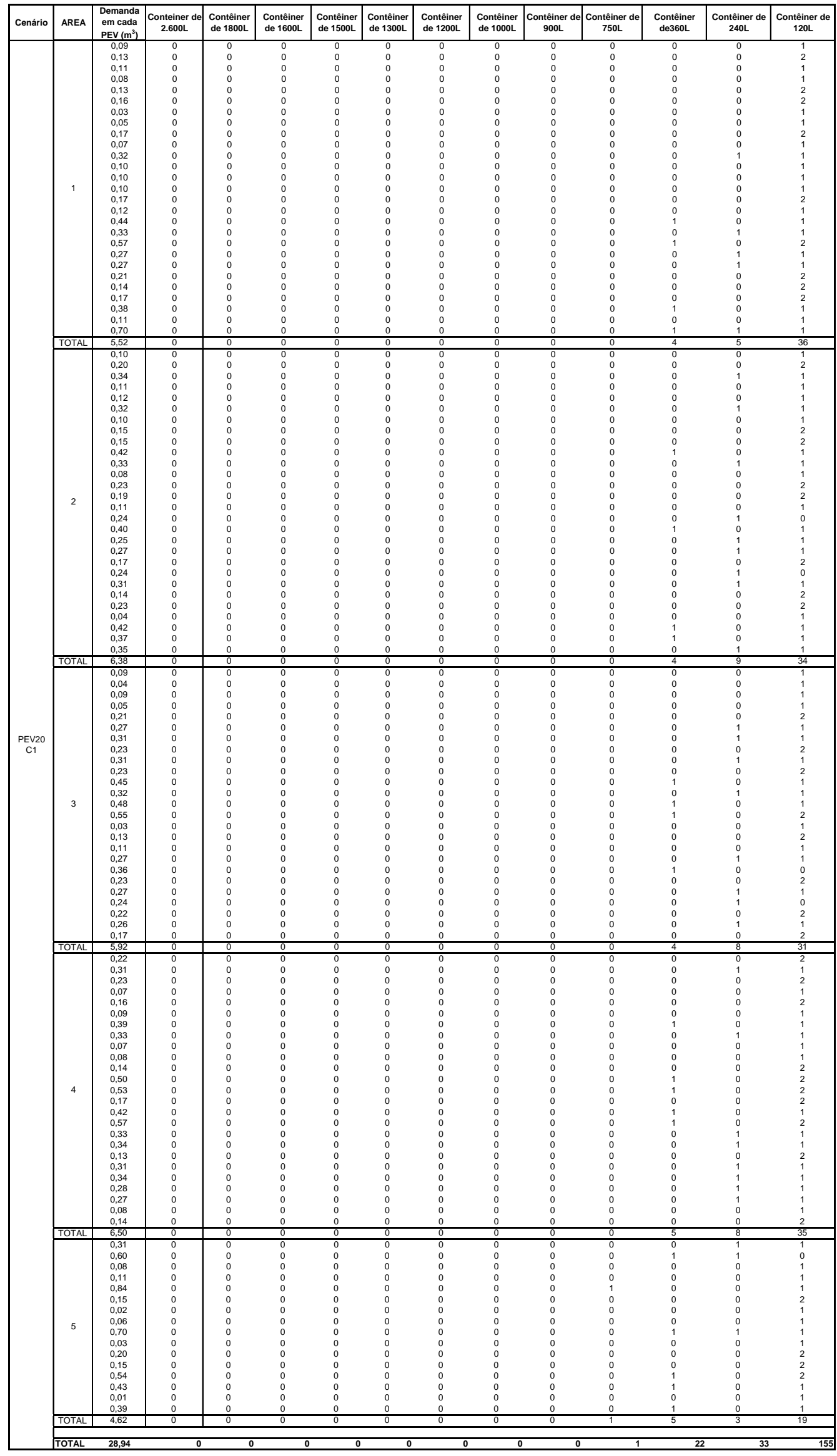


Planilha 24. Número de contêineres para o cenário PEV40 e configuração C1

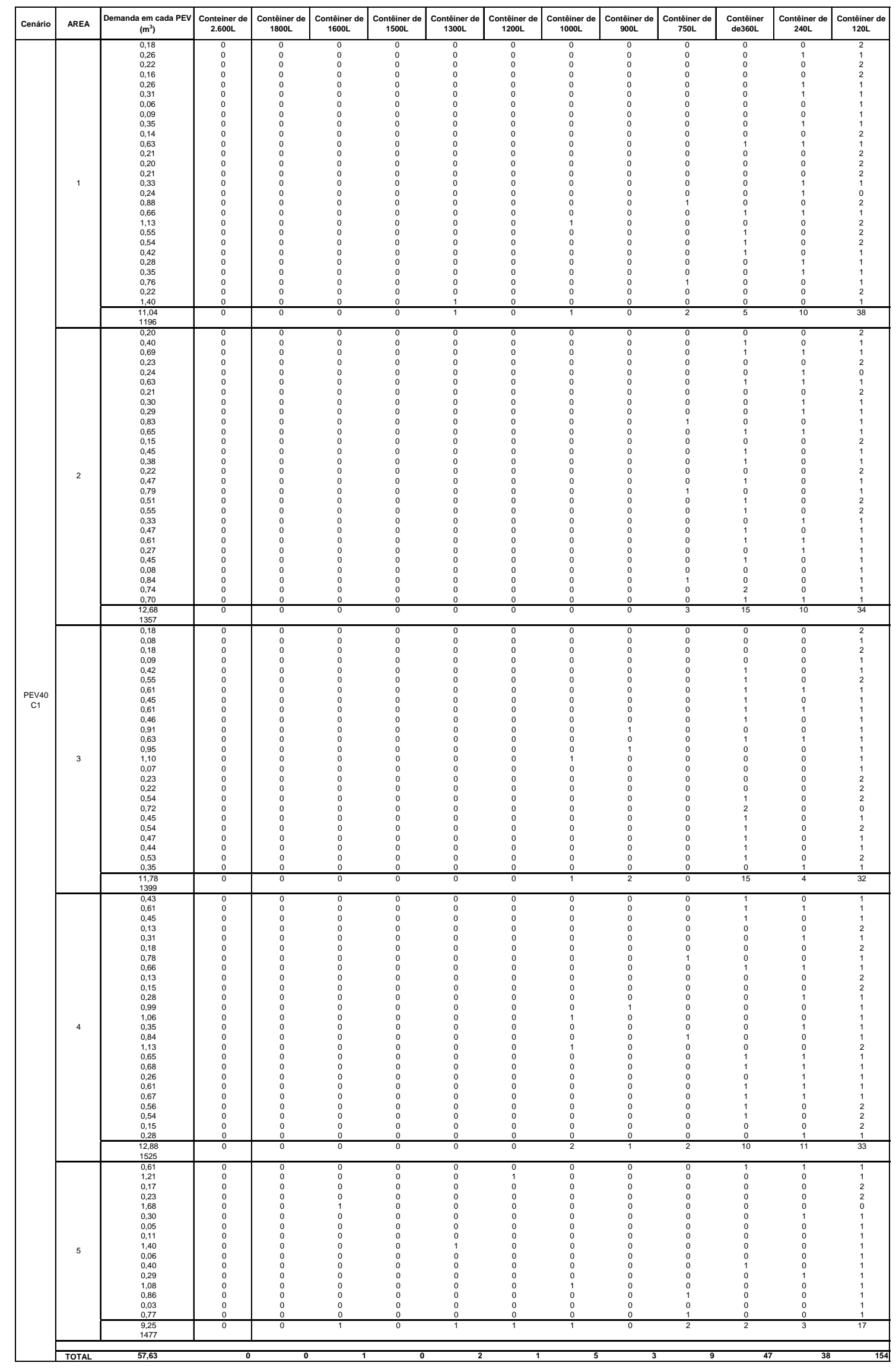


Planilha 25. Número de contêineres para o cenário PEV60 e configuração C1

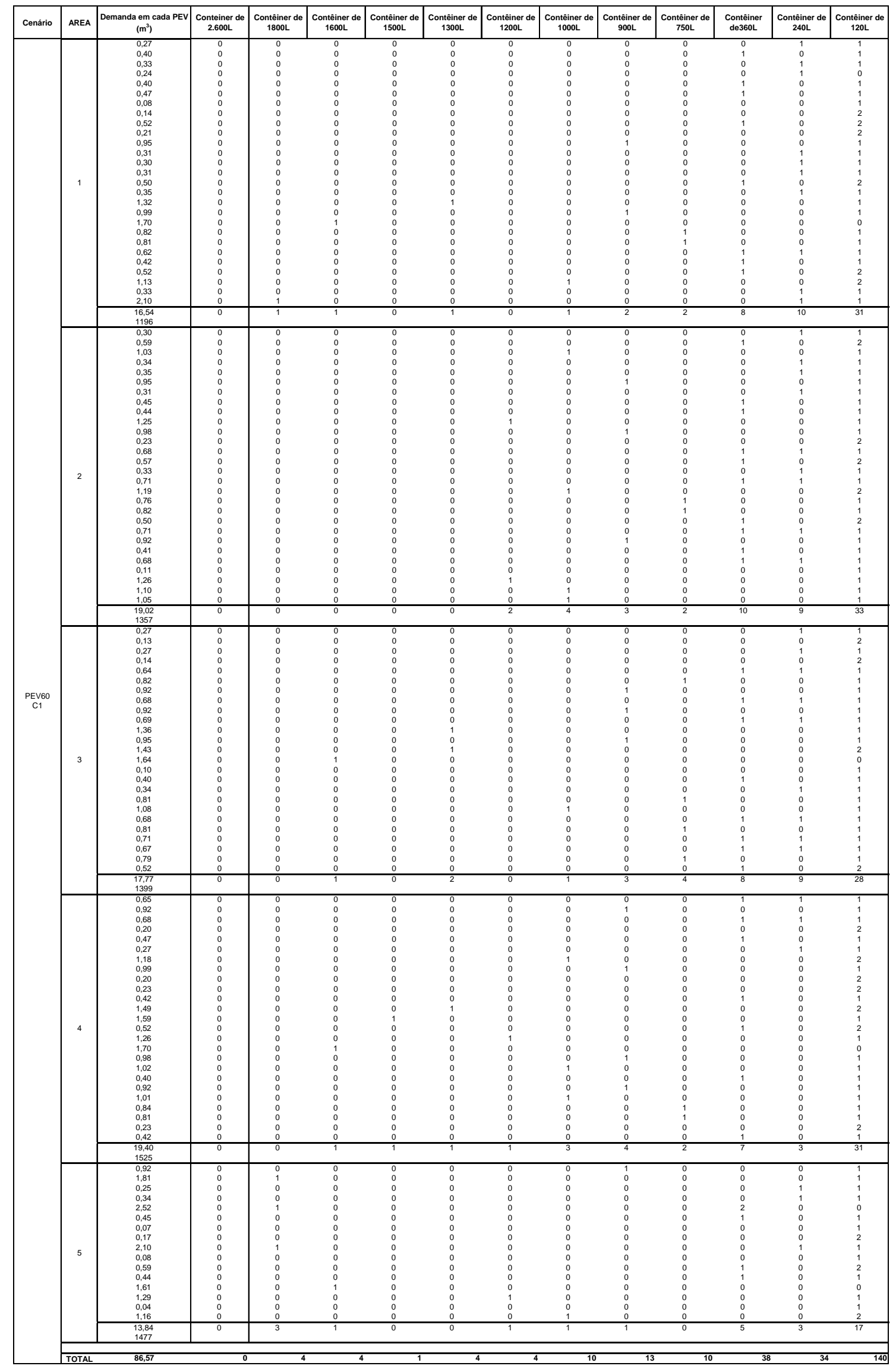


Planilha 26. Número de contêineres para o cenário PEV80 e configuração C1

\begin{tabular}{|c|c|c|c|c|c|c|c|c|c|c|c|c|c|c|}
\hline Cenário & AREA & \begin{tabular}{|c} 
Demanda em cada PEV \\
$\left(\mathrm{m}^{3}\right)$
\end{tabular} & $\begin{array}{c}\text { Conteiner de } \\
2.600 \mathrm{~L}\end{array}$ & $\begin{array}{c}\text { Contêiner de } \\
1800 \mathrm{~L}\end{array}$ & $\begin{array}{c}\text { Contêiner de } \\
1600 \mathrm{~L}\end{array}$ & $\begin{array}{c}\text { Contêiner de } \\
1500 \mathrm{~L}\end{array}$ & $\begin{array}{c}\text { Contêiner de } \\
1300 \mathrm{~L}\end{array}$ & $\begin{array}{c}\text { Contêiner de } \\
1200 \mathrm{~L}\end{array}$ & $\begin{array}{c}\text { Contêiner de } \\
1000 \mathrm{~L}\end{array}$ & $\begin{array}{c}\text { Contêiner de } \\
900 \mathrm{~L}\end{array}$ & $\begin{array}{c}\text { Contêiner de } \\
750 \mathrm{~L}\end{array}$ & $\begin{array}{l}\text { Contêiner } \\
\text { de360L }\end{array}$ & $\begin{array}{c}\text { Contêiner de } \\
240 \mathrm{~L}\end{array}$ & $\begin{array}{c}\text { Contêiner de } \\
120 \mathrm{~L}\end{array}$ \\
\hline \multirow{10}{*}{$\begin{array}{l}\text { PEV80 } \\
\text { C1 }\end{array}$} & \multirow[t]{2}{*}{1} & $\begin{array}{l}0,36 \\
0,53 \\
0,43 \\
0,32 \\
0,53 \\
0,62 \\
0,11 \\
0,19 \\
0,70 \\
0,28 \\
1,27 \\
0,42 \\
0,40 \\
0,42 \\
0,466 \\
0,47 \\
1,76 \\
1,32 \\
2,27 \\
1,10 \\
1,08 \\
0,83 \\
0,57 \\
0,70 \\
1,51 \\
0,43 \\
2,80 \\
\end{array}$ & $\begin{array}{l}0 \\
0 \\
0 \\
0 \\
0 \\
0 \\
0 \\
0 \\
0 \\
0 \\
0 \\
0 \\
0 \\
0 \\
0 \\
0 \\
0 \\
0 \\
0 \\
0 \\
0 \\
0 \\
0 \\
0 \\
0 \\
0 \\
1 \\
\end{array}$ & $\begin{array}{l}0 \\
0 \\
0 \\
0 \\
0 \\
0 \\
0 \\
0 \\
0 \\
0 \\
0 \\
0 \\
0 \\
0 \\
0 \\
0 \\
0 \\
0 \\
1 \\
0 \\
0 \\
0 \\
0 \\
0 \\
0 \\
0 \\
0 \\
0 \\
\end{array}$ & $\begin{array}{l}0 \\
0 \\
0 \\
0 \\
0 \\
0 \\
0 \\
0 \\
0 \\
0 \\
0 \\
0 \\
0 \\
0 \\
0 \\
0 \\
1 \\
0 \\
0 \\
0 \\
0 \\
0 \\
0 \\
0 \\
0 \\
0 \\
0 \\
\end{array}$ & $\begin{array}{l}0 \\
0 \\
0 \\
0 \\
0 \\
0 \\
0 \\
0 \\
0 \\
0 \\
0 \\
0 \\
0 \\
0 \\
0 \\
0 \\
0 \\
0 \\
0 \\
0 \\
0 \\
0 \\
0 \\
0 \\
1 \\
0 \\
0 \\
\end{array}$ & $\begin{array}{l}0 \\
0 \\
0 \\
0 \\
0 \\
0 \\
0 \\
0 \\
0 \\
0 \\
0 \\
0 \\
0 \\
0 \\
0 \\
0 \\
0 \\
0 \\
0 \\
1 \\
0 \\
0 \\
0 \\
0 \\
0 \\
0 \\
0 \\
0 \\
0 \\
0\end{array}$ & $\begin{array}{l}0 \\
0 \\
0 \\
0 \\
0 \\
0 \\
0 \\
0 \\
0 \\
0 \\
1 \\
0 \\
0 \\
0 \\
0 \\
0 \\
0 \\
0 \\
0 \\
0 \\
0 \\
0 \\
0 \\
0 \\
0 \\
0 \\
0 \\
\end{array}$ & $\begin{array}{l}0 \\
0 \\
0 \\
0 \\
0 \\
0 \\
0 \\
0 \\
0 \\
0 \\
0 \\
0 \\
0 \\
0 \\
0 \\
0 \\
0 \\
0 \\
0 \\
1 \\
1 \\
0 \\
0 \\
0 \\
0 \\
0 \\
0 \\
\end{array}$ & $\begin{array}{l}0 \\
0 \\
0 \\
0 \\
0 \\
0 \\
0 \\
0 \\
0 \\
0 \\
0 \\
0 \\
0 \\
0 \\
0 \\
0 \\
0 \\
0 \\
0 \\
0 \\
0 \\
0 \\
0 \\
0 \\
0 \\
0 \\
0 \\
\end{array}$ & $\begin{array}{l}0 \\
0 \\
0 \\
0 \\
0 \\
0 \\
0 \\
0 \\
0 \\
0 \\
0 \\
0 \\
0 \\
0 \\
0 \\
0 \\
0 \\
0 \\
0 \\
0 \\
0 \\
1 \\
0 \\
0 \\
0 \\
0 \\
0 \\
\end{array}$ & $\begin{array}{l}1 \\
1 \\
1 \\
0 \\
1 \\
1 \\
0 \\
0 \\
1 \\
0 \\
0 \\
1 \\
1 \\
1 \\
1 \\
1 \\
0 \\
1 \\
1 \\
0 \\
0 \\
1 \\
1 \\
0 \\
1 \\
0 \\
\end{array}$ & $\begin{array}{l}0 \\
0 \\
0 \\
1 \\
0 \\
1 \\
0 \\
0 \\
1 \\
1 \\
0 \\
0 \\
0 \\
0 \\
1 \\
0 \\
0 \\
0 \\
0 \\
0 \\
0 \\
0 \\
0 \\
1 \\
0 \\
0 \\
0 \\
\end{array}$ & $\begin{array}{l}0 \\
2 \\
1 \\
1 \\
2 \\
1 \\
1 \\
2 \\
1 \\
1 \\
1 \\
1 \\
1 \\
1 \\
1 \\
1 \\
0 \\
1 \\
1 \\
1 \\
1 \\
2 \\
1 \\
1 \\
1 \\
2 \\
\end{array}$ \\
\hline & & $\begin{array}{r}22,08 \\
1196 \\
\end{array}$ & 1 & 1 & 1 & 1 & 1 & 1 & 2 & 0 & 1 & 15 & 6 & 30 \\
\hline & \multirow[t]{2}{*}{2} & $\begin{array}{l}0,40 \\
0,79 \\
1,38 \\
0,45 \\
0,47 \\
1,27 \\
0,42 \\
0,60 \\
0,59 \\
1,66 \\
1,30 \\
0,30 \\
0,91 \\
0,76 \\
0,43 \\
0,94 \\
1,60 \\
1,02 \\
1,10 \\
0.66 \\
0,94 \\
1,23 \\
0,55 \\
0,91 \\
0,15 \\
1,68 \\
1,47 \\
1,40 \\
\end{array}$ & $\begin{array}{l}0 \\
0 \\
0 \\
0 \\
0 \\
0 \\
0 \\
0 \\
0 \\
0 \\
0 \\
0 \\
0 \\
0 \\
0 \\
0 \\
0 \\
0 \\
0 \\
0 \\
0 \\
0 \\
0 \\
0 \\
0 \\
0 \\
0 \\
0 \\
0 \\
\end{array}$ & $\begin{array}{l}0 \\
0 \\
0 \\
0 \\
0 \\
0 \\
0 \\
0 \\
0 \\
0 \\
0 \\
0 \\
0 \\
0 \\
0 \\
0 \\
0 \\
0 \\
0 \\
0 \\
0 \\
0 \\
0 \\
0 \\
0 \\
0 \\
0 \\
0 \\
\end{array}$ & $\begin{array}{l}0 \\
0 \\
0 \\
0 \\
0 \\
0 \\
0 \\
0 \\
0 \\
1 \\
0 \\
0 \\
0 \\
0 \\
0 \\
0 \\
1 \\
0 \\
0 \\
0 \\
0 \\
0 \\
0 \\
0 \\
0 \\
1 \\
0 \\
0 \\
\end{array}$ & $\begin{array}{l}0 \\
0 \\
0 \\
0 \\
0 \\
0 \\
0 \\
0 \\
0 \\
0 \\
0 \\
0 \\
0 \\
0 \\
0 \\
0 \\
0 \\
0 \\
0 \\
0 \\
0 \\
0 \\
0 \\
0 \\
0 \\
0 \\
0 \\
0 \\
0 \\
\end{array}$ & $\begin{array}{l}0 \\
0 \\
1 \\
0 \\
0 \\
0 \\
0 \\
0 \\
0 \\
0 \\
1 \\
0 \\
0 \\
0 \\
0 \\
0 \\
0 \\
0 \\
0 \\
0 \\
0 \\
0 \\
0 \\
0 \\
0 \\
0 \\
1 \\
1 \\
\end{array}$ & $\begin{array}{l} \\
0 \\
0 \\
0 \\
0 \\
0 \\
1 \\
0 \\
0 \\
0 \\
0 \\
0 \\
0 \\
0 \\
0 \\
0 \\
0 \\
0 \\
0 \\
0 \\
0 \\
0 \\
1 \\
0 \\
0 \\
0 \\
0 \\
0 \\
0 \\
\end{array}$ & $\begin{array}{l}0 \\
0 \\
0 \\
0 \\
0 \\
0 \\
0 \\
0 \\
0 \\
0 \\
0 \\
0 \\
0 \\
0 \\
0 \\
0 \\
0 \\
1 \\
1 \\
0 \\
0 \\
0 \\
0 \\
0 \\
0 \\
0 \\
0 \\
0 \\
\end{array}$ & $\begin{array}{l}0 \\
0 \\
0 \\
0 \\
0 \\
0 \\
0 \\
0 \\
0 \\
0 \\
0 \\
0 \\
1 \\
0 \\
0 \\
1 \\
0 \\
0 \\
0 \\
0 \\
1 \\
0 \\
0 \\
1 \\
0 \\
0 \\
0 \\
0 \\
\end{array}$ & $\begin{array}{l}0 \\
1 \\
0 \\
0 \\
0 \\
0 \\
0 \\
0 \\
0 \\
0 \\
0 \\
0 \\
0 \\
0 \\
0 \\
1 \\
0 \\
0 \\
0 \\
0 \\
0 \\
0 \\
0 \\
0 \\
0 \\
0 \\
0 \\
0 \\
0 \\
0 \\
0 \\
\end{array}$ & $\begin{array}{ll} & \\
0 & \\
0 & \\
1 \\
1 \\
0 \\
1 \\
1 \\
1 \\
0 \\
0 \\
0 \\
0 \\
0 \\
1 \\
0 \\
0 \\
0 \\
0 \\
1 \\
0 \\
0 \\
1 \\
0 \\
0 \\
0 \\
0 \\
0 \\
\end{array}$ & $\begin{array}{l}0 \\
0 \\
0 \\
0 \\
0 \\
0 \\
0 \\
1 \\
0 \\
0 \\
0 \\
1 \\
0 \\
0 \\
0 \\
0 \\
0 \\
0 \\
0 \\
1 \\
0 \\
0 \\
0 \\
0 \\
0 \\
0 \\
0 \\
0 \\
\end{array}$ & $\begin{array}{l}1 \\
1 \\
1 \\
1 \\
1 \\
1 \\
1 \\
0 \\
2 \\
0 \\
0 \\
1 \\
1 \\
1 \\
1 \\
1 \\
0 \\
1 \\
1 \\
1 \\
1 \\
2 \\
1 \\
2 \\
0 \\
1 \\
\end{array}$ \\
\hline & & $\begin{array}{r}25,38 \\
1357 \\
\end{array}$ & 0 & 0 & 3 & 0 & $\frac{1}{4}$ & 2 & 2 & 4 & 2 & 9 & 3 & 27 \\
\hline & \multirow[t]{2}{*}{3} & $\begin{array}{l}0,36 \\
0,17 \\
0,36 \\
0,19 \\
0,195 \\
1,10 \\
1,23 \\
0,91 \\
1,23 \\
0,93 \\
1,81 \\
1,27 \\
1,91 \\
2,19 \\
0,13 \\
0,53 \\
0,45 \\
1,08 \\
1,44 \\
0,91 \\
1,08 \\
0,94 \\
0,89 \\
1,06 \\
0,70 \\
\end{array}$ & $\begin{array}{l}0 \\
0 \\
0 \\
0 \\
0 \\
0 \\
0 \\
0 \\
0 \\
0 \\
0 \\
0 \\
0 \\
0 \\
0 \\
0 \\
0 \\
0 \\
0 \\
0 \\
0 \\
0 \\
0 \\
0 \\
0 \\
\end{array}$ & $\begin{array}{l}0 \\
0 \\
0 \\
0 \\
0 \\
0 \\
0 \\
0 \\
0 \\
0 \\
1 \\
0 \\
1 \\
1 \\
0 \\
0 \\
0 \\
0 \\
0 \\
0 \\
0 \\
0 \\
0 \\
0 \\
0 \\
\end{array}$ & $\begin{array}{l}0 \\
0 \\
0 \\
0 \\
0 \\
0 \\
0 \\
0 \\
0 \\
0 \\
0 \\
0 \\
0 \\
0 \\
0 \\
0 \\
0 \\
0 \\
0 \\
0 \\
0 \\
0 \\
0 \\
0 \\
0 \\
\end{array}$ & $\begin{array}{l}0 \\
0 \\
0 \\
0 \\
0 \\
0 \\
0 \\
0 \\
0 \\
0 \\
0 \\
0 \\
0 \\
0 \\
0 \\
0 \\
0 \\
0 \\
0 \\
0 \\
0 \\
0 \\
0 \\
0 \\
0 \\
\end{array}$ & $\begin{array}{l}0 \\
0 \\
0 \\
0 \\
0 \\
0 \\
0 \\
0 \\
0 \\
0 \\
0 \\
0 \\
0 \\
0 \\
0 \\
0 \\
0 \\
0 \\
0 \\
0 \\
1 \\
0 \\
0 \\
0 \\
0 \\
0 \\
0 \\
0\end{array}$ & $\begin{array}{l}0 \\
0 \\
0 \\
0 \\
0 \\
0 \\
1 \\
0 \\
1 \\
0 \\
0 \\
1 \\
0 \\
0 \\
0 \\
0 \\
0 \\
0 \\
0 \\
0 \\
0 \\
0 \\
0 \\
0 \\
0 \\
\end{array}$ & $\begin{array}{l}0 \\
0 \\
0 \\
0 \\
0 \\
1 \\
0 \\
0 \\
0 \\
0 \\
0 \\
0 \\
0 \\
0 \\
0 \\
0 \\
0 \\
1 \\
0 \\
0 \\
1 \\
0 \\
0 \\
1 \\
0\end{array}$ & $\begin{array}{l}0 \\
0 \\
0 \\
0 \\
0 \\
0 \\
0 \\
1 \\
0 \\
1 \\
0 \\
0 \\
0 \\
0 \\
0 \\
0 \\
0 \\
0 \\
0 \\
1 \\
0 \\
1 \\
0 \\
0 \\
\end{array}$ & $\begin{array}{l}0 \\
0 \\
0 \\
0 \\
1 \\
0 \\
0 \\
0 \\
0 \\
0 \\
0 \\
0 \\
0 \\
0 \\
0 \\
0 \\
0 \\
0 \\
0 \\
0 \\
0 \\
0 \\
0 \\
0 \\
1 \\
0 \\
0\end{array}$ & $\begin{array}{l}1 \\
0 \\
1 \\
0 \\
0 \\
0 \\
0 \\
0 \\
0 \\
0 \\
0 \\
0 \\
0 \\
1 \\
0 \\
1 \\
1 \\
0 \\
0 \\
0 \\
0 \\
0 \\
0 \\
0 \\
1 \\
\end{array}$ & $\begin{array}{l}0 \\
0 \\
0 \\
0 \\
0 \\
0 \\
0 \\
0 \\
0 \\
0 \\
0 \\
0 \\
0 \\
0 \\
0 \\
0 \\
0 \\
0 \\
0 \\
0 \\
0 \\
0 \\
0 \\
0 \\
0 \\
1 \\
\end{array}$ & $\begin{array}{l}0 \\
2 \\
0 \\
0 \\
2 \\
1 \\
1 \\
1 \\
1 \\
1 \\
1 \\
1\end{array}$ \\
\hline & & $\begin{array}{r}23,72 \\
1399 \\
\end{array}$ & 0 & 3 & 0 & 0 & 1 & 3 & 4 & 4 & 2 & 6 & 1 & 29 \\
\hline & \multirow[t]{2}{*}{4} & $\begin{array}{l}0,87 \\
1,23 \\
0,91 \\
0,26 \\
0,62 \\
0,36 \\
1,60 \\
1,32 \\
0,26 \\
0,30 \\
0,57 \\
1,98 \\
2,12 \\
0,70 \\
1,68 \\
2,27 \\
1,30 \\
1,36 \\
0,53 \\
1,23 \\
1,34 \\
1,11 \\
1,08 \\
0,30 \\
0,57\end{array}$ & $\begin{array}{l}0 \\
0 \\
0 \\
0 \\
0 \\
0 \\
0 \\
0 \\
0 \\
0 \\
0 \\
0 \\
0 \\
0 \\
0 \\
0 \\
0 \\
0 \\
0 \\
0 \\
0 \\
0 \\
0 \\
0 \\
0 \\
0 \\
0\end{array}$ & $\begin{array}{l}0 \\
0 \\
0 \\
0 \\
0 \\
0 \\
0 \\
0 \\
0 \\
0 \\
0 \\
1 \\
1 \\
0 \\
0 \\
1 \\
0 \\
0 \\
0 \\
0 \\
0 \\
0 \\
0 \\
0 \\
0 \\
\end{array}$ & $\begin{array}{l}0 \\
0 \\
0 \\
0 \\
0 \\
0 \\
1 \\
0 \\
0 \\
0 \\
0 \\
0 \\
0 \\
0 \\
1 \\
0 \\
0 \\
0 \\
0 \\
0 \\
0 \\
0 \\
0 \\
0 \\
0\end{array}$ & $\begin{array}{l}0 \\
0 \\
0 \\
0 \\
0 \\
0 \\
0 \\
0 \\
0 \\
0 \\
0 \\
0 \\
0 \\
0 \\
0 \\
0 \\
0 \\
0 \\
0 \\
0 \\
0 \\
0 \\
0 \\
0 \\
0 \\
\end{array}$ & $\begin{array}{l}0 \\
0 \\
0 \\
0 \\
0 \\
0 \\
0 \\
1 \\
0 \\
0 \\
0 \\
0 \\
0 \\
0 \\
0 \\
0 \\
1 \\
1 \\
0 \\
0 \\
1 \\
0 \\
0 \\
0 \\
0\end{array}$ & $\begin{array}{l}0 \\
1 \\
0 \\
0 \\
0 \\
0 \\
0 \\
0 \\
0 \\
0 \\
0 \\
0 \\
0 \\
0 \\
0 \\
0 \\
0 \\
0 \\
0 \\
1 \\
0 \\
0 \\
0 \\
0 \\
0 \\
\end{array}$ & $\begin{array}{l} \\
0 \\
0 \\
0 \\
0 \\
0 \\
0 \\
0 \\
0 \\
0 \\
0 \\
0 \\
0 \\
0 \\
0 \\
0 \\
0 \\
0 \\
0 \\
0 \\
0 \\
0 \\
1 \\
1 \\
0 \\
0 \\
\end{array}$ & $\begin{array}{l} \\
0 \\
0 \\
1 \\
0 \\
0 \\
0 \\
0 \\
0 \\
0 \\
0 \\
0 \\
0 \\
0 \\
0 \\
0 \\
0 \\
0 \\
0 \\
0 \\
0 \\
0 \\
0 \\
0 \\
0 \\
0 \\
\end{array}$ & $\begin{array}{l}1 \\
0 \\
0 \\
0 \\
0 \\
0 \\
0 \\
0 \\
0 \\
0 \\
0 \\
0 \\
0 \\
0 \\
0 \\
0 \\
0 \\
0 \\
0 \\
0 \\
0 \\
0 \\
0 \\
0 \\
0 \\
\end{array}$ & $\begin{array}{l}0 \\
0 \\
0 \\
0 \\
1 \\
1 \\
0 \\
0 \\
0 \\
0 \\
0 \\
1 \\
0 \\
0 \\
1 \\
0 \\
1 \\
0 \\
0 \\
1 \\
0 \\
0 \\
0 \\
0 \\
0 \\
1 \\
\end{array}$ & $\begin{array}{l}0 \\
0 \\
0 \\
0 \\
1 \\
1 \\
0 \\
0 \\
0 \\
1 \\
1 \\
0 \\
0 \\
1 \\
1 \\
0 \\
0 \\
0 \\
0 \\
0 \\
0 \\
0 \\
0 \\
0 \\
1 \\
0\end{array}$ & $\begin{array}{l}1 \\
1 \\
1 \\
1\end{array}$ \\
\hline & & $\begin{array}{l}25,87 \\
1522\end{array}$ & 0 & 3 & 2 & 0 & 4 & 2 & 2 & 1 & 1 & 7 & 7 & 25 \\
\hline & \multirow[t]{2}{*}{5} & $\begin{array}{l}1,23 \\
2,42 \\
0,34 \\
0,45 \\
3,36 \\
0,60 \\
0,09 \\
0,23 \\
2,80 \\
0,11 \\
0,79 \\
0,59 \\
2,15 \\
1,72 \\
0,06 \\
1,55 \\
\end{array}$ & $\begin{array}{l}0 \\
0 \\
0 \\
0 \\
1 \\
0 \\
0 \\
0 \\
1 \\
0 \\
0 \\
0 \\
0 \\
0 \\
0 \\
0 \\
\end{array}$ & $\begin{array}{l}0 \\
1 \\
0 \\
0 \\
0 \\
0 \\
0 \\
0 \\
0 \\
0 \\
0 \\
0 \\
1 \\
0 \\
0 \\
0 \\
\end{array}$ & $\begin{array}{l}0 \\
0 \\
0 \\
0 \\
0 \\
0 \\
0 \\
0 \\
0 \\
0 \\
0 \\
0 \\
0 \\
1 \\
0 \\
0 \\
\end{array}$ & $\begin{array}{l}0 \\
0 \\
0 \\
0 \\
0 \\
0 \\
0 \\
0 \\
0 \\
0 \\
0 \\
0 \\
0 \\
0 \\
0 \\
0 \\
1 \\
\end{array}$ & $\begin{array}{l}0 \\
0 \\
0 \\
0 \\
0 \\
0 \\
0 \\
0 \\
0 \\
0 \\
0 \\
0 \\
0 \\
0 \\
0 \\
0 \\
0 \\
\end{array}$ & $\begin{array}{l}1 \\
0 \\
0 \\
0 \\
0 \\
0 \\
0 \\
0 \\
0 \\
0 \\
0 \\
0 \\
0 \\
0 \\
0 \\
0 \\
\end{array}$ & $\begin{array}{l}0 \\
0 \\
0 \\
0 \\
0 \\
0 \\
0 \\
0 \\
0 \\
0 \\
0 \\
0 \\
0 \\
0 \\
0 \\
0 \\
0 \\
\end{array}$ & $\begin{array}{l}0 \\
0 \\
0 \\
0 \\
0 \\
0 \\
0 \\
0 \\
0 \\
0 \\
0 \\
0 \\
0 \\
0 \\
0 \\
0 \\
0 \\
\end{array}$ & $\begin{array}{l}0 \\
0 \\
0 \\
0 \\
1 \\
0 \\
0 \\
0 \\
0 \\
0 \\
1 \\
0 \\
0 \\
0 \\
0 \\
0 \\
\end{array}$ & $\begin{array}{l}0 \\
1 \\
0 \\
1 \\
0 \\
1 \\
0 \\
0 \\
0 \\
0 \\
0 \\
1 \\
0 \\
0 \\
0 \\
0 \\
\end{array}$ & $\begin{array}{l}0 \\
1 \\
1 \\
0 \\
0 \\
1 \\
0 \\
0 \\
0 \\
0 \\
0 \\
0 \\
1 \\
0 \\
0 \\
0 \\
\end{array}$ & $\begin{array}{l}1 \\
1 \\
1 \\
1 \\
1 \\
0 \\
1 \\
2 \\
2 \\
1 \\
1 \\
2 \\
1 \\
0 \\
1 \\
1 \\
\end{array}$ \\
\hline & & $\begin{array}{l}18,49 \\
1477 \\
\end{array}$ & 2 & 2 & 1 & 1 & 0 & 1 & 0 & 0 & 2 & 4 & 4 & 17 \\
\hline & STAL & 115,54 & & & & & & & 10 & & & & 21 & 128 \\
\hline
\end{tabular}


Planilha 27. Número de contêineres para o cenário PEV100 e configuração C1

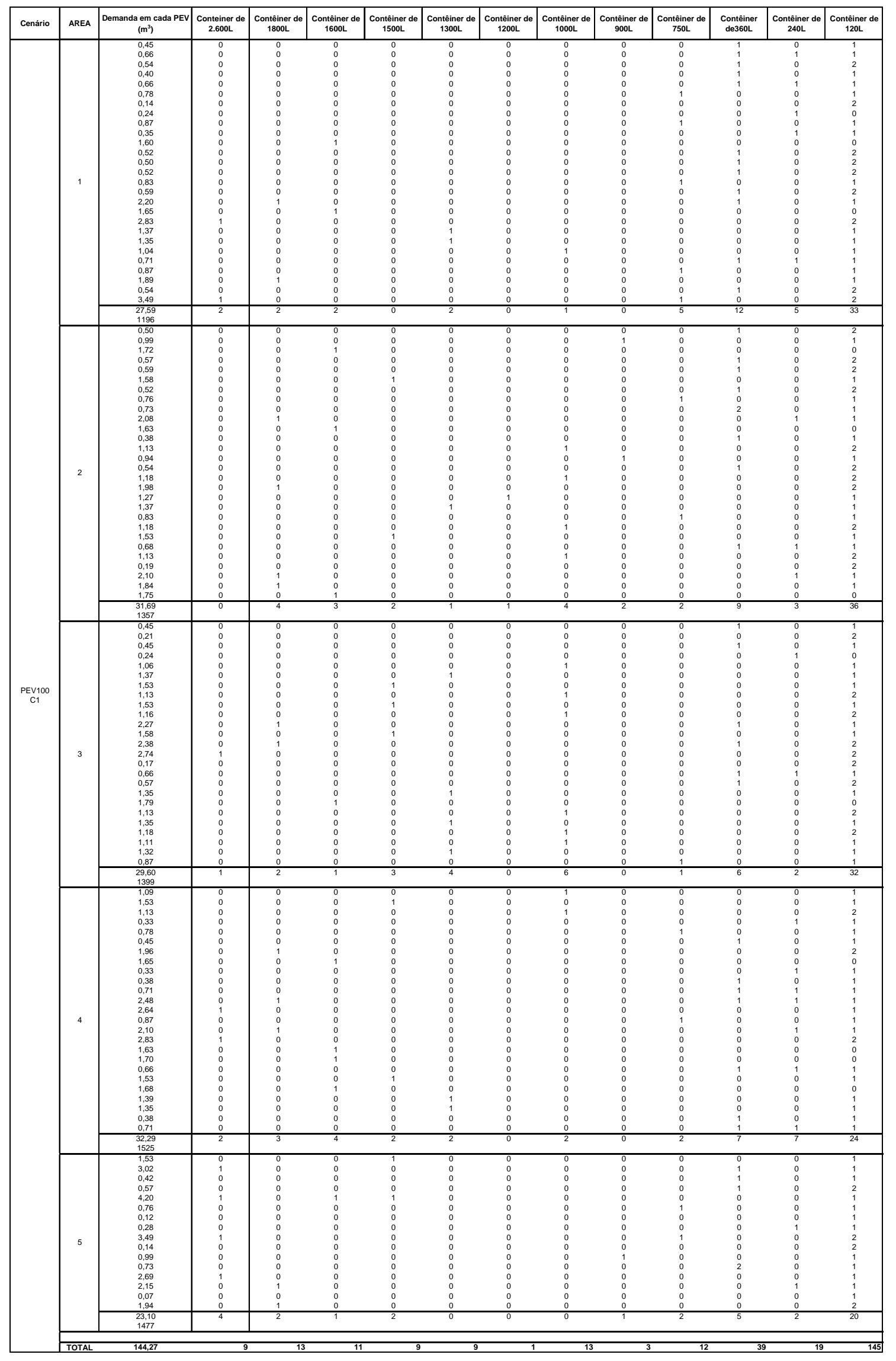

170 
Planilha 28. Número de contêineres para o cenário PEV20 e configuração C2

\begin{tabular}{|c|c|c|c|c|c|c|c|c|c|c|}
\hline Cenário & AREA & $\begin{array}{c}\text { Demanda em cada PEV } \\
\qquad\left(\mathrm{m}^{3}\right)\end{array}$ & $\begin{array}{c}\text { Conteiner de } \\
2.600 \mathrm{~L}\end{array}$ & $\begin{array}{c}\text { Contêiner de } \\
1200 \mathrm{~L}\end{array}$ & $\begin{array}{l}\text { Contêiner de } \\
240 \mathrm{~L}\end{array}$ & AREA & $\begin{array}{c}\text { Demanda em cada PEV } \\
\left(\mathrm{m}^{3}\right)\end{array}$ & $\begin{array}{l}\text { Conteiner } \\
\text { de } 2.600 \mathrm{~L}\end{array}$ & $\begin{array}{l}\text { Contêiner } \\
\text { de } 1200 \mathrm{~L}\end{array}$ & $\begin{array}{l}\text { Contêiner } \\
\text { de } 240 \mathrm{~L}\end{array}$ \\
\hline \multirow{14}{*}{$\begin{array}{c}\text { PEV20 } \\
\text { C2 }\end{array}$} & \multirow[t]{3}{*}{1} & $\begin{array}{l}0,09 \\
0,13 \\
0,11 \\
0,08 \\
0,13 \\
0,16 \\
0,03 \\
0,05 \\
0,17 \\
0,07 \\
0,32 \\
0,10 \\
0,10 \\
0,10 \\
0,17 \\
0,12 \\
0,44 \\
0,33 \\
0,57 \\
0,27 \\
0,27 \\
0,21 \\
0,14 \\
0,17 \\
0,38 \\
0,11\end{array}$ & 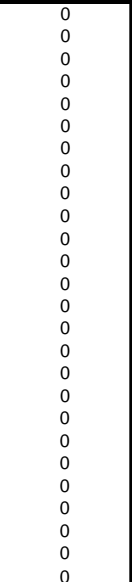 & $\begin{array}{l}0 \\
0 \\
0 \\
0 \\
0 \\
0 \\
0 \\
0 \\
0 \\
0 \\
0 \\
0 \\
0 \\
0 \\
0 \\
0 \\
0 \\
0 \\
0 \\
0 \\
0 \\
0 \\
0 \\
0 \\
0 \\
0 \\
0 \\
0 \\
0 \\
0 \\
0 \\
0 \\
0 \\
0 \\
0 \\
0\end{array}$ & $\begin{array}{l}1 \\
1 \\
1 \\
1 \\
1 \\
1 \\
1 \\
1 \\
1 \\
1 \\
2 \\
1 \\
1 \\
1 \\
1 \\
1 \\
2 \\
2 \\
3 \\
2 \\
2 \\
1 \\
1 \\
1 \\
2 \\
1\end{array}$ & 3 & $\begin{array}{l}0,09 \\
0,04 \\
0,09 \\
0,05 \\
0,21 \\
0,27 \\
0,31 \\
0,23 \\
0,31 \\
0,23 \\
0,45 \\
0,32 \\
0,48 \\
0,55 \\
0,03 \\
0,13 \\
0,11 \\
0,27 \\
0,36 \\
0,23 \\
0,27 \\
0,24 \\
0,22 \\
0,26 \\
0,17 \\
5,92\end{array}$ & 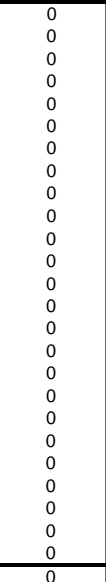 & $\begin{array}{l}0 \\
0 \\
0 \\
0 \\
0 \\
0 \\
0 \\
0 \\
0 \\
0 \\
0 \\
0 \\
0 \\
0 \\
0 \\
0 \\
0 \\
0 \\
0 \\
0 \\
0 \\
0 \\
0 \\
0 \\
0 \\
0 \\
0 \\
0 \\
0 \\
0 \\
0 \\
0 \\
0 \\
0 \\
0\end{array}$ & $\begin{array}{l}1 \\
1 \\
1 \\
1 \\
1\end{array}$ \\
\hline & & 0,70 & 0 & 0 & 3 & \multirow{4}{*}{4} & 0,22 & 0 & 0 & 1 \\
\hline & & 5,52 & 0 & 0 & 37 & & 0,31 & 0 & 0 & 2 \\
\hline & \multirow[t]{6}{*}{2} & $\begin{array}{l}0,10 \\
0,20 \\
0,34 \\
0,11 \\
0,12 \\
0,32 \\
0,10 \\
0,15 \\
0,15 \\
0,42 \\
0,33 \\
0,08 \\
0,23 \\
0,19 \\
0,11 \\
0,24 \\
0,40 \\
0,25 \\
0,27 \\
0,17 \\
0,24 \\
0,31 \\
0,14\end{array}$ & $\begin{array}{l}0 \\
0 \\
0 \\
0 \\
0 \\
0 \\
0 \\
0 \\
0 \\
0 \\
0 \\
0 \\
0 \\
0 \\
0 \\
0 \\
0 \\
0 \\
0 \\
0 \\
0 \\
0 \\
0 \\
0 \\
0 \\
0 \\
0 \\
0 \\
0 \\
0 \\
0 \\
0\end{array}$ & $\begin{array}{l}0 \\
0 \\
0 \\
0 \\
0 \\
0 \\
0 \\
0 \\
0 \\
0 \\
0 \\
0 \\
0 \\
0 \\
0 \\
0 \\
0 \\
0 \\
0 \\
0 \\
0 \\
0 \\
0 \\
0 \\
0 \\
0 \\
0 \\
0 \\
0 \\
0\end{array}$ & $\begin{array}{l}\text { 1 } \\
1 \\
2 \\
1 \\
1 \\
1\end{array}$ & & $\begin{array}{l}0,23 \\
0,07 \\
0,16 \\
0,09 \\
0,39 \\
0,33 \\
0,07 \\
0,08 \\
0,14 \\
0,50 \\
0,53 \\
0,17 \\
0,42 \\
0,57 \\
0,33 \\
0,34 \\
0,13 \\
0,31 \\
0,34 \\
0,28 \\
0,27 \\
0,08 \\
0,14 \\
\end{array}$ & $\begin{array}{l}0 \\
0 \\
0 \\
0 \\
0 \\
0 \\
0 \\
0 \\
0 \\
0 \\
0 \\
0 \\
0 \\
0 \\
0 \\
0 \\
0 \\
0 \\
0 \\
0 \\
0 \\
0 \\
0 \\
0 \\
0 \\
0 \\
0 \\
0 \\
0 \\
0 \\
0\end{array}$ & $\begin{array}{l}0 \\
0 \\
0 \\
0 \\
0 \\
0 \\
0 \\
0 \\
0 \\
0 \\
0 \\
0 \\
0 \\
0 \\
0 \\
0 \\
0 \\
0 \\
0 \\
0 \\
0 \\
0 \\
0 \\
0 \\
0 \\
0 \\
0 \\
0 \\
0 \\
0 \\
0 \\
0 \\
0\end{array}$ & $\begin{array}{l}1 \\
1 \\
1 \\
1 \\
1 \\
2 \\
2 \\
2 \\
1 \\
1 \\
1 \\
3 \\
3 \\
3 \\
1\end{array}$ \\
\hline & & 0,23 & 0 & 0 & 1 & & 6,50 & 0 & 0 & 41 \\
\hline & & $\begin{array}{l}0,04 \\
0,42\end{array}$ & $\begin{array}{l}0 \\
0\end{array}$ & $\begin{array}{l}0 \\
0\end{array}$ & $\begin{array}{l}1 \\
2\end{array}$ & \multirow{6}{*}{5} & $\begin{array}{l}0,31 \\
0,60\end{array}$ & $\begin{array}{l}0 \\
0\end{array}$ & $\begin{array}{l}0 \\
0\end{array}$ & $\begin{array}{l}2 \\
3\end{array}$ \\
\hline & & 0,37 & 0 & 0 & 2 & & 0,08 & 0 & 0 & 1 \\
\hline & & 0,35 & 0 & 0 & 2 & & 0,11 & 0 & 0 & 1 \\
\hline & & 6,38 & 0 & 0 & 39 & & 0,84 & 0 & 0 & 4 \\
\hline & & & & & & & $\begin{array}{l}0,15 \\
0,02 \\
0,06 \\
0,70 \\
0,03 \\
0,20 \\
0,15 \\
0,54 \\
0,43 \\
0,01 \\
0,39 \\
\end{array}$ & $\begin{array}{l}0 \\
0 \\
0 \\
0 \\
0 \\
0 \\
0 \\
0 \\
0 \\
0 \\
0 \\
\end{array}$ & $\begin{array}{l}0 \\
0 \\
0 \\
0 \\
0 \\
0 \\
0 \\
0 \\
0 \\
0 \\
0 \\
\end{array}$ & $\begin{array}{l}1 \\
1 \\
1 \\
3 \\
1 \\
1 \\
1 \\
3 \\
2 \\
1 \\
2 \\
\end{array}$ \\
\hline & & & & & & & 4,62 & 0 & 0 & 28 \\
\hline & \multicolumn{10}{|c|}{ TOTAL } \\
\hline & \multicolumn{3}{|c|}{ Demanda PEV $\left(m^{3}\right)$} & \multicolumn{2}{|c|}{ Conteiner de $2.600 \mathrm{~L}$} & \multicolumn{2}{|c|}{ Contêiner de $1200 \mathrm{~L}$} & \multicolumn{3}{|c|}{ Contêiner de 240L } \\
\hline & \multicolumn{3}{|c|}{28,94} & \multicolumn{2}{|r|}{0} & \multicolumn{2}{|r|}{0} & \multicolumn{3}{|c|}{182} \\
\hline
\end{tabular}


Planilha 29. Número de contêineres para o cenário PEV40 e configuração C2

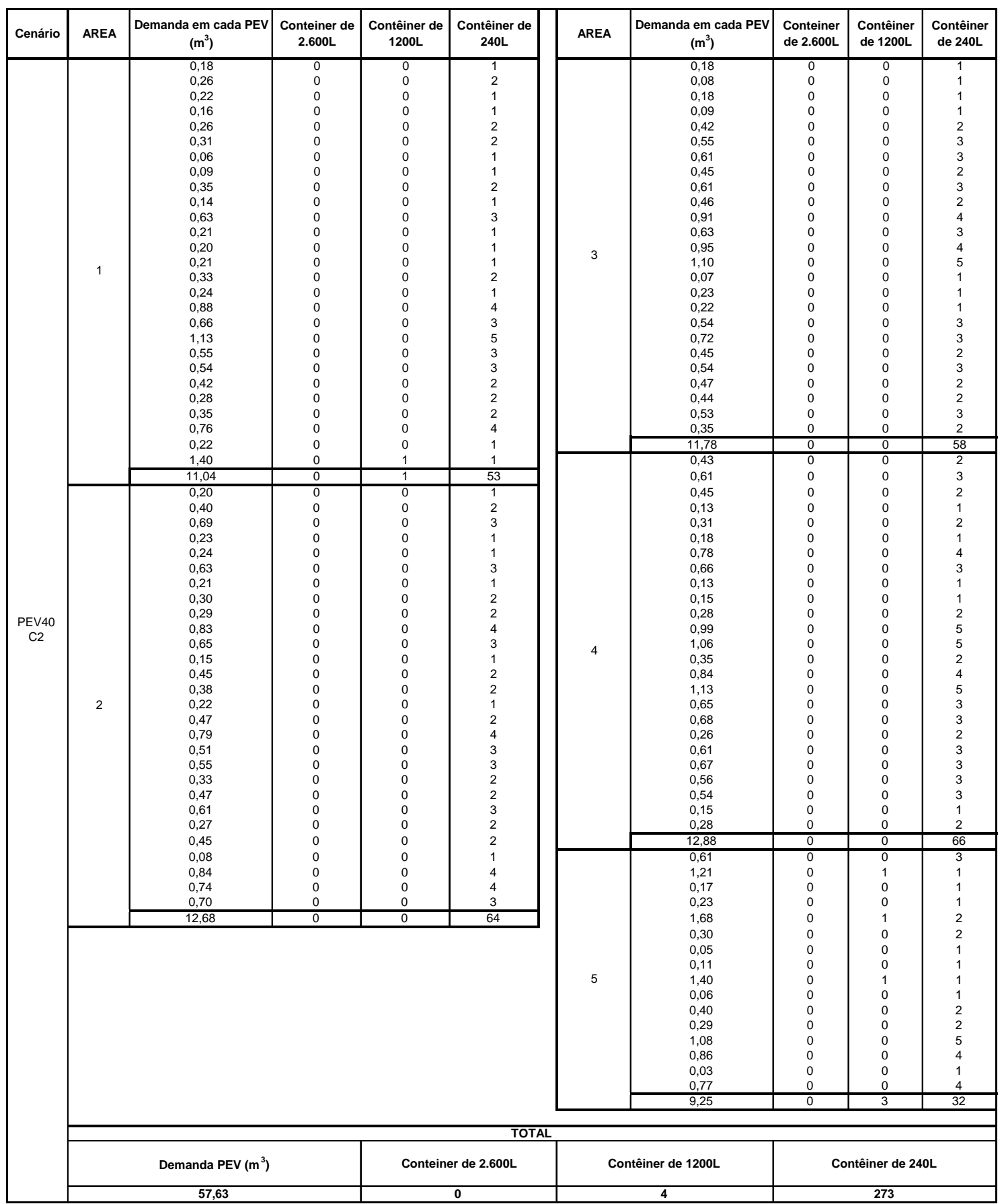


Planilha 30. Número de contêineres para o cenário PEV60 e configuração C2

\begin{tabular}{|c|c|c|c|c|c|c|c|c|c|c|}
\hline Cenário & AREA & $\begin{array}{c}\text { Demanda em cada PEV } \\
\qquad\left(\mathrm{m}^{3}\right)\end{array}$ & $\begin{array}{c}\text { Conteiner de } \\
2.600 \mathrm{~L}\end{array}$ & $\begin{array}{c}\text { Contêiner de } \\
1200 \mathrm{~L}\end{array}$ & $\begin{array}{l}\text { Contêiner de } \\
240 \mathrm{~L}\end{array}$ & AREA & $\begin{array}{c}\text { Demanda em cada PEV } \\
\left(\mathrm{m}^{3}\right)\end{array}$ & $\begin{array}{l}\text { Conteiner } \\
\text { de } 2.600 \mathrm{~L}\end{array}$ & $\begin{array}{l}\text { Contêiner } \\
\text { de } 1200 \mathrm{~L}\end{array}$ & $\begin{array}{l}\text { Contêiner } \\
\text { de } 240 \mathrm{~L}\end{array}$ \\
\hline \multirow{14}{*}{$\begin{array}{c}\text { PEV60 } \\
\text { C2 }\end{array}$} & \multirow[t]{3}{*}{1} & $\begin{array}{l}0,27 \\
0,40 \\
0,33 \\
0,24 \\
0,40 \\
0,47 \\
0,08 \\
0,14 \\
0,52 \\
0,21 \\
0,95 \\
0,31 \\
0,30 \\
0,31 \\
0,50 \\
0,35 \\
1,32 \\
0,99 \\
1,70 \\
0,82 \\
0,81 \\
0,62 \\
0,42 \\
0,52 \\
1,13 \\
0,33\end{array}$ & $\begin{array}{l}0 \\
0 \\
0 \\
0 \\
0 \\
0 \\
0 \\
0 \\
0 \\
0 \\
0 \\
0 \\
0 \\
0 \\
0 \\
0 \\
0 \\
0 \\
0 \\
0 \\
0 \\
0 \\
0 \\
0 \\
0 \\
0\end{array}$ & $\begin{array}{l}0 \\
0 \\
0 \\
0 \\
0 \\
0 \\
0 \\
0 \\
0 \\
0 \\
0 \\
0 \\
0 \\
0 \\
0 \\
0 \\
1 \\
0 \\
1 \\
0 \\
0 \\
0 \\
0 \\
0 \\
0 \\
0\end{array}$ & $\begin{array}{l}2 \\
2 \\
2 \\
1 \\
2 \\
2 \\
1 \\
1 \\
3 \\
1 \\
4 \\
2 \\
2 \\
2 \\
3 \\
2 \\
1 \\
5 \\
3 \\
4 \\
4 \\
3 \\
2 \\
3 \\
5 \\
2 \\
\end{array}$ & 3 & $\begin{array}{l}0,27 \\
0,13 \\
0,27 \\
0,14 \\
0,64 \\
0,82 \\
0,92 \\
0,68 \\
0,92 \\
0,69 \\
1,36 \\
0,95 \\
1,43 \\
1,64 \\
0,10 \\
0,40 \\
0,34 \\
0,81 \\
1,08 \\
0,68 \\
0,81 \\
0,71 \\
0,67 \\
0,79 \\
0,52 \\
17,77\end{array}$ & $\begin{array}{l}0 \\
0 \\
0 \\
0 \\
0 \\
0 \\
0 \\
0 \\
0 \\
0 \\
0 \\
0 \\
0 \\
0 \\
0 \\
0 \\
0 \\
0 \\
0 \\
0 \\
0 \\
0 \\
0 \\
0 \\
0 \\
0\end{array}$ & $\begin{array}{l}0 \\
0 \\
0 \\
0 \\
0 \\
0 \\
0 \\
0 \\
0 \\
0 \\
1 \\
0 \\
1 \\
1 \\
0 \\
0 \\
0 \\
0 \\
0 \\
0 \\
0 \\
0 \\
0 \\
0 \\
0 \\
3\end{array}$ & $\begin{array}{l}2 \\
1 \\
2 \\
1 \\
3 \\
4 \\
4 \\
3 \\
4 \\
3 \\
1 \\
4 \\
1 \\
2 \\
1 \\
2 \\
2 \\
4 \\
5 \\
3 \\
4 \\
3 \\
3 \\
4 \\
3 \\
69\end{array}$ \\
\hline & & 2,10 & 0 & 1 & 4 & \multirow{4}{*}{4} & 0,65 & 0 & 0 & 3 \\
\hline & & 16,54 & 0 & 3 & 68 & & 0,92 & 0 & 0 & 4 \\
\hline & \multirow[t]{6}{*}{2} & $\begin{array}{l}0,30 \\
0,59 \\
1,03 \\
0,34 \\
0,35 \\
0,95 \\
0,31 \\
0,45 \\
0,44 \\
1,25 \\
0,98 \\
0,23 \\
0,68 \\
0,57 \\
0,33 \\
0,71 \\
1,19 \\
0,76 \\
0,82 \\
0,50 \\
0,71 \\
0,92 \\
0,41\end{array}$ & $\begin{array}{l}0 \\
0 \\
0 \\
0 \\
0 \\
0 \\
0 \\
0 \\
0 \\
0 \\
0 \\
0 \\
0 \\
0 \\
0 \\
0 \\
0 \\
0 \\
0 \\
0 \\
0 \\
0 \\
0 \\
0\end{array}$ & $\begin{array}{l}0 \\
0 \\
0 \\
0 \\
0 \\
0 \\
0 \\
0 \\
0 \\
1 \\
0 \\
0 \\
0 \\
0 \\
0 \\
0 \\
0 \\
0 \\
0 \\
0 \\
0 \\
0 \\
0\end{array}$ & $\begin{array}{l}2 \\
3 \\
3 \\
5 \\
2 \\
2 \\
2 \\
4 \\
2 \\
2 \\
2 \\
1 \\
5 \\
1 \\
3 \\
3 \\
2 \\
2 \\
3 \\
5 \\
4 \\
4 \\
3 \\
3 \\
3 \\
4 \\
2\end{array}$ & & $\begin{array}{l}0,68 \\
0,20 \\
0,47 \\
0,27 \\
1,18 \\
0,99 \\
0,20 \\
0,23 \\
0,42 \\
1,49 \\
1,59 \\
0,52 \\
1,26 \\
1,70 \\
0,98 \\
1,02 \\
0,40 \\
0,92 \\
1,01 \\
0,84 \\
0,81 \\
0,23 \\
0,42 \\
\end{array}$ & $\begin{array}{l}0 \\
0 \\
0 \\
0 \\
0 \\
0 \\
0 \\
0 \\
0 \\
0 \\
0 \\
0 \\
0 \\
0 \\
0 \\
0 \\
0 \\
0 \\
0 \\
0 \\
0 \\
0 \\
0 \\
0 \\
0 \\
\end{array}$ & $\begin{array}{l}0 \\
0 \\
0 \\
0 \\
0 \\
0 \\
0 \\
0 \\
0 \\
1 \\
1 \\
0 \\
1 \\
1 \\
0 \\
0 \\
0 \\
0 \\
0 \\
0 \\
0 \\
0 \\
0 \\
0 \\
\end{array}$ & $\begin{array}{l}3 \\
1 \\
2 \\
2 \\
5 \\
5 \\
1 \\
1 \\
2 \\
2 \\
2 \\
3 \\
1 \\
3 \\
5 \\
5 \\
2 \\
4 \\
5 \\
4 \\
4 \\
1 \\
2 \\
\end{array}$ \\
\hline & & 0,68 & 0 & 0 & 3 & & 19,40 & 0 & 4 & 72 \\
\hline & & $\begin{array}{l}0,11 \\
1,26\end{array}$ & $\begin{array}{l}0 \\
0\end{array}$ & $\begin{array}{l}0 \\
1\end{array}$ & $\begin{array}{l}1 \\
1\end{array}$ & \multirow{6}{*}{5} & $\begin{array}{l}0,92 \\
1,81\end{array}$ & $\begin{array}{l}0 \\
0\end{array}$ & $\begin{array}{l}0 \\
1\end{array}$ & $\begin{array}{l}4 \\
3\end{array}$ \\
\hline & & 1,10 & 0 & 0 & 5 & & 0,25 & 0 & 0 & 2 \\
\hline & & 1,05 & 0 & 0 & 5 & & 0,34 & 0 & 0 & 2 \\
\hline & & 19,02 & 0 & 2 & 82 & & 2,52 & 0 & 2 & 1 \\
\hline & & & & & & & $\begin{array}{l}0,45 \\
0,07 \\
0,17 \\
2,10 \\
0,08 \\
0,59 \\
0,44 \\
1,61 \\
1,29 \\
0,04 \\
1,16 \\
\end{array}$ & $\begin{array}{l}0 \\
0 \\
0 \\
0 \\
0 \\
0 \\
0 \\
0 \\
0 \\
0 \\
0 \\
\end{array}$ & $\begin{array}{l}0 \\
0 \\
0 \\
1 \\
0 \\
0 \\
0 \\
1 \\
1 \\
0 \\
0 \\
\end{array}$ & $\begin{array}{l}2 \\
1 \\
1 \\
4 \\
1 \\
3 \\
2 \\
2 \\
1 \\
1 \\
5 \\
\end{array}$ \\
\hline & & & & & & & 13,84 & 0 & 6 & 35 \\
\hline & \multicolumn{10}{|c|}{ TOTAL } \\
\hline & \multicolumn{3}{|c|}{ Demanda PEV $\left(m^{3}\right)$} & \multicolumn{2}{|c|}{ Conteiner de $2.600 \mathrm{~L}$} & \multicolumn{2}{|c|}{ Contêiner de $1200 \mathrm{~L}$} & \multicolumn{3}{|c|}{ Contêiner de $240 \mathrm{~L}$} \\
\hline & \multicolumn{3}{|c|}{86,57} & \multicolumn{2}{|r|}{0} & \multicolumn{2}{|r|}{18} & \multicolumn{3}{|c|}{326} \\
\hline
\end{tabular}


Planilha 31. Número de contêineres para o cenário PEV80 e configuração C2

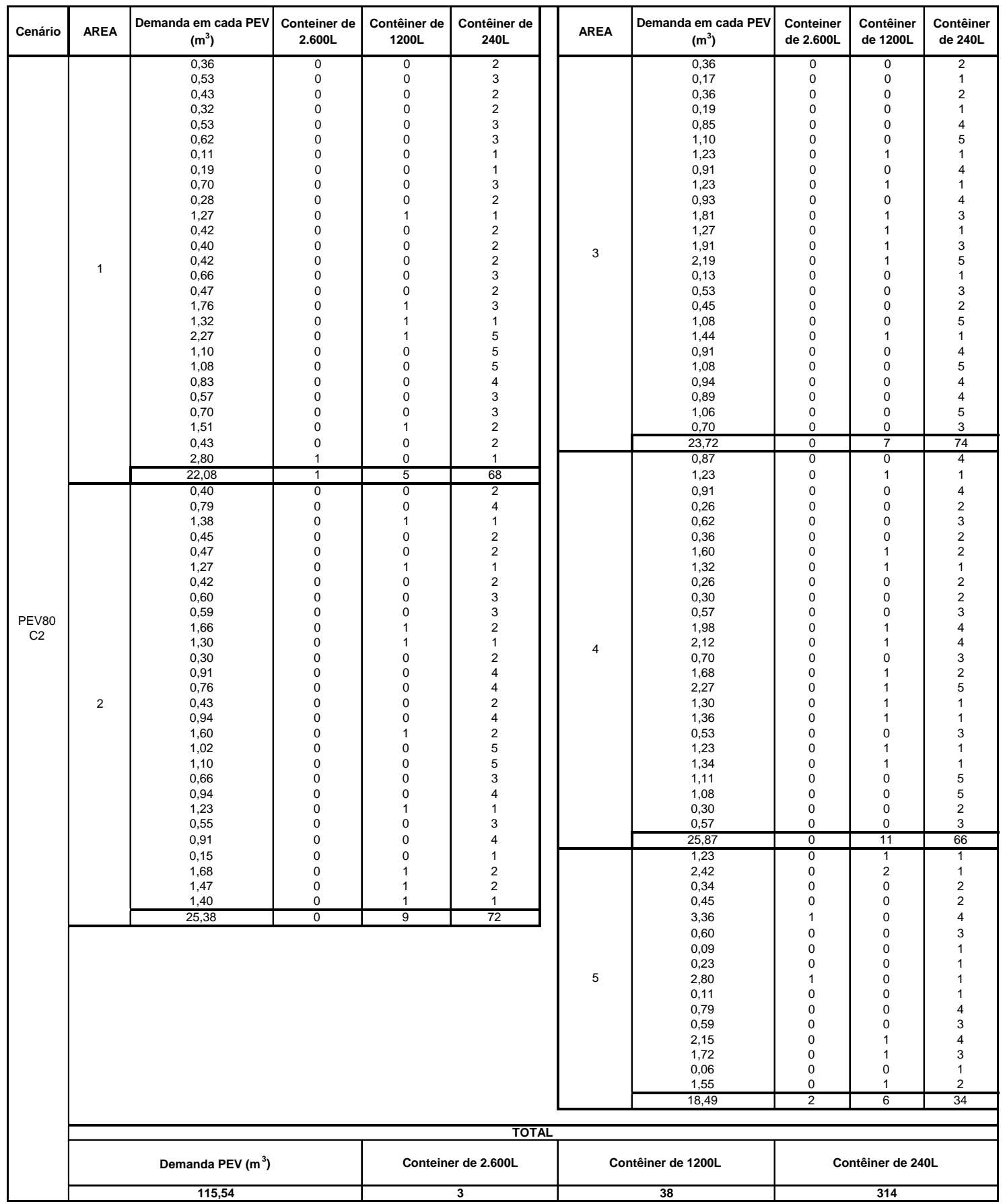


Planilha 32. Número de contêineres para o cenário PEV100 e configuração C2

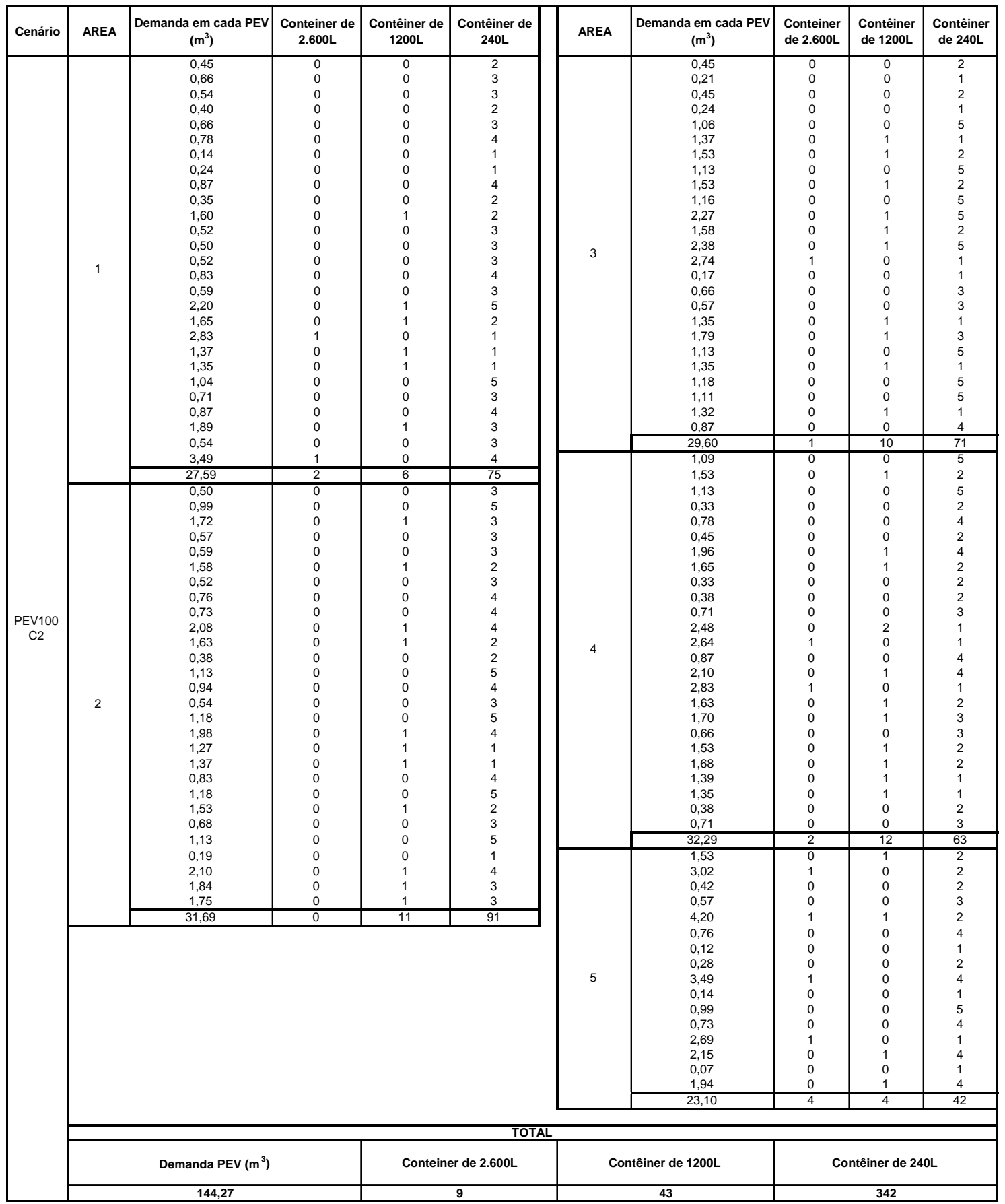


Planilha 33. Número de contêineres para o cenário PEV20 e configuração C3

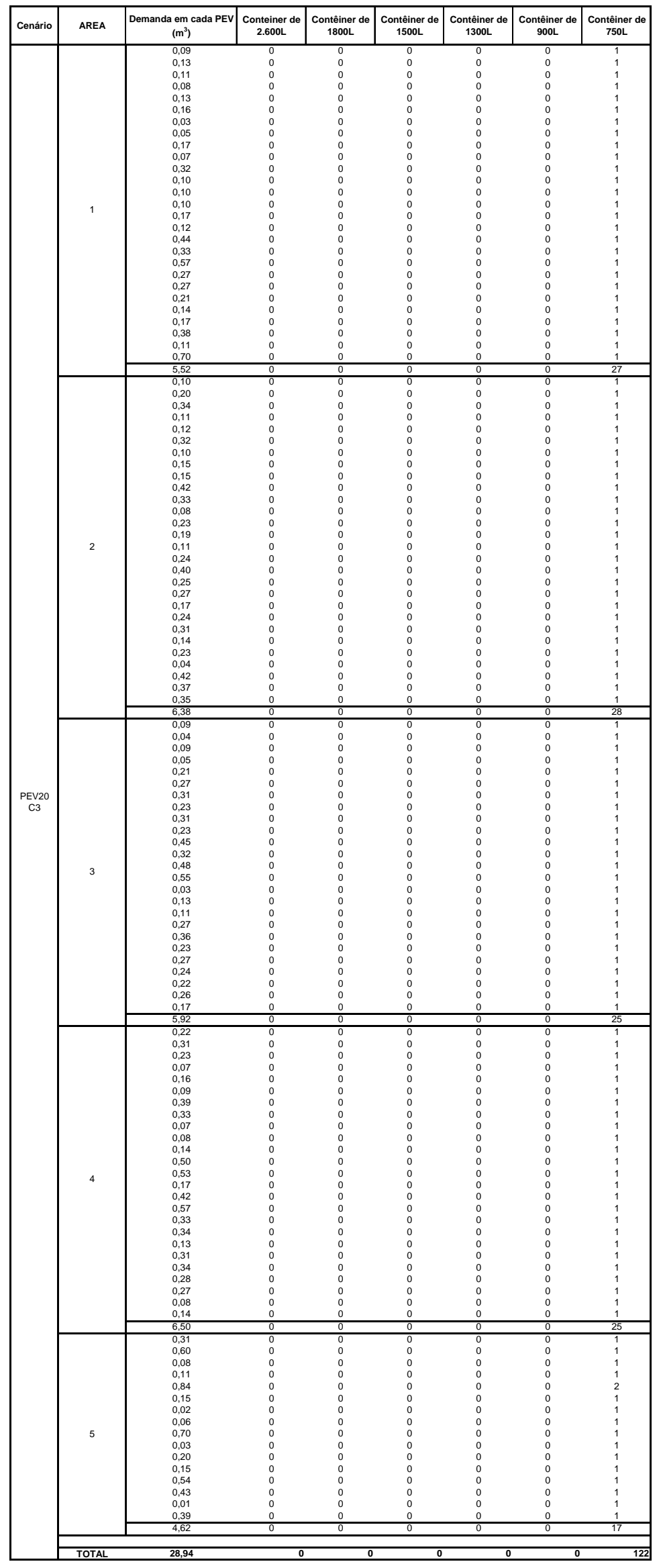


Planilha 34. Número de contêineres para o cenário PEV40 e configuração C3

\begin{tabular}{|c|c|c|c|c|c|c|c|c|}
\hline Cenário & AREA & \begin{tabular}{|c} 
Demanda em cada PEV \\
$\left(\mathrm{m}^{3}\right)^{2}$
\end{tabular} & $\begin{array}{c}\text { Conteiner de } \\
2.600 \mathrm{~L}\end{array}$ & \begin{tabular}{|c|}
$\begin{array}{c}\text { Contêiner de } \\
1800 \mathrm{~L}\end{array}$ \\
\end{tabular} & \begin{tabular}{|c|}
$\begin{array}{c}\text { Contêiner de } \\
1500 \mathrm{~L}\end{array}$ \\
\end{tabular} & \begin{tabular}{|c|} 
Contêiner de \\
$1300 \mathrm{~L}$
\end{tabular} & $\begin{array}{c}\text { Conteiner de } \\
9000 \mathrm{~L}\end{array}$ & \begin{tabular}{|c|}
$\begin{array}{c}\text { Conteiner de } \\
7500\end{array}$ \\
\end{tabular} \\
\hline \multirow{6}{*}{$\begin{array}{l}\text { PEV40 } \\
\text { C3 }\end{array}$} & 1 & $\begin{array}{l}0,18 \\
0,26 \\
0,22 \\
0,16 \\
0,0,26 \\
0,31 \\
0,06 \\
0,099 \\
0,35 \\
0,14 \\
0,063 \\
0,21 \\
0,20 \\
0,21 \\
0,233 \\
0,24 \\
0,88 \\
0,066 \\
1,13 \\
0,55 \\
0,54 \\
0,442 \\
0,28 \\
0,235 \\
0,76 \\
0,22 \\
1,40\end{array}$ & $\begin{array}{l}0 \\
0 \\
0 \\
0 \\
0 \\
0 \\
0 \\
0 \\
0 \\
0 \\
0 \\
0 \\
0 \\
0 \\
0 \\
0 \\
0 \\
0 \\
0 \\
0 \\
0 \\
0 \\
0 \\
0 \\
0 \\
0 \\
0\end{array}$ & $\begin{array}{l}0 \\
0 \\
0 \\
0 \\
0 \\
0 \\
0 \\
0 \\
0 \\
0 \\
0 \\
0 \\
0 \\
0 \\
0 \\
0 \\
0 \\
0 \\
0 \\
0 \\
0 \\
0 \\
0 \\
0 \\
0 \\
0 \\
0\end{array}$ & $\begin{array}{l}0 \\
0 \\
0 \\
0 \\
0 \\
0 \\
0 \\
0 \\
0 \\
0 \\
0 \\
0 \\
0 \\
0 \\
0 \\
0 \\
0 \\
0 \\
0 \\
0 \\
0 \\
0 \\
0 \\
0 \\
0 \\
0 \\
0\end{array}$ & $\begin{array}{c}0 \\
0 \\
0 \\
0 \\
0 \\
0 \\
0 \\
0 \\
0 \\
0 \\
0 \\
0 \\
0 \\
0 \\
0 \\
0 \\
0 \\
0 \\
0 \\
0 \\
0 \\
0 \\
0 \\
0 \\
0 \\
0 \\
1 \\
\end{array}$ & $\begin{array}{l}0 \\
0 \\
0 \\
0 \\
0 \\
0 \\
0 \\
0 \\
0 \\
0 \\
0 \\
0 \\
0 \\
0 \\
0 \\
0 \\
0 \\
0 \\
1 \\
0 \\
0 \\
0 \\
0 \\
0 \\
0 \\
0 \\
0\end{array}$ & $\begin{array}{l}1 \\
1 \\
1 \\
1 \\
1 \\
1 \\
1 \\
1 \\
1 \\
1 \\
1 \\
2 \\
1 \\
1 \\
1 \\
1 \\
1 \\
1 \\
2 \\
1 \\
1\end{array}$ \\
\hline & 2 & 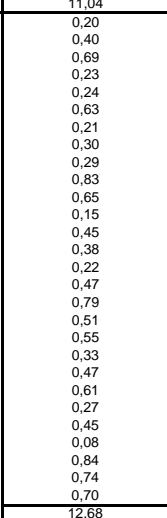 & $\begin{array}{l}0 \\
0 \\
0 \\
0 \\
0 \\
0 \\
0 \\
0 \\
0 \\
0 \\
0 \\
0 \\
0 \\
0 \\
0 \\
0 \\
0 \\
0 \\
0 \\
0 \\
0 \\
0 \\
0 \\
0 \\
0 \\
0 \\
0 \\
0 \\
0 \\
\end{array}$ & $\begin{array}{l}0 \\
0 \\
0 \\
0 \\
0 \\
0 \\
0 \\
0 \\
0 \\
0 \\
0 \\
0 \\
0 \\
0 \\
0 \\
0 \\
0 \\
0 \\
0 \\
0 \\
0 \\
0 \\
0 \\
0 \\
0 \\
0 \\
0 \\
0 \\
0 \\
0 \\
\end{array}$ & $\begin{array}{c}0 \\
0 \\
0 \\
0 \\
0 \\
0 \\
0 \\
0 \\
0 \\
0 \\
0 \\
0 \\
0 \\
0 \\
0 \\
0 \\
0 \\
0 \\
0 \\
0 \\
0 \\
0 \\
0 \\
0 \\
0 \\
0 \\
0 \\
0 \\
0 \\
\end{array}$ & $\begin{array}{c}1 \\
0 \\
0 \\
0 \\
0 \\
0 \\
0 \\
0 \\
0 \\
0 \\
0 \\
0 \\
0 \\
0 \\
0 \\
0 \\
0 \\
0 \\
0 \\
0 \\
0 \\
0 \\
0 \\
0 \\
0 \\
0 \\
0 \\
0 \\
\end{array}$ & $\begin{array}{l}1 \\
0 \\
0 \\
0 \\
0 \\
0 \\
0 \\
0 \\
0 \\
0 \\
0 \\
0 \\
0 \\
0 \\
0 \\
0 \\
0 \\
0 \\
0 \\
0 \\
0 \\
0 \\
0 \\
0 \\
0 \\
0 \\
0 \\
0 \\
0 \\
\end{array}$ & $\begin{array}{l}1 \\
1 \\
1 \\
1 \\
1 \\
1 \\
2 \\
1 \\
1\end{array}$ \\
\hline & 3 & 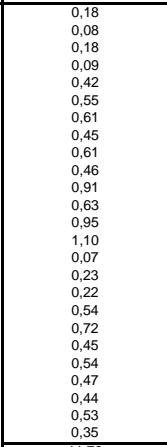 & $\begin{array}{l}0 \\
0 \\
0 \\
0 \\
0 \\
0 \\
0 \\
0 \\
0 \\
0 \\
0 \\
0 \\
0 \\
0 \\
0 \\
0 \\
0 \\
0 \\
0 \\
0 \\
0 \\
0 \\
0 \\
0 \\
0 \\
\end{array}$ & $\begin{array}{l}0 \\
0 \\
0 \\
0 \\
0 \\
0 \\
0 \\
0 \\
0 \\
0 \\
0 \\
0 \\
0 \\
0 \\
0 \\
0 \\
0 \\
0 \\
0 \\
0 \\
0 \\
0 \\
0 \\
0 \\
0 \\
\end{array}$ & $\begin{array}{l}0 \\
0 \\
0 \\
0 \\
0 \\
0 \\
0 \\
0 \\
0 \\
0 \\
0 \\
0 \\
0 \\
0 \\
0 \\
0 \\
0 \\
0 \\
0 \\
0 \\
0 \\
0 \\
0 \\
0 \\
0\end{array}$ & $\begin{array}{l}0 \\
0 \\
0 \\
0 \\
0 \\
0 \\
0 \\
0 \\
0 \\
0 \\
0 \\
0 \\
0 \\
0 \\
0 \\
0 \\
0 \\
0 \\
0 \\
0 \\
0 \\
0 \\
0 \\
0 \\
0\end{array}$ & $\begin{array}{l}0 \\
0 \\
0 \\
0 \\
0 \\
0 \\
0 \\
0 \\
0 \\
0 \\
1 \\
0 \\
1 \\
1 \\
0 \\
0 \\
0 \\
0 \\
0 \\
0 \\
0 \\
0 \\
0 \\
0 \\
0\end{array}$ & $\begin{array}{l}1 \\
1 \\
1 \\
1 \\
1 \\
1\end{array}$ \\
\hline & 4 & 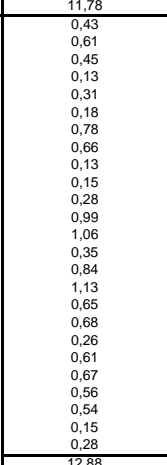 & $\begin{array}{l}0 \\
0 \\
0 \\
0 \\
0 \\
0 \\
0 \\
0 \\
0 \\
0 \\
0 \\
0 \\
0 \\
0 \\
0 \\
0 \\
0 \\
0 \\
0 \\
0 \\
0 \\
0 \\
0 \\
0 \\
0 \\
0 \\
\end{array}$ & $\begin{array}{l}0 \\
0 \\
0 \\
0 \\
0 \\
0 \\
0 \\
0 \\
0 \\
0 \\
0 \\
0 \\
0 \\
0 \\
0 \\
0 \\
0 \\
0 \\
0 \\
0 \\
0 \\
0 \\
0 \\
0 \\
0 \\
0 \\
\end{array}$ & $\begin{array}{l}0 \\
0 \\
0 \\
0 \\
0 \\
0 \\
0 \\
0 \\
0 \\
0 \\
0 \\
0 \\
0 \\
0 \\
0 \\
0 \\
0 \\
0 \\
0 \\
0 \\
0 \\
0 \\
0 \\
0 \\
0 \\
0 \\
\end{array}$ & $\begin{array}{l}0 \\
0 \\
0 \\
0 \\
0 \\
0 \\
0 \\
0 \\
0 \\
0 \\
0 \\
0 \\
0 \\
0 \\
0 \\
0 \\
0 \\
0 \\
0 \\
0 \\
0 \\
0 \\
0 \\
0 \\
0 \\
0 \\
\end{array}$ & $\begin{array}{l}3 \\
0 \\
0 \\
0 \\
0 \\
0 \\
0 \\
0 \\
0 \\
0 \\
0 \\
0 \\
1 \\
1 \\
0 \\
0 \\
1 \\
0 \\
0 \\
0 \\
0 \\
0 \\
0 \\
0 \\
0 \\
0\end{array}$ & $\begin{array}{l}1 \\
1 \\
1 \\
1 \\
1 \\
1 \\
1\end{array}$ \\
\hline & 5 & $\begin{array}{l},, 60 \\
1,21 \\
0,17 \\
0,23 \\
1,68 \\
0,30 \\
0,05 \\
0,11 \\
1,40 \\
0,06 \\
0,40 \\
0,29 \\
1,08 \\
0,86 \\
0,03 \\
0,77 \\
, 07\end{array}$ & $\begin{array}{l}0 \\
0 \\
0 \\
0 \\
0 \\
0 \\
0 \\
0 \\
0 \\
0 \\
0 \\
0 \\
0 \\
0 \\
0 \\
0 \\
\end{array}$ & $\begin{array}{l}0 \\
0 \\
0 \\
0 \\
0 \\
0 \\
0 \\
0 \\
0 \\
0 \\
0 \\
0 \\
0 \\
0 \\
0 \\
0 \\
0 \\
0\end{array}$ & $\begin{array}{l}0 \\
0 \\
0 \\
0 \\
0 \\
1 \\
0 \\
0 \\
0 \\
0 \\
0 \\
0 \\
0 \\
0 \\
0 \\
0 \\
0 \\
\end{array}$ & $\begin{array}{l}0 \\
0 \\
0 \\
0 \\
0 \\
0 \\
0 \\
0 \\
0 \\
1 \\
0 \\
0 \\
0 \\
0 \\
0 \\
0 \\
0 \\
\end{array}$ & $\begin{array}{l}3 \\
1 \\
1 \\
0 \\
0 \\
0 \\
0 \\
0 \\
0 \\
0 \\
0 \\
0 \\
0 \\
1 \\
0 \\
0 \\
0 \\
\end{array}$ & $\begin{array}{l}1 \\
1 \\
1 \\
1 \\
1 \\
2 \\
1 \\
2 \\
\end{array}$ \\
\hline & & 57,63 & & & & & & \\
\hline
\end{tabular}


Planilha 35. Número de contêineres para o cenário PEV60 e configuração C3

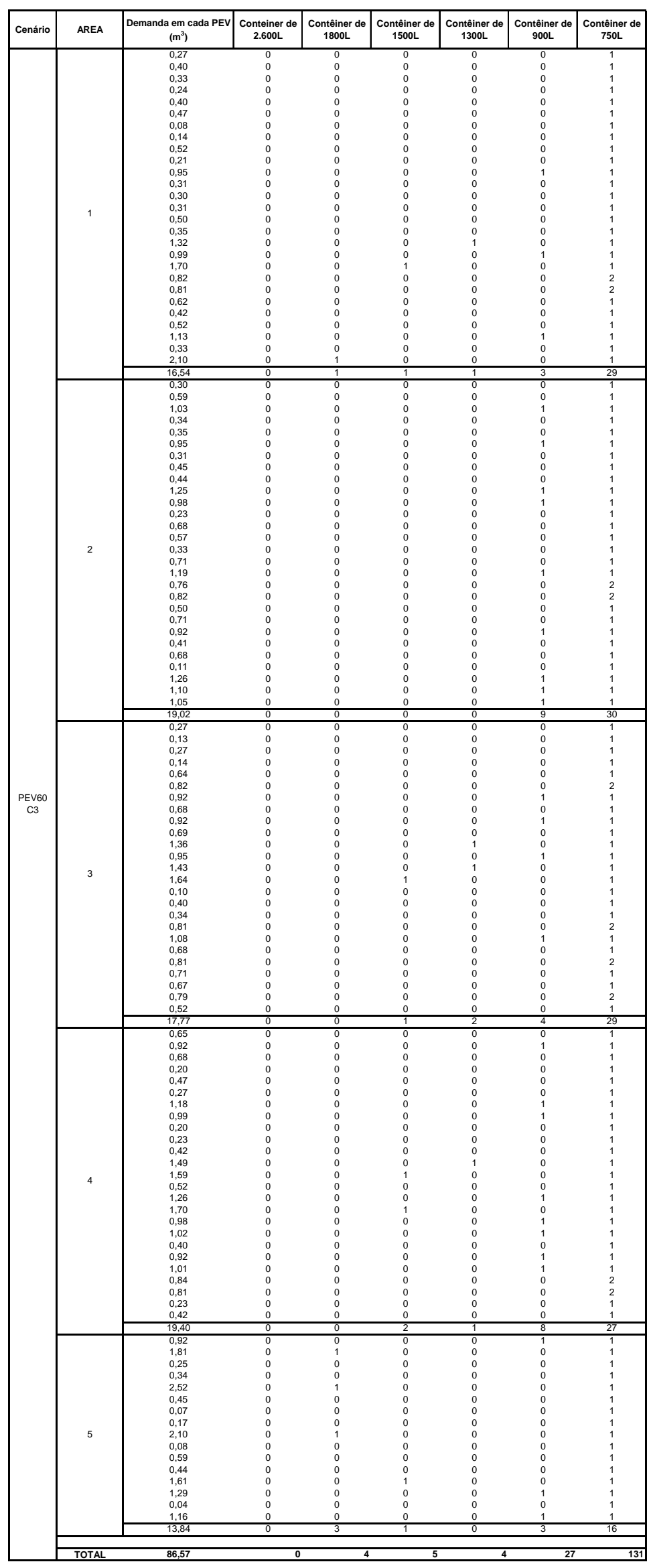

178 
Planilha 36. Número de contêineres para o cenário PEV80 e configuração C3

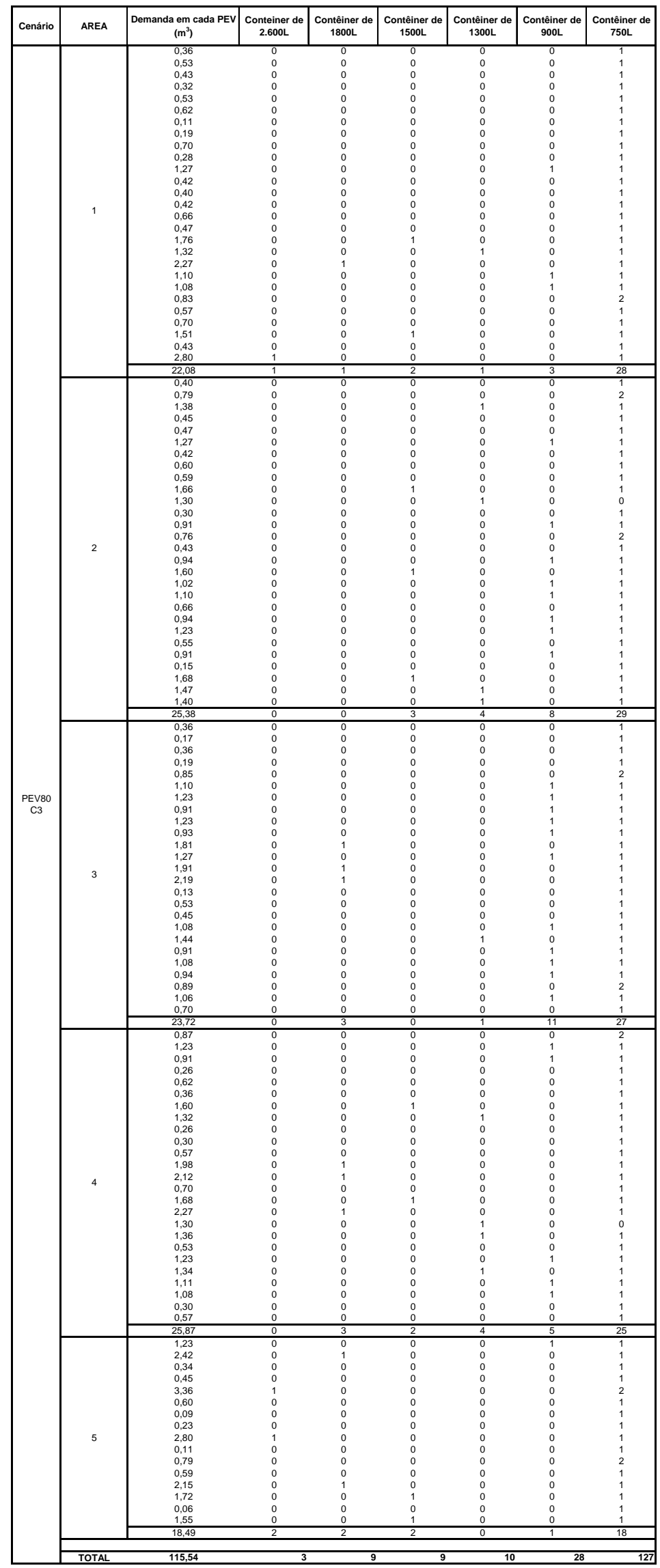


Planilha 37. Número de contêineres para o cenário PEV100 e configuração C3

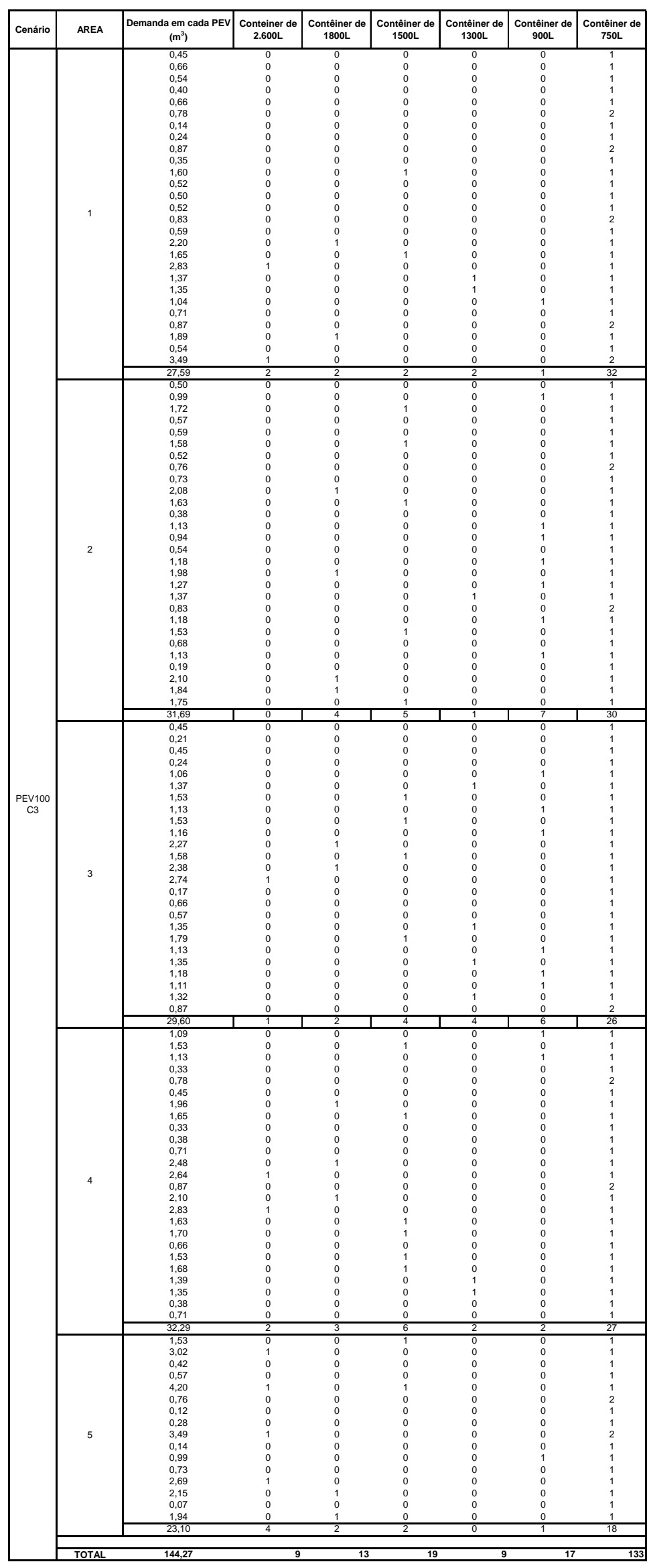

180 
Planilha 38. Número de contêineres para o cenário PEV20 e configuração C4

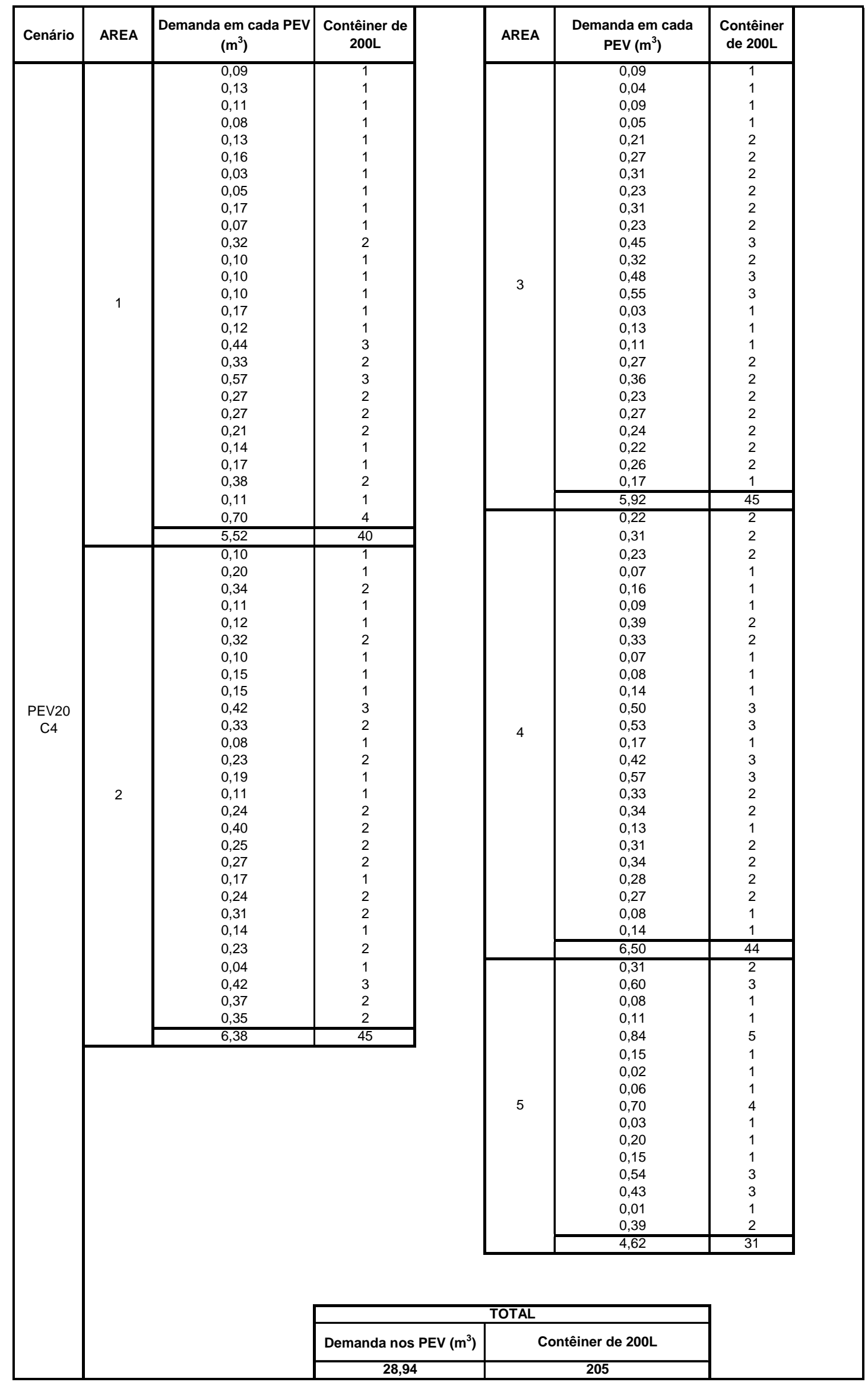


Planilha 39. Número de contêineres para o cenário PEV40 e configuração C4

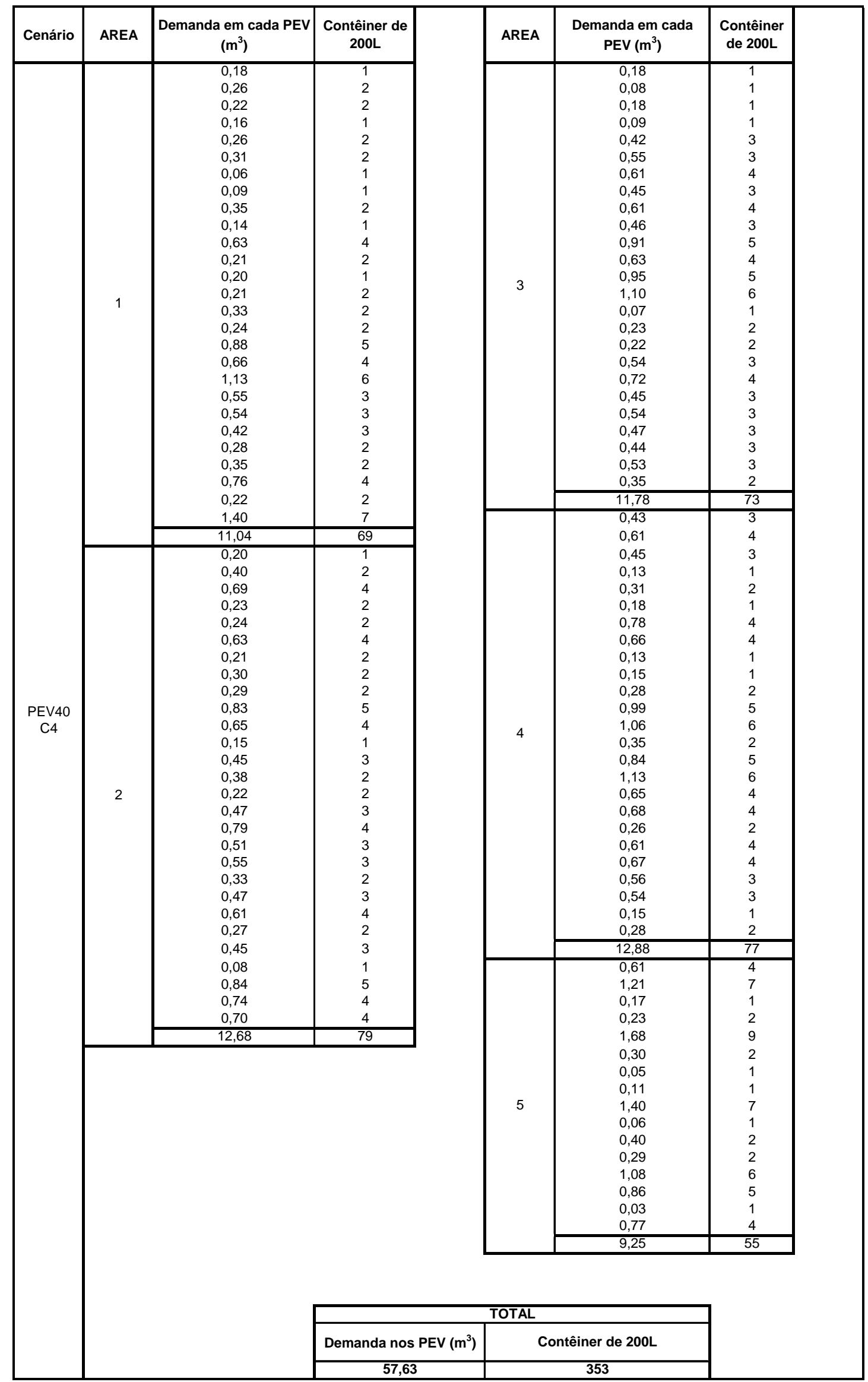


Planilha 40. Número de contêineres para o cenário PEV60 e configuração C4

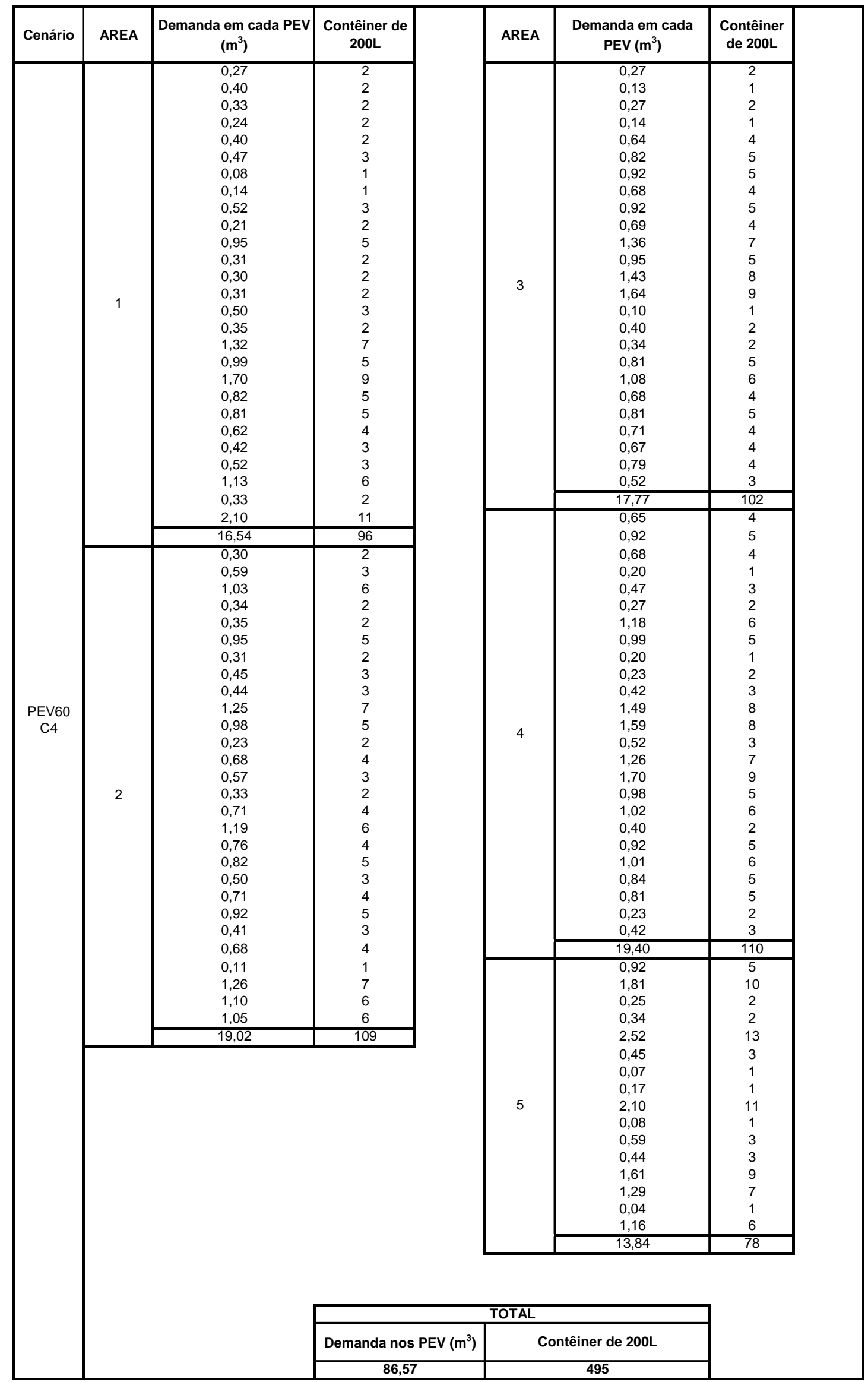


Planilha 41. Número de contêineres para o cenário PEV80 e configuração C4

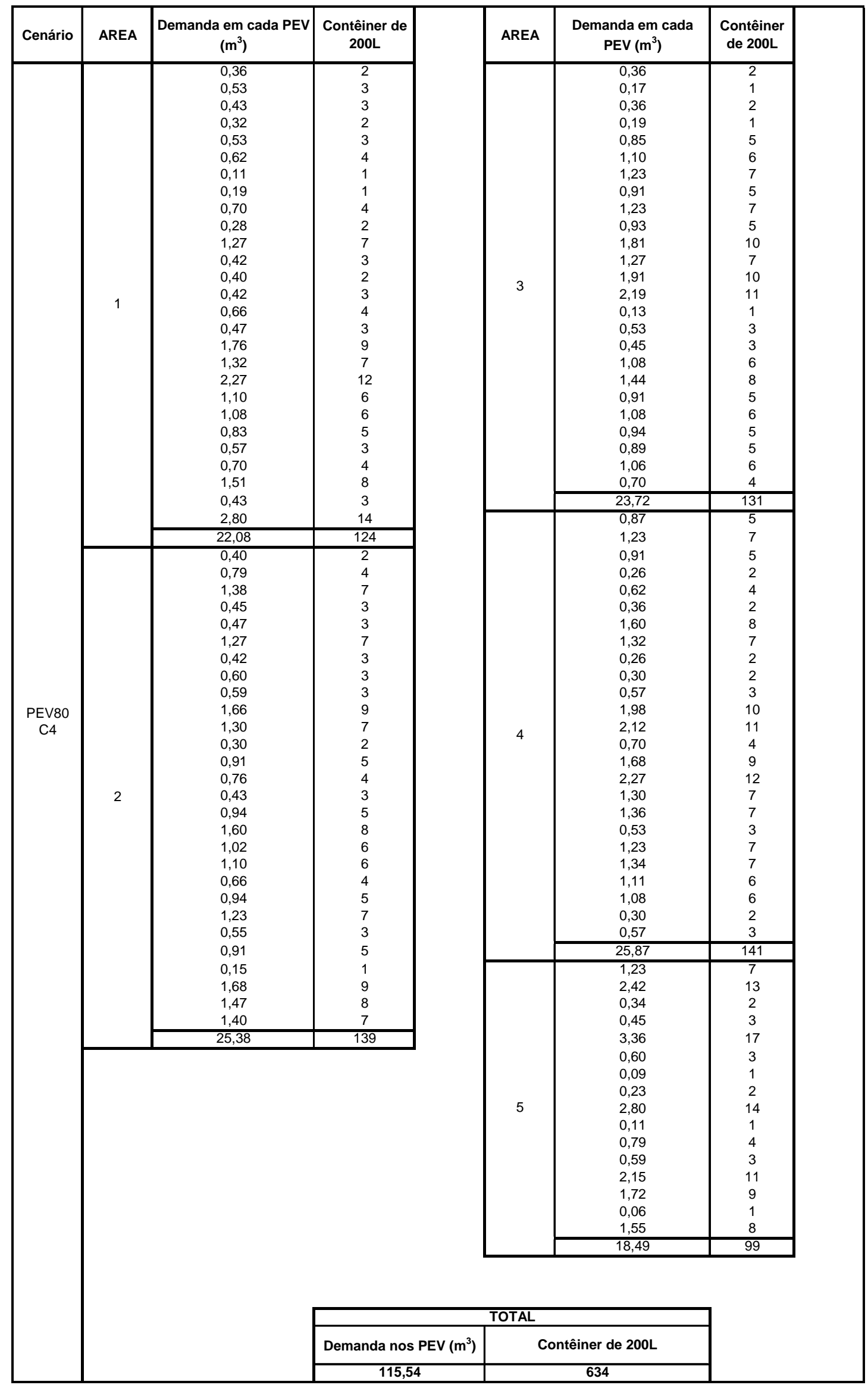


Planilha 42. Número de contêineres para o cenário PEV100 e configuração C4

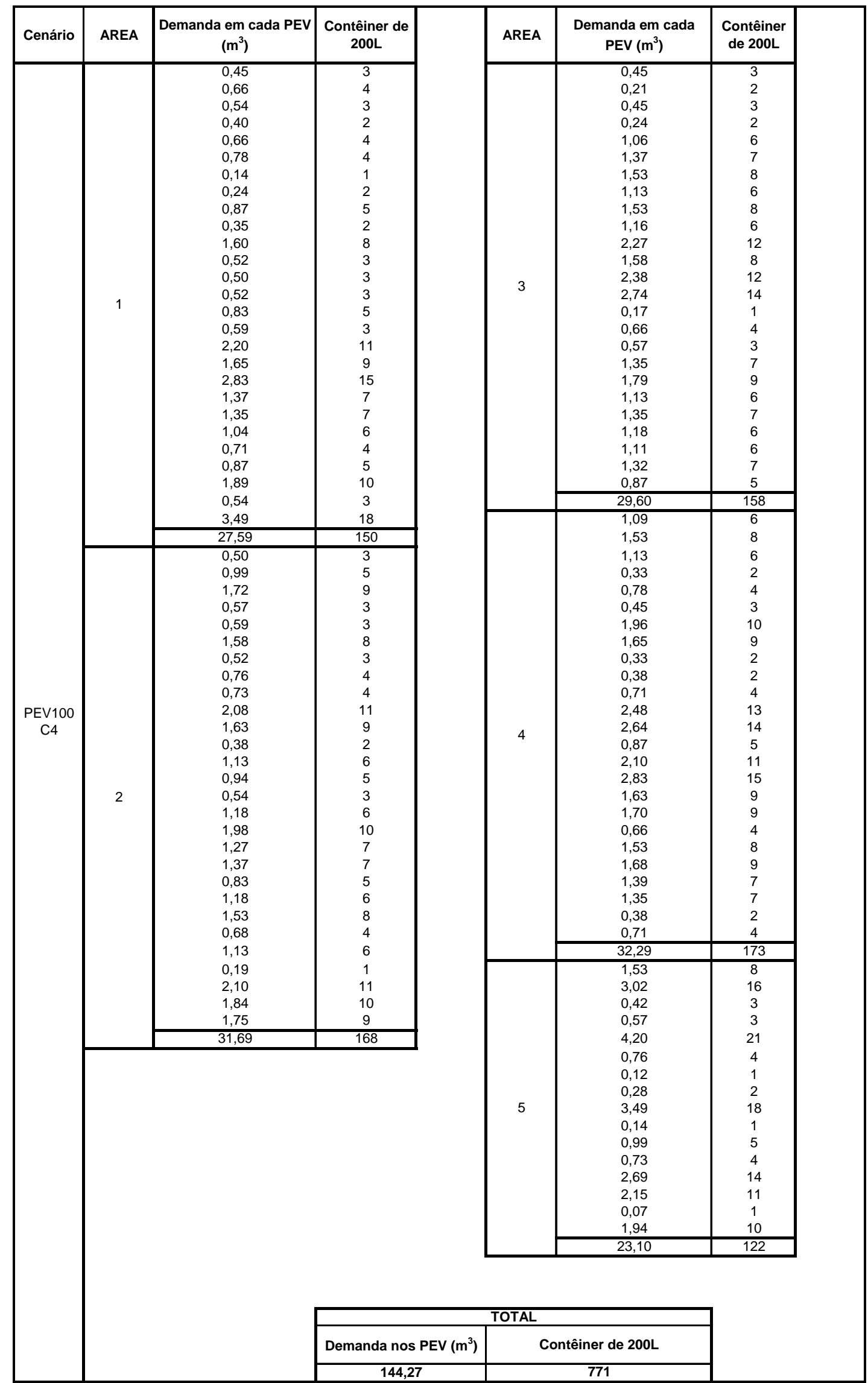


ANEXO A

Alguns modelos comerciais de contêineres utilizados para a coleta de resíduos

sólidos 


\section{CONTÊINERES DE FIBRA DE VIDRO}

Figura 1. contêineres de fibra de vidro reforçados com aço

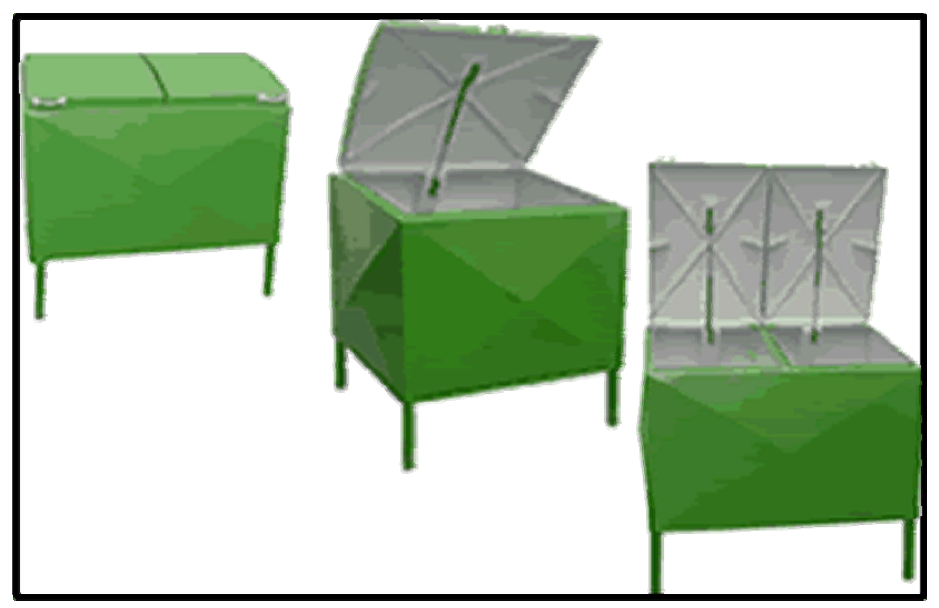

Fonte: adaptado de www.aartedafibra.cjb.net

\begin{tabular}{l|l|l|l}
\multicolumn{1}{c|}{ Capacidade } & \multicolumn{1}{c|}{ Dimensões } & \multicolumn{1}{c|}{ Fornecedor } & \multicolumn{1}{c}{ Obs. } \\
\hline 750 Litros & $1,00 \times 1,00 \times 0,80 \times 0,70 \mathrm{~m}$. & Arte de Fibra & 01 Tampa \\
\hline 900 Litros & $1,20 \times 1,00 \times 0,80 \times 0,70 \mathrm{~m}$ & Arte de Fibra & 02 Tampas \\
\hline 1.300 Litros & $1,50 \times 1,00 \times 0,80 \times 0,70 \mathrm{~m}$ & Arte de Fibra & 02 Tampas \\
\hline 1.500 Litros & $2,00 \times 1,00 \times 0,80 \times 0,70 \mathrm{~m}$ & Arte de Fibra & 02 Tampas \\
\hline 1.800 Litros & $2,40 \times 1,00 \times 0,80 \times 0,70 \mathrm{~m}$ & Arte de Fibra & 04 Tampas \\
\hline 2.600 Litros & $3,00 \times 1,00 \times 0,80 \times 0,70 \mathrm{~m}$ & Arte de Fibra & 04 Tampas
\end{tabular}

\section{CONTÊINERES DE POLIETILENO E POLIPROPILENO}

Figura 2. contêineres de polietileno de alta densidade - de 120 a 360 litros de capacidade

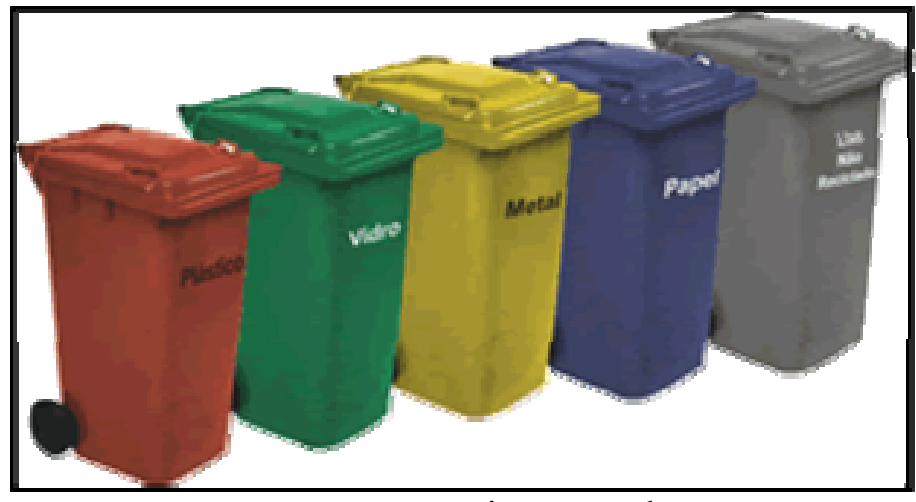

Fonte: www.virgo.com.br 
Figura 3. contêiner de polietileno de alta densidade do tipo CYCLEA 2500 litros de capacidade

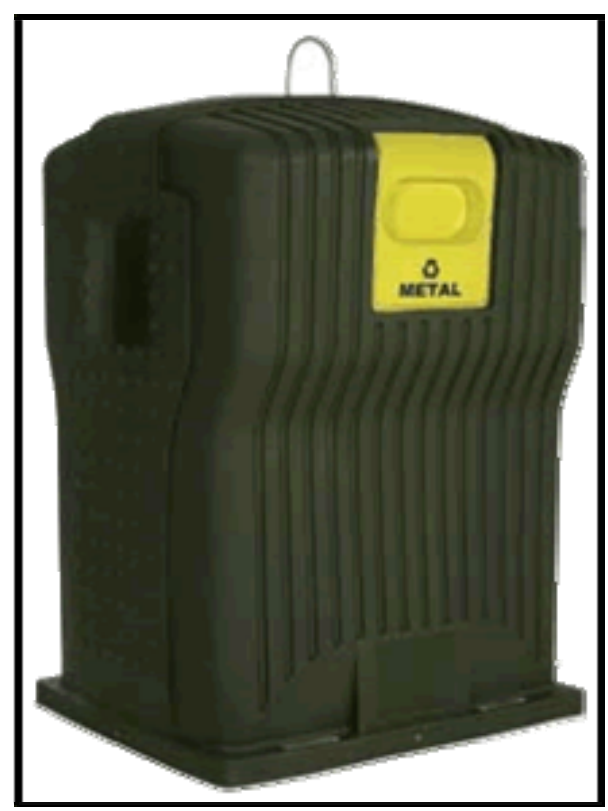

Fonte: www.orionclean.com.br

Figura 4. contêineres de Polietileno de média densidade - de 1000 e 1200 litros de capacidade

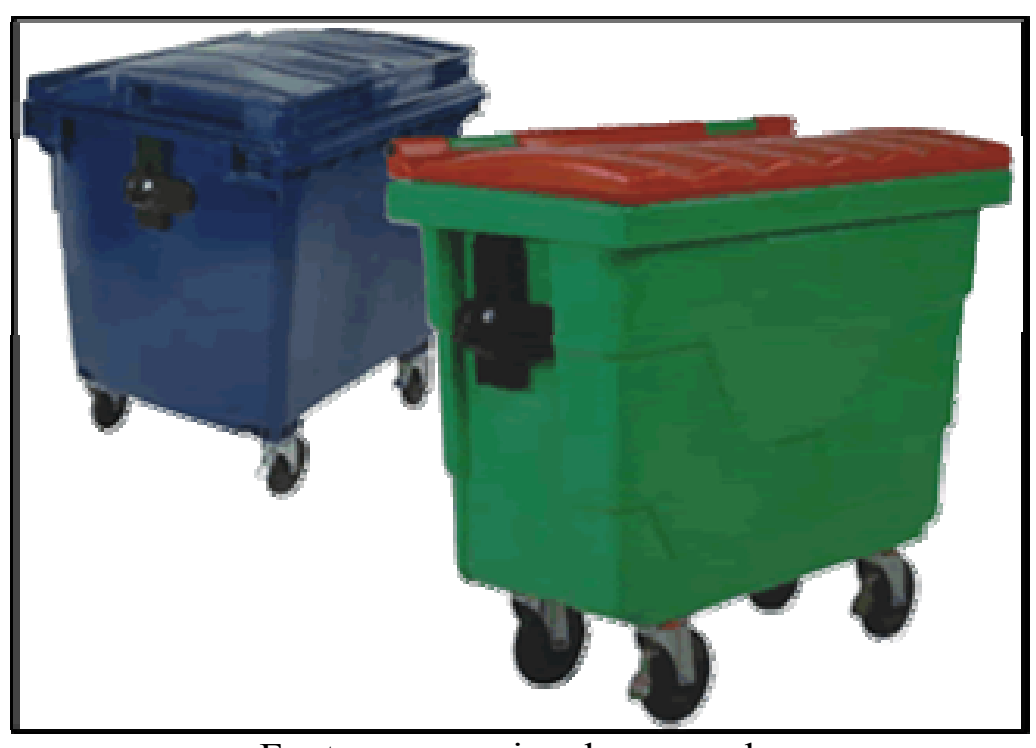

Fonte: www.orionclean.com.br 
Figura 5. contêiner de propileno - 240 litros de capacidade

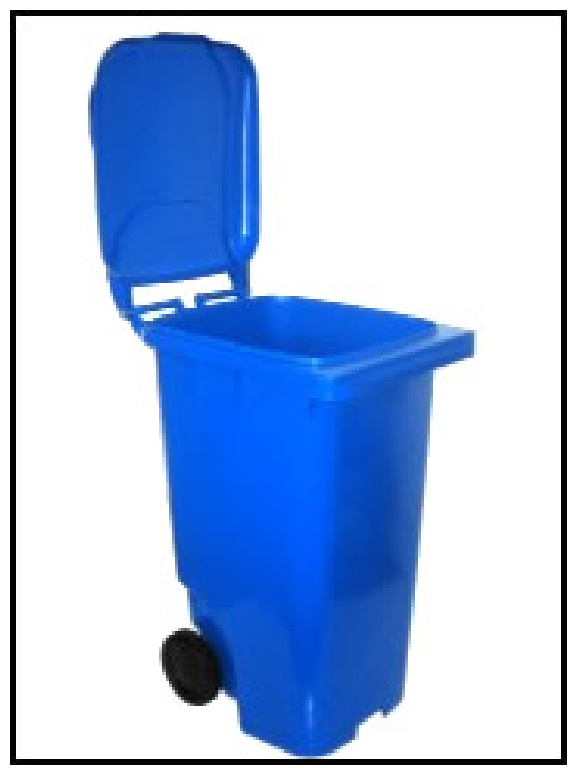

Fonte: www.dixhigiene.com.br

\begin{tabular}{l|l|l|l}
\multicolumn{1}{c|}{ Capacidade } & \multicolumn{1}{|c|}{ Dimensões } & \multicolumn{1}{|c}{ Fornecedor } & \multicolumn{1}{c}{ Obs. } \\
\hline 1.000 Litros & N/F & Dix Higiene & Polietileno de alta densidade \\
\hline 240 Litros & N/F & Dix Higiene & Polipropileno \\
\hline 120 Litros & N/F & Brasil Virgo & Polietileno de alta densidade \\
\hline 240 Litros & N/F & Brasil Virgo & Polietileno de alta densidade \\
\hline 360 Litros & N/F & Brasil Virgo & Polietileno de alta densidade \\
\hline 2.500 Litros & N/F & Orion Clean & Cyclea \\
\hline 1.200 Litros & N/F & Orion Clean & \\
\hline 1.000 Litros & N/F & Orion Clean &
\end{tabular}




\section{CONTÊINERES DE AÇO}

Figura 6. contêiner de aço - 1200 litros de capacidade

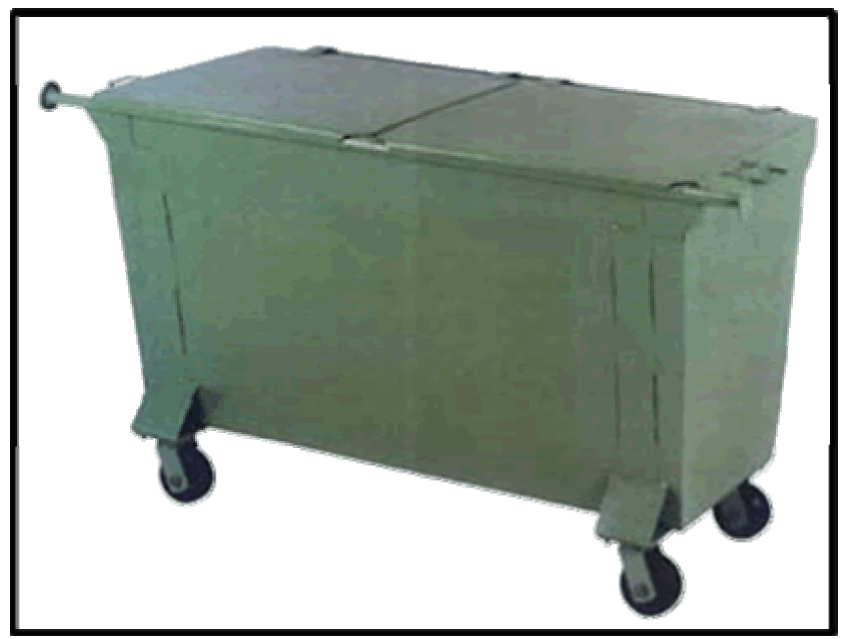

Fonte. www.terrabras.com.br

Figura 7. Tambores de aço - 200 litros de capacidade

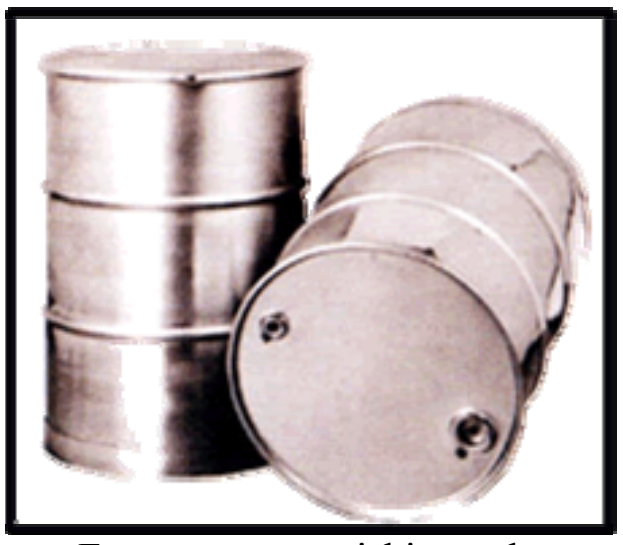

Fonte: www.conishi.com.br

\begin{tabular}{l|l|l|l}
\multicolumn{1}{c|}{ Capacidade } & \multicolumn{1}{|c|}{ Dimensões } & \multicolumn{1}{c|}{ Fornecedor } & \multicolumn{1}{c}{ Obs. } \\
\hline 1200 Litros & $1,60 \times 0,80 \times 0,90 \mathrm{~m}$ & Terrabras & Chapa de aço ${ }^{\mathbf{0}} 14$ \\
\hline 200 Litro & N/F & Conishi & Tambor \\
\hline 1200 Litro & N/F & Conishi & \\
\hline 1600 Litro & N/F & Conishi &
\end{tabular}

